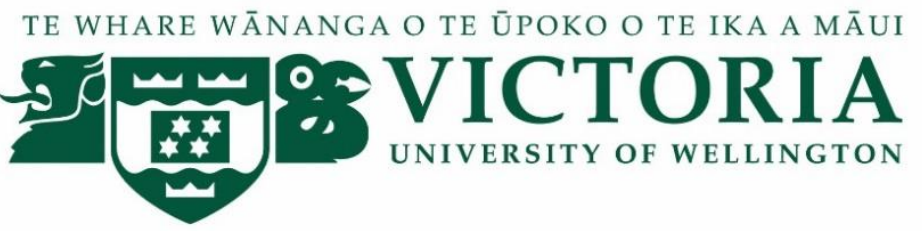

\title{
Accessibility and development in rural Sarawak. \\ A case study of the Baleh river basin, Kapit District, Sarawak, Malaysia.
}

Regina Garai Abdullah

A thesis submitted to Victoria University of Wellington in fulfilment of the requirements for the degree of Doctor of Philosophy 2016

School of Geography, Environment and Earth Sciences,

Victoria University of Wellington,

New Zealand 


\section{Abstract}

To what degree does accessibility to markets correlate with levels of development? This is an important question for those living in remote, underdeveloped parts of Southeast Asia during the final phases of de-agrarianisation.

My study recounts the experience of rural-based Iban households living in the Baleh river basin of the Kapit District (population of 54,200 ) within a day or less travel by river to the small market town of Kapit (with a population of 18,000 ). With no connecting roads to the rest of Sarawak and reliant almost entirely on river transport, the local economy remains underdeveloped and is losing population.

My field work among 20 villages in three accessibility zones of the Baleh river basin was undertaken over the three month period of May-July 2014. Structured interviews were conducted with 20 village headmen (tuai rumah), 82 heads of household, and 82 individuals within the households. Data was also systematically collected on 153 other individuals, including both residents and non-resident members of these bilik-families.

My conceptual framework draws on von Thünen's model of agricultural land use in order to generate expectations about the possible effects of market accessibility. While the sale of vegetables and other commodities accords with expected patterns, most rural households are in fact dependent on other, largely non-agricultural sources of income. As a result there has emerged a disjuncture between the nominal and actual residence as those working age family members with residential rights to the bilik undertake paid work well beyond the agricultural margin.

Unable to achieve desired standards of living by accessing local markets and services in a division with no cities or roads, the working age members of the bilik sustain their families by dividing their residence between two or more locations in what I call multi-local living. The income of nominally rural households is being increasingly determined by the human capital that individuals now apply to non-agricultural labour markets. This, in turn, is leading to a widening distribution of levels of 'development', across individuals, their multi-generational families and their rural communities. Multi-local living is unsustainable beyond the transitional phase of de-agrarianisation and as labour shifts out of agriculture and people move to towns, connections with rural residence are likely to diminish, notwithstanding the cultural ties, and disputes over realising market values of largely untitled land will continue to complicate the transition. 


\section{Acknowledgements}

My three and a half year journey as a PhD student has been one of the most intense, yet memorable parts of my life so far, and I owe a debt of gratitude to the following people for helping me throughout this journey.

An enormous gratitude to my supervisor, Professor Philip Morrison, who has been there with me throughout this entire journey. Thank you for the faith you have in me when I first applied for the programme, for your unwavering support, encouragement, calm presence when I am panicking, and endless questions that made me think critically about my work. I could not have asked for a more dedicated, understanding and supportive supervisor.

Many utmost gratitude to all my participants - thank you for your time and patience in dealing with me. My time with you has been a learning curve for me. Mr Meringai, Madam Jamayah and Aya Masing and their respective families - thank you for all your help and guidance. You all went out of your way to help me and for that I will forever be grateful.

My cousin, Bobby Kinyang and his family, thank you for hosting me when I was in Kapit and introducing me to everyone. You have made my stay very comfortable - a home away from home, and even took time to accompany me when I visited the longhouses.

My friends in New Zealand, Malaysia and Europe - distance does not matter as we have proved over the last three years. All of you have been with me throughout this journey regardless of our geographical distance. You have shared my ups and downs, my moments of panics, my joy and excitement. As I said in this thesis, technologies make distance irrelevant! Liz, Fendi and Ita - thanks for listening and always cheering me on. Sayang korang! Jimmie sisters - where do I even begin with you girls: thank you for the crazy, memorable moments, sharing my burdens, and picking me up when I was down. I know I can totally depend on the three of you. A debt of gratitude to Rashidah Bolhassan for introducing me to my Jimmie's sisters as well as being my shoulders to cry on. My friends who (were forced to) read my initial drafts of the thesis - thank you for making time to read my numerous draft chapters and providing feedback: Anita, Kiky, Lynette, Denise, Geo, Dr M, and Shu. A massive thank you to Sandra Koenigseder for helping me with the maps. 
I would also like to thank Pedram - the best officemate ever! I have been lucky to share an office with someone who is always positive and pushes me to do my best at all times. Thank you for the motivational speeches, the inspiring quotes on our office whiteboard, and the endless supply of food and audio books.

I would also like to acknowledge the support from Universiti Malaysia Sarawak and the Ministry of Higher Education for my scholarship.

My greatest thank you is reserved for my family - thank you for being there and always believing in me. Your unfailing support humbled me. One of the things that kept me going is remembering how my dad had to leave his home at a young age to get an education. This thesis is dedicated to my dad - my number one supporter from day one! 


\section{TABLE OF CONTENTS}

Abstract $\quad$ ii

$\begin{array}{lc}\text { Acknowledgements } & \text { iii }\end{array}$

$\begin{array}{ll}\text { Preface } & \text { ix }\end{array}$

Glossary $\quad$ xii

$\begin{array}{ll}\text { List of Figures } & \text { xvi }\end{array}$

List of Maps xviii

List of Photographs $\quad$ xix

List of Tables $\quad$ Xx

1.0 Introduction 1

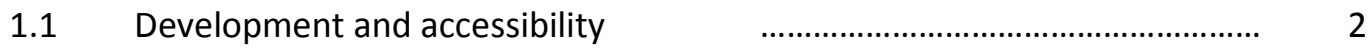

Exploring the accessibility-development relationship $\quad$.............................. 3

Sarawak: History and development issues $\quad$ S....................................... 4

1.3.1 Historical and political background $\quad$.............................................. 7

1.3.2 Socio-economic development of Sarawak ...................................... 9

$1.4 \quad$ Baleh river basin, Kapit District, Sarawak $\quad$.......................................... 16

1.4.1 Accessibility in Baleh $\quad$................................................... 21

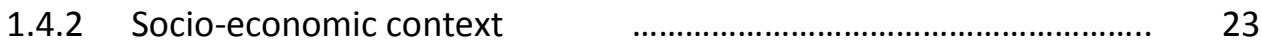

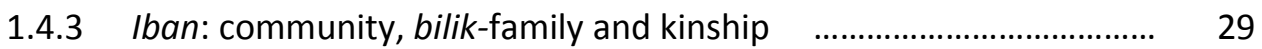

1.4.3.1 The cultural context $\quad$......................................................... 30

1.4.4 Iban and multi-local living practice $\quad$......................................... 31

$1.5 \quad$ Future development in Baleh river basin ................................................. 34

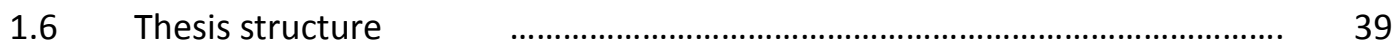

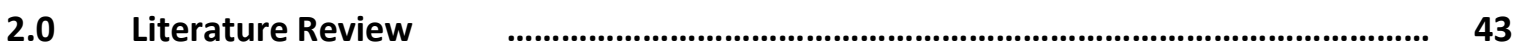

$2.1 \quad$ Concepts of development $\quad$.............................................................. 44

2.1.1 Measuring development $\quad$.................................................... 47

2.1.1.1 Human capital and education as development indicators 48

2.1.1.2 Basic needs as a development indicator $\quad$................ 51

2.1.1.3 Diversification as development indicator $\quad$............... 52

2.1.1.4 Subjective measures of development $\quad$............................ 53

2.2 Understanding accessibility $\quad$........................................................ 54

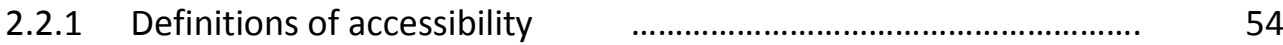

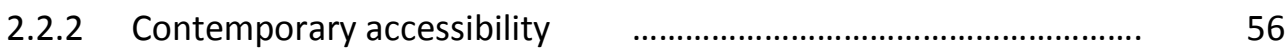




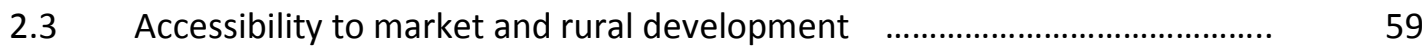

$2.4 \quad$ De-agrarianisation $\quad$............................................................................... 61

2.4.1 Preconception of rural-ness $\quad$.............................................................. 63

2.4.2 De-agrarianisation and multi-local living $\quad$.................................. 64

2.4.3 Education and de-agrarianisation $\quad$.............................................. 68

2.4.4 De-agrarianisation and inequality $\quad$.............................................. 69

2.5 Summary

3.0 Conceptual Framework

3.1 The von Thünen land use model ....................................................................

3.1.1 Effects of changes in prices and cost $\quad$............................................. 78

3.2 Extensions of the model ……………................................................... 81

3.2.1 Multiple transport modes ………………………………..... 82

3.2.2 More than one market ……………………………….... 84

3.2.3 Land ownership $\quad$................................................................. 86

3.3 Relationship between development and accessibility $\quad$.............................. 86

3.4 Summary

4.0 Research Design and Methodology $\quad$.............................................................................. 89

$4.1 \quad$ Research design $\quad$.............................................................................. 89

4.2 Case study area: selection method ………………………………...... 90

4.2.1 Unit of analysis _.................................................................... 93

4.3 Data preparation and analysis $\quad$................................................................... 94

4.3.1 Tuai rumah dataset _....................................................................... 95

4.3.2 Bilik-family dataset $\quad$....................................................................... 97

4.3.3 Individual dataset _............................................................... 98

4.3.4 Bilik-member dataset $\quad$................................................................... 98

4.3.5 Handling missing data _....................................................................... 98

4.3.6 Subjective responses to measuring accessibility and development 100

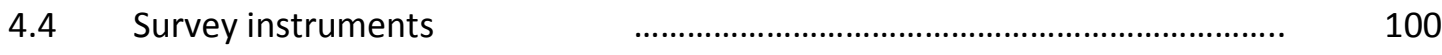

4.4.1 Negotiating the cultural maze ……………...................................... 103

4.4.2 Informed consent and confidentiality _.............................................. 105

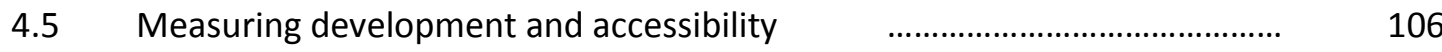

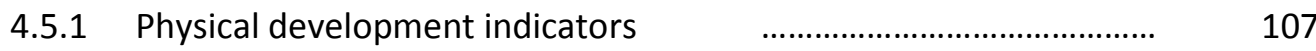

4.5.2 Income indicators ………………......................................... 109

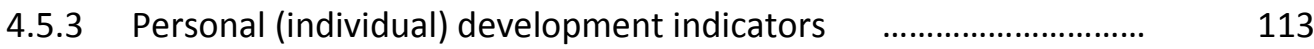


4.5.4 Subjective measures of development $\quad$............................................ 115

4.5.5 Measuring accessibility $\quad$............................................................ 116

4.5.6 Measuring physical accessibility $\quad$............................................... 117

4.5.7 Measuring contemporary accessibility $\quad$................................. 120

4.6 Summary

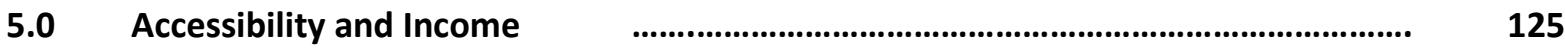

5.1 Measure of accessibility …………………........................................ 126

$5.2 \quad$ Income and accessibility

5.2.1 Relationship between income from commodity sales and proximity to Kapit Town

5.2.2 Relationship between in-situ income and proximity to Kapit Town 135

5.2.3 Relationship between remittances and proximity to Kapit Town ..... 142

5.2.4 Relationship between total household income and proximity to Kapit Town

$5.3 \quad$ Summary $\quad$..................................................................................... 148

6.0 Accessibility, Physical Development and Human Capital $\quad \ldots$

6.1 Accessibility to market and basic infrastructure provision $\quad$.................... 151

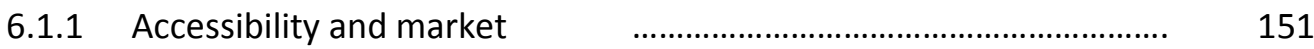

6.2 Accessibility to market, basic infrastructure and connectivity $\quad$.................... 156

6.3 Infrastructure development: an elaboration ………................................... 159

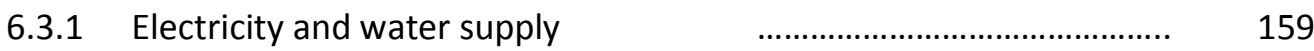

6.3.2 Schools and primary education $\quad$................................................ 161

6.3.3 Health services $\quad$....................................................................... 164

6.3.4 Road connection and mobile coverage $\quad \ldots \ldots \ldots \ldots \ldots \ldots \ldots \ldots \ldots \ldots \ldots \ldots . . . . . . . . . . . . . . . . .168$

6.4 Accessibility and human capital development $\quad$................................... 171

6.4.1 Levels of education of heads of household _................................. 172

6.4.2 Future human capital $\quad$......................................................... 174

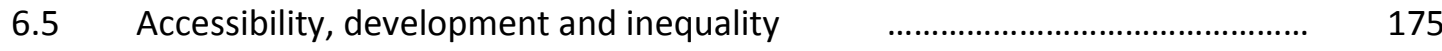

6.5.1 Inequality in access to market and services $\quad$................... 176

6.6 Does location matter? $\quad$ …………………………………………..... 178

6.7 Summary

7.0 Multi-local Living and the Changing Structure of Iban Bilik-family $\quad \ldots . . . . . . . . . . . . . . . . . . .181$

7.1 Implications of de-agrarianisation at household and individual levels $\quad \ldots . . . \quad 181$

7.1.1 Multi-local living as a result of de-agrarianisation $\quad$.................. 183 
7.1.1.1 Profiles of bilik-members practicing multi-local living

7.1.2 Multi-local living and the accessibility-development relationship

7.1.2.1 Multi-local living and individual income

7.1.2.2 Dual residency and implication on household development 193

7.1.2.3 Multi-local living and human capital development $\quad \ldots \quad 196$

7.2 Implications of multi-local living on household structure

198

7.2.1 Changes in traditional Iban bilik-family structure

198

7.2.1.1 Concept of Pun

200

7.2.1.2 Iban bilik-family structure $\quad$................................................. 201

7.2.1.3 Evolution of the contemporary Iban household in Baleh ..... 207

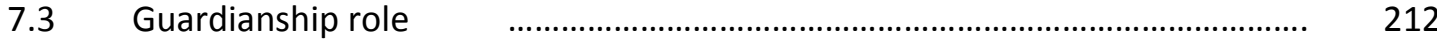

7.3.1 Disappearing farmers in Baleh?

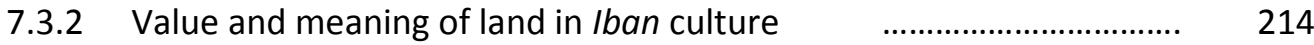

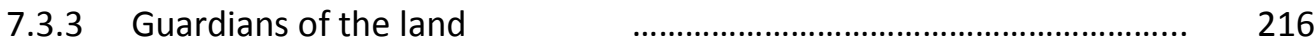

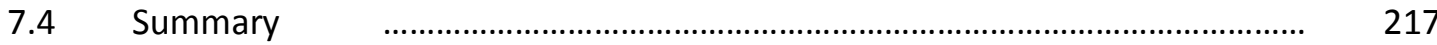

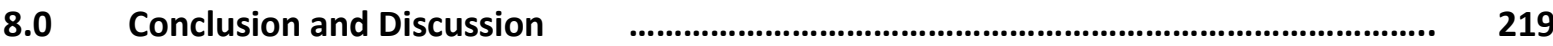

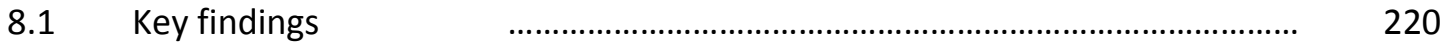

8.2 Future of the Iban in Kapit District

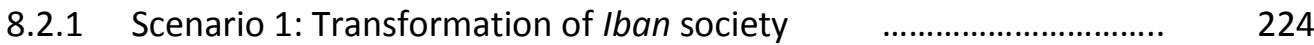

8.2.1.1 Permanent move to the urban centres …............................. 226

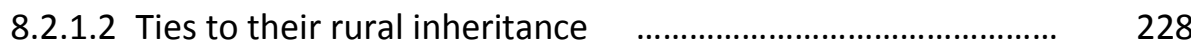

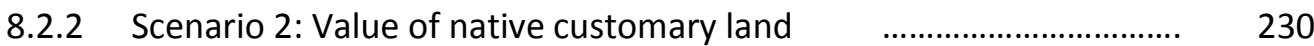

8.2.3 Scenario 3: Joint ventures _ ............................................................ 232

8.3 Significance and contribution of the research ………….................................. 232

8.4 Limitations of the research _.......................................................................... 236

8.5 Direction of future research ……………........................................................ 237

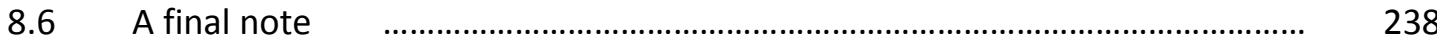

References

Appendix 1: Tuai rumah questionnaire

Appendix 2: Head of household (bilik-family) questionnaire $\quad$............................................... 255

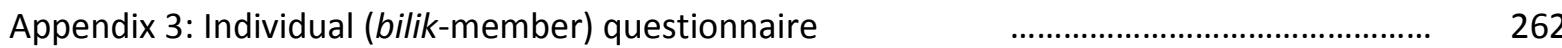




\section{Preface}

I have written this preface to place myself in the context of this study. I am an Iban born and raised in Sri Aman, Sarawak and currently employed as a lecturer at Universiti Malaysia Sarawak (UNIMAS). I received my primary and secondary education in Sri Aman, before continuing my education at the University of Newcastle upon Tyne, United Kingdom, in the field of town planning. I worked as a town planner both in the United Kingdom and in Malaysia before joining UNIMAS in 2007. I was granted study leave to pursue a PhD in Human Geography in the School of Geography, Environment and Earth Sciences, Victoria University of Wellington and a scholarship from the Malaysian Government. Upon its completion, I will return and resume my post at UNIMAS.

When I joined UNIMAS as a lecturer in its Development Planning and Management Programme (Faculty of Social Sciences), I became involved in several research projects exploring rural issues in Sarawak. These piqued my interest in rural development and its various challenges. Being an Iban, and a Sarawakian myself, the issue of rural development is very close to my heart. I have witnessed many instances how rural Iban households face challenges especially in this era of globalisation and have seen my relatives struggle to cope financially when the prices of commodities fluctuate. They compete not only against the market and lack of opportunities, but also face external challenges in their pursuit of a better standard of living. This got me thinking about the rural households in Kapit District because they are particularly disadvantaged due to their lack of accessibility. I, therefore, decided to study households in Baleh river basin, the site of Freeman's study of the Iban some 60 years earlier.

When I began this study of the relationship between development and accessibility, I was keenly aware of how remote and inaccessible Baleh river basin was in relation to rest of Sarawak - there are virtually no roads and Kapit District remained unconnected by road to the rest of the State. My interest in the area was mainly informed by discussions with family members who had worked and lived in the District. They are not from the area and only moved to Kapit Town due to work commitments. Their description of Kapit Town and Baleh river basin were both unflattering and unfamiliar, but this motivated me to explore the area further. I wanted to understand how a place that remote and inaccessible could function and how its rural population could cope in this day and age.

Admittedly, I came into the research with some pre-conceived ideas but, during and, after my fieldwork and over the course of the last three and a half years, I have learned that what I thought I knew was rather limited indeed. While my educational background gave me some insights, there is also no doubt that I carried pre-conceived assumptions about development through my exposure to 
the Western, developed economy through both academic and popular lenses. I had to reflect, therefore, on how to position myself explicitly in this research. I was conscious of my position both as an 'indigenous' and 'insider' researcher, and of the privilege that goes with that status. At the same time, I was aware of potential bias that I might bring to the field as a result of my pre-conceived notion of development.

The fieldwork that I conducted in mid-2014 was an eye opener. I spent approximately three months living in the Kapit District - with my cousin and his family in Kapit Town and staying overnight in different longhouses along Batang Baleh during the data collection trips. I was often out of my comfort zone having to be constantly interacting with 'strangers'. The three month fieldwork limit meant that my schedule was very tight and I was doing many back-to-back interviews at different longhouses over a sustained period of time. What affected me most was the river journeys by longboat in different weather and river conditions. It was only then I realised how challenging and dangerous those river trips could be and how completely dependent on river the rural population in Baleh river basin are. What I assumed to be a straight-forward data collection trip turned out to be a more challenging, reflective exercise than I expected. I have discovered that rural change is far from simple or straight forward. It is multi-dimensional, with layer upon layer of complexities.

Admittedly, as an Iban, I was accepted in most quarters as an insider researcher. At the same time, my unfamiliarity with the case study area and longhouse customs meant there were respondents who considered me an outsider. An outsider is someone who has a structurally imposed incapacity to comprehend alien groups, status, cultures and society and that he/she has neither been socialised in the group nor has engaged in the run of experience that makes up its life (Sultana, 2007; p.378). This definition implies that an outsider cannot have the direct, intuitive sensibility that alone makes emphatic understanding possible.

Logistical difficulties necessitated me to stay overnight in several longhouses during the course of my fieldwork. However, my urban upbringing and my living and working overseas for more than ten years meant I was not very well versed in longhouse ways of living, culture and customs. Other researchers such as Farhana Sultana (2007) and Elizabeth Chacko (2004) describe similar experiences in their field research in Bangladeshi and Indian villages respectively. Sultana, for instance, describes how people placed her in certain categories, exerted authority/subservience, and 'othered' her during her field research. 
It would have been naïve of me to assume that I could fit in as an 'insider', with equal power relations, in this situation. Several participants addressed me as "cikgu" (which means teacher) when I told them that I was a lecturer at a local university and currently on study leave pursuing my doctoral study. Addressing me as such is an act of deference which already put me in an unequal position. At the same time, I was also keenly aware of their acceptance of my presence in the area, as an outsider doing 'useful' research (Sultana, 2007, p. 379). I also tried my best to 'fit in' by using those things that we have in common - language, ethnicity and histories. There were also instances where I joined a group of female market gardeners selling vegetables at the market at six o'clock in the morning until they finished just after midday or for occasional trips to their farms or visiting their relatives. These shared experiences helped me to bond and gain their trust as well as providing them with the opportunities to know me and ask questions about my research.

Being mindful of my indigenous background, life experience and positionality in the context of conducting this research among the Iban in Baleh river basin helped me negotiate my approach to ensure that my research design and methodology were both culturally appropriate and effective. I was conscious from the onset of the need to be respectful and not be seen as an outsider who does not understand the participants' custom and culture. It was not an easy task but I believed that I did achieve that goal to the best of my abilities.

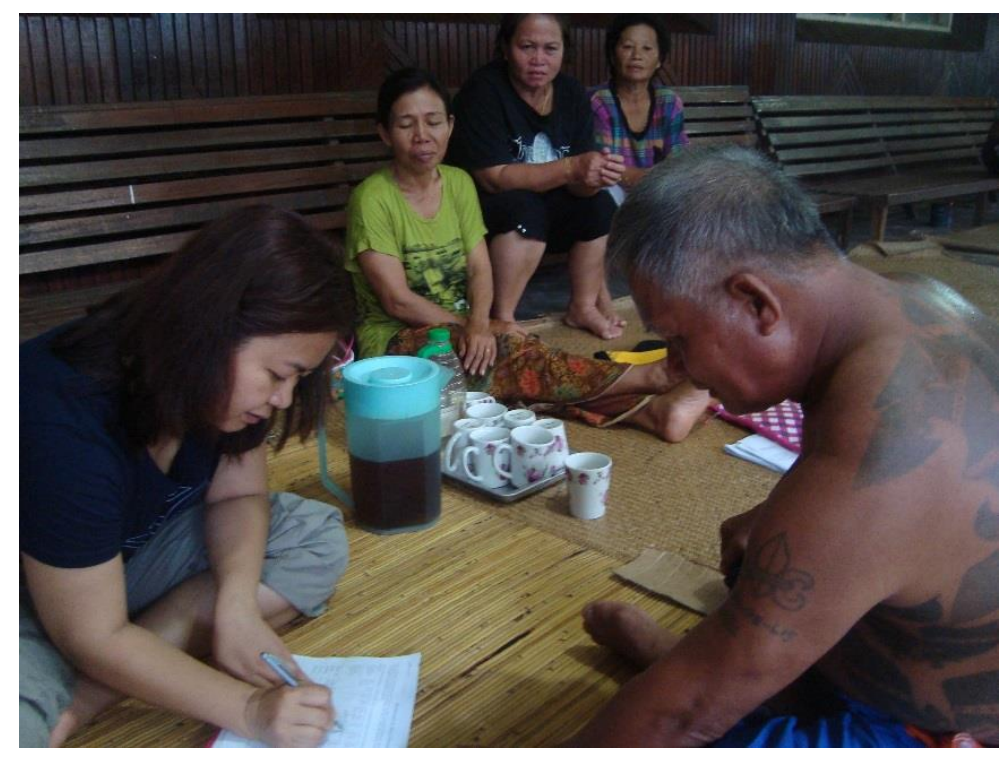

My interview with a head of household, while his family members looked on. 


\section{Glossary}

The aim of this glossary is to explain the meaning of commonly used Iban words and key concepts used throughout the thesis.

Adat

Ai besai

Ai langkang

Anak biak

Bejalai

Bekebun

Betanam betupi

Bilik

Bilik-family

Bilik-member

Bumai

Chabi

Dayak
Customary law, which is instrumental for maintaining law and order, and the common means for administering disputes in the Iban community. Adat is under the custodian of the village headman in every Iban community.

High water (river) level

Low water (river) level

Anak biak (or sometimes spelled as anembiak) is the other members of the longhouse, under the jural responsibility of a tuai rumah. Therefore, anak biak refers to members of longhouse community.

An Iban tradition, which encourages young males to leave the village with the specific aim of earning money and improving individual and household prestige upon their return. Bejalai as it was traditionally conducted is no longer practiced today, but, it has established a cultural legitimacy to the practice of moving out of the village in search of employment.

Refers to farming and planting activities (e.g. rubber, pepper and vegetable) other than paddy cultivation.

Literally translated as 'planting and rearing' activities. Can be used to describe 'subsistence activity' but the definition, if taken literally, is too narrow to cover the definition of subsistence activities

A bilik refers to the privately owned unit in an Iban longhouse, i.e. their ancestral home. It is also sometimes used to describe an Iban household or its nuclear family unit.

An Iban term for household, it is basically an independent domestic unit whose members may consist of up to four generations. As a single household, they share resources and collectively have usufruct rights to bilik's properties.

There are four ways for an individual to become a bilikmember of an Iban household: by birth, through marriage, adoption or integration (affinal links).

Generally refers to rice planting.

Chillies

Dayak communities refers to several tribal groups: Iban, Bidayuh, Kayan, Kenyah, Kelabit, Murut, Lun Bawang and Penan. 
De-agrarianisation

Dual residency

Express boat

Gawai

Gunny sack

Iban

Klinik desa

Longboat

Longhouse

Longhouse community
A shift from farm-based economy into non-farm based economic activity.

A type of multi-local living, but refers specifically to a situation where the bilik-members have two main homes, and they divided their time between these two homes. E.g. students who live at their boarding schools during school term, but living at parents' home during weekends and school holidays. The term is used interchangeably with multi-local living or multi extended households in this thesis.

Main mode of river transport in Kapit District. Express boats operate much in the same way as public buses. They carry goods and passengers, whereby goods are placed on top of the express boats and the passengers sit within the compartments inside the boat. Different compartments charge different fares (business class and economy class fares).

Dayak's main festival. Also known as Harvest Festival

A burlap sack, made either from natural fibres or polypropylene, which is used to store and transport rice (or other agricultural products such as cocoa or grains). A standard-size gunny sack can hold approximately 50 to 70 kilogram of rice (that has been processed).

Natives to Borneo, and originally from upper Kapuas in Central Borneo (what is now Kalimantan, Indonesia). Arrived in Sarawak in mass migration in early 1800 s. Nowadays Iban is the largest of all ethnic group in Sarawak.

Rural health clinic: usually one rural clinic is provided for an area with a population between 1500 to 2000 people. The clinic is equipped with a general clinic, a delivery room, a maternal and child health clinic, and a few 'rest beds'. The rural clinic is manned by a health team comprising of a hospital assistant, two community nurses, a rural health supervisor and support staff.

A mode of river transportation. Photo supplied in the thesis.

Traditional Iban settlement, with a single structure, which accommodates separate bilik-family within its structure. It usually has between 15 to 60 individual doors. This community is usually bound by kinship and affinity.

In order to be part of a longhouse community, an individual has to belong to a bilik-family in that longhouse. There are terms and conditions that must be satisfied in order to maintain that membership, and such conditions are at the discretion of the tuai rumah and/or its committee. The most common condition is that a bilik must not be left empty, and if all the bilik members live away from the longhouse, they (not necessarily every member) must come back at least once a year (depending on the duration agreed by their 
Market gardening

Multi-local living

Native Area Land (NAL)

Native Customary Land (NCR)

Orang Ulu

Outboard motor/engine

Pala menoa

Pemakai menoa

Pemansang

Pun

Pun bilik

Ringgit Malaysia (RM)

Ruai longhouses) for a visit. It should be noted that different longhouse have different conditions for establishing or maintaining such membership.

Growing of vegetables for market, but is also commonly associated with the cultivation of fruits and flowers.

A situation where acknowledged member(s) of a household live separately from the main home, either temporarily (temporal, seasonal or circular movement) or permanently. The main home refers to their ancestral bilik.

Lands held under titles that only indigenous peoples (natives) of Sarawak have the right to possess. Cannot be sell or mortgaged to non-natives.

Lands held under customary rights that was indicated by the clearing of virgin forest. Often referred to as Native Customary Rights (NCR) land and this category of land is not held under title.

A collective name for a tribe that comprises of Kayan, Kenyah, Kelabit, Murut, Lun Bawang and Penan.

A propulsion system for boats, and the most common motorised method for propelling small boat along Batang Baleh. The most commonly used outboard engine is the 15 horsepower and 40 horsepower engine.

Refers to the last Iban settlement, and beyond which no other Iban settlements can be established. Established during the Brooke's government as an attempt to stop the Iban from expanding further into the interior of Baleh.

Refers to a specific land area, where the Iban carry out their subsistence activities such as hunting and gathering, farming, and earning their livelihood from generation to generation. It is communal in nature, "governed" by adat and enforced by local community (under the jurisdiction of a tuai rumah).

Commonly used term to denote development. The term 'mansang' means 'forward'.

Literally means the root or the foundation. It is a concept that emphasises on the continuity of Iban household

Usually the most senior members of the household, who has either founded the bilik-family or has inherited one from the previous branch of his/her family.

Malaysian currency. At the time of the field work, July 2014, one New Zealand dollar equals RM2.70

A common corridor (covered varandah) that runs through the entire length of a longhouse. Functions as a communal space and a focal point of many longhouse activities (e.g. receiving and entertaining visitors). 
Sapit tuai rumah

Shifting cultivation

Sijil Pelajaran Malaysia (SPM)

Sijil Rendah Pelajaran (SRP)

Sijil Tinggi Pelajaran Malaysia (STPM)

Social exclusion

Sungai

Swidden farming

Tongkang

Tuai rumah (TR)
Deputy or assistant to tuai rumah, managing the longhouse affairs in the absence of the tuai rumah.

Synonymous with land use system of slash-and-burn agriculture and swidden farming in Southeast Asia. These terms are used interchangeably through this thesis. In the context of Iban farming, shifting cultivation refers to hill paddy cultivation, interspersed with other secondary crops such as maize, cassava, and bananas.

Qualification obtained after eleven years of schooling.

Qualification obtained after nine years of schooling

Qualification obtained after thirteen years of schooling. Usually, after obtaining SPM, students may opt to pursue further education, i.e. STPM, to obtain this certificate or to pursue other post-school qualification.

Social exclusion is a constraints-based process which causes individuals or groups not to participate in the normal activities of the society in which they are resident. It has important spatial ramifications (Raje, 2006, in Preston and Raje, 2007, p. 151)

River (e.g. Sungai Sut means Sut River). Batang also denotes river, but a larger one than sungai (e.g. Batang Baleh). Sungai is a tributary of a Batang.

Synonymous with shifting cultivation, and these terms are used interchangeably throughout this thesis.

Barge or large vessels, used to transport, among others, logs, other timber products, machineries and sand, to and from timber camps along Batang Baleh.

Iban village headman, whose position in his/her community is to act as the leader of a village, and in modern days, as an intermediary between his/her longhouse and the administrative system (Freeman, 1970, pg. 110). A tuai rumah also acts at the custodian of adat, the community juridical warden and principal arbiter. 


\section{List of Figures}

Figure 1.1 Sarawak's Gross Domestic Product at constant 2005 prices, 2005-2014 10

Figure 1.2 Percentage distribution of employed population in agriculture, sales, 13

clerical and professional sectors, Sarawak, 1970-2010

Figure 1.3 De-agrarianisation in Baleh river Basin 27

$\begin{array}{lll}\text { Figure 3.1 Von Thünen's model of agricultural land use } & 77\end{array}$

Figure 3.2 The locational consequences of rising urban demand for agricultural $\quad 79$ produce

Figure 3.3 The locational consequences of reduction in transport cost 80

Figure 3.4 von Thünen model with changes in mode of transport 83

Figure 3.5 von Thünen model with multiple markets $\quad 85$

$\begin{array}{lll}\text { Figure 4.1 Categorisation of accessibility zones } & 91\end{array}$

Figure 4.2 Sampling procedure $\quad 92$

Figure 4.3 Description of survey datasets 95

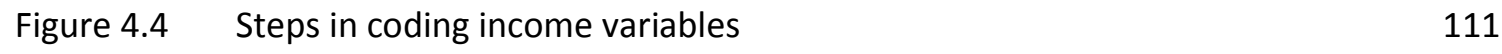

Figure 5.1 Proximity to Kapit Town (in minutes), by accessibility zone, 2014

Figure 5.2 Types of commodity by accessibility zone, at household level, $2014 \quad 128$

Figure 5.3 Relationship between income from vegetable sales and average travel time 129 to Kapit Town, at household level, Baleh river basin, 2014

Figure 5.4 The post-estimated probability of vegetable sales to Kapit Town by log 130 average travel time to Kapit, Sarawak, 2014

Figure 5.5 Main market place for vegetables as identified by head of households, 131 2014

Figure 5.6 Relationship between income from commodity sales and accessibility to 133 Kapit Town, at household level, 2014

Figure 5.7 Relationship between average travel time to market, income from 136 commodity sales, and in-situ income at village level, Baleh river basin, Sarawak, 2014

Figure 5.8 Average in-situ income by accessibility zone, Baleh river basin, Sarawak, 2014

Figure 5.9 Relationship between in-situ income and accessibility to market at 138 household level, Baleh river basin, Sarawak, 2014

Figure 5.10 Relationship between in-situ income per worker and accessibility to Kapit 141 Town, at household level, Baleh river basin, Sarawak, 2014

Figure 5.11 Relationship between remittance and accessibility to market, at village $\quad 142$ level, Baleh river basin, Sarawak, 2014

Figure 5.12 Relationship between remittance and accessibility to market, at household 144 level (outliers removed), Baleh river basin, Sarawak, 2014

Figure 5.13 Average in-situ income (without remittance) at household level, $2014 \quad 146$

Figure 5.14 Average in-situ income (including remittance) at household level, Baleh $\quad 145$ river basin, Sarawak, 2014

Figure 5.15 Relationship between total household income and proximity to Kapit 147 Town, at household level, Baleh river basin, Sarawak, 2014

Figure 6.1 Relationship between physical development score and travel time to 153 market, Villages (longhouses) in Baleh river basin, Sarawak, 2014

Figure 6.2 Relationship between physical development score and accessibility to market, by accessibility zone in Baleh river basin, Kapit District, 2014 
Figure 6.3 Relationship between the augmented score for physical development and average travel time to Kapit Town, Villages (longhouses) in Baleh river basin, Sarawak, 2014

Figure 6.4 Relationship between the augmented development score and accessibility to market, by accessibility zone, Baleh river basin, Sarawak, 2014

Figure 6.5 Examples of longhouse relocation

Figure 6.6 Average travel time to rural clinic facilities at sampled longhouses, by accessibility zone, Kapit District, 2014

Figure 6.7 Highest level of education of the heads of households in case study area, by accessibility zone, Kapit District, 2014

Figure 7.1 Main and secondary sources of income according to tuai rumahs, sample longhouses, Kapit District, 2014

Figure 7.2 Distribution of households with bilik-members who are practicing multilocal living, by accessibility zone, 2014

Figure 7.3 Reasons for practicing multi-local living, at individual level, by accessibility zone, 2014

Figure 7.4 Individual income of respondents who practice multi-local living by distance to Kapit Town, 2014

Figure 7.5 Example of small bilik-family unit

Figure 7.9 Example of bilik-family with family members breaking away from the pun bilik. 


\section{List of Map}

Map 1.1 Southeast Asia, Malaysia, Sarawak and Kapit District $\quad 5$

$\begin{array}{ll}\text { Map } 1.2 & 17\end{array}$

Map 1.3 Case study area, Baleh river basin, Kapit District, Sarawak, 2014

Map 4.1 Accessibility zones and settlement locations within Kapit District study 90 area, Sarawak, Malaysia, 2014

Map 4.2 Estimated cost and travel time to Kapit Town using longboat, Kapit District, 119 2014

Map 5.1 Approximate distance to Kapit Town by longboat, 2014127

Map 6.1 Location of clinic facilities in Baleh river basin, Kapit District, Sarawak, 2014155

Map 6.2 Distribution of schools in Baleh river basin, Kapit District, Sarawak, $2014 \quad 162$

Map 6.3 Distribution of rural clinic and the locations of sampled longhouses, Baleh 165

river basin, Kapit District, Sarawak, 2014

Map 7.1 Dispersion of (sampled) households at national and international level, 187

2014

Map 7.2 Dispersion of (sampled) households within Kapit District, and within 187

Sarawak, 2014 


\section{List of Photograph}

Photo 1.1 Express boats from Sibu arriving at Kapit Wharf, Kapit District, Sarawak 6

Photo 1.2 Longboats - the main river transportation in the Baleh river basin 21

Photo 4.1 Examples of longhouses in the case study area 97

Photo 4.2 Assembled anak biak during my first visit at several longhouses, $2014 \quad 104$

Photo 5.1 Market scene at the 'other vegetable market', Baleh river basin, Sarawak, 132 2014

Photo 5.2 Market scene at Kapit Market in Kapit Town, Sarawak, 2014 


\section{List of tables}

Table 1.1 Sarawak's major export commodities, 2011-2013 11

Table 1.2 Percentage distribution of employed population by occupation, Sarawak, 12 $1970-2010$

Table 1.3 Size and population of Kapit District, Kapit Division and Sarawak, 2014

Table 1.4 Iban population in Sarawak and Kapit Division, 1960-2010 20

Table 1.5 Population of Baleh river basin, 2014

Table 1.6 Estimated village/longhouse profile involved in agriculture, Kapit Division, 25 2010

Table 2.1 Capability levels required for different communication and information 58 technologies

Table 3.1 Assumptions in von Thünen's model and present day conditions 82

Table 4.1 Number of interviews conducted, Kapit District, Sarawak, May-July 201493

Table 4.2 Measuring physical development at village level 108

Table 4.3 Measuring economic development via income at the household level $\quad 110$

Table 4.4 Individual development indicators 114

Table 4.5 Subjective measure - respondents satisfaction and perception of services 116

Table 4.6 Mode of transportation used by members of the sampled longhouses, $\quad 117$

Kapit District, 2014

Table 4.7 Number of longhouses in the sample that are still dependent on river $\quad 118$ transportation, Kapit District, 2014

Table 4.8 Cost and average travel time, using different modes of transport, from 120 sampled longhouses to Kapit Town, Kapit District, 2014

Table 4.9 Elements of contemporary accessibility 122

Table 5.1 Average travel time to Kapit Town (in minutes) by sampled settlements, 126 Kapit District, 2014

Table 5.2 Average monthly in-situ income per household and per worker at 140

Table 6.1 Electricity and water supply provision in sampled settlements, Kapit 159

District, 2014

Table 6.2 Schools and their distances from sampled settlements, Kapit District, $2014 \quad 161$

Table 6.3 Distance of rural clinic from sampled settlements and the mode of 166 transport to clinic, Kapit District, 2014

Table 6.4 Road connection and mobile coverage in case study area, Kapit District, 168

Table 6.5 Number of households with in-situ members still schooling/studying at $\quad 174$ post-school level, case study area, Kapit District, 2014

Table 7.1 Profiles of individuals from sampled households who are practicing multi- 189 local living, by accessibility zone, 2014 


\section{Chapter 1}

\section{Introduction}

Accessibility to markets and services has been identified as one of the key factors in enabling economic development. In developing economies, where there are marked differences in standards of living between large urban centres and remote rural villages, increasing accessibility to local commodity and labour markets as well as to educational and health services is seen as fundamental to raising living standards.

The role of accessibility to markets and services is played out in the history of urbanisation. Accessibility allows labour, capital and land to be combined in ways that raise average incomes and living standards. The historical result of this process is urbanisation which, according to the World Development Report (WDR) 2009, involves spatial concentration, agglomeration, higher population density and specialisation, and in turn, is central to economic growth (World Bank, 2009).

Such is the accepted wisdom. Theoretically, the idea is appealing and, as the empirical correlation between urbanisation and development experience suggests, so too is the evidence. However, the historical process linking accessibility to higher standards of living is far from clear. There is no single path but rather a multitude of routes which are highly conditional on circumstances in time and place. At any given time, there will be disjuncture and anomalies, and circumstances where the facts do not fit the theory. More importantly, however, there will be circumstances where the very notion of accessibility and development needs very close scrutiny.

With each new appreciation of the subtlety of 'development' and 'accessibility' comes a re-evaluation of the connection between the two. The recent history of the rapidly changing state of Sarawak, Malaysia, highlights the challenges involved in any simple connection of the two: the road-less, riverine system that provides the means of accessibility to markets and services in the Baleh tributary of Kapit District challenges any simple positive relationship between accessibility and development. Instead, what emerges is a more subtle understanding of this complex relationship, one with important lessons not only for Sarawak but for other developing regions of Southeast Asia. 


\subsection{Development and accessibility}

Conceptualising development is difficult as its nature and meaning changes over time and from one place to another (Hopper, 2012). It also depends on the unit of analysis: whether one is talking about a country, a region or within regions, about a community, a household or an individual. 'Development' means different things to each of these units and requires appropriate levels of measurement. Not surprisingly there are many different approaches, theories and areas of interest.

While development means progress or improvement, the very terms 'progress' and 'improvement' are open to many different interpretations. The term development is often viewed in tandem with modernisation and urbanisation. The most common measure of development is monetary-based, ranging from the sum of monetary transactions known as Gross National Product (GNP), its domestic measure, Gross Domestic Product (GDP), and its representation on a per capita basis. Measures like GDP per capita have been heavily criticised as being too focused on 'economic performance' and failing to capture the full multi-dimensional nature of development. Consequently, other noneconomic objective measures have been introduced over time. They include health and education related indicators, e.g. fertility and mortality rates, and literacy rate. The Human Development Index is an example of an attempt to generate a wider measure of development.

Each of these measures of development mentioned so far are collectively known as objective measures; they are measures of external conditions made by others, of individuals or collective such as regions, based on the different levels of 'performance' such as average levels of income, education, or longevity. More recently, Sen and other authors of the Stiglitz report (Stiglitz, Sen, \& Fitoussi, 2009) have argued that it is also necessary to have people express their own internal interpretations of development. These subjective measures are self-assessments such as satisfaction with one's life so far or quality of life. In the development context, personal assessments or ratings on certain development indicators constitute subjective measures. An important feature of subjective and objective measures is that they often do not coincide or correlate. Not only might one person's perception of the level of development at a given time and place may differ from another but they may also not correlate with conventional objective measures. This disjuncture further complicates any measuring of development. How one defines development, therefore, depends as much on the subjective as it does the objective, and both can be applied at different levels from the country down to the individual. However, this problem of measurement is not confined to standards of living. It also applies to measuring accessibility. 
The term accessibility is typically associated with the ease with which people and goods can reach other places, measured in terms of time, cost, or distance (Olsson, 2009, p. 478). This understanding of accessibility has seen past studies on the subject placing significant emphasis on transport and transportation issues such as how to get from point $A$ to point $B$, how to minimise travel cost, how to make travel more convenient, and which among alternative modes of transport to choose (Guy, 1983; Joseph \& Bantock, 1982; Morris, Dumble, \& Wigan, 1979). Like development, accessibility is also a broad, and often contested, concept and there are objective and subjective measures of the same journey.

The critics of conventional measures of accessibility, however, often argue that the frequently adopted measures are often oversimplified. The legacy of moving people and physical goods from $A$ to $B$ continues to influence on thinking about accessibility. Today, however, much of the trade in services is costless in transportation terms, with transactions conducted over the internet. There is an on-going shift beyond the current physical representation of accessibility, which is fundamentally spatial in nature, to non-spatial aspects of accessibility such as electronic communication and the internet. The implication of these technological advances for development is profound but complicated.

\subsection{Exploring the accessibility-development relationship}

As my literature review in Chapter Two will show, many studies have addressed the accessibilitydevelopment relationship (W. G. Hansen, 1959; Leinbach, 2000; Ogunsanya, 1987; Olsson, 2009). While they have aided our understanding of the complexity of the accessibility-development paradigm, these studies have had a tendency to focus on spatial aggregation of people such as regions, towns and villages and, as a summary, measure development in averages.

The limitation of a focus on averages is that it deflects attention from the distribution of 'development' about the average. The growing economies, in particular, are differentially distributed within aggregates - within region, communities and even households, and, hence, across individuals. It is quite common, for example, to find communities with similar average levels of development (as measured by average per capita income for example) but for the averages to hide marked differences within the community. Similarly when it comes to households, an individual's own level of development (operationalised from measures made up, for instance, of income, education and 
experience) may be affected by his or her accessibility to markets and services in ways in which differ from that of the household as a whole, as well as that of the community or village.

The difference between the average and the distribution is particularly important in any discussion of the relationship between accessibility and development. For this reason, I have adopted a multi-level approach in my exploration of the relationship; an approach which is designed to address the distributional consequences of particular configurations of development and accessibility as well as the average consequences. Therefore, the research that follows focuses on the impact of differential levels of accessibility to markets and services on 'development' at three levels: the individual, the household and the village (which, in the Sarawak rural $I b a n^{1}$ case usually refers to the longhouse ${ }^{2}$ ). The way development is measured across these three different units of analysis conditions the empirical accessibility-development relationship.

Two questions drive my research.

1. Does accessibility drives development?

2. Is the ensuing development accompanied by increased inequality: at the level of individual, the household and community (longhouse/ village)?

I address both these questions empirically by undertaking field work. My field research is based on the present day situation in the Baleh river basin in Kapit District, one of the most remote regions in the state of Sarawak in Malaysia. The area, which is only accessible by river, is inhabited predominantly by the Iban. As described in Chapter Four, I identify three different areas in the watershed of Batang Baleh, according to their accessibility to the market town of Kapit. In order to appreciate that local context, it is necessary to offer the following geographical and historical background.

\subsection{Sarawak: History and development issues}

Sarawak, located on the island of Borneo, is one of the thirteen states incorporated into Malaysia in 1963 (refer Map 1.1). It is the largest Malaysian state at 124,450 square kilometres with a population of 2.64 million in 2013 (State Planning Unit, 2014). For administrative purposes, Sarawak is divided into twelve divisions, with Kuching as the State's capital. Each division is further divided into districts and sub districts.

\footnotetext{
${ }^{1}$ See Glossary.

${ }^{2}$ See Glossary.
} 


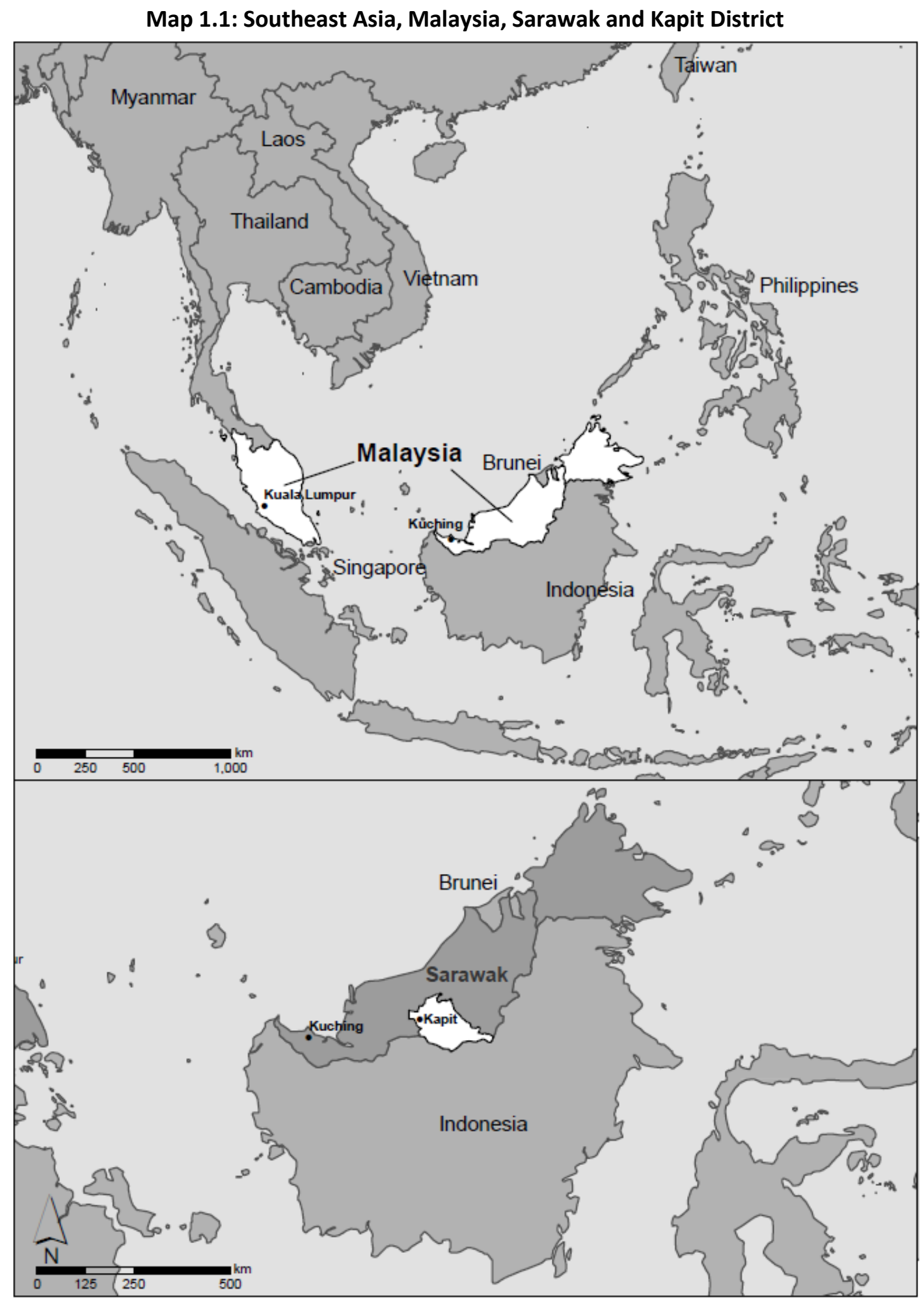

The State of Sarawak, which accounts for approximately 37.5 percent of the entire land mass of Malaysia, is largely made up of coastal lowlands, a hilly inland with undulating hills and a mountainous terrain extending towards its border with Kalimantan (Sarawak Government, 2016). Approximately 70 percent of the land in Sarawak is hilly, and is deemed unsuitable for large-scale commercial agriculture 
(Colchester, Wee, Wong, \& Thomas, 2007)3. Such topography, coupled with its sheer size and rugged terrain, contributes to Sarawak's sparse population. Many of its settlements can be found along the coastal lowlands and along its many river systems.

Sarawak is characterised by a network 35 gazetted rivers with a combined length of about $5,000 \mathrm{~km}$, of which $3,300 \mathrm{~km}$ are navigable (UNDP, 2008, p. 4). This extensive network of navigable rivers continues to provide the main means of transport in remote rural areas that are inaccessible by road. The rivers connect rural settlements in inland areas with various coastal towns. The express boat service, with scheduled services operated by private companies under authorised river transport permits from the Sarawak Rivers Board (SRB $)^{4}$, is widely popular in Sarawak and is the main mode of transport in remote areas without a road network (UNDP, 2008, p. 11). Photo 1.1 shows the express boats that ply Batang Rajang and Batang Baleh. They are the primary means of carrying passengers and goods to and from Kapit Division.

\section{Photo 1.1: Express boats from Sibu arriving at Kapit Wharf, Kapit District, Sarawak}

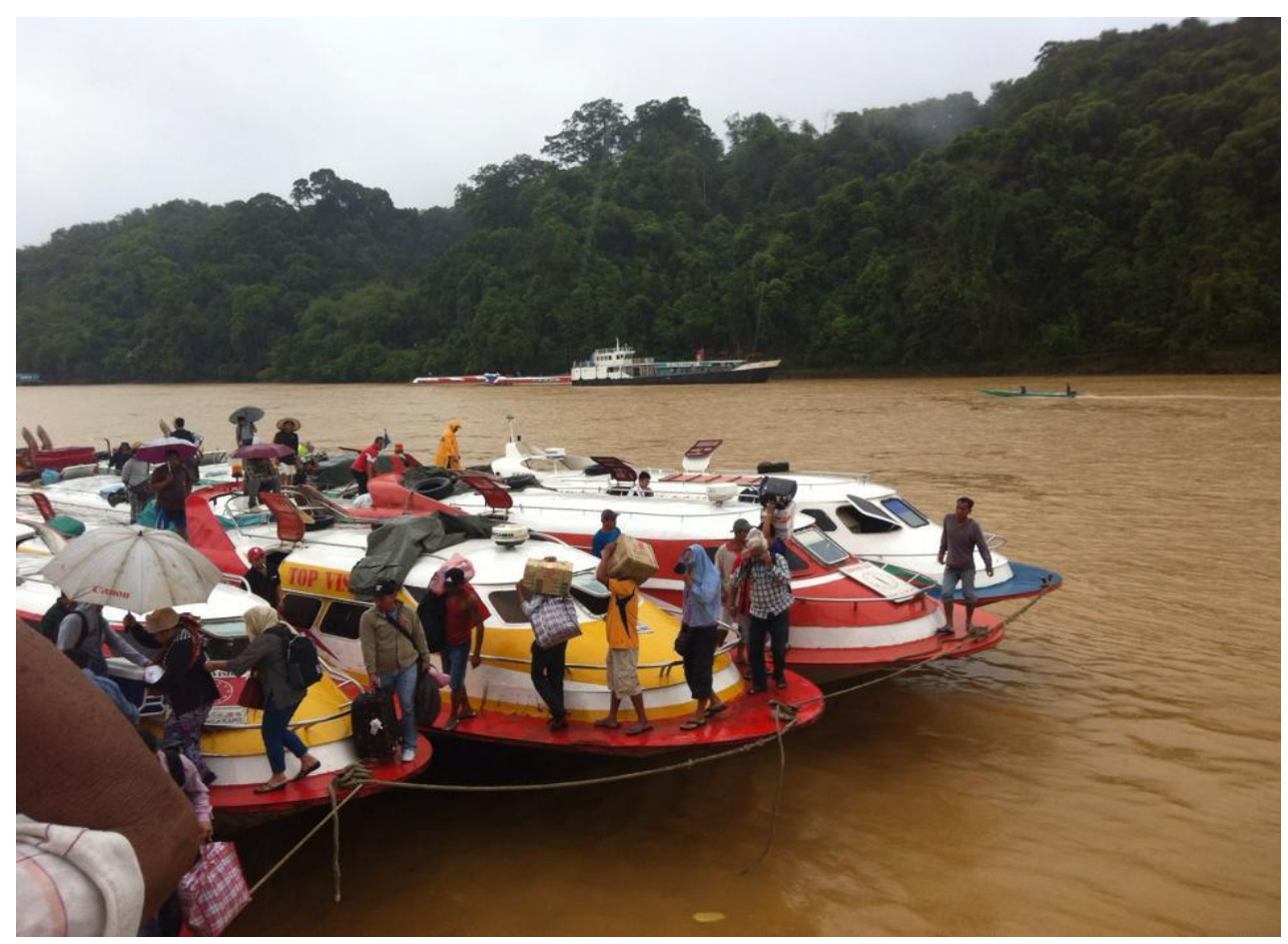

Source: Author. Field work, May-July 2014

\footnotetext{
${ }^{3}$ Only 3.5 million hectares of the land in Sarawak is considered somewhat suitable for agriculture, but since 1990s Sarawak has experienced, and still continues to experience, a rapid expansion of oil palm estates (Colchester et al., 2007, p. 6)

${ }^{4}$ Sarawak River Board (SRB) is responsible for the planning and management of the inland waterway transport system in Sarawak. It was established under the Sarawak River Ordinance in 1993.
} 
Approximately 600,000 people (or one-quarter of Sarawak's total population) still depend on river transportation (UNDP, 2008, p.30). This high dependence on river transportation, particularly among the rural poor, largely from the Iban and Orang Ulu ethnic groups, highlights the importance of accessibility and connection to the socio-economic performance of rural areas. The Ninth Malaysia Plan 2006-2010 recognised the importance of river transportation in Sarawak and, consequently, indicates that it will continue to support the socio-economic and cultural development of Sarawak (Economic Planning Unit Malaysia, 2006, p. 384).

Sarawak has a very low population density compared to the other Southeast Asian economies. With only 20 persons per square kilometres, Sarawak has less than a quarter of the population density in Malaysia as a whole, at 86 persons per square kilometres 5 . Sarawak also has poor transport and urban infrastructure, and a correspondingly modest level of development compared to the more highly connected urbanised regions in Peninsular Malaysia. Sarawak's population has always been largely rural based until recently. Its level of urbanisation had shown an increase from 40 percent in 2000 to 53.8 percent in 2010, which is among the four lowest State levels in Malaysia6.

\subsubsection{Historical and political background}

Sarawak joined Peninsular Malaysia, Singapore ${ }^{7}$ and Sabah in forming an independent Malaysia in September 1963. Before that, Sarawak had a colourful history, with a hundred-year-old reign by the Brooke dynasty (1841-1941), a brief occupation by the Japanese (1941-1945), under British Military administration (1945-1946), and as a British Crown Colony (1946-1963) (Sarawak Government, 2016).

The states in Peninsular Malaysia were governed by Malay kingdoms before they became protectorates of the British Empire until 1946, and formed the Federation of Malaya in 1948, then Malaysia in 1963. Sarawak, on the other hand, was initially part of the Brunei Sultanate before it was governed by the Brookes. Sarawak is more ethnically diverse and multi-cultural with over 35 ethnic groups, compared to Peninsular Malaysia with its three main ethnic groups. The latter comprises Malay (63\%), Chinese (25\%) and Indian (7\%), whereas in Sarawak, the largest ethnic group is Iban (29\%), and followed by Chinese (23\%) and Malay (22\%).

\footnotetext{
${ }^{5}$ In the context of Southeast Asia, population density in Malaysia is low compared to its neighbours. For example, Thailand, Vietnam and Indonesia recorded a population density of 131, 285 and 133 persons per square kilometre respectively in 2010.

${ }^{6}$ Malaysia's rate of urbanisation was 34.2\% in 1980, 50.7\% in 1991, 62\% in 2000 and 71\% in 2010 (Department of Statistics, 2011).

${ }^{7}$ Singapore later left the Federation of Malaysia to form an independent republic in 1965.
} 
According to the Constitution, Sarawak is governed by a two-tier system: Federal government and State government. The Federal government is responsible for matters like foreign policy, defence and education. Meanwhile, the State has responsibility for all matters regarding the land, which includes agriculture and forestry, local governance, and immigration (State Planning Unit, 2016). In practice, the Federal government has assumed many more powers than stipulated by the Constitution (Chin, 1997), and now has major influence on what is going on in Sarawak. For example, most of the development policies applied to Sarawak are now drawn up at Federal level based on the needs of Peninsular Malaysia, where they are then adopted nation-wide. As a result, the policies do not necessarily match the needs or the requirements of all parts of the Federation. Chin (1997, p.107) argues that the general perception among the people of Sarawak is that the Federation of Malaysia has benefitted the Peninsular Malaysians more, especially in economic terms ${ }^{8}$.

Aside from the perception of uneven development between the Peninsular Malaysia and Sarawak, there is an uneven distribution of development within Sarawak itself. Development efforts in Sarawak are often complicated by political conflicts and structural rigidities imposed by prevailing socioeconomic and political systems (Ngidang, 1995, p. 306). Development is often linked with ethnicity, and prevailing client-patron relationships. Soda, for example, notes how in Sarawak,

"...the Malay/Melanau (Muslim Bumiputera ${ }^{9}$ ), who mainly live in the coastal plains, are considered a political beneficiary group in the context of Muslim-preferred policy, and the Chinese are widely considered to enjoy a monopoly on urban economy. On the other hand, the Dayak ${ }^{10}$ have often been regarded as indigenous groups who live in the interior and subsist on traditional shifting cultivation..."

(Soda, 2003, pp. 460-461)

Politicians, regardless of ethnicity, tend to frame the problem of regional disparities in terms of urban and rural, or the advanced centre versus the underdeveloped interior, as an issue of the relationship between the majority and the minorities (Soda, 2003, p. 461). Despite being the largest ethnic group in Sarawak, the Iban is categorised as 'minorities' when it comes to development. The minorities here

\footnotetext{
${ }^{8}$ Sarawak is one of the states which contributes oil revenue to Malaysia but in return only receives five percent of the oil royalty back to the state (Chin, 1997).

${ }^{9}$ Bumiputera, according to Soda (2003), is a political term that was created to combine all indigenous people into one group. It comprises of the Muslim bumiputera (predominantly the Malays) and non-muslim bumiputera (the Dayaks).

${ }^{10}$ Dayak in strict sense comprises the Sea Dayak (Iban) and Land Dayak (Bidayuh), but since the late 1980s, it has become increasingly common to refer to the Iban, Bidayuh, and Orang Ulu (Kayan, Kenyah, Kelabit, Murut, Lun Bawang and Penan) as Dayaks.
} 
refer to indigenous groups, who, despite their size, do not possess the same leverage in influencing decisions as the other urban-based ethnic groups. When combined with the politics of patronage, the practice of developing rural Sarawak becomes quite complex. Politics of patronage in Sarawak, according to Ngidang, is commonplace,

"Rewarding political allegiance is not unusual: every government does it. Longhouse communities which support government policy are rewarded with development projects, while those which oppose it are consigned to rely on self-help."

(Ngidang, 1995, p. 310)

In summary, Sarawak has been at a disadvantage geographically as part of an underdeveloped island (Borneo), in terms of its mountainous terrains and historical backgrounds (Soda, 2000). Different emphasis on development priorities, and intended development beneficiaries, along the line of ethnicity, urban-rural bias, and the politics of patronage, may be controversial issues in Sarawak, but, like it or not, these issues have been instrumental in making Sarawak what it is today (Chin, 1997; Ngidang, 1995, 2012; Soda, 2003). Many areas in the interior, which are inhabited by indigenous Dayak communities, are still backwards and isolated (Chan, 2010; Ngidang, 2012). For example, Chan (2010, p.144) argues that although billions of ringgit have been spent by both State and Federal governments on roads and bridges, the construction of roads and bridges has yet to extend into the interior of Sarawak. There is a general consensus among the rural Dayak communities themselves that the government needs to do more than just provide rural infrastructure, it needs to focus on policies which expedite rural development. The latter includes policies and actions which can bring the largely Dayak communities into mainstream economic development (Chan, 2010).

\subsubsection{Socio-economic development of Sarawak}

Despite its uneven development, the current rates of economic growth in the State have been relatively high compared to the other Malaysia states. For example, Sarawak records the third highest in terms of GDP in the 2005 to 2010 period, after Selangor and the Federal Territory of Kuala Lumpur. Figure 1.1 below shows the Sarawak's GDP for 2005 to 2014. 
Figure 1.1: Sarawak's Gross Domestic Product at constant 2005 prices, 2005-2014

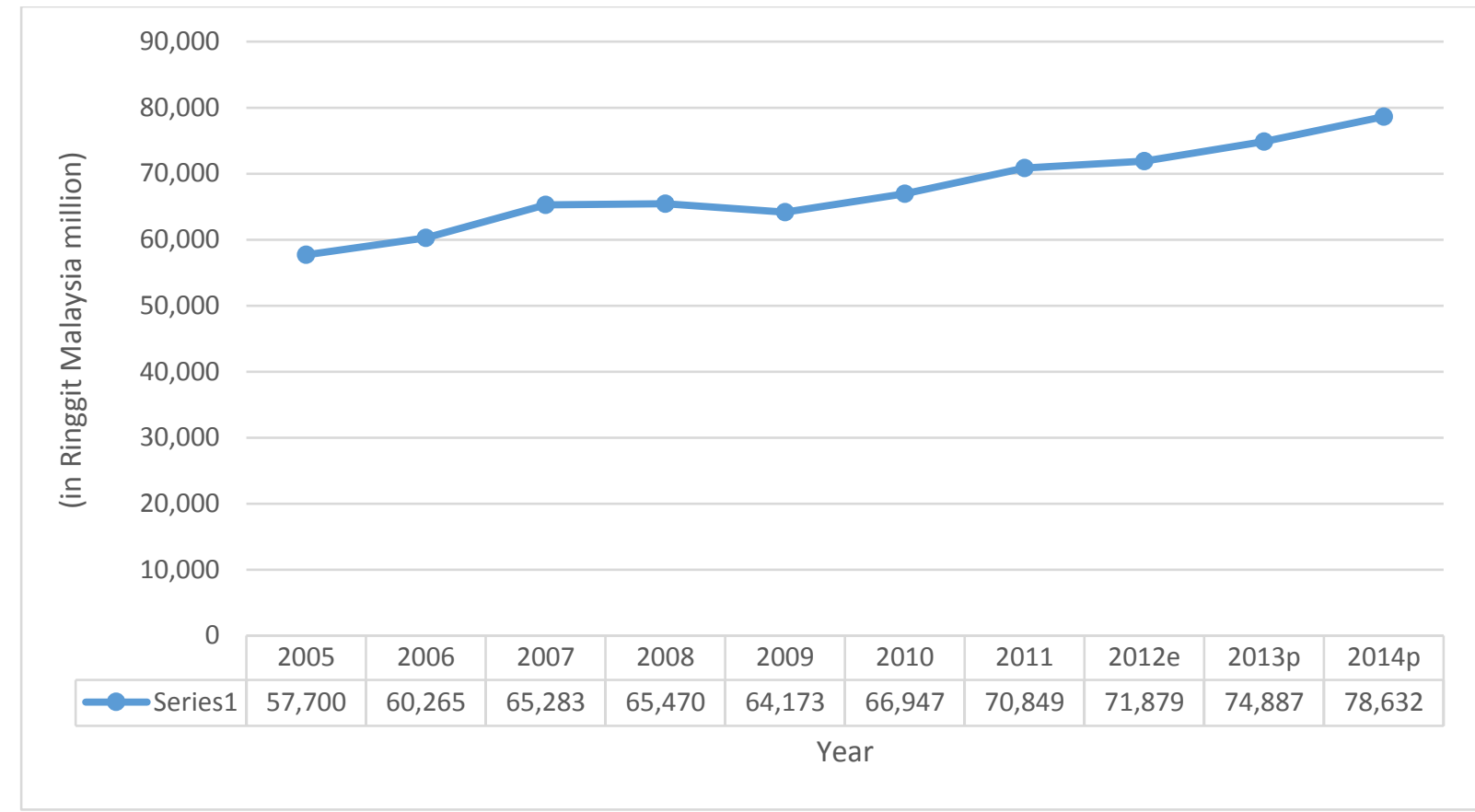

Note: e estimate

$P$ preliminary

Source: State Planning Unit (2014)

The Sarawak economy experienced an average growth of 3.3 percent per annum between 2006 and 2010, which according to the State Planning Unit, was in tandem with the decline in growth of global economies;

"Growth in the initial years was better than average at 4.4 percent in 2006 and peaked at 6.9 percent before dipping to -1.4 percent in 2009 as a result of the international financial crisis ... The quick recovery of the global economy as well as the accelerated implementation of fiscal stimulus measures and an accommodative monetary environment, the growth momentum of the State economy escalated to 5.4 percent in 2010... By 2011, Sarawak recorded a GDP growth of 4.5 percent."

(State Planning Unit, 2016)

Sarawak's economy is largely export-oriented and dependent on its natural resources, as can be seen from Table 1.1 below. In 2013, Sarawak's principal export values are derived from petroleum ${ }^{11}$ (89\%), agricultural products (8.5\%) and timber ${ }^{12}(2.5 \%)$. These three sectors have been dominating Sarawak's economy since Malaysian independence. While petroleum's contribution to the State's export value has been increasing over the years (from 54\% of Sarawak export value in 1997 to $73 \%$ in 2010, and to

\footnotetext{
11 Liquefied Natural Gas (LNG) and crude petroleum

12 In the form of saw logs and sawn timber.
} 
$89 \%$ in 2013), the opposite is true for timber (declining from $15 \%$ in 1997 to $4 \%$ in 2010 , and to $2.5 \%$ in 2013). Meanwhile, agricultural products have been contributing a small portion to the State's export value until very recently. The 8.5 percent value in 2013 was an increase from its usual four to five percent since 1997. Moreover, by far the largest proportion of export value of agricultural products in Sarawak in 2013 is contributed by oil palm (94.3\%) and pepper (3.7\%).

Table 1.1: Sarawak's major export commodities, 2011-2013

\begin{tabular}{|c|c|c|c|}
\hline Commodities & 2011 & 2012 & 2013 \\
\hline \multicolumn{4}{|l|}{ Rubber } \\
\hline Quantity (tonnes) & 38,153 & 27,258 & 20,004 \\
\hline Value (RM ‘000) & 501,908 & 265,729 & 154,237 \\
\hline Export price (RM/tonnes fob) & 13,155 & 9,749 & 7,710 \\
\hline \multicolumn{4}{|l|}{ Black pepper } \\
\hline Quantity (tonnes) & 11,886 & 9,118 & 10,591 \\
\hline Value (RM ‘000) & 207,872 & 187,419 & 216,385 \\
\hline Export price (RM/tonnes fob) & 17,489 & 20,555 & 20,431 \\
\hline \multicolumn{4}{|l|}{ White pepper } \\
\hline Quantity (tonnes) & 2,901 & 2,098 & 2,470 \\
\hline Value (RM ‘000) & 76,531 & 63,883 & 73,479 \\
\hline Export price (RM/tonnes fob) & 26,381 & 30,449 & 29,749 \\
\hline \multicolumn{4}{|l|}{ Palm oil (crude \& processed) } \\
\hline Quantity (tonnes) & $2,597,462$ & $2,772,161$ & $3,122,912$ \\
\hline Value (RM ‘000) & $8,274,544$ & $7,959,252$ & $7,345,326$ \\
\hline Export price (RM/tonnes fob) & 3,186 & 2,871 & 2,352 \\
\hline \multicolumn{4}{|l|}{ Liquefied Natural Gas (LNG) } \\
\hline Quantity (tonnes) & 24,487 & 23,350 & 24,873 \\
\hline Value (RM ‘000) & $52,048,817$ & $56,129,089$ & $59,566,089$ \\
\hline Export price (RM/tonnes fob) & 2,126 & 2,404 & 2,395 \\
\hline \multicolumn{4}{|l|}{ Crude Petroleum } \\
\hline Quantity (tonnes) & 8,482 & 7,702 & 8,426 \\
\hline Value (RM ‘000) & $22,701,219$ & $21,273,792$ & $22,976,672$ \\
\hline Export price (RM/tonnes fob) & 2,676 & 2,762 & 2,727 \\
\hline \multicolumn{4}{|l|}{ Saw logs } \\
\hline Quantity (tonnes) & 2,998 & 2,787 & 2,814 \\
\hline Value (RM ‘000) & $1,793,221$ & $1,556,387$ & $1,697,641$ \\
\hline Export price (RM/tonnes fob) & 598 & 558 & 603 \\
\hline \multicolumn{4}{|l|}{ Sawn timber } \\
\hline Quantity (tonnes) & 766 & 828 & 709 \\
\hline Value (RM ‘000) & 704,624 & 783,220 & 630,722 \\
\hline Export price (RM/tonnes fob) & 920 & 946 & 890 \\
\hline
\end{tabular}

Source: State Planning Unit (2014)

The 2010 Census showed that approximately 25 percent of the labour force was employed in the agricultural sector. This is a very large figure for an industry which only contributes less than 10 percent of the State's GDP. In a trend of considerable importance in this thesis, there has been a steady decline in the labour force in the agricultural sector. From 67.8 percent in 1970, the percentage of labour force in agricultural sector had dropped to 28.5 percent in 2000 and to 25 percent in 2010 
(Department of Statistics Malaysia, 1997, 2012). By contrast, employment in the service (tertiary) sector has been steadily rising during the same 40 year period. For instance, the percentage of labour force in the clerical sector rose from 3.1 percent in 1970 to 8.5 percent in 2010, while the same figure for the professional and technical category rose from three percent in 1970 to 10.2 percent in 2010 (refer Table 1.2 below).

Table 1.2: Percentage distribution of employed population by occupation, Sarawak, $1970-2010$

\begin{tabular}{|l|c|c|c|c|c|c|}
\hline & $\mathbf{1 9 7 0}$ & $\mathbf{1 9 8 0}$ & $\mathbf{1 9 9 1}$ & $\mathbf{1 9 9 6}$ & $\mathbf{2 0 0 7}$ & $\mathbf{2 0 1 0}$ \\
\hline $\begin{array}{l}\text { Professional, technical and related } \\
\text { workers }\end{array}$ & 3.0 & 5.1 & 7.6 & $\mathbf{8}$ & 10.7 & 10.2 \\
\hline $\begin{array}{l}\text { Administrative and managerial } \\
\text { workers (including government } \\
\text { administrators) }\end{array}$ & 0.5 & 0.7 & 1.1 & 2.0 & 0 & 0 \\
\hline $\begin{array}{l}\text { Technicians and associated } \\
\text { professionals }\end{array}$ & 0 & 0 & 0 & 0 & 11.9 & 11.6 \\
\hline Clerical and related workers & 3.1 & 5.2 & 8.2 & 8.9 & 8.3 & 8.5 \\
\hline Sales workers & 3.9 & 5.3 & 6.9 & 9.0 & 11.8 & 12.5 \\
\hline Service workers & 4.9 & 7.4 & 8.7 & 9.7 & 0 & 0 \\
\hline $\begin{array}{l}\text { Agricultural, animal husbandry \& } \\
\text { forestry workers, fishermen \& } \\
\text { hunters }\end{array}$ & 67.8 & 56.5 & 45.3 & 33.8 & 27.3 & 24.6 \\
\hline $\begin{array}{l}\text { Production \& related workers, } \\
\text { transport equipment operators \& } \\
\text { labourers }\end{array}$ & 9.9 & 14.6 & 22.1 & 28.5 & 0 & 0 \\
\hline Craft \& related trade workers & 0 & 0 & 0 & 0 & 11.5 & 12.4 \\
\hline $\begin{array}{l}\text { Plant and machine operators and } \\
\text { assemblers }\end{array}$ & 0 & 0 & 0 & 0 & 8.6 & 9.4 \\
\hline Elementary occupation & 0 & 0 & 0 & 0 & 8.6 & 9.4 \\
\hline $\begin{array}{l}\text { Occupation/Activities inadequately } \\
\text { described }\end{array}$ & 6.9 & 0.9 & 0 & 0 & 0 & 0 \\
\hline Occupation unknown & 0 & 4.3 & 0.1 & 0 & 0 & 0 \\
\hline
\end{tabular}

Note: The figure for sales workers and service workers are added together for 2000

Adapted from Department of Statistics Malaysia (1997) and Department of Statistics Malaysia (2012)

Figure 1.2 below highlights the decline of the labour force in agricultural sector in Sarawak over the 40-year period of 1970 -2101. This decline has been noted in several studies on Sarawak over the last few decades (Cramb, 2012; Morrison, 1997; Ngidang, 2012; Padoch et al., 2007; J Windle \& Cramb, 1997). Morrison (1997, p. 303), for example, explains that, while the proportion employed in agriculture has fallen circa 1990s in Sarawak and that much of agriculture's contribution to livelihood was in-kind and did not feature as a market transaction and, hence, is underrated in GDP terms. Similarly, J Windle and Cramb (1997) state that the role of agriculture in rural development is more than just to enhance economic development, but agriculture is the basic means of livelihood especially for the poor. In the context of Sarawak, this dependence is largely correlated with rice cultivation, 
which is considered the main household activity by the Dayaks even if their yields are rarely sufficient (Padoch et al., 2007, p. 35).

Figure 1.2: Percentage distribution of employed population in agriculture, sales, clerical and professional sectors, Sarawak, 1970-2010

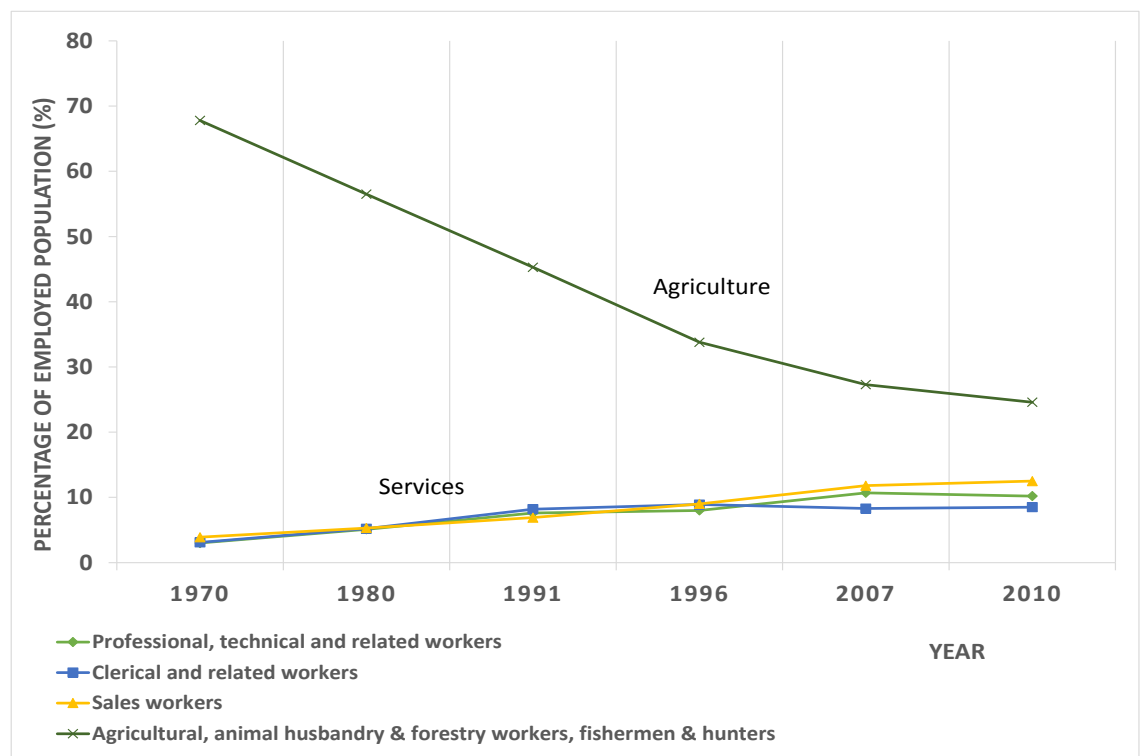

Adapted from Department of Statistics Malaysia (1997) and Department of Statistics Malaysia (2012)

The present day situation differs slightly from that observed by Morrison (1997). The percentage of people employed in agriculture has declined further (see Figure 1.2) but the number of people completely relying on agriculture for livelihood has also declined, as more people are shifting to nonagricultural, and more diversified economic activities for their livelihood strategies. Despite the labour shift out of agriculture, the size of area used for rice cultivation in Sarawak, however, remains within the same range, i.e. between 127,000 to 131,000 hectares from 1998 till $2011^{13}$. In 2014, the area used for rice cultivation dropped to 123,500 hectares; the lowest since comparable statistics were collected (2013). This variation in the area used for rice cultivation exists due to the nature of rice cultivation itself - same land being left fallow and then re-used for planting after a few years.

Since Independence, a number of development strategies have been adopted by the State government in order to eradicate rural poverty. The main aim has been to modernise the agricultural sector, which basically means discouraging shifting cultivation practices. One of the objectives is to move Iban shifting cultivators away from low yield subsistence crops such as hill rice, and low-income

\footnotetext{
${ }^{13}$ The size of planted area for rice was 127,600 hectares in 1998, and rose to 130,900 in 2000. In 2005 and 2011, it was approximately 127,000 hectares and 127,100 hectares respectively.
} 
traditional rubber crops onto a plantation-based agriculture system, which could potentially enhance the Iban's standard of living (King, 1992 in Ngidang, 2002, p.159). Those development strategies include the introduction of agrarian resettlement schemes in the 1960s, in-situ development programmes in the 1970s and the joint venture concept (JVC) of development in the 1990s. The first two strategies, i.e. the agrarian resettlement schemes and the in-situ development which involved resettlement of Iban communities with focus on agrarian reform, did not fare as well as expected due to a number of reasons. For example, the resettlements of Iban with a focus on rubber plantation was a failure due to falling rubber prices in the 1960s (Ngidang, 2002). These strategies, which Ngidang described as 'domesticating' in nature, failed as,

"Relocating Iban populations to new environments 'forced' them to adopt mono-cropping farm schemes ... their employment security was not guaranteed in the schemes because they did not have access to and control over land resources. No doubt the schemes provided cash incomes, but the absence of land for growing food crops to meet household subsistence requirements ... people have had to buy food using the limited income derived from the schemes. When the prices if agricultural commodities such as rubber, pepper and cocoa plunged, the effect was disastrous on the settles ...nothing to fall back on ..."

(Ngidang, 2002, p. 161)

By contrast, the JVC approach, a much favoured land development strategy in the 1990s, did not involve relocation of communities, but, it did 'release the land' in production terms by using uses 'underutilised' native rights land (NCR land) for large scale commercial plantation projects. The strategy is to bring together native customary rights landowners with their land and the private sector with their capital and expertise. Under this approach, the customary landholders agree to assign their land rights to the Land Custody and Development Authority (LDCA), which then forms a joint venture company with a private sector partner (Cramb, 2011a, p. 77). The joint venture approach was initiated primarily to enable large scale commercial land development for oil palm. Consolidated land covering an area of at least 5000 hectare is assigned to the joint venture company for a 60 -year period. Again, the idea behind this approach is to shift from subsistence-based agriculture, which is often associated with low productivity and insufficient returns, to large scale, commercialised plantation agriculture (Ngidang, 2002) ${ }^{14}$. On a practical level, this approach has two aims, firstly to divest the State of its financial risks in plantation development by encouraging direct investment by the private sector, and,

\footnotetext{
${ }^{14}$ It should be noted, up to this point, the joint venture approach has not been applied in Kapit District, and, I believe, the main reasons for that was its inaccessibility and remote rural location. Conversations with government officials from Department of Agriculture, District Office, Resident Office and with researchers from the local university also revealed inaccessibility as the main barrier to the joint venture approach (oil palm plantation) in Kapit District. I discuss the implication of increasing accessibility for such large-scale development in Chapter Eight.
} 
secondly, to provide a mechanism to acquire customary lands and make them securely available in large blocks of over 5,000 hectares in order to attract developers (Colchester et al., 2007, pp. 29-30).

In order to achieve the transfer from small holder controlled to large scale company controlled, large tracts of land are needed. The obstacle to this re-agrarianisation approach, however, is not lack of land, but rights of use - specifically the customary nature of rural land in Sarawak. The land law in Sarawak (1958 Land Code), which reflects the legacy of the Brooke's administration, recognises the 'native customary rights' of the Dayaks. Therefore, the land, which was perceived as underutilised or idle ${ }^{15}$, is tied up with claims of native customary rights (Cramb, 2011b, p. 282). To circumvent this issue of customary rights, the State made several amendments to the Land Code;

"...the Code was amended in 1994 to enable the resumption of land for large-scale private development. In 1996, and again in 1998, the Code was amended to streamline the extinguishment of native customary rights ... A 1997 amendment allows the government to amalgamate Native Customary Land within a 'development area' into a single large parcel of land, and to grant a lease of up to 60 years over the land to a body corporate approved by the Minister..."

(Cramb, 2011b, p.283-284).

By 2015 , approximately 77,688 hectares of rural NCR land has been converted in oil palm plantation through this joint venture concept, which is an increase from 33,193 hectare in 2006 (Ministry of Land Development Sarawak, 2016).

In the case of small-scale agricultural activities, studies show that despite encouragement from the State government, through subsidies and other assistance, rural communities have continued to face obstacles in marketing their agricultural produce (Ngidang, 1995, 2002; J Windle \& Cramb, 1997). The sales of agricultural products tend to be affected by world price fluctuations (e.g. rubber and pepper) and become vulnerable to market shocks. Their vulnerability is also affected by, what Ngidang (1995) terms the internal market due to the manipulative activities of middlemen. The reasons such middlemen are able to exploit the internal market price due to the limited accessibility to markets experienced by most of Sarawak rural locations. Because of poor accessibility to market, rural dwellers often rely on middlemen to trade their produce, albeit at discounted prices.

\footnotetext{
15 The land was assumed to be underutilised or idle, because the people who occupy them are idle - without taking into consideration other factors that could lead to the land being underutilised in the first place, for example, Sarawak's historical and geographical factors (Cramb, 2011b, p.279).
} 
Poor accessibility to markets and services is common in interior parts of Sarawak. Their remoteness means that many rural areas lag behind in terms of development and infrastructure provision ( $\mathrm{J}$ Windle \& Cramb, 1997) which, in turn, affects their standard of living and the livelihood strategies they adopt as a result. Past studies on rural change have used the concept of accessibility to evaluate the performance of rural areas and rural economy in Sarawak (Jill Windle, 2002; J Windle \& Cramb, 1997). For example, Windle and Cramb studied the economic impacts of settlements relative to their levels of accessibility (i.e. comparing economic changes experienced by settlements with different levels of road access). Similar application of this accessibility concept has also been used by other scholars studying similar field in, amongst others, Philippines (Olsson, 2009), Vietnam (Alther, Castella, Novosad, Rousseau, \& Hieu, 2002), and Africa (Ogunsanya, 1987). All three studies examined the influence of road on socio-economic development of their respective communities by comparing areas with different levels of physical accessibility.

In summary, Sarawak's economic performance is different from the other economic regions in Southeast Asia (e.g. Thailand, Vietnam, and Indonesia), and even differs from that of rural areas in Peninsular Malaysia. Sarawak has experienced a slower rate of de-agrarianisation compared to these regions despite having similar socio-economic and geographical characteristics: low population, poor infrastructure, and rural location. Morrison (1997, p. 303) attributes that difference to Sarawak's low population density i.e. the sparse population itself has not created the same pressure as Southeast Asian regions.

\subsection{Baleh river basin, Kapit District, Sarawak}

My research into the relationship between development and accessibility was conducted in Baleh river basin, in Kapit District of Sarawak, Malaysia as described in Map 1.2. Kapit District, together with Song and Belaga form Sarawak's Seventh Administrative Division or Kapit Division. The Division is the largest Division in Sarawak in terms of land area but is sparsely populated. It is located in central Sarawak and shares an international border with Indonesian's Kalimantan (as shown in Map 1.2). Due to its isolated geographical location and inaccessibility, Kapit Division is often described as the last frontier of Iban settlement. 
Map 1.2: Kapit District, Sarawak

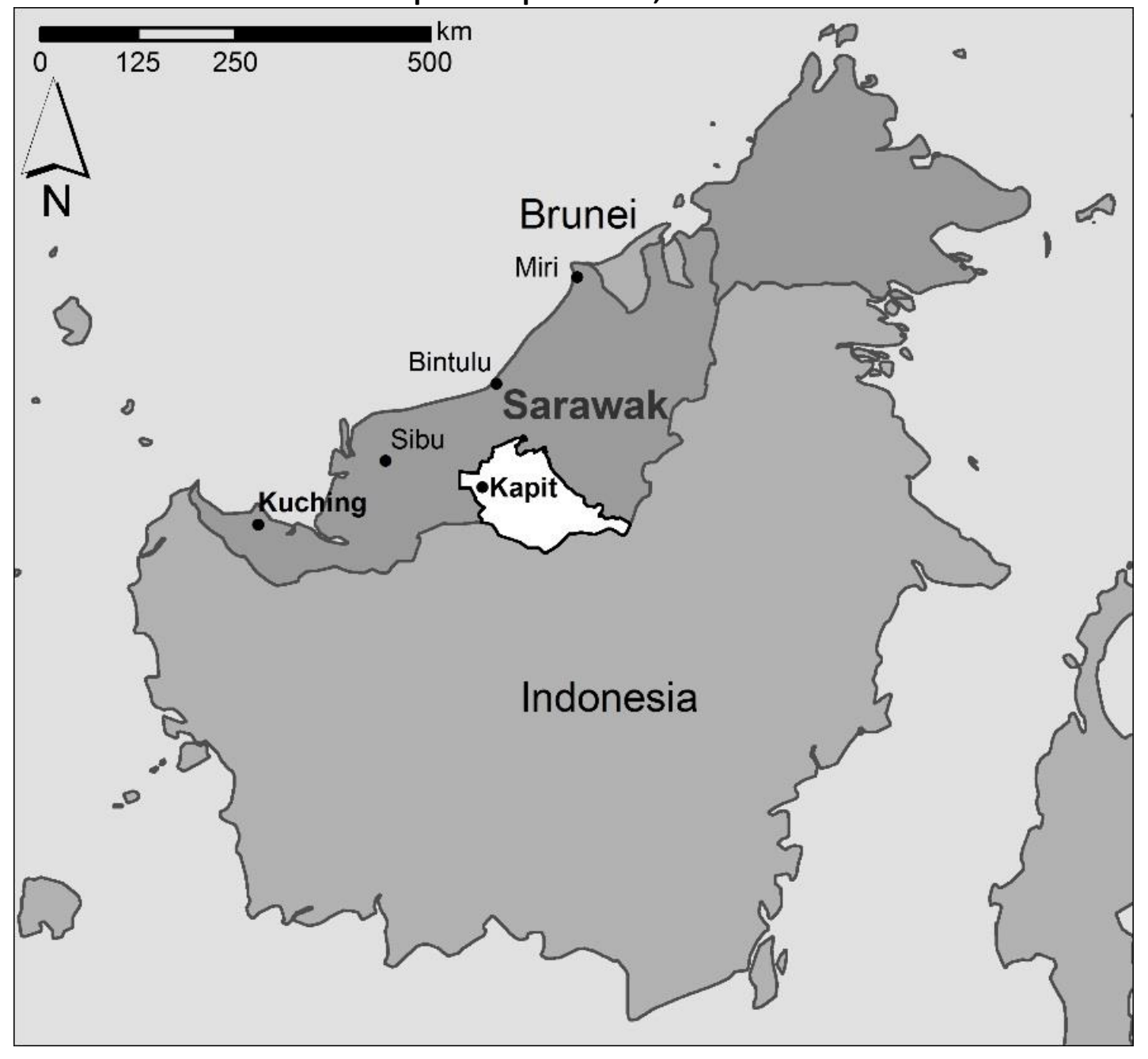

At 38,934.0 square kilometres, Kapit Division takes up approximately 31.3 percent of Sarawak land area (refer Table 1.3). The Division is divided into three districts: Kapit (15,595.6 sq. km), Song (3,935.2 sq. km) and Belaga (19,403.2 sq. km). Meanwhile, Kapit District covers about 40 percent of the Division with a total population of 54,200. Kapit Town, the administrative centre of the Division, had a population of 6,988 in 2010 (Department of Statistics Malaysia, 2012), or approximately 12 percent of the total population of Kapit District. The other remaining 88 percent of the District's population reside in the rural hinterland. There are about 352 longhouses in Kapit District, and nearly all of these are Iban longhouses ${ }^{16}$. Kapit Division and Kapit District has one of the highest concentration of Iban population in Sarawak, with approximately 81 percent of the total population in the District are Iban.

\footnotetext{
${ }^{16}$ Only very few settlements are that of Orang Ulu but they are located beyond the pala menoa, i.e. the last point where an Iban settlement is located.
} 
Table 1.3: Size and population of Kapit District, Kapit Division and Sarawak, 2014

\begin{tabular}{|c|c|c|c|}
\hline & Kapit District & Kapit Division & Sarawak \\
\hline Area (sq.km) & $15,595.6$ & $38,934.0$ & $124,449.5$ \\
\hline $\begin{array}{l}\text { Population (estimated figure for } \\
\text { 2014) }\end{array}$ & 54,200 & 114,700 & 2.6 million \\
\hline Male & 27,000 & 60,500 & 1.35 million \\
\hline Female & 27,100 & 54,100 & 1.23 million \\
\hline Population density per sq. km & 3.5 & 2.9 & 20.8 \\
\hline Number of villages (longhouses) & 352 & 560 & $\mathrm{n} / \mathrm{a}$ \\
\hline $\begin{array}{l}\text { Average population annual growth } \\
\text { rate }(\%)(2000-2010)\end{array}$ & -0.4 & 1.0 & 1.8 \\
\hline
\end{tabular}

Source: Department of Agriculture Sarawak (2013), State Planning Unit (2016)

Despite Sarawak being part of an independent Malaysia since 1963, half a century later Kapit Division is the only administrative division in Sarawak that is not linked to any part of the State by road network. As shown in the above table, Kapit District is exhibiting signs of under-development. The District is losing its population when Sarawak as a whole is experiencing an average growth rate of 1.8 percent in 2000-2010. Secondly, Kapit District has higher female population than that of Kapit Division or Sarawak. This figure implies the males might be working and living outside of the Division. Both of these are indicators of under-development. The mountainous terrain and the existence of two major river systems (Batang Rajang and Batang Baleh, and their tributaries) in the area make it highly inaccessible except by river, and very costly to connect by road. Accessibility to the only town, Kapit Town, is therefore at a premium.

Map 1.3 depicts the geographical context for the case study area. It shows Kapit District, which is one of the three districts that form the Kapit Division, the other two districts are Song and Belaga. Covering an area of 15,595.6 square kilometres, Kapit District is characterised by two river systems: Batang Rajang and Batang Baleh. Kapit Town, located at the bank of Batang Rajang, is the centre of administration for Kapit Division. It is also the District's only town and caters for the needs of the 352 villages in the District. Key government services and main facilities (e.g. banking facilities), as well as shops and other amenities, are available only in Kapit Town. The residents along Batang Baleh and its tributaries come to Kapit Town to restock their household supplies, and banking and other administrative purposes. Residents from the hinterland also need to come down to Kapit Town first before they can travel to Sibu, i.e. the nearest town, and outside of the District. This is because Kapit wharf, which is the main hub of river transportation in the District, is located here. 
Map 1.3: Case study area, Baleh river basin, Kapit District, Sarawak, 2014

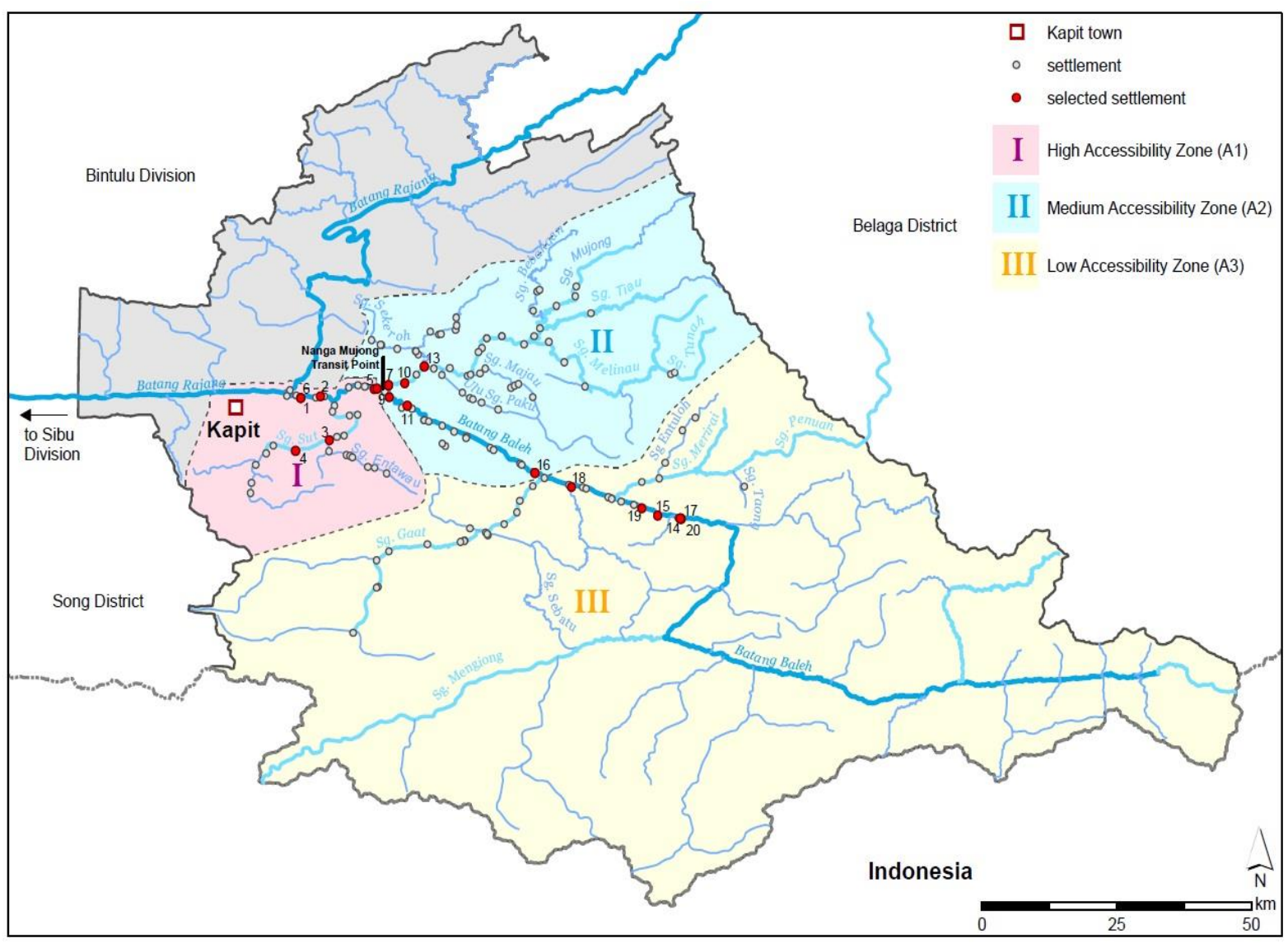

Source of base map: Series MY91001R, Edition 1-PPNM, Department of Survey and Mapping Malaysia (2010)

Settlements, which are predominantly Iban longhouses, are scattered along the major rivers as depicted in Map 1.3. However, the above map only depicts the settlements distribution along Baleh river basin, which is my study area, and does not include the settlements along Batang Rajang. Its pala menoa, which means the last point beyond which no lban settlements can be located, is at Entawau, shown as position number 20 in Map 1.3. James Brooke ruled that by fixing specific points (known as pala menoa) along Batang Baleh would stop the Iban from advancing further inland in the late 1880s. There were a few pala menoa in the Baleh river basin, including Entawau. This explains why there are no Iban settlements beyond Entawau. Sampled longhouses are in red and its selection will be explained in Chapter Four along with the three different accessibility zones.

My research focuses solely on the Iban communities, who inhabit longhouses along Batang Baleh and its tributaries. Iban is the largest ethnic group in Sarawak, and also in Kapit Division. Table 1.4 shows the Iban population from 1960 to 2010 for Sarawak and Kapit Division, while Table 1.5 shows the Iban population in Baleh river basin in 2014. There are approximately 154 Iban longhouses along Batang Baleh and its tributaries. This covers the area from the mouth of Batang Baleh towards the last Iban 
settlements at Entawau, and all settlements along the many tributaries of Batang Baleh. These are occupied by an estimated total of 3444 households or bilik-families making up a total 'rural' population of 29,164 (Kapit District Office, 2014).

Table 1.4: Iban population in Sarawak and Kapit Division, 1960-2010

\begin{tabular}{|l|c|c|c|c|c|c|}
\hline & 1960 & 1970 & 1980 & 1991 & 2000 & 2010 \\
\hline Sarawak & 237,741 & 303,461 & 368,508 & 483,468 & 603,737 & 693,358 \\
\hline Kapit Division* & 30,822 & 38,455 & 30,483 & 44,188 & 47,900 & 45,405 \\
\hline
\end{tabular}

Note : $\quad$ * Kapit Division comprises of three districts: Kapit, Song and Belaga. Sources: $\quad$ Department of Statistics Malaysia (2011); Lam (2006)

Table 1.5: Population of Baleh river basin, 2014

\begin{tabular}{|l|c|}
\hline \multicolumn{1}{|c|}{ Category } & Number \\
\hline Number of longhouses & 154 \\
\hline Number of households & 3444 \\
\hline Total population & 29164 \\
\hline Average household per longhouse & 22 \\
\hline
\end{tabular}

Source: Kapit District Office (2014)

A majority of the longhouses in the area still rely very much on river transportation in their daily lives. Only the longhouses located at the periphery of Kapit Town, which are those settlements along Jalan Selirik towards Nanga Mujong transit point and along Jalan Antaroh in Sungai Sut area, have direct road access to town but a majority of these longhouse residents still rely on river transport to go to their farmland, orchards and neighbouring longhouses. The only road network that is available is located within Kapit Town, and as far as Nanga Mujong transit point ${ }^{17}$ (refer Map 1.3 above). Nearly all longhouses in Baleh, Mujong and Sut are dependent on longboats (see Photo 1.2) as their only mode of transportation.

\footnotetext{
${ }^{17}$ At the time of the fieldwork, there are no direct road connection from Nanga Mujong transit point to the mid and upper Baleh areas. Residents and visitors alike have to cross Batang Baleh at Nanga Mujong transit point in order to go to the settlements in the area. Residents here prefer to use their own longboats to go to Nanga Mujong transit point (refer Photo 1.3), and from there they continue their journey to Kapit Town by land transportation. This mode of travel has only been feasible in the last six years.
} 
Photo 1.2: Longboats - the main river transportation in the Baleh river basin
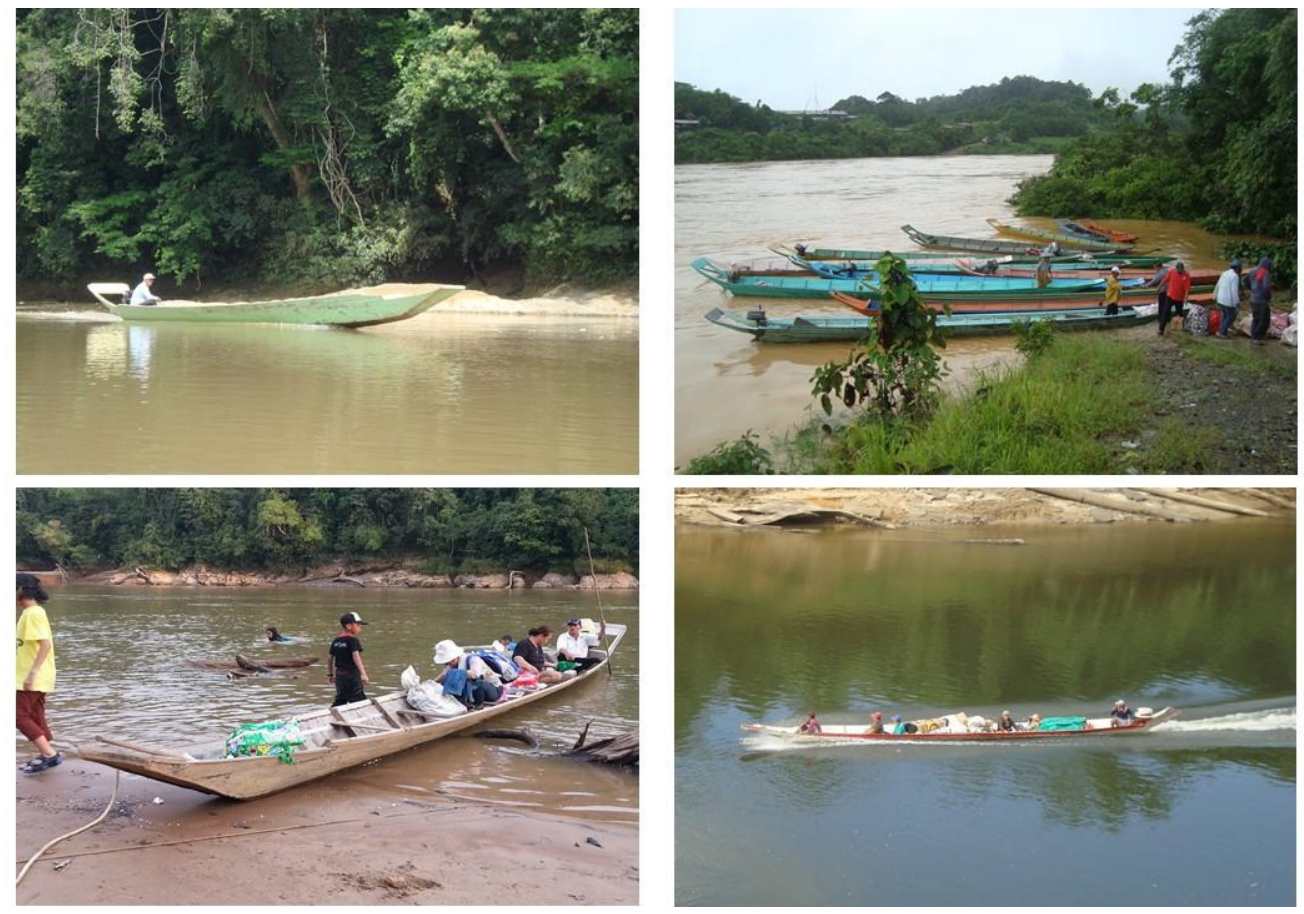

Source: Author. Field work, 2014

\subsubsection{Accessibility in Baleh}

Kapit Town is accessible from its rural hinterland either by express boat from upper Baleh, boat and road from mid-Baleh, or by road for longhouses in the periphery of the town. However, measuring accessibility to Kapit Town and other destinations in Baleh river basin is not straight forward. It is not just about travelling from one point to another, using one of the modes of travel at a certain (fixed) travel cost. Accessibility to market and services, including how residents access their preferred mode of transport, is contingent upon various other local factors. The main factor is the cost of transportation, which is highly associated with individual and households' level of affordability and type of accessibility. It means the frequency of travel by individual and households is contingent upon, among other things, whether they can afford the cost. Affordability then determines one's level of accessibility. Other factors, such as river level and types of transportation used, are also influential in determining one's level of accessibility to market and services.

Movement of people and goods along Batang Baleh and its tributaries is very much river dependent, with slight differences in the preferred modes of transportation depending on the location of settlements along the accessibility continuum. Residents from settlements in mid-Baleh area depend on river transportation mostly to cross Batang Baleh before they can continue their journey to Kapit 
town using land transportation. Those who live further away in the upper Baleh area depend entirely on river transportation for transport. In the case of the latter, they rely on express boat as their main mode of transport to town.

Along Batang Baleh, express boats can be described as the riverine version of public buses. They stop at settlements along Batang Baleh, but do not venture into any of its tributaries, to pick up and drop off passengers and goods. Express boat operators charge different fares. The most common fares range from RM15 to RM20 and RM30 depending on the seat chosen ${ }^{18}$. The passengers choose their own fare. Some may opt for the higher fare for convenience and comfort (e.g. more leg room and less crowded compartment) while others may not have a choice and end up in the pricier compartments if the 'cheaper' section of the boat is full by the time they join the boat. This pricing structure means that those passengers from the last settlements along upper Baleh have more chance of enjoying the lowest fare (RM15) compared to those who join the boat mid-way along Batang Baleh on their way to Kapit Town.

The express boats ply the area twice a day from upper Baleh to Kapit Town (at 4.00 am and 11.00 am respectively from Entawau (i.e. the last Iban settlement in Baleh) and once a day from Kapit Town $(11.00 \mathrm{am})$. There is no express boat service outside these times, which adds another layer of complexity to the measurement of accessibility. Alternative modes of transport during the hours in which express boats do not operate involve households or individuals using their own river transport (i.e. longboat or speedboat). A number may pool resources and share transportation cost with friends and neighbours using one longboat or speedboat to town. Pooling of resources (e.g. in terms of the cost of fuel) is more prevalent in organised trips such as monthly medical appointments, visiting nearby longhouses for festivities and other community events, sending school-going children to the nearest school, and trips to sell products at Kapit market. These are planned trips aimed at cutting the cost of travel. In cases of emergencies, however, there is greater tendency for people to use their own transport to go to town outside of the express boat operating hours.

The alternative cost of going to town from the upper Baleh area is approximately RM200 to RM250 19 for a return trip. This alternative cost is very high indeed considering that the average monthly income of rural dwellers in the area is between RM400 to RM600. Not many people can afford to pay such

\footnotetext{
${ }^{18}$ At the time of the field work in 2014, the exchange rate is 0.27 (i.e. one New Zealand dollar is equals to RM2.70)

${ }^{19}$ Equivalent to NZD77 - NZD96 at the time of the interview.
} 
amount. Hence, the preferred mode of transport is the express boat, with return fare of approximately RM30 per person.

Although very few of the local residents can afford transport alternatives, they sometimes have no option. For example:

"Using own speedboat is the only way to get to town if you are in a hurry or the express boat is full and not taking passengers. My family and I often have to travel using our own transport as that is more convenient and we can travel any time we like...leave the boat at Nanga Mujong (transit point) and take our car to Kapit. We always leave our car at Nanga Mujong for that purpose."

(HH No.82, A3; June 2014)

"... the problem with express boat is that it is often full by the time it reaches this settlement. We either have to postpone our trip to town or to use our own transport. Sometime we pool our money to buy fuel for the trip and that saves us the time as well as the cost...but the trip can be quite dangerous especially if the water level is very high..."

(HH No.60, A3; June 2014)

One of the respondents from LH10 commented that;

"..if there is five of us wanting to go to Kapit Town, it is so much cheaper ${ }^{20}$ to use our own longboat and engine - by sharing the cost of fuel to get there and back..."

(HH No.34, A2, June 2014)

These differences in costs of transport effectively determine the degree of accessibility any given individual or family faces in making the trip to Kapit Town. Factors such as affordability and convenience play a role determining one's accessibility to town. Accessibility is a function of income as much as it is the infrastructure and the mode of transport as well as the circumstances surround most trips to town.

\subsubsection{Socio-economic context}

Historically, Kapit Division has been sidelined from development for a long time and, as a result, is lagging behind the rest of the state, both in terms of infrastructure and economic development (Berma, 2001; Ngidang, 2012). This is reflected, in turn, by its slow population growth, its loss of half of its potential Iban population. Kapit District has a negative overall growth between 2000 and 2010

\footnotetext{
${ }^{20}$ Using a van and river crossing will cost each person RM26 (i.e. RM130 for five people) but if sharing a boat it will costs them five gallons of fuel, which is approximately RM65 for the trip (i.e. RM13 per person)
} 
when it lost 2495 of its population, or 5.2 percent of its population, while Sarawak as a whole grew in 14.8 percent at the same period.

Kapit Division has only three small towns to cater for the urban needs of its population: Kapit Town, Song and Belaga. Of the three, Kapit Town is the largest, and it is the administrative centre for Kapit Division.

The remote location of Kapit District, and its lack of socio-economic opportunities are among the key development challenges in the District. Kapit Town, which is approximately 126 kilometres from Sibu, the nearest divisional town, can only be reached by river transportation. The journey from Sibu to Kapit Town takes approximately three and a half hours by express boat, and the last express boat to reaches Kapit Town at 6.00 in the evening ${ }^{21}$. Thereafter, Kapit Town is virtually an island with no public transport coming in or going out until the express boat services resume at 5.45 the following morning 22 . As Ngidang (2012, p.170) points out, "if it were not for the existence of the Rajang waterway and express boats plying the area between Sibu and Kapit Division, Kapit District would be completely isolated". This limited accessibility is an obvious obstacle to residents as it restricts their accessibility to market and services outside of Kapit District.

Limited accessibility also affects the size of the agriculture commodity market, and, hence, the level of incomes which is possible from agricultural commodity sales. Due to limited accessibility to the commodity market, potential farmers have limited options as to which commodity and the volume they can produce. For example, at the moment, residents cannot participate in oil palm plantations as the limited accessibility in the District means they cannot access the processing mills. For the same reason, the District's remote location and inaccessibility is not attractive for investors of large scalecommercial agriculture - an issue which I will revisit in the concluding Chapter Eight ${ }^{23}$.

Fluctuations in global prices for commodities, such as rubber, also affect the socio-economy of rural dwellers in the District. However, on top of the fluctuating market price for rubber, the residents also have to incur extra cost in order to market their commodity. This is because they have bear additional transportation charges, when using the express boats or their own longboats, to market their rubber (and other commodities) in Kapit Town. In some cases, when the global price is low, they may have to

\footnotetext{
${ }^{21}$ Leaving Sibu at 2.30 p.m.

${ }^{22}$ The first express boat leaves Kapit Town at $5.45 \mathrm{am}$, and after that there are boats leaving for, and arriving from Sibu at every half an hour until the last express boat leaves Kapit Town at 3.15 in the afternoon.

${ }^{23}$ Based on conversations with officials from Kapit District Office, Resident Office and Department of Agriculture.
} 
stop tapping altogether as it is not profitable to continue. These problems, which arise partly due to their remote location and are exacerbated by poor accessibility, may push the people in the District to stop farming or rubber tapping altogether earlier than that of rural dwellers facing the same problems of fluctuating market prices but located in a more accessible region. The uncertainly of profit, lack of markets, and limited socio-economic options pose problems for the local community in the District who, have increasingly resorted to migration and multi-local living as a livelihood strategy.

In 2013, the population in Kapit District was largely made up of three main ethnic groups: Iban (81\%), Chinese (6.4\%) and Malay (3.7\%) (State Planning Unit, 2014). Between 2000 and 2010, Kapit District experienced a negative population growth rate $(-0.4 \%)$, while the Division as a whole experienced at 1.8 percent population growth for the same period. Both are comparatively lower than the rate of population growth of two percent for Sarawak for the same time period.

My thesis focuses solely on the Iban. The Iban population normally resides in longhouses which are located along the major rivers in the area. Their livelihood is often described as centred around their farming activities, particularly growing hill rice as well as other cash crops like rubber, fruit trees and vegetables. For example, statistics from Department of Agriculture Sarawak (2016) indicate that a large majority of the rural population are involved in farming as their key source of income. The estimated figures for farming families and the farming population in Kapit District and Kapit Division are shown in Table 1.6 below.

Table 1.6: Estimated village/longhouse profile involved in agriculture, Kapit Division, 2010

\begin{tabular}{|l|c|c|c|}
\hline & $\begin{array}{c}\text { No. of villages/ } \\
\text { longhouses }\end{array}$ & Farming families & Farming population \\
\hline Kapit District & 357 & $\mathbf{7 , 7 4 6}$ & 51,973 \\
\hline Kapit Division & $\mathbf{5 6 5}$ & $\mathbf{1 2 , 1 8 2}$ & $\mathbf{7 5 , 5 6 1}$ \\
\hline
\end{tabular}

Source: Department of Agriculture Sarawak (2013)

It is estimated that there were approximately 7,746 farming families with a total population of 51,973 in Kapit District in 2010. That is approximately 93 percent of Kapit District's population for that year. I believe that number of actual farming families is less than the official figure. One of the arguments I will develop in the following chapters is that the official statistics fail to capture the reality of Iban settlement in Kapit District in the $21^{\text {st }}$ century. Official data collection such as that reported by the Department of Agriculture and District Office still views the rural area as agricultural-based and lists farming as the main occupation despite extensive de-agrarianisation in the Division for more than seven decades. As Berma points out, 
"While there is lively rural involvement in non-agricultural activities, past and contemporary studies of rural Malaysia (particularly Sarawak) have tended to "agrarianise" the countryside ... to write about rural economy and commodities as if they were involved exclusively in agricultural activities and agrarian production relations."

(Berma, 2001, p. 99)

This misreading of the reality of economic and settlement activity also affects the way contemporary Iban describe their own economic identity - despite living lives quite at variance with this description. Most people see themselves as farmers despite the fact that the majority of their household income is generated through off-farm work (T. Hansen \& Mertz, 2006, p. 146). This difference between the labels they use and the livelihood they live has a strong cultural base even if it is at variance with economic reality. The older generation tend to identify as farmers because that is the only thing they can identify with. An observation has been made by Firman (1994) in his account of the livelihood strategy used in Javanese villages where the Javanese contract labourers continued to identify themselves as farmers when interviewed for his research.

There are other examples where the realities of Iban life, particularly in this District do not match official narratives or even the narratives of many Iban themselves. This is namely because of their history and, in particular, the relatively sparse documentation of the post-war history of the Iban in the region. Casting a long shadow over contemporary understanding is the monumental legacy left by anthropologist Derek Freeman in his 1955 report on pioneering Iban agriculture (Freeman, 1955), and followed by his 1970 Report on the Iban (Freeman, 1970) (Ngidang, 2012). As Ngidang has demonstrated, the value of Freeman's work is not as a guide to any contemporary interpretation but as a basis for comparing the situations of Baleh in the 50s with present day Baleh. The comparisons are as stark as they are instructive. Basically, I am exploring the differences which occurred in the District between 1955-2015, a time span of 60 years or a span of three generations. Freeman's study focused on three villages located along the Sungai Sut, and Sungai Mujong's tributaries of Sungai Tiau and Sungai Melinau (refer Map 1.3, p.19). My case study area covers these areas as well but none of my randomly selected sample came specifically from Sungai Tiau and Sungai Melinau, although I did cover other settlements in Sungai Mujong.

Although it is a simplification, it is useful to characterise the economic history of the Iban in Kapit District or Baleh river basin since Freeman's study as an accelerated process of de-agrarianisation. Based on the proportion of the resident population who are farming, Figure 1.1 divides the economic history into three phases: predominantly subsistence agriculture (based on hill rice) a mode which still 
prevailed at the time of Freeman's study. Cash cropping was introduced late in Kapit Division relative to other parts of Sarawak and only occupied a minor percentage of its rural land. For example, pepper plantation and rubber plantation in the District occupied approximately 527.7 hectares and 4,185 hectares of land respectively in 2013 (Department of Agriculture Sarawak, 2016). These figures account for 3.4 percent for pepper and 26.8 percent for rubber of the total land area in Kapit District. The figures are low compared to Sarawak's total plantation at $14,908.7$ hectare for pepper and 157,332 hectare for rubber as a whole for the same year. Furthermore Ngidang (2012) states that traditional cash crops like rubber and pepper were planted in the District but only on a small scale because deteriorating soil fertility and mountainous topography in the area made planting these crops unprofitable. Work became available in timber camps from 1960s onwards with the arrival of timber extraction. This ushered in an era of off-farm work. The range of this work grew through the 1990s and by the turn of the century very few bilik-family relied on agriculture as a livelihood.

Figure 1.3: De-agrarianisation in Baleh river Basin

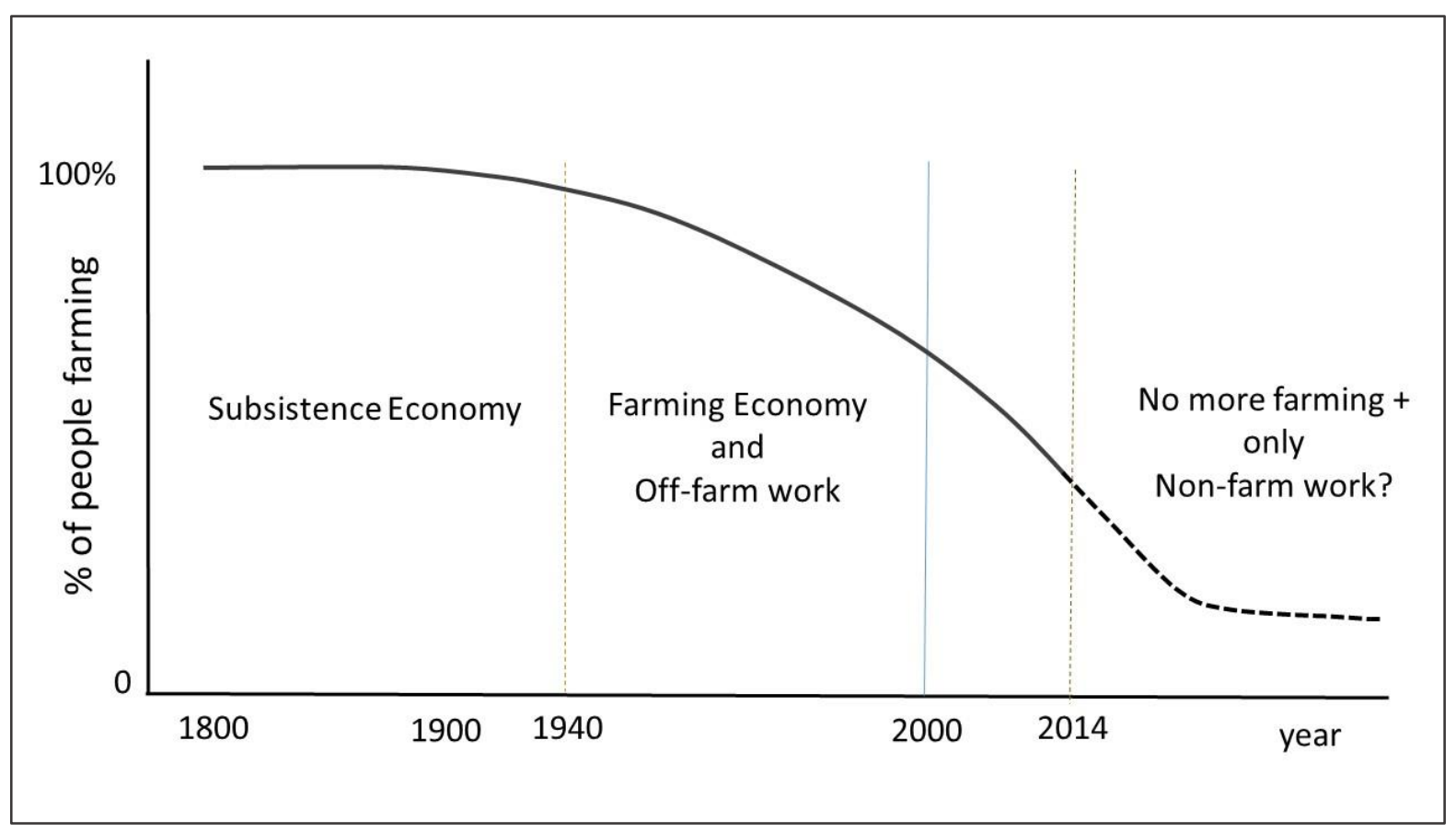

Since their mass migration into Baleh river basin in the 1800s, the pioneering Iban relied on subsistence agriculture, which is mainly hill rice cultivation, as their only source of livelihood. By the 1940s, their hill rice harvest was not as abundant as in their pioneering years. This led to a period which Ngidang (2012) argues was the start of de-agrarianisation in Baleh, i.e. when families failed to produce sufficient rice for their own bilik consumption. This shortage was caused by the over- 
cultivation of their farmland (Freeman, 1970; Ngidang, 2012). As a result, families sought other means of sustaining their livelihood, and this resulted in the emergence of off-farm economies. Ngidang notes that,

\begin{abstract}
"The demise of shifting cultivation ... marked the beginning of the end for traditional Iban agrarian longhouse communities in the frontier region of Kapit. Today, many regard this transition as the end of Iban identity; the argument here is that the loss of hill rice cultivation led to a disappearance of farm rituals and/or ceremonies which are central to the Iban rice culture and the very livelihood of people who depended in rice for their survival."
\end{abstract}

(Ngidang, 2012, p. 165)

The Baleh basin was far from unique in experiencing this sequence of events depicted in Figure 1.1. In Southeast Asia in general, the de-agrarianisation process was observed way back in the 60s and early 70s with a high number of rural-urban movements as rural dwellers coped with changes in livelihoods (Rigg, 2003; Rigg \& Nattapoolwat, 2001; Rungmanee, 2014). A similar pattern of rural-urban movement has seemed to be taking place in Kapit Division specifically, or Sarawak generally, only since the mid-90s. This lack of rural-urban movement earlier was due to the operations of the timber industry in the area in the late 1960s, peaking in the 70s and 80s (Ngidang, 2012). At the time when rice farming was in crisis in 1960s, i.e. insufficient yields for families' own needs, the timber industry provided a much needed alternative source of livelihood for the Iban farming families. Their surplus farm labour shifted into working at the logging camps for wage and/or salary. This shift of employment, according to Ngidang (2012), actually prevented out-migration from Kapit rural area as logging became the main off-farm employment-provider.

The industry provided employment, with high wages (comparative to civil servants' salaries), to the local males, and those job opportunities enabled them to stay in the area. The boom in the timber industry in Kapit therefore was responsible for slowing down the process of rural to urban multi-local living and movement outside of Kapit District. That was until the Asian economic crisis of the mid 90s, which resulted in unemployment and limited job opportunities. Even to this day, a number of Iban households in the region still depend on the timber industry for their main source of income and employment. Nonetheless, the timber industry is a sunset industry, with its declining productivity and operations, and subsequently, with less employment opportunities available in the region.

In order to understand the contemporary relationship between accessibility and development in the Baleh region, it is necessary see patterns not just as a snapshot in a rapidly changing dynamic characterised as summarised in Figure 1.1. The cultural base at which the Iban community, bilik-family 
and kinship are central is also vital for exploring this contemporary relationship. In this context, understanding the ethnography of the Iban is quite important in order to appreciate the particular role accessibility takes in modifying development opportunities.

\subsubsection{Iban: community, bilik-family and kinship}

In order to understand the contemporary relationship between accessibility and development my research is focused on residents of primarily Iban longhouses along Batang Baleh and its tributaries. Kapit Division has been a significant place in the history of Iban migration (Freeman, 1970; Pringle, 1970) (Freeman, 1970; Pringle, 1970). The mass migration of the Iban into Baleh river basin started in the 1800 s and descendants from those pioneering Iban now occupy the Baleh river basin (Freeman, 1970, p. 132).

Iban, a native tribe to Borneo, is well known for their head-hunting and territorial expansion practices. Originating from Kapuas River in west Kalimantan (now a part of Indonesia), the Iban had migrated en mass into what is now Sarawak in the 1800 s. Initially settling predominantly along Batang Lupar, the movement continued further in a northerly direction, as the Iban searched for fertile land moving into Lemanak, Saribas, Padeh and eventually Rajang (Sandin, 1967). Movement into Rajang originated from two areas; the first movement from Lemanak, Skrang and Layar rivers into the headwaters of Kanowit river, and the second movement from the headwaters of the Batang Lupar, and the Kanyau (a tributary of Kapuas), into Katibas river (Freeman, 1970, pp. 131-132). Freeman explains that the second movement was initiated by people whose descendants now occupy Batang Baleh, and other tributaries of the Rajang (i.e. the case study area).

The Iban's entry into Baleh basin started circa 1860s against Brooke government's attempt to constrain their movement.

"...the Iban continued to advance, and in 1874, the Government deemed it advisable to build a fort on the low-lying headland that marks the point where the Baleh join the main flow of the Rajang. Three years later, however, the station was moved several miles downriver to its present site in Kapit. No attempt was made to restrain the Iban, and by 1880 , the lower reaches of the Baleh river had become quite thickly populated by them."

(Freeman, 1970, pp. 134-135)

Freeman describes the attempts of the Brooke Government to curtail Iban's headhunting and territorial expansion practices by banning them from expanding further into Batang Baleh. That was 
unsuccessful as the Iban continued to expand into Sungai Sut, and then to Mujong, Gaat, and Merirai against the Government's order. The expansion continued until they were defeated by the Government in 1910s and the entire Batang Baleh were emptied of $I b a n^{24}$. They were only allowed to reoccupy Batang Baleh in 1922 after the Government was satisfied that the Iban no longer posed a threat.

Those Iban who were obedient to the Government were allotted advantageous positions for their settlements, usually at the head of the rivers. This was also the point in time when the Brooke government decided to contain the Iban by fixing points along Batang Baleh and its tributaries, and beyond which no lban settlements or farming was permitted (pala menoa). One of the identified pala menoa is in Entawau, which denotes the last Iban settlements the upper reaches of Batang Baleh.

There are no other Dayak settlements along the river and this homogeneity helps in interpreting the socio-economic processes that accompany de-agrarianisation ${ }^{25}$. These have to be interpreted using the context of Iban culture as the overarching frame to interpret the economic geography of contemporary lban settlement in the area.

\subsubsection{The cultural context}

Based on his observations in Baleh circa 1950s, Freeman states that all men are equal under the Iban adat (custom) by which he meant that, unlike other indigenous groups in Sarawak (e.g. Melanau and Orang Ulu), the Iban are not constrained by a hierarchical or rigid social structure. They are free to make their own decisions and not tied up to customary restrictions or obligations based on status in the group. Decisions on livelihood strategy, including on the allocation of resources, for instance, are largely made at either individual or household level (known as bilik-family). This point was emphasised by Freeman (1970, p. 129) who found that "each domestic unit (bilik-family) or individual household is a power unto itself, managing its own affairs and acknowledging no other family to be its superior, or master". So, an Iban bilik-family play a key role in decision-making relating to their households. This cultural trait has been a salient characteristic that has allowed Iban families to adapt to and be flexible in the face of rural change. The Iban adapt differently as individuals and as a family unit. Different households and/or different individuals within a household have different livelihood strategies. As a

\footnotetext{
${ }^{24}$ According to Freeman (1970), the Iban were removed to areas below Kapit or compelled to leave their settlements during that time. The Baleh were deserted for three years until 1922.

25 The Kayan and Kenyah tribes having been repulsed by the Great Kanyan Expedition of 1863.
} 
result, each bilik-family is free to develop differently (and at different rate) relative to other families residing within the same community or longhouse.

This feature of relative autonomy in Iban culture conditions how Iban households participate in the market economy. It also has the scope for the emergence of new intra and inter-household inequalities. It also differentiates how the Iban participate in the free market compared to the other indigenous groups who are bound by elitist structures. For example, the Iban households are free to participate in the economy, subject to their own decisions, unlike the Melanau (or other groups with embedded hierarchical status) where access to new markets simply allowed those at the top to increase their wealth. In the traditional Iban case, there was no institutionalised 'top' and 'bottom' to the society. Whatever form social inequality takes in contemporary Iban society comes not from inherited positions or family wealth but from individual ability, opportunity and possibly luck. In other words, instead of ascribed wealth, it is achieved wealth that distinguishes the contemporary economic (and political) stratification of Iban society.

There are structural economic limits to the degree of inequality possible in a subsistence economy in which all 'men' (families) had roughly equal access to land, labour and capital. Today, in a world of multiple modes of production and globalisation and increased affluence, those economic limitations have been largely removed. The result has been the emergence of greater levels of inequality from one Iban family to another within the longhouse and between individuals within the family. Nowhere is this quest for improvement, for personal and family 'development' clearer than in the emerging patterns of multi-local living.

\subsubsection{Iban and multi-local living practice}

This individualism characteristic of bilik-families has been one of the enabling factors responsible for the growing practice of multi-local living among Iban households during de-agrarianisation. Multi-local living refers to situation where bilik-members live in two or more separate households, beyond the original longhouse. For example, a son may live at one location overseas, a daughter and partner in a town elsewhere in Sarawak, while their parents retain their bilik in the longhouse. The emergence of the multi-local household is largely a response to the demands for an improved livelihood by rural based populations in a region whose agricultural economy has been unable to provide the family with the same living standards that are possible in urban areas. 
Although they live apart, family members are still regarded as members of the bilik-family. The latter is usually based at a longhouse, in a rural location. The disbursement of the family occurs when individuals leave the longhouse in search of employment or to pursue their education. Ngidang has described this phenomenon as follows,

"... during the pioneering era, Iban mobility was related to shifting cultivation and was in the direction of the frontier regions. But today, the migration of $21^{\text {st }}$ century Iban apparently goes in the opposite direction, i.e., from frontier regions to urban centres. For modern Iban, the city has become their "farm"..."

(Ngidang, 2012, p. 167)

The practice of multi-local living is not unique to the Baleh area or to Sarawak. This practice is associated with the process of adaptation to the structural change phenomena we are referring to as de-agrarianisation rather than a particular place. Many other studies of rural change that accompany de-agrarianisation in Southeast Asia have documented similar responses by rural dwellers in pursuit of better livelihoods (Firman, 1994; Kelly, 2011; McKay, 2005; Rigg, 2003; Rigg \& Salamanca, 2011). Firman, for example, had described how rural Javanese households became more dependent on urban-based economic opportunities for their source of livelihoods, which necessitates the reallocation of rural labour. Similarly, Rigg and Salamanca explain how migration among rural Thai women has become as prevalent as that of men, and that the practice has resulted in multi-sited households and growing geriatrification of farming, which has altered the basis of rural livelihood in Thai villages. Farming in rural Thailand, according to them, is largely carried out by the older generations as the younger generations are seeking employment elsewhere.

What may be unique about the multi-local living being experienced in Kapit District is the strategic nature of the households' multi-local decision-making. Households reorganise themselves spatially in order to reap the advantages of having some members live in the urban areas while others reap the benefits of living in the longhouse. In the Baleh area, it is the division between residence in Kapit Town and the predominantly rural district where multi-local living finds its most frequent expression. For example, Ngidang's study observed how the influx of Iban migrants to Kapit Town differs from the practice of multi-location living practiced in other parts of Sarawak. He notes how,

"... 68.5\% of the men who moved into Kapit Town left their spouses and children in Kapit (town), while they work elsewhere, outside Kapit Town. Only $31.5 \%$ of the migrant households actually both live and work in Kapit Town. Officials may perceive it as ruralurban migration, but upon closer examination, it is not exactly an urban environment in 
which they now reside; it is a familiar village or longhouse environment within the vicinity of town."

(Ngidang, 2012, p. 168)

The 'familiar village environment' that Ngidang mentions refers to houses that Iban 'migrants' actually built themselves in the periphery of Kapit Town, usually on native customary land bought from relatives, or host communities. The 'migrants' have the tendency to settle among their relatives or other Iban communities, and, hence, as Ngidang argued, end up residing in a familiar village environment except in an urban location. However, not all those who practice multi-local living are residing in this way. Those who are more educated, with at least post-secondary school qualifications, and better paying jobs, such as in professional or technical sectors, tend to live in the bigger cities of Kuching, Sibu, Miri and Bintulu, or in other cities in Peninsular Malaysia, either renting or buying own houses in residential estates.

What is distinctive about these contemporary patterns of Iban settlement during de-agrarianisation is that, despite being geographically dispersed, these 'migrants' still maintain ties with their longhouse and bilik-family. These links include frequent visits to the longhouse, remittances, and involvement in decision-making (Hew, 2011; Lam, 2006; Soda, 2001). Soda (2001; 2005; 2007) has written extensively about how urban Iban maintain ties with their rural villages, which he claims are a significant part of the urban Iban's survival strategy. He highlights the fact that the majority of Iban migrants want to maintain dual-residency. They want to live and enjoy the infrastructure of the urban centres, while at the same time insisting on belonging to the longhouse back in the village. The latter enables them to be part of the longhouse community and publicly stake their claim to their bilik's assets and inheritance. It should be noted that in Iban society, only acknowledged members of the bilik-family have the rights to inherit. Hence, there is a need to make known to everyone within the family and longhouse community whether one is belonging to the one bilik, despite living under different roofs for much of the time.

Membership of a bilik-family is of paramount importance in Iban custom, with several scholars even arguing that, "to be an Iban, one has to belong to a longhouse" (Kedit, 1993; Sutlive, 1992). Every individual in Iban society, asserted Freeman, is born into one particular bilik, either his/her father's ancestral bilik or his/her mother's natal bilik; and it is a custom that an Iban can only belong to one bilik at one time. Under Iban customary law, the longhouse into which an Iban is born, marries, or moves to is recognised as his/her legal residence even if he/she may work and reside in another area for eleven months out of the year. This cultural imperative underscores the significance of 'continuity' 
of an Iban bilik (Sutlive, 1992, p.49). The continuity of a bilik is very important to Iban families; there should always be at least one child, who is either married or has reached maturity, who remains with the parent(s) to maintain the continuity of the ancestral bilik (Cramb, 2012; Freeman, 1970; Sather, 2006). This notion of continuity is explained using the concept of pun in Iban society ${ }^{26}$.

The term 'pun' literally means the root or the foundation of a bilik (Freeman, 1970) and signifies the person who is the senior member of a bilik-family, by right of descent (Freeman, 1970, p.31). There is one pun bilik, who is usually the most senior member of the household, in every Iban bilik-family. $\mathrm{He} / \mathrm{she}$ has either founded the bilik-family or has inherited it from the previous branch of his/her family. A new pun bilik is formed when one or more siblings break away from the ancestral bilik to form a new and independent household (Freeman, 1955, p. 8). When this happens the new head of the household becomes the new pun bilik for the newly created bilik-family. This continuing succession of pun bilik, according to Sather (2006, p. 84), symbolises the continuing life of the bilik-family.

This concept of pun, or continuity of a bilik-family, is still practiced among the rural Iban. However, due to the prevalence of a multi-local living practice, the interpretation of pun bilik is also changing along with the structure of Iban household itself. The practice of multi-local living has resulted in bilikmembers being spatially dispersed within and outside Sarawak. This movement of people, from longhouses within the Baleh river basin has been driven by the changing nature and location of markets, notably from agricultural to resource exploitation to growing opportunities within service sector, which is mainly urban-based. As reliance on non-agricultural resources grows, accessibility to those market becomes paramount. What is particularly salient, therefore, is the form the economy of Kapit District is likely to take in the years to come.

\subsection{Future development in Baleh river basin}

As an area with rich history and poor economic performance (Ngidang, 2012), Kapit District is an interesting place of study due to its potential. The currently slow-paced rural district is expected to transform into a busier and more dynamic, environment in a very near future. This is due to a number of major development projects currently planned for the region, which are expected to transform both the region and options available to the 54,000 people who currently live in the Kapit District as well as the wider Kapit Division. This transformation will begin with radical changes to accessibility.

\footnotetext{
${ }^{26}$ Pronounced as poon.
} 
Playing a pivotal role in this transformation will be a construction project aimed at linking Sibu to Kapit by road. The construction is being done in stages and depends on the availability of funding ${ }^{27}$. Road connection of this scale is linking Kapit District by road to the rest of Sarawak for the first time is expected to open up this currently inaccessible region to a range of investments, most notably commercial oil palm.

Up until this point and, unlike any other districts in Sarawak, Kapit District has not been selected for any large commercialised agricultural plantations. However, within the wider Kapit Division a total of 49,579.84 hectares was planted with oil palm in 2013, which contributes approximately 4.8 percent of the total area of oil palm in Sarawak (Department of Agriculture Sarawak, 2016). While this figure is low compared to that of other divisions such as Miri (30\%), Mukah (16.4\%) and Bintulu (15.8\%), the potential is considerable. Its impact on the rural Iban is a matter of considerable speculation based on experiences elsewhere in the country. The current oil palm plantation in the Division is located in Song District and the upper part of Belaga District, of the total area planted with oil palm, only five percent is managed by independent smallholders, while the other 95 percent is managed by estates (Department of Agriculture Sarawak, 2016) ${ }^{28}$.

Another huge project currently planned for the region is the Baleh Hydroelectric (HEP) Dam, located in upper Baleh area, and approximately 95 kilometres from its confluence with the Batang Rajang. The site, located beyond the last Iban settlements of Entawau, covers a catchment area of 5,625 square kilometres and runs to the Sarawak-Kalimantan border (Sarawak Energy, 2016). Baleh HEP is one of the projects under the Sarawak Corridor of Renewable Energy (SCORE), one of Malaysia's five economic corridors, and aims to capitalise on Sarawak's energy resources. One of SCORE's priorities for its 2008-2030 development plan is to focus on developing the energy sector. Twelve sites within SCORE's area have been identified for HEP development for this period and are expected to generate a total capacity of 7,000 megawatts of power (RECODA, 2016b). Due to its geographical terrain, Kapit Division was identified as an area with great hydroelectricity harnessing potential (RECODA, 2016b; Sarawak Energy, 2016). Since 2008 massive efforts have been directed at the exploitation of these resources. Under SCORE's development plan, five areas were identified as potential sites for hydroelectricity dam projects. Two of the HEPs have already been completed: Bakun HEP and Murum HEP, both of which are located in the Belaga District of Kapit Division. The third, i.e. Baleh HEP is

\footnotetext{
${ }^{27}$ Based on my personal conversation with officers in various government departments in Kapit Town.

${ }^{28}$ Based on my personal conversation with officers in various government departments in Kapit Town.
} 
currently underway. All three HEPS have a capacity of more than 5000 megawatts each. Besides that, two other sites for HEP projects, with lower than 5000 megawatt capacity, have also been identified in Kapit Division: Pelagus and Punan Bah HEPs.

The first dam built under SCORE's development plan was Murum HEP, completed in 2013, with a capacity of 944 megawatts $^{29}$. Baleh HEP is next, and construction is expected to start in 2016 and is scheduled to complete by 2024 (Sarawak Energy, 2016). At the time of the fieldwork, the government was still negotiating with the affected rural dwellers regarding land compensation for Baleh HEP. Ten longhouses in upper Baleh area were involved in this negotiation, as the proposed dam covers their customary land. However, unlike the other two HEP dams in Sarawak, Bakun and Murum Dams, Baleh HEP will not involve any resettlement of villages in its area. This is because there is no settlement within its reservoir area (Sarawak Energy, 2016).

Clearly the Baleh HEP, and so some extent the Pelagus and Punan Bah HEPs to its north, are going to have the most immediate local impact on the Baleh river basin, and Kapit Division in general. The agencies involved in Baleh HEP state that the implementation of the Sarawak Corridor of Renewable Energy (SCORE), via its HEP projects, is set to vastly improve road connectivity to Baleh in Kapit Division (RECODA, 2016a). For example, when Murum Dam was constructed the government undertook to build an access road to the site. Similarly, for the construction of the Baleh Dam to proceed, the construction companies require road access from Kapit Town to the site in order to move the construction materials as well as the workforce for the project.

Access roads and bridges will be built in stages, linking Nanga Mujong transit point to the site of the Baleh HEP. This 73 kilometre road, with an estimated cost of RM 1.4 billion, will open up the areas in between these two sites (Ruekeith, 2016). The access road project is expected to be completed by 2019. One of the first stages of this development is the construction of Baleh Bridge at Nanga Mujong. This RM77 million bridge was still under construction when I conducted my fieldwork but was completed in December 2015. At the end of this road project, the currently inaccessible, road-less area of upper Baleh (from Nanga Mujong transit point on wards) will, therefore, be transformed. The current three-hour journey to Kapit Town is expected to take only one hour by road from upper Baleh area (Ruekeith, 2016). In general, residents in these areas will have a higher level of accessibility and have more options in their modes of transportation.

\footnotetext{
${ }^{29}$ Bakun HEP, with a capacity of 2400 megawatt, is owned by the Federal government, unlike the other proposed hydro-electricity dam projects which are under the purview of SCORE.
} 
Improvement in accessibility will spur socio-economic changes in the area, with both direct and indirect implications on accessibility and development at all levels of society: the community, the households and the individual members of households. These two developments, road construction (from Sibu to Kapit, as well as the road access within Kapit District) and hydroelectricity power projects, will open up this isolated District (and Division), making it more accessible, and, consequently, providing more choices in terms of livelihood strategies for the rural residents. The implications will not necessarily be all positive, as we have to bear in mind that improved accessibility to market and services can facilitates both inward and outward investment and migration could also potentially widen the gap between, and within, households and communities.

Improvement in accessibility, from newly constructed roads, is arguably a positive development in enabling previously isolated rural settlements to be linked by road to the rest of Sarawak. On the other hand, improved accessibility could bring disadvantages to certain population groups more than others. While a newly built road improves one's accessibility to markets and services, it necessitates the ownership of, and ability to operate, cars and vehicles. The elderly and the poorer sections of the population might be greatly disadvantaged as they now have to learn new skills (i.e. driving instead of using longboat) or buy new modes of transport (car instead of longboat). Here, accessibility is also tied up with affordability (to pay the fare or to buy the vehicles) and ability to utilise the new road (e.g. ability to drive a car or obtain driver's license). Thus, improved accessibility through newly constructed road access may not be beneficial to all members of the rural Kapit District.

Another possible tension from this predicted accessibility-development relationship arises from the customary nature of the land in rural Baleh. Customary rights (NCR) to land have little economic value if the land cannot be sold on the formal market or used as collateral. However, the land can be sold in the informal market among the Iban as described by Ngidang (2012) but the value depends very much on the demand by the Iban alone, and the location of the land. In future, when the region has become more accessible, what will become of these ancestral lands? There is a general sense of insecurity on the part of landowners because they do not have land title and, therefore, they cannot sell it on the formal market. At the same time, they risk losing it to large, government-backed commercial agricultural ventures as has happened elsewhere in Sarawak (Andersen et al., 2016; Colchester et al., 2007). 
This potential for land loss is particularly significant as the Kapit Division is located within the SCORE development area, and one of the plans for the SCORE hinterland area is oil palm. Since the 1990s, the State government, through its joint venture concept, has encouraged native landowners to develop their land for large scale oil palm plantation. In theory it is a win-win situation, with landowners providing the land and the private sector providing the capital and expertise. In reality a number of difficulties have arisen over the implementation of this arrangement. For example, "there is a lack of clarity about exactly how native landowners get benefits from these schemes and how they can reclaim their land after the expiry of the 60-year leases" (Colchester et al., 2007, p. 2). Such controversies have led to land disputes in Sarawak courts between the native landowners and the private companies ${ }^{30}$.

Suffice to say that when the area becomes more accessible, the future of land becomes more uncertain. Improved accessibility gives the rural dwellers more options: to sell in informal market (subject to demand), to participate in joint venture arrangement (if their land is selected), to venture into oil palm plantations (or other commodity) as pre-emptive action to indicate that their ancestral land is not idle, or to leave the land as it is. The third option, i.e. becoming an independent smallholder, has become a popular option in the last decade. Independent smallholders are usually found near the large-scale estates and mills and, according to Cramb:

"... landowners are developing their own land using their own labour and capital, without assistance from a government agency ... some of this planting is pre-emptive, that is, to prove to government agencies who may seek to allocate the land for a private estate or joint venture estates that it is being productively used (Majid-Cooke, 2006)."

(Cramb, 2011b, p. 287)

These precedents open up different possible outcomes. They range from improved accessibility in Kapit District from the hydroelectricity power dam and road construction to, and within Kapit District. The socio-economic implications are monumental, and the currently lagging-behind District, and its community, households and individuals, are faced with greater choices. These choices, as I outline above, could have far reaching consequence - in particular to the Iban's claim on their ancestral land. My thesis will explore the implications at the community, household and individual levels in relation to the different levels of accessibility-development relationships, specifically looking at the income and standard of living.

\footnotetext{
${ }^{30}$ Owing to conflicting interpretations of 'Native Customary Rights' and disputes about compensation, there are now over 100 cases in the courts of Sarawak filed on behalf of the native plaintiffs, and some 40 cases are related to oil palm (Colchester et al., 2007, p. 2). In 2014, there are more than 300 cases of land disputes pending in courts, and a majority was due to the conflicting definition of native customary land (Borneo Post, 2014).
} 


\subsection{Thesis structure}

My thesis is presented in eight chapters. This first chapter has introduced the concepts of accessibility and development, their contested nature and the possible ways in which they are related. This chapter has introduced the field context in which the relationship between accessibility to markets for agricultural commodities has been explored and conditioned, the livelihood of the rural Iban who have settled in the Baleh river basin since the 1880s.

The descendants of these early settlers three generations later face a very different set of accessibility challenges. No longer able to sustain modern living standards as farmers, the population and the land has experienced de-agrarianisation - the process of withdrawal of agricultural labour from the land leaving formerly cultivated land fallow and unused for the most part.

While conventional agricultural land-use exhibit von Thünen's patterns, these are now legacies of a former low-income economy which is no longer sustainable. Formerly agriculturally-based Iban households have responded to the changing set of economic opportunities in a pattern which has now become characteristic of de-agrarianisation - the evolution of the multi-local household. Former farm families are now trying to bridge the shift from a fading subsistence/commodity labour intensive agricultural existence to a rapidly expanding capital intensive urban economy, by re-locating the family across the two sectors. The older parents are managing younger children in sparsely occupied longhouses while their children work off-site: the more educated in the service sectors of the cities and the less educated in the informal economy, in diminishing timber industry and off-shore sectors.

As a result, in this era of de-agrarianisation, where multi-sited households is a norm, there is a clear shift in Iban household organisation. In a traditional, subsistence economy, every member of the Iban farming household lives under the same roof, in one location (usually the longhouse), and everyone participates in farming activities. However, in the current transitional phase, multi-local living is a norm, and the farming family is now having to reallocate its labour in different fields and different geographical locations. In other words, members of a household are living separately, in different locations, as well as working in different fields (i.e. multiple sources of livelihoods). However, it is expected that, in the future, a contemporary Iban society will emerge. This contemporary Iban society will be urban-based, working in non-farm sectors and, like the household organisation in the traditional phase, all members of its household will be based under one roof again. 
I ended this first chapter by pointing to the future; one marked by highly capital intensive modes of production, hydro-electricity plants and oil palm plantations, neither of which will offer much employment to those families who still call the Baleh their home. Hydro-electricity plants are run by highly trained engineers and the oil palm labour is largely dominated by Indonesian workers. Where this leaves the 54,200 Iban who currently see the Baleh river basin at least as their spiritual home, is unclear.

In Chapter Two, I will discuss the contextual background to the research. I attempt to explain the highly contested concepts of development and accessibility by examining these two concepts from both objective and subjective perspectives. I highlight how different forms of measurement result in different interpretations about the levels of development and accessibility. I also highlight the fact that rural areas have always been viewed through 'traditional' lenses, as largely agricultural-based economies inhabited by farming families. However in today's reality, that is no longer entirely true. Recognising this change, I elaborate on the concept of de-agrarianisation, multi-local living, and coping strategies adopted by rural communities, linking the processes occurring in Sarawak to parallel developments elsewhere in Southeast Asia.

Chapter Three outlines the conceptual framework underpinning this research. I begin conventionally by viewing development as a positive function of accessibility as outlined by von Thünen in his model of agricultural land use. Although outdated and often disregarded, this $19^{\text {th }}$ century spatial economic model is valuable precisely because its simplicity stands in marked contrast to the more complex nature of the accessibility-development relationships in $21^{\text {st }}$ century rural Sarawak. The exceptions to the model help highlight some of the tensions between accessibility and development: accessibility to what, by whom, when and where and the manifold meanings of 'development', from that of the village, the household and the individual. This three level conceptual framework is used to frame the empirical research design outlined in Chapter Four.

In Chapter Four, I outline the research design. I present my research methodologies, the rationale for choosing the units of analysis, data preparation and analysis, highlighting the obstacles that I faced throughout my fieldwork, and how I addressed those shortcomings. I will explain how I conducted this research, starting with my research design and how I navigated the research process. A total of 20 longhouses in Baleh river basin were randomly selected for analysis, and from that selection, a total of 82 households and 82 individuals were also randomly selected and interviewed. This three tiers of 
selection enable me to analyse the different accessibility-development relationships at these three levels: the community, the household and the individual.

Chapter Five, is the first of three chapters which present the findings of my field research. This chapter focuses on examining the relationship between income and accessibility to markets. I show how contemporary levels of development in the region depend not only on proximity to agricultural commodity markets, but also on employment opportunities off the farm by both in-situ residents (who return wages) and non-resident members of the households (who remit earned income). My field data highlights how accessibility to market should not be taken at face value, i.e. based on one's proximity to its nearest town. There is more to the notion of accessibility to market than what is seen at face value.

Chapter Six continues with more exploration of the relationship between accessibility and development, using non-income variables: basic infrastructure provision, education and human capital. The findings illustrate how government intervention, e.g. via its policies pertaining to schools and health clinics, has consistently modified the pure effect of accessibility to local commodity markets. This chapter also highlights the significance of accessibility to services in helping to form a sound basis for individual's and household's development. In particular it highlights the significance of education in promoting human capital, and socio-economic development.

The significance of multi-local living among the rural Iban household is further elaborated in Chapter Seven. I show how the practice of multi-local living is changing the nature and structure of traditional Iban households. The enhanced ability of different household members to simultaneously source employment in various locations has led to the evolution of, not only multi-local living, but also affects how land is managed and valued. The elder parents, who still reside in rural areas, are increasingly becoming 'guardians of the estate', a shift from actively farming the land to a passive role of being guardians of the land. Meanwhile their children, increasingly urbanised, remit and visit, in an attempt to ameliorate the tensions of the transition from rural to urban. The tension is particularly acute because of the considerable uncertainty over both the cultural and economic value of the land and the connection to the pun-bilik, a tension which is made more acute by the diminishing share each individual member of the traditional household will have in any market realisation of the land.

I reflect on these findings in Chapter Eight, focusing on how the changes are brought about by improvement in accessibility. I reflect on how the notion of accessibility is more complex than what I 
initially thought it was at the beginning of my research. My study highlights the contingent nature of the positive correlation between accessibility and development, with its direction and strength of relationship dependent on access to multiple markets. Equally important is the accessibility to services as it helps to provide a stepping stone for individuals (and households) to pursue a greater level of development. Accessibility to markets and services in a contemporary rural society means more than just accessing its main commodity market because, as shown in this research, the notion of markets is not static. Those who have the means to take advantage tend to be better off when there is an improvement in the level of accessibility compared to those with less access to capital (both financial and human capital) and related opportunities. This uneven attributes result in widening inequality within and between households. I finish by describing the different scenarios that could happen in the region, particularly in response to the major developments currently on-going in Kapit District. 


\section{Chapter 2}

\section{Literature Review}

Where there are marked differences in standards of living between large urban centres and remote rural villages, increasing accessibility to local commodity markets on one hand and to educational and health services on the other is seen as fundamental to raising living standards. This argument, outlined in Chapter 1, anticipated several different ways of conceptualising both development and accessibility and recognised alternative ways in which the development could be affected by accessibility at the level of the individual, the households and the villages. The background to considering these connections is the process of de-agrarianisation - the gradual but accelerating shift from labour's dependence on the land for livelihood to its increasing reliance on capital, both human and manmade. Associated with this transition is the process of urbanisation. Each of these processes pose particular challenges to a relatively remote and comparatively undeveloped region in which my field work was conducted. At the same time, the experience in the Baleh river basin is far from unique, notwithstanding the particular culture and history of the Iban, the unique history of Sarawak and the increasing economic and political influence of the Malaysian Federation of which it has been a part of since 1963.

The aim of this chapter, therefore, is to recognise that these wider processes influencing livelihood in the Baleh river basin are also present in other parts of the world, in Southeast Asia in particular, and have precedents in the recent history of other parts of Sarawak itself. Therefore this chapter discusses the concepts of development and accessibility, and elaborates how both concepts are linked to deagrarianisation, multi-local living, remittance economy, and education as precursor to social mobility. This wider context, documented in the literature, also opens up opportunities for others to learn from the experience I document in the Baleh region itself.

I begin with the concept of development, turn to that of accessibility and consider the relationship between the two, in the context of de-agrarianisation. 


\subsection{Concepts of development}

'Development' is a frequently used term and yet its meaning and nature is often highly contested. This ubiquitous term, which appears in fields such as urban and land use planning, agriculture, economic and trade, has been used as though its meaning is commonly understood and shared (Hopper, 2012).

While the meanings attached to the term 'development' do vary there are commonalities and, in most cases, the term development is associated with the notion of 'becoming modern' (Hopper, 2012; Rist, 2007; Willis, 2005). At the same time, as Rist (2007, p. 485) argues that the specific meaning of development remains elusive despite the term being 'in vogue' for the past 60 decades, mainly because it depends on where and by whom it is used. Similarly, Crush $(1995$, p. 2) states that the ambiguity is demonstrated by the number of development dictionaries that had emerged in the recent decades which attempt to explain the meaning and purpose of the term.

As Cowen and Shenton (1995, p. 25) observe, the literature defines development using phrases such as 'good versus bad' development, or 'under versus over' development as well as more trendconscious terms like 'sustainable development' and 'gender-conscious development'. Attempts at defining development are often vague and explanations are riddled with buzzwords and jargons (Cornwall, 2007; Crush, 1995; Rist, 2007). Most development literature talks about what development should be, how it works, why it fails and how it can be better implemented (Crush, 1995, p. 3).

Hopper (2012, p. 11) explains how conceptualising development is difficult as its nature and meaning changes over time, and determining the intention of development is made more difficult over time as it involves many different approaches, theories and area of interests. As Rigg states,

"... development can be a noun, a verb or an adjective ... it is therefore a state, a process and a characterization all encapsulated in a word that, perhaps more than any other, deserves to be corralled within inverted commas".

(Rigg, 2003, p. 1)

The broadly agreed definition of development often equate with 'progress' or 'improvement' and the term development has become widely used "to convey the idea that tomorrow things will be better, or that more is necessarily better" (Rist, 2007, p. 485). While development means progress or improvement, other definitions include "a process of enlarging people's choices", of enhancing "participatory democratic processes" and the "ability of people to have a say in the decisions that shape their lives", of "providing human beings with the opportunity to develop their fullest potential" 
and of "enabling the poor, women, and free independent peasants' to organise themselves to work together" (Cowen \& Shenton, 1995, p. 26).

This brings me to another fundamental question in the discourse of development: 'development for whom?' Scholars have recognised that, in order for development to take place, sacrifices have to be made. For example, farmers are dispossessed of their lands to make way for development, or improvement in technology brings economic advantages to those who are able to keep up technologically but not to the elderly generation. These are just two examples but they highlighted the fact that the notion of development is still very much highly contested. This also explains why there is disagreement when development is defined as 'good change' or 'positive progress' (Hooper, 2012). The implications of development tend to vary and this makes it hard to actually define what development means.

Development is often equated with modernity, which in itself is another term which is vague and contestable. For instance, development can be seen as a vision of better life, a life materially richer, institutionally more 'modern', and technologically more efficient, and an array of means to achieve that vision (Goulet, 1992, p. 467). This notion of development and modernity is highly linked to Western presumption that non-Western world has to 'catch up' and the benchmark on 'development' is as set by Western standard. This observation is highlighted by a number of scholars, including Kingsbury et. al, and Parpart:

"The problem of development became one of bringing 'backward' colonial peoples into the modern (i.e. developed) world. This was seen more as a logistical problem - how to go about it, how quickly it could be achieved and so on - than as a goal that might itself be questioned."

(Parpart, 1995, p. 250)

"... development is concerned with how 'developing countries' can improve their living standards and eliminate absolute poverty ..."

(Kingsbury, Remenyi, McKay, \& Hunt, 2004, p. 1)

This is known as Eurocentrism, and has been widely criticised as an imposition of Western values on others, namely the developing countries, usually by Western scholars and/or development experts (Goulet, 1992; Hopper, 2012; Kingsbury et al., 2004; Parpart, 1995; Willis, 2005). In essence, the Western model 'dictates' what and how developing countries are expected to achieve in order to 'develop'. The Western countries provide the mould and the rest of the developing counties were expected to use the same mould and follow the Western worlds' 'path to modernisation'. These views 
have been criticised namely for failing to take into consideration the local context of different countries (Escobar, 1992, 2011; Pieterse, 1998).

Despite those criticisms, many developing countries, including countries in Southeast Asia still evaluate or measure their countries development and progress using the Western models. Their national development progress, including the priority, types and measures of development and their administrative style, are based on their Western counterparts. For example, this practice is common in Malaysia, where the country is governed by a two-tier system: federal and state governments. There has been constant intervention from the Federal government on state matters (Chin, 1997), and the 'mould' of development is often decided at Federal level and imposed on the rest of the state governments. This dominance by the Federal government, which is very much the same as the notion of Eurocentrism albeit on a localised scale, has been the practice in Malaysia since its independence.

As mentioned earlier, discourses in development often fail to take into consideration the local context when talking about 'development'. Development - its meaning and nature - are often described and interpreted from the standpoints of Western theorists and are based on experiences and personal views of Western scholars, and differences in cultural background, traditional beliefs and way of life are often inadequately addressed or misinterpreted. This often alluded to as uni-linearity, universalism, lack of sensitivity to cultural variations, tendency towards reductionism and racial superiority (Rigg, 2003, p. 47).

Post-development scholars, who criticise development as ethnocentric, see lack of engagement with cultural diversity, and the perpetuation of Western ideology, argue for alternatives to development (Escobar, 1992; Pieterse, 1998). Alternative development makes the case for valuing indigenous knowledge and supporting grassroots movement to counter Eurocentrism in development (Escobar, 1992). It is about introducing alternative practices and redefining the goals of development (Pieterse, 1998, p. 344). This changing discourse in development has led to movement away from development sciences in particular and a partial, strategic move away from conventional Western modes of knowing in general in order to make room for other types of knowledge and experience (Escobar, 2011, p. 216). Escobar argues that renegotiation on class, gender, and ethnic relations at local and regional levels have to be undertaken in order for local communities, in both the West and the developing countries, to have a more conducive environment to incorporate themselves into world economy. 


\subsubsection{Measuring development}

Development is often understood in economic term and measured against economic indicators (Esteva, 2010; Hopper, 2012; Remenyi, 2004; Rogers, 2000). For example, Esteva (2010, p. 8), points out that when development is reduced to economic growth, it is simply construed as growth in the income per person. The most common measures are Gross Domestic Product (GDP), Gross National Product (GNP) and income per capita. GDP is a measure of the value of all goods and services produced in a country by its population expressed in terms of money, while GNP is a measure of all goods and services produced by a country's population both within its own country and abroad (Rogers, 2000, p. 40). Per capita income, which is income per resident of a country, can then be derived by dividing the total GDP or GNP by a country's population.

It has been argued that GDP, GNP or income per capita alone is not comprehensive enough to measure development. These measures have been criticised as focusing more on measuring development of a place (or country) rather than measuring development of the people within (or human progress). The standard measure of income per capita, for example, is often use to indicate material welfare or to designate a goal of development, but it is unsatisfactory if many people change their welfare by changing where they reside (Clemens \& Pritchett, 2008, p. 395).

Aside from that, it is also argued that focusing only on one aggregate measure (e.g. income) hides others. For example,

"... low income alone is not enough to predict who is experiencing different types of deprivation: poor housing, poor health and access to health services, and low education are clearly related to low income but are distinct aspects of social exclusion..."

(Aglietta et al., 2011, p. 59)

Similarly, Amartya Sen has argued that 'real development' is more than just about a rise in personal income or country's GDP. Instead, development is a process of expanding the real freedoms that people enjoyed;

"... and that viewing development in this term directs attention to the ends that make development important, rather than merely to some of the means that, inter alia, play a prominent part in the process."

(Sen, 2001, p. 3)

Sen's Development as Freedom's proposition is that we should evaluate development in terms of the expansion of the capabilities of people to lead the kind of lives they value - and have reasons to value 
(Evans, 2002, pp. 54-55). Freedom, seen in this context as the purpose of development, is dependent on people's capabilities; their socio-economic attributes, political and civil rights, and access to opportunities (Sen, 2001). This broader concept of development embraces the idea that development is oriented towards enriching human freedom, through choices and opportunities.

A comprehensive approach to development should be more than just economic-oriented. Hicks and Streeten $(1979$, p. 570), for example, explain that social indicators, which attempt to cover areas and aspects that cannot be reflected in most income-based measures, should be used to measure development. Such measures include looking at health, nutrition, housing, income distribution and other aspects of social and cultural development. Hicks and Streeten $(1979$, p.571) also argued that, "while GNP per head follows an ascending order from the poorest to the richest countries, social indicator can point to common and shared values or problems across these countries". Therefore, incorporating social indicator, in addition to economic measures, will ensure that the nature of multidimensionality of development is taken into account.

Arguing for development measures that include more 'human' dimension had resulted in the first Human Development Report, published by the UNDP in 1990. That report, amongst other, defines human development using a combination of three variables: wealth, health and education (Rogers, 2000, p. 40). Known as the Human Development Index (HDI), it shows that countries with a similar GDP may have different levels of development measured in human terms.

\subsubsection{Human Capital and education as development indicators}

In this section I will discuss the element of human capital development, which is related to the education variable in the Human Development Index. This includes discussing the role of education in forming human capital and how it affects development at community, household and individual settings.

"Although it is obvious that people acquire useful skills and knowledge, it is not obvious that these skills and knowledge are a form of capital, that this capital is in substantial part a product of deliberate investment, that has grown in Western societies at a much faster rate than conventional (non-human) capital, and that its growth may well be the most distinctive feature of the economic system."

(Schultz, 1961, p. 1) 
Schultz (1961) identifies 'human capital' in early 1960s in his attempt to address the difficulty to explain economic growth at the time, which could not be explained by the then commonly used factors: physical capital, labour, land and management. He defined human capital as the knowledge and skills that people acquire through education and training. Schultz also argues that people are an important part of the wealth of nations and that investment that people put in themselves are valuable for economic growth.

Since then, a number of definitions of human capital have been introduced but include variables such as the rate of growth, education, increased productivity, and employment and earning (Nafukho, Hairston, \& Brooks, 2004). Blaug (1976) defines human capital as the idea that people spend on themselves, by purchasing education and training for the sake of future pecuniary and non-pecuniary returns and not for the sake of present enjoyment. Romer (1986) uses human capital to develop 'new growth theory', which regards knowledge creation as endogenous responding to market incentive (e.g. for better education). Coleman (1988, p. 100), describes human capital as a result of changes in persons that bring about skills and capabilities that make them able to act in new ways. Similarly, Son (2010, p. 20) explains human capital as representing the productive capacity of the people, and denotes the skills of the labour force, how well and efficiently workers can transform raw materials and capital into goods and services.

In general terms, therefore, human capital represents the investment people make in themselves that enhance their skills, knowledge and productivity. Being embodied in the skills and knowledge acquired by individual means it is less tangible and therefore any such discussion has to cover elements of education. Furthermore, the human capital framework rests on the assumption that formal education is highly instrumental and even necessary to improve the productive capacity of a population (Olaniyan \& Okemakinde, 2008, p. 479). That is why popular proxy measures for human capital development include the literacy rate, number of years spent schooling, and the enrolment rate. It is also argued that human capital is not strictly about its direct effects on output and incomes, but also to take into account its indirect effect on labour reallocation (Fafchamps \& Quisumbing, 1999).

Past literature highlights the significance relationship between human capital development and economic growth (Olaniyan \& Okemakinde, 2008; Ranis, Stewart, \& Ramirez, 2000; Schultz, 1961; Son, 2010) as well as social mobility (Neelsen, 1975). Son (2010, p.20), for example, explains that the link between education and economic development is realised through the labour market, whereby skills learned in the educational system should be used by firms in the production of goods and services so 
that workers will be paid wages commensurate with their productivity. In the same vein, Zhiqiang (2008, p. 521) argues that rural-urban migration is an essential part of economic development, through which human resources move from the agricultural sector to urban industrial sector. He further explains that educational attainment of an individual remains positively related to the propensity to migrate. Similar view was expressed by Schultz decades earlier,

"Economic growth requires much internal migration of workers to adjust to changing job opportunities... Young men and women move more readily than older workers. Surely this makes economic sense when one recognises the costs of such migration are a form of human investment."

(Schultz, 1961, p. 4)

In Human Capital theory, education and schooling are seen as deliberate investments that prepare the labour force and increase productivity of individuals and organisations, as well as encouraging growth and development at international level (Nafukho et al., 2004, p. 546). Son (2010, p.1) in turn views education as an investment, which equips individuals with knowledge and skills that improve their employability and productive capacities, thereby leading to higher earnings in the future. Ranis et al. (2000, p. 202) also believe that higher level of human capital development affect the economy through enhancing people's capabilities, creativity and productivity.

There is also a view that education is positively related to social mobility (Fafchamps \& Quisumbing, 1999; Neelsen, 1975). Although a vast majority saw education from a perspective of 'what it could do for them in economic term' (therefore linking it with employment prospects and financial stability), there is a view that education is responsible for labour reallocation, i.e. a shift from farm to non-farm activities. Fafchamps and Quisumbing (1999, p. 398), for instance, find that reallocation of labour away from low productivity farming to high productivity non-farm work raises income by an additional 0.4 percent. This is based on their case study of rural Pakistani households, which saw one third of the increase in non-farm income are due to better education resulting in households shifting labour resources away from farming.

Despite the positive contributions, education has also been viewed as promoting inequality. For example, Bronchi (in Olaniyan \& Okemakinde, 2008, p.481) asserts that raising level of education in a society can increase the inequality in income distribution. Realising the significance of education, especially in reducing poverty and inequality, many developing countries have intervened in ensuring education is affordable and the benefits are spread more evenly throughout the society (Olaniyan \& Okemakinde, 2008). 
At the same time, education alone cannot transform an economy or increase one's social mobility. Education maybe a precondition for social mobility, but, as Neelson (1975) points out, education is often irrelevant to job productivity. In other words, education is a mean for social mobility but not the end of the whole process. Anand and Sen (2000, p. 2039) argue that there is a tendency in most human development approach to see men and women only as 'human capital'. This approach, according to them, should be rejected and, instead, they argue we should see human development as having both direct and indirect importance. In other words, the human development approach includes the significance of human capital without making that perspective supplant the view that human beings are the end of the exercise, as opposed to simply being the means of production and consumption.

\subsubsection{Basic needs as a development indicator}

Past studies on basic needs deprivation have usually been linked with policies or programmes on poverty eradication (Burki \& Haq, 1981; Isenman, 1980; Streeten, 1984). Meeting basic needs has been one of the main objectives of national development efforts under the World Bank programmes in late 70s and early 80s (Burki \& Haq, 1981, p. 167). Key sectors have included education, health, shelter, water supply and sanitation. Burki and Haq (1981, p. 168) argue that increased productivity of the poor is needed in efforts to eradicate absolute poverty. In order to achieve this, they argued for recognition of how education and health, in addition to machines, land and credit are to the people.

An adequate supply of infrastructure services has also been considered essential for economic development by both academics and policymakers (Calderón \& Servén, 2014, p. 2). Infrastructure influences growth and its development potentially has differential effects on the incomes of the poor. The main issue here is how enhanced infrastructure helps people from lower economic background to better connect to market and opportunities, especially through lower transport costs and better transport options. Such improvements may result in a rise (albeit in small increments) in their income which may then indirectly result in higher levels of human capital.

Past studies have also highlighted that provision of facilities in rural area should also be looked at in terms of their other indirect benefits (Calderón \& Servén, 2014; Van de Walle, 2002). Aside from its role in economic development, infrastructure provision is also significant in terms of the accumulation of other inputs, and may result in other non-economic benefits (Calderón \& Servén, 2014, p. 5). Ogunsanya (1987, p.39), for example, describes how provision of educational and medical facilities, water supply and electricity has been the adopted approach in Nigeria as a solution to rural problems, 
and stresses that accessibility is a necessary preconditioned for the success of these facilities. Improved access to electricity, according to Calderón and Servén, may potentially result in better educational attainment (e.g. due to increase study time). Other key benefits of infrastructure provisions include those accruing to individuals and to society from increased attendance to schools, health and other facilities (Van de Walle, 2002, p. 577).

At the same time, the distribution of facilities has never been uniform across states and regions, and between urban and rural areas. This is often acknowledged as a problem of inequality, in accessing basic facility or as gender inequality, income inequality, or place-based inequality. A review of literature indicates a widespread concerns regarding inequality and lack of uniform access to basic facilities particularly in rural regions (Burki \& Haq, 1981; Ellis, 2000; Folbre, 1986; Li \& Zhu, 2006). Uneven access to basic facilities raises the level of inequality experienced by rural dwellers. Therefore improved rural facilities, i.e. via the road connection or improved information and communication technologies, may help rural dwellers to improve their household economic development, as well potentially widening the gap between the rural households (Bravo, 2002; Ogunsanya, 1987; Olsson, 2009).

\subsubsection{Diversification as development indicator}

A review of the literature indicates how, during de-agrarianisation, rural households come to rely on multiple sources of income, through non-farm employment, off-farm, and remittances. Ellis (1998, p. 4) defines livelihood diversification as the process by which rural families construct a diverse portfolio of activities and social support capabilities in their struggle for survival and in order to improve their standards of living. This, in turn, has raises questions about the changing nature of the household economy, and how households cope with rural change (Ellis, 2000; Elmhirst, 2012; Rigg, 2006) including how the roles within a household are reworked (Folbre, 1986; Hew, 2011; Kelly, 2011). One such phenomenon involves household being "stretched across space" (Kelly, 2011, p. 481). Instead of being locationally concentrated around the family agricultural enterprise, the family becomes spatially dispersed as different members look for employment in other areas or in other field altogether.

One of the consequences of extended patterns of employment within the household is income diversification. Ellis (2000), for example, argues that people in developing countries tend to diversify as a result of changes that occur in their rural area. He categorises such diversification into diversification as a matter of survival and diversification as a matter of choice. The former refers to 
people who adopt strategies of diversification because that is the only option while the latter refers to those people who diversify in order to improve their current livelihood and standard of living. Such decisions are highly individualised and tend to vary from household to household and from area to area as well as within households themselves. The resulting polarisation has been observed in a number of rural studies (Kelly, 2011; McKay, 2003; Rigg, 2003).

\subsubsection{Subjective measures of development}

Aside from the objective measures outline above, development can also be measured subjectively. Unlike the objective measures of assessing 'progress' against a set of pre-determined criteria which is quantifiable (e.g. fertility and mortality rates, income, and provision of infrastructure), subjective measures involve personal judgement, self-reported, and self-rated assessment. Kahneman and Krueger (2006) explain that while using subjective measures alone has been heavily criticised as they advocate personal preferences and exclusive reliance of individual choice, but on the other hand, subjective measure can provide an external check on economic (and other) pre-set indicators;

"...it is fruitful to distinguish among different conceptions ... rather than presume to measure a single, unifying concept that motivates all human choices and registers all relevant feelings and experiences ..."

(Kahneman \& Krueger, 2006, p. 4)

One way to measure subjectively is to ask for respondents' self-rated assessment and/or ranking regarding a point or category. This includes asking participants to rate their level of satisfaction and views on the development changes that had occurred in their locations within a specific timeframe. This line of questioning, and measuring, provides researchers with self-rated responses based on the performance of a location as viewed by the participants themselves. Their responses may vary from those obtained from objective measures and the academy is still trying to decipher where and when the two measures diverge and why.

Many of the same multiplicity of definitions and understanding that characterise the term 'development' also apply to 'accessibility'. 


\subsection{Understanding Accessibility}

Accessibility is both an important concept, and a powerful evaluation criterion in various fields. The term has been used to monitor and/or evaluate the effectiveness of policy and decision making in fields such as transportation planning (Morris et al., 1979), spatial technologies ${ }^{31}$ (Shen, 1998), geography (Kwan \& Weber, 2003), land-use allocation (Guy, 1983; W. G. Hansen, 1959) and social exclusion (Kamruzzaman \& Hine, 2012; Mahapa \& Mashiri, 2001; Páez, Mercado, Farber, Morency, \& Roorda, 2010; J. Preston \& Rajé, 2007). These studies have illustrated the widespread influence of the concept of accessibility in a variety of fields. Yet, accessibility has often been criticised as being broad and ambiguous, and difficult to measure (Doi, Kii, \& Nakanishi, 2008; Morris et al., 1979). Accessibility is commonly identified as a relative concept commonly associated with affordability and availability of socio-economic opportunities (Mahapa \& Mashiri, 2001, p. 366).

\subsubsection{Definitions of accessibility}

W. G. Hansen (1959, p. 73) defines accessibility as the potential of opportunities for interaction and states that, in general terms, accessibility is a measurement of the spatial distribution of activities about a point, adjusted for ability and the desire of people or firms to overcome spatial separation. Two decades later, Morris et al. (1979, p. 91) use similar definition of accessibility, describing accessibility in terms of some measure of spatial separation of human activities i.e. denoting the ease with which activities may be reached from a given location using a particular transportation system. Similarly, Páez, Scott, and Morency $(2012$, p. 141) define accessibility as the potential for reaching spatially distributed opportunities (for employment, recreation, social interaction).

These definitions focus on the spatial aspects of accessibility, sometimes referred to as place accessibility (Kwan \& Weber, 2003) or the concept of nearness (Weibull, 1980). This traditional concept of accessibility is often measured by ease of access (Guy, 1983), financial cost and time taken to travel (Doi et al., 2008; Perle, Bauder, \& Beckett, 2002) and mode of transportation (Davidson, 1977). This understanding of accessibility has seen past studies place significant emphasis on transport and transportation issues: how to get from Point A to Point $B$, how to minimise travel cost, how to make travel more convenient, and choosing alternative modes of transport (Guy, 1983; Joseph \& Bantock, 1982; Morris et al., 1979). These extend into other related studies, such as examining the relationship between accessibility and facility provision or location (Joseph \& Bantock, 1982; Wachs \&

\footnotetext{
${ }^{31}$ The term 'spatial technologies' is a collective name for the transportation, communication, networks and digital information technologies that modify spatial relations (Shen, 1998, p. 447)
} 
Kumagai, 1973), economic development and livelihood strategies (Alther et al., 2002; Ogunsanya, 1987; Olsson, 2009), and social exclusion (Páez et al., 2010; J. Preston \& Rajé, 2007). All such studies used the concept of remoteness (i.e. the opposite of accessibility) to measure their respective performances.

There are critics of these conventional measures of accessibility and they argue that the frequently adopted measures to evaluate and measure accessibility (i.e. space-time elements) are often oversimplified (Doi et al., 2008; Kwan, Murray, O'Kelly, \& Tiefelsdorf, 2003; Kwan \& Weber, 2003; Shen, 1998). Such simplification in methods often excludes significant multi-dimensional elements of people's values (Doi et al., 2008, p. 1098) and ignore the emergence of new technologies (Kwan \& Weber, 2003). The complexities arising from increasing significance of information and communication technologies (ICTs) in peoples' daily lives, they argue, should be taken into consideration (Kwan \& Weber, 2003, p. 342). Similar criticism is voiced by Doi et al. (2008, p. 1098) who states that the conventional measures, while easy to understand and apply, are highly simplified representation of opportunities without appropriate consideration of people's values or behavioural criteria and abilities.

Hence, there is a need to move beyond those representations of accessibility, which are fundamentally spatial in nature, in order to take into account non-spatial aspects of accessibility. Keeling and Blomley (2007, p. 280), for example, suggest that while past transportation research provides useful template for understanding how society, place and space interacts, there is a need to develop new theories and techniques that can bring social aspects of accessibility and mobility more cohesively into the fold. This view is echoed Kwan and Weber (2003; pg.342) who believe that there is a need to re-examine the concepts and methods in accessibility research to take into account the major changes in the past decade which, amongst other thing, include the increasing importance of information and technologies in people's everyday lives.

Taking these criticisms of conventional measures of accessibility into consideration, I opt for a broader conception which combines and highlights the multi-dimensionality of the accessibility concept. The operational definition of 'accessibility' used for the purpose of this research is the ease at which one obtain desired opportunities and it includes not just the necessary travel (physical accessibility) but also contemporary means of obtaining desired goods and services (e.g. through education and internet). This 'new' direction provides a more comprehensive perspective regarding the level of actual and perceived accessibility in the case study area. In other words, this definition includes the 
actual level of accessibility as experienced by respondents as well as their perceived accessibility, which refers to the potentials arising from improved accessibility which are intangible (e.g. through information and communication technology).

Past studies on accessibility have highlighted the fact that findings at the community, city or country level may not be accurate due to the diversity of individual behaviours and experiences (Fox, 1995; Kwan \& Weber, 2003; Morris et al., 1979). For example, Fox (1995), in his review of literature on transport planning and human activities, found that human behaviour cannot always be explained through observed behaviour or aggregated statistical sources. Though human behaviours in the context of accessibility is hard to explain, it does not mean that the issue should be neglected. Kwan \& Weber (2003) state that the complexities of individual behaviours in relation to accessibility should be taken into account when measuring individual accessibility experiences. This points out to the need to study accessibility at a more micro level.

\subsubsection{Contemporary accessibility}

Studies by Keeling and Bloomley (2007) and Kwan and Weber (2003) highlight the need to include contemporary accessibility into account when exploring rural change. They argue that there has been an increased usage and application of information and communication technologies in people's daily life around the globe. However, there is an uneven distribution of benefits of these information and communication technologies as reported between developed and developing nations, and that rapidly growing disparities in the utilisation, expenditure, and the availability of technology are apparent worldwide (Pick \& Azari, 2008, p. 91). This disparity, according to Pick \& Azari, is known as the digital divide. Digital divide occurs when there is a growing gap in the utilisation, expenditure and availability of information and communication technology between areas (e.g. rural and urban), regions and even countries. Consequently, this disparity has great implications to those who do not have the same levels of access to the information and communication technologies as others. The disparity and implications could be seen, for example, in the economy, education and social aspects of individual, household, region or even countries.

Warren (2007) uses the term 'digital exclusion' to describe results of the unequal access to these information and communication technologies. He defines digital exclusion as " $a$ situation where a discrete sector of the population suffers significant lags in its adoption of information and communication technologies through circumstances beyond its immediate control" (Warren, 2007, p. 
375). Warren highlights that certain groups, especially children from rural poor and those without access to the internet, are at a growing disadvantage. He bases this argument on the findings in the United States study of digital gap. This result implies how those without access to information and communication technologies, including the internet, is lagging behind from their urban-based counterparts who have access to the said technologies.

Along a similar vein, Berma, Shahadan, and Abdul Gapor (2006, p. 57) state that one of the problems faced by the rural poor is information deficit, which is mainly due to accessibility. They were referring to people's access to language, infrastructure, and education, which influence how one obtains information. Information deficit, which ranges from misunderstanding the Government policies and programmes and to the exclusion from development programmes and projects, can be exacerbated by the lack of accessibility. Remote and isolated location as well as poor infrastructure make disseminating information in rural area a challenge (Berma et al., 2006; Cecchini \& Scott, 2003; Jaafar, 1998; Katungi, Edmeades, \& Smale, 2008). James (2005 in Pick \& Azari, 2008, p.93) states that,

"... the traditional measurement of the global digital divide in terms of direct access to technologies makes sense in the rich countries, where individual ownership is widespread among the population, but less so in low-income countries. In low-income nations, illiterate and poor population often located in geographically remote areas lack direct access to the Internet but can nevertheless gain its benefits indirectly through intermediaries. For instance this population listens to community radio stations, which obtain enriched news through the Internet..."

(James, 2005 in Pick \& Azari, 2008, p.93)

James has described some of these different capability levels as they relate to different technologies (in Table 2.1). 'Access' to technologies is dependent on a number of factors, e.g. education, competence, and language. Technologies which are user-friendly (can be used by all ages, and gender), easily available (hence accessible) and affordable can improve one's level of contemporary accessibility. However, when new technology is introduced, it is often the case that new skills to 'utilise' the technology is needed and, often, the elderly and the poor are often disadvantaged when new technology is introduced. This is because they need to 'invest' in the new technology as well as to acquire new sets of skills to utilise the technology. 
Table 2.1: Capability levels required for different communication and information technologies

\begin{tabular}{|c|c|c|c|c|c|c|}
\hline & & $\begin{array}{c}\text { No } \\
\text { literacy }\end{array}$ & $\begin{array}{l}\text { Basic } \\
\text { literacy }\end{array}$ & $\begin{array}{l}\text { High literacy/ } \\
\text { language skills }\end{array}$ & $\begin{array}{c}\text { Computer } \\
\text { literacy }\end{array}$ & $\begin{array}{c}\text { Technical } \\
\text { competence }\end{array}$ \\
\hline Oral communication & & $*$ & & & & \\
\hline Radio & & $*$ & & & & \\
\hline Television & & $*$ & & & & \\
\hline Fixed line telephone & & $*$ & & & & \\
\hline Mobile telephone & & $*$ & & & & \\
\hline Public phone & & $*$ & & & & \\
\hline $\begin{array}{l}\text { Newspapers and } \\
\text { sources }\end{array}$ & printed & & $*$ & & & \\
\hline Fax machine & & & $*$ & & & \\
\hline E-mail & & & & $*$ & $*$ & $*$ \\
\hline Internet & & & & $*$ & $*$ & $*$ \\
\hline
\end{tabular}

Source: James (2005, p. 116)

Cecchini and Scott (2003), based on their study in rural India, argue that information and communication technologies can help to reduce poverty and improve access to basic services. The later includes accessibility to market, health care, government services and microfinance. Cecchini and Scott also recognise the unequal access that rural dwellers face with regards to information and communication technologies and its application,

"Even if information infrastructure reaches rural areas, there is no guarantee that the poor will access ICT applications. Many of the projects that attempt to provide access to the Internet in rural India, for instance, end up favouring middle and upper-class men ... Rural women tend to be excluded because of their restricted mobility, lack of education, and, in some cases, male control over information and media..."

(Cecchini \& Scott, 2003, p. 80)

Unlike radio and television, internet-based communication and information sources are not as accessible to rural dwellers. As implied in Table 2.1 above, Kenny (2002, p. 149), too explains that internet is a tool which requires a fairly high level of education and computer literacy in order for it to be used constructively. In order to utilise email and internet as sources of communication and information, one has to have high literacy and language skills, computer literacy and technical competence James (2005). Kenny further explains that,

"The poor face multiple barriers both to internet utilisation and to benefitting from that use. They have little to spend on communications, lives in areas where internet is costly and complex to provide, have low rates of education and speak languages ill-represented on the World Wide Web."

Kenny (2002, p. 152) 
Most of the available literature on accessibility to information in Malaysia talks about the nation's tremendous development in ICTs, and how the Government is committed to promote IT culture among its society (Jaafar, 1998). However, most of this literature focuses on situations in urban areas and in the Peninsular Malaysia. It rarely addressed the issues in remote areas, such as internet connection or communication infrastructure in the Sarawak interior. In fact there is a marked digital divide between states in Malaysia, as well as between urban and rural locations (Kakroo, 2007). Kakroo (2007) states that the information and communication technology infrastructure in Malaysia has been concentrated largely in urban area. He also attributes the digital divide in Malaysia exists due to illiteracy, low incomes, ethnicity as well as uneven access to the technology itself. Later, in Chapter Six I focus on how accessibility to market influence how rural dwellers access information and how one's level of 'accessibility' can be improved by having access to information and communication.

\subsection{Accessibility to market, and rural development}

A review of the literature worldwide highlights the significance of accessibility to market as determinant of rural development (Bravo, 2002; Ogunsanya, 1987; Olsson, 2009; J Windle \& Cramb, 1997). Olsson (2009, p. 477) argues that road improvement, in his case study of rural Philippines, leads to direct effects in the form of reduced journey time, reduced costs and improved reliability, which benefits the locals. Cook and Butz (2011, p. 31), through their observation in a remote mountain village in Pakistan, highlight how relative isolation limits rural community's accessibility to market, and consequently to better finance, which then affects their farming and children's education. Their study also shows that the villagers themselves believe that improved accessibility to market is a positive step in enhancing the material circumstances of villager's lives.

The effects of improved road connection or new road construction are multi-dimensional. For instance, as shown by Olsson in his study, the road project has opened up more than just economic opportunities in a fishing village of 8000 population with poor accessibility;

"...the benefits of road improvement were considerable and benefitted a great majority of the population in the fishing community ...extensive direct effects of the improved road, a number of complementary factors that lead to substantial indirect effects. These included: a potential for technical innovation that increased production and productivity; available investment to support the increased production..."

(Olsson, 2009, p.476) 
Similarly, Jill Windle (2002, p. 832) in her study of rural Sarawak, Malaysia finds that new road benefits rural population by offering economic choices, in particular enabling people to access a wider range of cash income sources. Same observation was made by Ogunsanya (1987) in his study of rural villages in Nigeria.

Aside from road connection and improvement, the relationship between accessibility to market can also be seen from the perspective of size. The larger (the size) the market, so does the potential levels of development. This market size is one of the reason people in rural areas flock to town and cities as it offers more economic opportunities. For example, Firman finds that, in his case study of a Javanese village, villagers went to find casual, unskilled work in larger urban areas of Jakarta and Bandung as economic opportunities in these larger cities are bigger than those smaller cities (e.g. Sragen) that are nearer to their village. Rural-urban mobility, according to Firman (1994, p. 99) ensures that meagre income of poor rural household are supplemented by flows of remittance from urban wage earners.

However, it was also argued that improved accessibility might not be all positive. For example, Olsson's study also highlights how improved accessibility may benefit one group more than others;

"Both work opportunities and incomes increased considerably among all income groups engaged in fishing-related activities after the road project. While this was positive, in terms of distribution, these income increases were much higher among the upper income deciles..."

(Olsson, 2009, p.482)

A review of literature also shows that women, more than men, experience greater obstacles in accessing market and services when faced with poor physical accessibility and transport service (Bravo, 2002; Mahapa \& Mashiri, 2001; Porter, 2007; Uteng, 2009). Bravo (2002), for example, finds that road improvement in rural Peru benefits everyone but the improvements as even greater for men than for women The different types of tasks and responsibilities of women and men implies that women and men have different transport needs (Fernando, 1998, p. 64). However, conventional transport policies has always treat communities as homogenous (Mahapa \& Mashiri, 2001, p. 366) and, therefore, ignoring the fact that people have varying degrees of accessibility needs and access.

These differences could be more pronounced during de-agrarianisation process when farming becomes less intensive and rural dwellers are seeking alternative income sources. 


\subsection{De-agrarianisation}

My investigation into the relationship between accessibility and development is far from universal. Rather I am concerned with the relationship during a particular phase of a country's development, namely when the labour force is leaving the rural land for employment elsewhere, and that is during the de-agrarianisation phase.

Bryceson (1996, p. 99) coins the terminology de-agrarianisation to describe "a process of economic activity reorientation (livelihood), occupational adjustment (work activity), and spatial realignment of human settlement (residence) away from agrarian patterns". Bryceson explains that the trend of deagrarianisation is not just observable in her case study area but applicable in most rural areas worldwide. The rate of de-agrarianisation, however varies between countries and regions. Ncube, Tanga, and Bhumira (2014, p. 399) state that de-agrarianisation is a global, regional and communal recurring challenge affecting many livelihoods especially in the developing nations which bear the brunt of Western colonialisation. Therefore, it is not surprising that scholars such as Reardon (1997), Rigg and Nattapoolwat (2001), Kelly (2011), Hall, Hirsch, and Li (2011), Bryceson, Kay, and Mooij (2000) and Rungmanee (2014), who study rural change in developing countries, have paid special attention to the implications of de-agrarianisation in Africa, Latin America and Asia.

Studies of de-agrarianisation document the fact that that farming and agricultural activities in their traditional forms are usually not enough to sustain livelihoods of rural residents (L. De Haan \& Zoomers, 2003; Ellis, 1998; Firman, 1994; Rigg, 2005). In most cases, subsistence activities is increasingly becoming less productive and even failing to meet the needs of households. Wittayapak (2012, p. 228), for instance, notices how the livelihood in Northern Thai villages changes from depending on the village and farming in 1990s to relying on works outside of the village as their main source of economic wellbeing by 2009. This change was attributed to the rise of employment outside the village and investment in higher education in the villages' younger generations.

In other words, rural dwellers are forced to look for other economic-generating activities. Agriculture becomes progressively less central to national economies and to the livelihoods of people even in rural area (Hall et al., 2011, p. 1). Income sources become more diverse and not geographically fixed in one location. This challenges the traditional preconception of rural economy and rural livelihood, and the dichotomies of urban-rural characteristics. 
Studies in Indonesia (Firman, 1994; Hugo, 1982; D. A. Preston, 1989), Thailand (Rigg, 2003, 2005; Rigg \& Salamanca, 2011; Rungmanee, 2014), Philippine (Kelly, 2011; McKay, 2003), Africa (Barrett, Reardon, \& Webb, 2001; Bryceson, 1996; Ncube et al., 2014), and Sri Lanka (Hewage, Kumara, \& Rigg, 2011), amongst other, have highlighted key characteristics of de-agrarianisation: migration (Firman, 1994; Hewage et al., 2011; McKay, 2005), livelihood diversification (Barrett et al., 2001; L. De Haan \& Zoomers, 2003; Ellis, 2000; Reardon, 1997), remittance income (Kelly, 2011; McKay, 2003; Rigg \& Salamanca, 2011), shifts in gender relations (Hew, 2011; McKay, 2005), marginalisation and exclusion (Hall et al., 2011) and the phenomenon of multi-local living (Fan, Sun, \& Zheng, 2011; Firman, 1994; Kelly, 2011; Soda, 2001). For example, it was observed in rural Thai villages that,

"The young are leaving in ever greater numbers and, it seems, staying away longer; the settlement is being hollowed out socially and the community covenant is becoming frayed. Farming is also being re-shaped ..."

(Rigg, Salamanca, \& Parnwell, 2012, p. 1478)

One of the main triggers of de-agrarianisation is improved physical accessibility to markets, especially as a result of improved infrastructure and communication (Bryceson, 1996; Cramb, 2012; Ellis, 1998; Rigg, 2006). Improvements in accessibility to market have enabled rural dwellers to venture out of their villages to towns and cities, locally and abroad, in search for employment. This, coupled with improvements in non-physical communication technologies (e.g. internet and money transfer facilities) creates a conducive environment whereby migrants can maintain their links with their home villages. Rigg (2005, p. 175) cites the work of Yujiro Hayami and Masao Kikuchi in Laguna province, Philippines that showed how improved accessibility permitted rural people to access ex situ opportunities while also bringing those 'outside' opportunities, via education and modernising agriculture, back with them to the rural areas. This improvement is set against the backdrop of deagrarianisation whereby land has become scarce and/or showing decline in productivity.

The literature has also demonstrated how rural households have come to rely on multiple sources of income, e.g. non-farm (and off-farm) employment ${ }^{32}$, and remittances (e.g. de Haan \& Zoomers, 2003; Ellis, 1998; Firman, 1994; Rigg, 2003). Ncube et al (2014: 404) for example found that deagrarianisation in a rural village in South Africa has been generated by a massive relocation of mostly the younger generations into towns and cities in search of employment, leaving the aged and disabled

\footnotetext{
${ }^{32}$ I am using the terminology 'off-farm', 'non-farm', and 'non-agricultural' work interchangeably throughout this thesis, to indicate work which is not directly associated with the production or gathering of unprocessed crops or livestock or forest or fish products from natural resources (Barrett et al., 2001, pp. 318-319). In general, it includes nonfarm income earned elsewhere by rural households, as well as the income earned in rural areas by rural households.
} 
with the responsibility of maintaining their rural land. Firman (1994) cites Hugo's study in Java which found that it was the poorer village households who went away to various urban centres in their attempt to overcome inadequate village income.

\subsubsection{Preconception of rural-ness}

Although rural, much of the activity carried out in the countryside does not include farming. However, there is a general preconception in literature that rural areas are predominantly farm-based. According to Rigg $(2003, \mathrm{p}$.197) this inaccurate perception of rural areas transpired because countryside is largely rural, and because the word 'rural' is synonymous with 'agriculture', then the people who reside in rural areas are, virtually by definition, farmers. The practice of assigning binary values has been practiced for decades and has not been a true reflection of the contemporary rural scenario for quite some times now.

In fact, many studies and statistics, including official data, still imply that the main economic activity in rural areas is agriculture and is farm-based. Hugo (in Firman, 1994, p.84) argued that census and large-scale survey in Indonesia had failed to detect the widespread temporary and seasonal ruralurban migration and, thereby, did not acknowledge the significance of non-farm activities. Rigg and Nattapoolwat (2001), also observe that their Thai village case study shows mixed of livelihoods that was not dominated by agriculture and farming as indicated in the official data. In his other paper on rural change, Rigg (2005) explains how resilience and persistence amongst the rural Thai farmers keep the farm going, despite its low productivity which is not even enough to sustain the farming family. He argued that they were able to sustain the farming practice as the limited productivity from farming is supported by other market-based non-farm works.

Similarly, Berma (2001, p. 99) points out that while there is a lively rural involvement in nonagricultural activities, past and contemporary studies of rural Malaysia (particularly Sarawak) have tended to 'agrarianise' the countryside. Scholars such as Hugo (1982), Ellis (1998), L. De Haan and Zoomers (2003), Kelly (2011), Schmidt-Kallert (2009), Rungmanee (2014) and McKay (2003), have also highlight these patterns of discrepancy in describing and understanding of rural area and associated rural livelihoods in their respective studies.

This practice of failing to see structural change within rural areas highlights the need to look at rural area and its associated rural economy and rural livelihood in a new light, away from the traditional 
dichotomous view of rural-ness. As argued by Barrett et al. (2001, p. 320), a household can be 'rural' in location but its activities may be a mix of urban and rural. One important expression of this decoupling of agriculture from rural living is the phenomena of multi-local living.

\subsubsection{De-agrarianisation and multi-local living}

The process of de-agrarianisation has raised questions about the nature of the household economy, and how households cope with rural change (Barrett et al., 2001; Ellis, 2000; Rigg, 2006) including how the roles within a household have been reworked in order to accommodate such changes (Folbre, 1986; Hew, 2011; Kelly, 2011).

Rigg and Nattapoolwat (2001, p. 948) note how difficult it was to pigeon hole the households in their case study area in Thailand as belonging to a particular occupational 'type'. They found that it is a common scenario in Thai villages to find a husband working on the land, a wife working in craft production at home, and their children works in a variety of ex-situ non-farm activities (Rigg \& Nattapoolwat, 2001, p. 948). Similarly, L. De Haan and Zoomers (2003, p. 356) argue that the bulk of the income of rural poor no longer originates from agriculture, and it is no longer realistic to classify rural population as small farmers or landless poor. Essentially, farming is no longer the lynchpin of village economy but is increasingly becoming one of the diverse rural economic activities (Bryceson et al., 2000; Ellis, 1998, 2000; Firman, 1994; Kelly, 2011; McKay, 2003; Rigg, 2003, 2005; Rungmanee, 2014).

This economic diversification of rural areas is achieved mainly by migration, either permanent or temporary, to places outside of their place of origin in search for employment opportunities. In some areas where job opportunities are very limited, migration is a necessary condition in order to improve accessibility to employment markets. Various studies have observed such movement from rural to urban centres and acknowledged that such movement is part of household livelihood strategies during de-agrarianisation (L. De Haan \& Zoomers, 2003; Ellis, 1998, 2000; Firman, 1994; Hugo, 1982). These movements, whether they are over short or long distance, or whether they involve movement over regional or national boundaries, have been facilitated, to a large extent, by communication and infrastructure advancement. Rapid urbanisation and improvements in communication and transport technology has resulted in a significant increase of mobility (L. De Haan \& Zoomers, 2003, p. 358). 
Additionally, an increasing number of individuals are practicing multi-local living, by moving back and forth between residences, mainly for economic reasons. This increased personal mobility had reflected the spatial dispersion of rural households, resulting in the changing structure of traditional household.

The phenomenon of dispersed households goes under several different names: multi-local living (Dick \& Reuschke, 2012; Greiner, 2012; Schier, Schlinzig, \& Montanari, 2015; Schmidt-Kallert, 2009; Weichhart, 2015; Wood, Hilti, Kramer, \& Schier, 2015), split households (Ellis, 1998; Fan et al., 2011; Greiner, 2012), dual residency (Soda, 2000, 2003) and multi-sited households (Cramb, 2012; Yamanaka, 2005).

Weichhart $(2015$, p. 378$)$ argues that multi-local living has become a mass phenomenon that occurs in most social systems and affects members of all social classes. To a large extent, this has been made possible by new and cheaper transportation systems and new forms of electronic communications (Wood et al., 2015, p. 364). One of the implications of this advancement in information and transport technology is its benefits to both the active and passive multi-local actors. Schier, Schlinzig, et al. (2015, p. 426) define multi-local living as living separately, in different locations, but, due to the improvement in communication and information technology, is able to "communicatively and interactively integrate across spatial distances into the life of the persons who are located in different locations".

Along the same vein, Fan et al. (2011, p. 2166) defines split households as "a situation where family members who under 'normal' circumstances would be living in the same place are in actuality living in separate places". Wood et al. (2015, p. 364) describe it as "a social practice which allows people to pursue their interests in different places either simultaneously or in alternating rhythms ${ }^{\prime \prime 3}$. Splithouseholds includes cases where an individual leaves his/her family due to work commitments in alternative locations during working days/months but returns to the family home on non-working days/months. It also includes couples who are both wage earners and live at separate houses in different cities but sharing main home elsewhere, children shuttling back and forth from separated parents' households and households with second and/or holiday homes. Schier, Schlinzig, et al. (2015, p. 426) describes this phenomenon as 'living one's life across two or more locations' and characterises

\footnotetext{
${ }^{33}$ According to Wood et al. (2015) the term alternating rhythm here refers to instances when a person leaves his/her family for several days every week, or several months every year, in order to go to work.
} 
it as living and being anchored in more than just one place, while at the same time repeatedly moving between these locations.

Looking through existing literature on this subject, I found distinctive differences between the Western and Asian discussions on multi-local living. The Western-based empirical studies focus more on examining the shifting nature of family and personal relationships (Schier, Hilti, et al., 2015), studies on second homes (Schier, Hilti, et al., 2015) and the theoretical and methodological framework for studying this concept (Schier, Schlinzig, et al., 2015; Weichhart, 2015). By contrast, the studies in Asia, and other developing countries, tend to focus more on multi-local living as a household livelihood strategy (Fan et al., 2011; Firman, 1994; Greiner, 2012; Kelly, 2011; Soda, 2001). This is also observed by Dick and Reuschke (2012, p. 190) who stated that multi-local living in the Global North tends to be associated with career and lifestyle aspirations of relatively well-paid and educated persons, whereas multi-local living in the Global South is primarily centred on survival and risk mitigation strategies.

Another difference between the North and South lies in the unit of analysis these studies are concerned with. The concept and definition of household unit in the Western and Asian studies of multi-local living differ significantly. The Western concept of household focuses on nuclear family unit (i.e. spouses and their children) whereas the Asian concept of household comprises of extended family (including spouses, children, siblings and their parents who live with them).

In the Asian case, it is often assumed that household members, by definition and popular understanding in family and household discourse, live together under one roof (Fan et al., 2011). This assumption is no longer valid especially when individuals within the household become more mobile and rural-urban migration, which leads to split households become a common livelihood strategy. In China and in Southeast Asia migration is a complex process that affects family organisation. Fan et al. (2011, p. 2168) illustrate this complexity in their example of the extended-family dimension of Chinese rural families and the role of the grandparents' in taking care of left-behind children and farmland in split household family. The role of the migrant is to send remittance to the family back home and the role of the parents and left-behind children is to maintain their rural connection. Similarly, Firman also describes how migration is important among poor Indonesian households that decision to migrate for employment, and a shift from farming to non-farm sector, usually involve the whole family;

"Family members discussed between them how to mobilise resources to cover transportation costs to Bandung and living expenses before receiving the first payment. 
Households were willing to do this because working in Bandung represented a good investment ..."

(Firman, 1994, p. 96)

In Southeast Asia, the increasing spatial and sectoral fragmentation of households is attributed to the on-going de-agrarianisation process. Kelly (2011, p. 481), for example, describes how households caught up in the de-agrarianisation phase are "stretched across space". Instead of being locationally concentrated around the family agricultural enterprise, the household becomes spatially dispersed as some look for employment in other areas or in other fields altogether. This household dispersion results in what Fan et al. (2011) describes as 'solo migration', 'couple migration' and 'family migration'. Each term refers to the splitting of households as a result of rural-urban migration. Hirsch (2012, p. 400) cites the works of Jonathan Rigg in Laos and Thailand to illustrate how the rural labour force makes their way into the urban area and how urban money make its way into the villages via remittances.

The process is two-way: de-agrarianisation leads to split-households and that later leads to further deagrariansation as more especially young people leave the land. Multi-local living can actually exacerbate the rate of de-agrarianisation because, with reduced labour supply households can no longer exploit the full potential of the rural land which in turn prompts the search for income elsewhere, by other economic avenues. As a result land is often left idle. A similar sentiment has been expressed by Ellis (1998) and Schmidt-Kallert (2009) in their review of literature on Asia, Africa and Latin America.

The migration associated with de-agrarianisation in Southeast Asia has been studied extensively in the past decades (Ellis, 1998; Firman, 1994; Hewage et al., 2011; Hugo, 1982; Lipton, 1980; McKay, 2005; Padoch, 1982; Rigg, 2003; Rigg \& Salamanca, 2011). Lipton (1980, p. 1) defines migration from rural areas as "the departure of individuals or households, for more than a week or so, from the small, primarily agricultural community in which they live". This definition illustrates the significance of migration, and its associated implication to rural dwellers.

In their study of migration and household relations in Sri Lanka, Hewage et al. (2011) describe migration as a marker or signifier of change, arguing that rural-urban migration occurs, either through choice, for a better livelihood or as the only way to carve a decent livelihood in the ever changing rural economy. Other scholars such as Firman (1994), Ellis (1998), Rigg (2003), Yamanaka (2005) and 
Rungmanee (2014) express similar views on the role of rural-urban migration in their case study areas. They comprises all types: seasonal, circular or permanent. Along the same lines, Dick and Reuschke (2012, p. 179) argue that labour-related circular migration, which has long been practiced in both the Global North and South, has increase significantly in the recent decades, mostly due to the economic transformation associated with de-agrarianisation, accompanying changes in spatial structure of economic opportunities, improvements in transportation and communication technology, and increased social fluidity.

\subsubsection{Education and de-agrarianisation}

Studies have shown that education and schooling are very significant in determining the performance of household and community economies as well as access to opportunities (Barrett et al., 2001; Hawley, 2004; Rigg \& Nattapoolwat, 2001; Rungmanee, 2014; Taylor \& Yunez-Naude, 2000). Literacy, is the most fundamental aspects of education, and is a key issue in empowerment and participation of local communities with its capacity to open opportunities for both individual and the local community (Kingsbury, 2004, p. 227). Kingsbury refers to empowerment as the need to develop people's abilities to understand, question and resist those structural conditions responsible for poverty.

Education and literacy have also been linked with de-agrarianisation (Hew, 2011; Rungmanee, 2014; Taylor \& Yunez-Naude, 2000). It is observed that, in most cases, as schooling levels in a household improve, the household tends to move away from crop production. Hew (2011, p. 603), for example, explained that in rural Sarawak, village children often spend their adolescent years away from their families because their schools are mostly clustered in towns. They only return to their villages on weekends, once a fortnight or a month and sometimes only at the end of the school semester. This, she argued, made the children inexperienced and unfamiliar with farming.

Similarly, Taylor and Yunez-Naude (2000, p. 288) pointed out that children's schooling is likely to increase their chances of migrating and participating in other forms of production and associated wage activities. Educational attainment is one of the most important determinants of nonfarm earnings, especially in remunerative salaried and skilled employment (Barrett et al., 2001, p.325). Therefore education gives the people choice whether to choose agrarian occupations or to work in those nonfarm sectors which offer greater opportunities (Rungmanee, 2014). 
Likewise, Rigg (2005) argued that education is important in "accelerating" the process of deagrarianisation as it can create aspirational context where rural dwellers reduce their farming activities or even stop farming altogether. In their study of Thai villages, Rigg et al $(2008 ; 365)$ concluded that education plays a central role in determining the type of jobs available for rural migrants and with basic education providing them with an entrée into factory work. The level of education differentiates the types of jobs as well as the wage received by the rural migrants. Older villagers may work as housekeepers while the younger generation, with up to lower secondary school qualification, are employed as waged workers on assembly lines, and those with higher qualifications may work in administrative positions in factories (Rigg et al, 2008: 365).

Earlier on, Rigg \& Nattapoolwat (2001) contend that education has been a significant determinant of upward mobility of Thai villagers. They explained the differences in terms of wages and employment opportunities for people with different level of education. Education can bestow significant added value in an economy that is becoming increasingly knowledge and skill dependent (Rigg \& Nattapoolwat, 2001, p. 952). They also state that the importance of education was accepted by parents and this was illustrated when the number of parents withdrawing their children from school during Thailand's economic crisis was much lower than predicted. Instead of withdrawing their children from schools, the parents adjusted their spending behaviour to enable their children to continue their education. This shows how they value education and how they are aware of the role of education in ensuring their family's upward mobility.

Hawley (2004), in his study of educational attainment in Thailand between 1985 and 1995, found that women's education had significantly improved, citing more women completing upper secondary education during the study period. He also found that individuals with upper secondary qualifications have higher earnings than those with lower secondary education regardless of gender. The demand for workers with such qualification from manufacturing industries in Thailand urban centres also increased at that time. In short, schooling (and education) has the tendency to influence households' choices of income activities as well as raising their incomes (Taylor \& Yunez-Naude, 2000, p. 296).

\subsubsection{De-agrarianisation and inequality}

Studies of rural change noted that inequality emerged when villagers shift from one income source to multiple income sources (Ellis, 1998; Lipton, 1980; McKay, 2003; Rigg, 2003, 2005). Farmers diversify as an income diversification strategy, reallocating their labour from purely farm-based to a mixed of 
farm and non-farm activities. Associated with this pluriactivity is a widening of income gaps among rural dwellers. Studies by Rigg et al (2008, p.374) show that growing wealth led to greater social stratification, and cited examples how the interests of factory workers conflict with the recalcitrant few who struggle to continue to farm. Lipton $(1980$, p. 11) also observes that remittances go disproportionately to those who are already better off; town-ward migrants, especially the remitters and, above all, the international remitters who send back really big sums, are seldom from the poorest village groups. The ability of the initially privileged to take advantage of higher income earning opportunities increases the income gap between households in a village, as well as the gap between villages.

Inequality is further compounded by increasingly individualised livelihoods and the erosion of communal solidarity (L. De Haan \& Zoomers, 2003, p. 351). Studies have shown that individuals pursue individual ways, ranging from moving to new place for employment opportunities to exploiting opportunities for individual advancement which may or may not be consistent with the decision of the household as a whole (L. De Haan \& Zoomers, 2003; McKay, 2005). This tendency towards individualism results in growing inequality between members of the household and between households in the community. It is argued that, although individuals remain member of the household, the traditional rural based solidarity-based principles of pooling incomes, consumption and labour force within the households has weakened considerably (L. De Haan \& Zoomers, 2003, p. 354).

Another implication of de-agrarianisation which fosters inequality is uneven access to rural landholdings. This is very much associated with the practice of land tenure and land management. Throughout Southeast Asia, land access is being reconfigured by state programmes that seek to include small farmers in formalized access to agricultural land, or transfer of ownership to them (Hall et al., 2011, p. 27). This creates a situation where residents are forced to re-examine how the households 'manage' their land, which is often non-titled and 'communal' in nature. It is a common practice in Southeast Asian countries that rural households have individual rights to land and these rights are recognised by the village community. These rural lands are inherited through generations, with no fixed title. When the issue of land become contentious and the demand for agricultural land raises the value of such land, families are forced to address the issue by giving land to certain individuals in the family. This becomes an issue as it can cause inequality between members of same households or between members of the community, when land is being 'owned' by certain groups within the community. 
Hall et al. (2011) write about land dilemmas in rural areas of Southeast Asian countries that have accompanied the de-agrarianisation process, specifically addressing the issues of land access and exclusion. They argue that the conversion of land in post-agrarian uses (e.g. for large-scale commercial uses) lead to conflicts amongst the kin, due in part to the nature of land rights, identity and belonging. They also argue that with crop booms (e.g. palm oil) are the central trigger for the sale of land and its subsequence conversion from agricultural to non-agricultural purposes, and these sales have been rising land prices and many farmers have been keen to take advantage of this higher land prices (Hall et al., 2011, p. 118).

\subsection{Summary}

My aim in this chapter has been to highlight the complex nature of both 'accessibility' and 'development' and the different consequences of their interaction. I also describe how the relationship between accessibility and development are seen in the context of de-agrarianisation.

Both development and accessibility are broad concepts, and consequently need to be 'anchored' down to as specific issue so that their multiple interpretations and relationship can be meaningful. In this research I am focusing on the relationship between accessibility and development against the backdrop of de-agrarianisation. In general, how significant the relationship depends on a number of factors, which include physical accessibility to markets (e.g. road connection), types of market, and education.

A review of literature has shown that improved accessibility can promote greater levels of development in rural area (Bravo, 2002; Kelly, 2011; McKay, 2003, 2005; Ogunsanya, 1987; Olsson, 2009; Rigg, 2003; J Windle \& Cramb, 1997). Kelly (2011) and McKay $(2003,2005)$ describe how increased levels of accessibility led to increased standards of living, through higher remittances, in rural Philippine villages. These past studies measured development in the socio-economic context, using indicators such as household income, and remittances. However improving accessibility to land can also accelerate the process of de-agrarianisation by making other labour markets more accessible. And to complicate the picture, improved accessibility can accompany and accelerate reagrarianisation in the form of commercial agriculture.

Among the significant changes increased accessibility brings to rural households is de-agrarianisation, and the associated practice of multi-local living. De-agrarianisation, which is a shift from farm labour 
to non-farm activities, is part and parcel of structural change, and forces rural dweller to re-think of their livelihood strategies. One of those strategies is the practice of multi-local living. As farming is no longer the lynchpin of many rural economies in the $21^{\text {st }}$ Century, rural dwellers have been increasingly involved in non-farm and, mostly, urban-based employment. This has been widely observed in Southeast Asia, especially in Thailand (Rigg, 2003; Rigg and Nattapoolwat, 2001, Rigg and Salamanca, 2011; Rungmanee, 2014), Vietnam (Alther et al., 2002), Philippine (Kelly, 2011; McKay, 2005), and Indonesia (Firman, 1994; Hugo, 1982).

A number of factors had helped to reshape the rural landscapes in light of improvement in accessibility. One crucial feature that stands out in terms of development, as a consequence of improvement in accessibility, is the increased level of education among rural dwellers. Education, especially among the younger generations, has undoubtedly helped to accelerate de-agrarianisation and structural change. By contrast, it can also be argued that de-agrarianisation had actually pushed rural dwellers to put more emphasis on education in order to reap more benefits in their shift from farm to non-farm employment.

The changes which are associated with a societal shift from physical capital (farm-based focus) to human capital (non-farm work which require knowledge-based capability), are aided by improved accessibility to markets. Changes in level of education contributes to improved individual and household levels of accessibility, and in the long run, can influence the rate of community's accessibility to market and perpetuate the practice of multi-local living.

Most of the literature discusses the consequences of de-agrarianisation in relation socio-economic development (McKay, 2003; 2005; Rigg, 2003). What is often missed from the discussion is the changing use to which rural farmland is put following de-agrarianisation. Past studies have explored the issues of being left-behind in villages, usually with reference to the elderly and the very young, their coping strategies and the significance of remittance and migration.

My research adds to the debate over de-agrarianisation and the development implications of improved accessibility which can precede and accompany the process. My field work to follow will investigate how geographically remote rural dwellers in Sarawak, in a very low accessibility environment are coping with on-going de-agrarianisation. Peninsular Malaysia together with its Southeast Asian neighbours, have already experienced this process but at a much earlier time period. What is happening in rural Sarawak at the moment replicates much of what happened in rural 
Southeast Asian regions in the 1960s and 1970s. Sarawak's unique socio-economic, cultural and historical conditions have, however, slow downed the process of rural-urban migration and multi-local living processes comparative to its neighbouring regions.

My study also has a specific focus on Iban households and their contemporary livelihood strategies in the face of continued inaccessibility in a relatively undeveloped region of the country. However, this is changing and is forecast to do so at an accelerated rate with the advancement in information and communication technologies and heavy investment in Hydroelectricity Power Plant and largescale oil palm plantation.

It is against the extensive of background de-agrarianisation in Southeast Asia in particular that I explore how the Iban community, who were an almost exclusively farming community, have experienced de-agrarianisation in a region with very little improvement in local accessibility or development.

Furthermore, the classic research on the Iban in Sarawak, which has been used as the cornerstone of many studies in Sarawak and on the Iban, were written by Freeman in the mid-1950s (Freeman, 1955, 1970). Freeman's case study villages were located along Sungai Sut, Sungai Tiau and Sungai Melinau all of which are the tributaries of Batang (River) Baleh, which is my research site. My research can potentially addresses this gap by reviewing the current practices among the Iban, their sources of livelihood and exploring how improvements in accessibility, and in information and communication technologies, play a role in the overall development experienced by Sarawak rural dwellers three generations after Freeman's study in the region was conducted. 


\section{Chapter 3:}

\section{Conceptual Framework}

The broad argument of this thesis is that as market size and accessibility to the market increases, so does the level of development. In the absence of market size and adequate transportation, however, opportunities are limited, incomes are unable to grow and the population diminishes. It is the latter situation that has characterised the livelihoods of those who have lived and continue to live in the Baleh river basin of Kapit Division of Sarawak. Still unconnected by road to the rest of the country and served by a main town of under 18,000 people (Kapit Town), it is hardly surprising that the area has witnessed high rates of relative and absolute deprivation, lower than average growth and net outmigration. This lack of development has seen a series of strategic adaptations by residents which have disrupted local communities, spatially dispersed members of the same household and disconnected individuals both economically and culturally. Above all it has estranged the mainly Iban population from their ancestral lands creating considerable uncertainty and potential discord within families over inheritance rights.

In the chapter to follow I introduce a conceptual framework within which to build an understanding of a livelihood in the study area, as gleaned from responses to the households interviewed in the field. The essential point is that the contemporary descendants from those pioneers who settled in Baleh in 1800s, whose children formed the generation studied by Freeman in the 1950s and whose grandchildren now live in or have migrated out of the area face economic and political forces which place them at a disadvantage - economically, socially and politically. The result is an unprecedented disconnect between the lives of the present generation of young men and women and their parents.

I begin a discussion of these forces by drawing on the concept of de-agrarianisation which I introduced briefly in Chapter One. The term refers to the gradual shift of economic opportunities away from work on the farm into industry and service jobs. Underlying the process of de-agrarianisation is a geographical shift in the distribution of income earning opportunities away from the rural to the urban. We see in this process a changing relationship between city and country as the population distributes itself in order to facilitate growth and social harmony at all levels of society.

The first argument I advance is that the process of de-agrarianisation fundamentally alters the relationship between income and accessibility necessitated by agricultural commodity production. I 
develop this argument over the following chapters in order to understand the economic geography of the Baleh Iban's response to low levels of agglomeration and accessibility. The chapter begins with von Thünen's model of agricultural land use. The expositional value of this very simple model lies in the way it highlights the importance of access to agricultural commodity markets. Faced with constraints on the size of these markets, households living within and beyond the limits of cultivation must access other markets on which they sell their own labour. The inaccessibility of the Baleh means this can only be done by splitting households, a practice referred to as multi-local living. In this way the von Thünen model helps expose the drivers and the complexity of the current pattern of Iban income generation.

The second argument introduced addresses one of the consequences of this substitution of labour out of agriculture and the associated locational shift to living in towns, namely the growing inequality among villages, between households and across individuals. At the end of the chapter I offer two hypotheses which I go on to test in the empirical chapters to follow.

\subsection{The von Thünen land use model}

One of the ways of thinking about the potential effects of accessibility on development is to draw on a simplified model of the process. In this instance, I draw on a model of agricultural land use, developed by the $19^{\text {th }}$ century German economist, von Thünen, famous for developing his own interpretation of land rent by showing how income from sales of farm commodities falls with farmers' distance to the market (rather than fertility as contemporary David Ricardo argued) (von Thünen \& Hall, 1966).

Johann Heinrich von Thünen was one of the pioneers of economic thought and the first to bring the concept of space as a speciality within economics, thus starting off the field of spatial economics and economic geography (Ozkul, 2015, p. 102). His analysis (and, to some extent, all subsequent theories of an economy in space) begins with a simple model of one urban centre and its rural hinterland (Hite, 1997, p. 231). Translating from his 1827 text, Hall quotes,

"Imagine a very large town, at the centre of a fertile plain which is crossed by no navigable river or canal. Throughout the plain the soil is capable of cultivation and of the same fertility. Far from the town, the plain turns into uncultivated wilderness which cuts off all communication between the State and the outside world ... The problem we want to solve is this: What pattern of cultivation will take shape in these conditions?; and how will the farming system of the different districts be affected by their distance from the Town?"

(von Thünen \& Hall, 1966, pp. 1-2) 
von Thünen addressed the above problem by using a model of agricultural land use based on net revenue, also known as 'land rent' or 'locational rent', the terms being used interchangeably in literature. They each refer to the residual net income left to the farmer from the sale of his/her produce after deducting the cost of production (Atkins, 1987, p. 130).

Figure 3.1 shows that the radial distance of land from the market as the horizontal axis and net revenue (also known as land rent) on the vertical axis. In the von Thünen model, the farmers are not landowners and are assumed to pay land rent to the landowner.

Figure 3.1 Von Thünen's model of agricultural land use

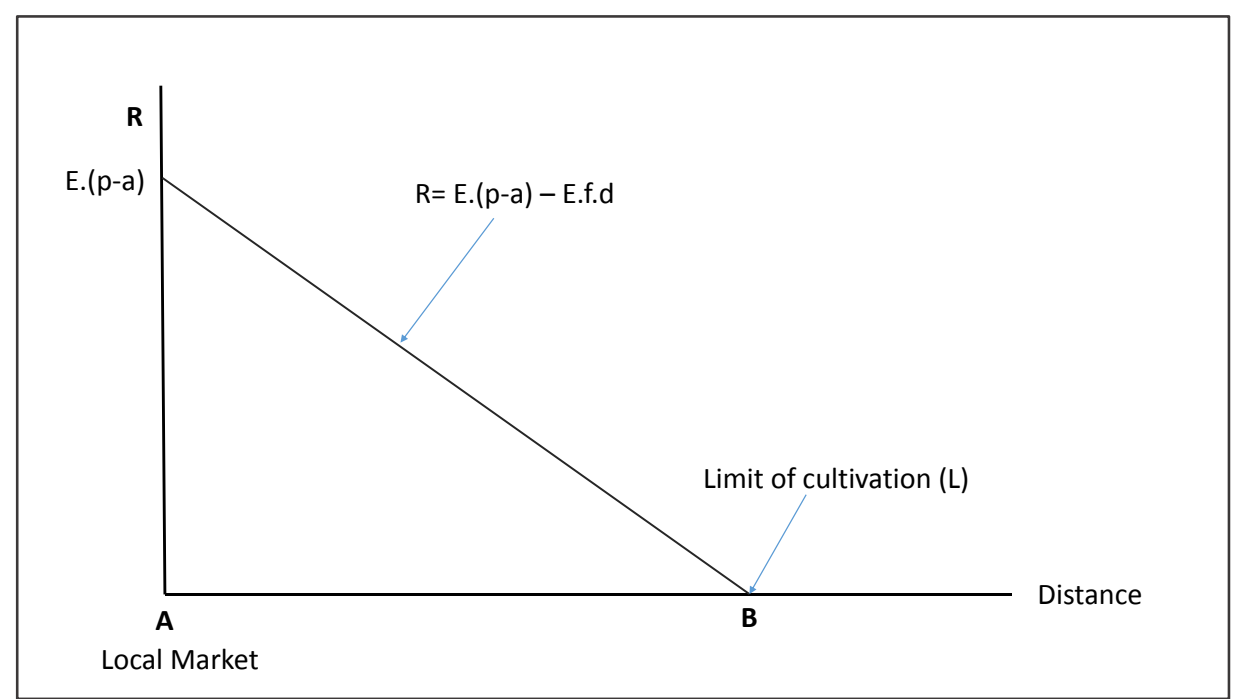

Source: Anderson (2012), Fig 17.1

I use Anderson's terminology (Anderson, 2012, p. 216) to define land rent as follows:

$$
R=E \cdot(p-a)-\text { E.f.d }
$$

where $\mathrm{R}$ is the rent bid by a typical farmer, $\mathrm{E}$ is the yield of the crop (in tonnes per hectare, for example), $p$ is the market price of the crop per tonne and $a$ is the production cost per tonne (including the farmers own drawings or implicit labour cost), and $f$ is the per unit cost of transportation per unit of distance $\mathrm{d}^{34}$ I have made the multiplications explicit in the equation by adding '. .

\footnotetext{
${ }^{34}$ We write this in full knowledge of the fact that von Thünen pointed out how his theorem would be upset in an area whose transport costs were reduced by the existence of a navigable river (Clark, 1967, p. 371). My data in Chapter Five shows why but this does not undermine the heuristic value of the model at this conceptual stage.
} 
According to equation $3.1 \mathrm{E} .(\mathrm{p}-\mathrm{a})$ is the market return from growing the crop in the absence of transportation costs. The model assumes that yield and production cost are independent of scale, so following Anderson, I imagine the land being offered for rent in one hectare plots. The transportation cost E.f.d depends on the transportation rate per kilometre $f$, and the distance from the market, $d$.

The implication of is that farmers will bid higher rents for land closer to the market. Figure 3.1 is a graphical expression of equation 3.1 which enables us to see that, at the centre of the market $(d=0)$, the rent payable is simply the return to farming, the positive net cost of production, Ep - Ea. Each unit of distance further from the market means a lower the net return to the point where $d=L$, the limit or margin of cultivation, beyond which no positive returns can be realised. The rent payable is, therefore, zero (because E. f. $\mathrm{L}=\mathrm{E}$. $(\mathrm{p}-\mathrm{a})$ ) and will be negative beyond that point. ${ }^{35}$

\subsubsection{Effects of changes in prices and costs}

One of the important implications of the von Thünen model is the relationship between the town market and the countryside. As the population (and/or per capita income) of those living in the town grows, so the demand for food rises. ${ }^{36}$ Other things equal, prices for food will rise, which as Figure 3.2 shows, will render production on the margin profitable again and extend the limit of cultivation, from $B$ to $D$ in this case. The size of the town (the market), therefore, has a direct effect on the extent of the agricultural hinterland. ${ }^{37}$ It also has a direct effect on land rent, and hence what the farmer can earn at any point.

\footnotetext{
${ }^{35}$ As Clark notes von Thünen wrote largely in response to the prevailing Ricardian model of land rent - "The essence of von Thünen's complaint against Ricardo ... is that Ricardo developed his theory of rent in terms of an undifferentiated agricultural products" (Clark, 1967, pp. 370-371). Anderson reminds us of an importance difference between the two which helps our appreciation of the role of L. Ricardo defined a zero-rent plot of land as the least productive plot in cultivation whereas von Thünen defined a similar plot as the most remote plot (located at L) in cultivation. In both cases, Anderson observed, "an increase in the price will drive cultivation onto more marginal plots and increase the rent of the best plots. It is just that in von Thünen, "marginal" and "best" are defined in terms of relative location rather than physical characteristics. Thus, while we may think of Ricardo and von Thünen as providing alternative views of agricultural land use, the economic mechanisms that drive their models are fundamentally the same" (Anderson, 2012, p. 217).

${ }^{36}$ Anderson treats price rises as completely exogenous, driven for example by international trends (p. 216). This exogeneity is compromised only slightly by allowing demand to be driven by the town's population, as long as we assume spatial (and economic) separation of urban and rural dwellers.

${ }^{37}$ Anderson goes on to show how because the margin of cultivation is the radius of a circular region in which crops are grown how the total output $Q$ in the region is, therefore, equal to the area of that circle times the yield, $Q=E \pi L^{2}$ (Anderson, 2012, p. 217). Therefore as $L$ increases, so does $Q$, so the increasing relationship between price and output that defines the supply function now has a spatial basis - a feature Anderson elaborates in his appendix (p. 227-229).
} 
Figure 3.2. The locational consequences of rising urban demand for agricultural produce.

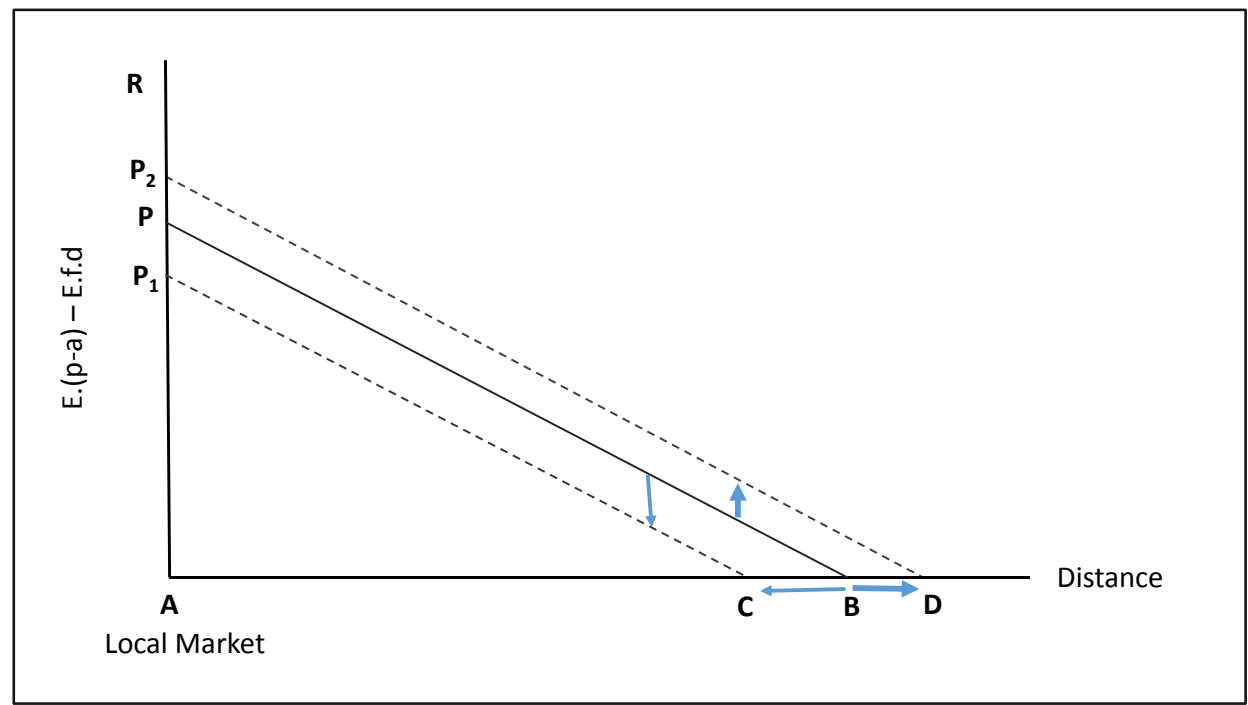

Source: Anderson (2012), Fig 17.3

The above argument also works in reverse. If the population and/or per capita income of the town falls, prices will fall and the margin of cultivation will shrink, from B to C in Figure 3.2 - all other things equal. A similar effect will prevail if farmers experience a rise in costs of production, such as might occur with respect to a rise in the costs of pesticides or fertilisers or both. However, possibly the most important, but less widely discussed rise in costs is the return the farmer wish to pay himself.

One of the consequences of uneven geographical development is the demonstration effect. Farmers and their families will compare their standard of living to those living elsewhere, particularly in the cities. This is particularly likely during de-agrarianisation because the process itself is an expression of shifts in tastes. The effect of rising aspirations among farmers is of course to raise their own internal costs of production a, which has the same impact as lowering prices in the von Thünen model. The net effect of either is to shrink the margin of production which in turn precipitates an exit from farming.

The other important implication of von Thünen's conceptualisation concerns changes in the second term of equation 3.1, namely transportation cost. Transport costs also have an effect on the limit of cultivation but through a different shift in the rent function. A rise in the cost of transport from $f$ to $f^{\prime}$ has no effect on those producing directly opposite the market itself. However with each successive unit of distance away, the greater the influence of the change in transport cost per kilometre unit. This uneven effect on rent with distance is shown as the dashed line in Figure 3.3. 
Figure 3.3. The locational consequences of reduction in transport cost.

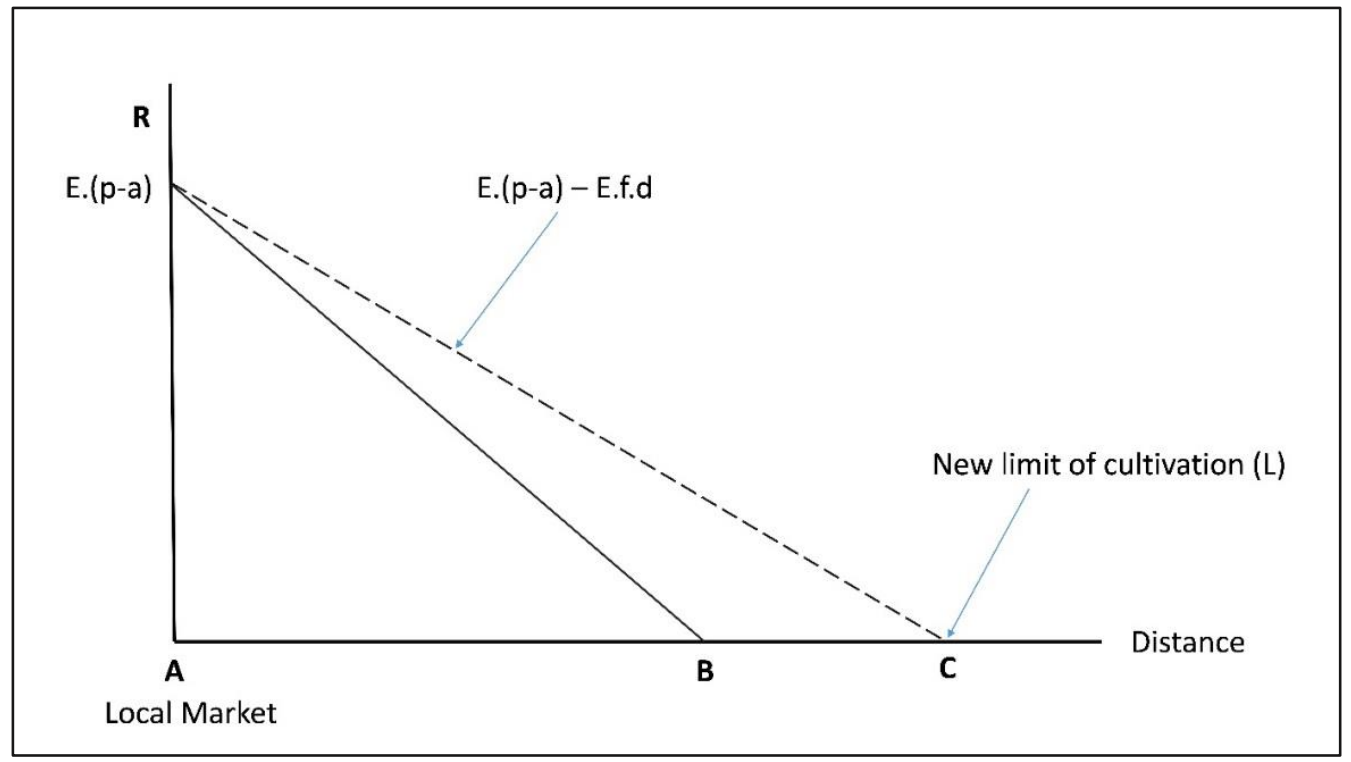

Source: Anderson (2012), Fig 17.4, p.219.

Therefore, as Anderson explains, when transport costs rise, "the spatial rent function does not shift outward so much as rotate outward around the rent at $d=0^{\prime \prime}$ (р. 219). In any case, a reduction in transportation costs, $\mathrm{f}$, causes an increase in the limit of cultivation and by extension crop production. A rise in per kilometre cost of transport therefore has its greater marginal effect at the cultivation limit. Changes in transport costs, therefore, have a central role in accounting for changes in the location of the cultivation margin.

It is well established in the conventional applications of land rent theory that different agricultural commodities have their own bid rent curve and land uses are dependent on their relative bidding power. However, unlike many applications in geography, my interest in von Thünen does not extend to the presence of multiple land uses. ${ }^{38}$ This is partly because of the low volume of agricultural commodity production and the relatively small range of crops in my field area, but also because, my interest centres more directly on the limits of cultivation implied by the model and the role other alternative markets play for holds living beyond the margin.

Von Thünen was primarily interested in exploring the relationship between markets and agricultural production and as such he was not centrally interested in the areas located beyond the agricultural margin (although as Clark's short piece showed he made a number of observations about how such

\footnotetext{
${ }^{38}$ Notwithstanding the fact that, according to Colin Clark, "Von Thünen's great achievement was to point out that transport costs were the cause, and rents the consequence, of important differentiations of agricultural, dairy, and forest production, according to distance from the market" (Clark, 1967, p. 371).
} 
land was used around the farm in the most distant locations, (Clark, 1967)). Contrary to the $19^{\text {th }}$ Century German case, what happens beyond the margin is of particular interest under conditions of de-agrarianisation in Southeast Asia albeit almost 200 years later. This is because under deagrarianisation the rising opportunity costs of labour in agriculture reduces the extent of the agricultural margin (via 'a' in equation 3.1) which leads to a growth of a surplus labour force which, in the absence of local urbanisation, results in out-migration to other more prosperous regions.

In summary, the value of this simple but economically reasoned model is threefold: it highlights the importance of market size through its effect on $p$, it shows how changes in ' $a$ ' the costs of production (and hence the farmers internal relative rate of return), and it exposes the critical role of transportation costs. All three affect the cultivation limit, the distance beyond which it pays the farmer to cultivate. In short, the von Thünen model helps bring order to the discussion of the much more complex relationship between 'development' and 'accessibility'39.

The von Thünen model is used extensively in related discussion (Grotewold, 1959; Hite, 1997; O'Kelly \& Bryan, 1996; Ozkul, 2015). Hite (1997, pg. 231), for example, argues that "the von Thünen model and kindred recent work labelled the 'new economic geography' supply a plausible paradigm for rural economic development policy". He noted that if we look at the relationship between accessibility to market and its 'development' indicators, von Thünen's model may still be relevant as a basis for explaining the changing rural dynamics. O'Kelly and Bryan (1996, p. 462) argue that "despite the changes and advancement experienced in today's economies, it does not mean that the model is invalid, nor does it imply that location rent is no longer the basic allocating mechanism". Along a similar line, Grotewold (1959, p. 353) write that "by substituting perishable agricultural commodities as services one might find that the basic principles of von Thünen's theory hold true even at this time".

\subsection{Extensions of the model}

The purpose of a model is to simplify. In so doing it exposes exceptions to the model's assumptions posed by the circumstances in the field. I briefly mention four of these: multiple transport modes, multiple markets, multiple members of farm households and land ownership. Table 3.1 summarises the differences between von Thünen's assumption and the reality faced by the Baleh Iban.

\footnotetext{
${ }^{39}$ As illustrated by Block and DuPuis (2001), the von Thünen model is also useful for comparing the different disciplines and theory. They illustrated the use of von Thünen model in their cross-analysis of these disciplines: geography, agriculture economics and sociology of agriculture.
} 
Table 3.1: Assumptions in von Thünen's model and present day conditions

\begin{tabular}{|l|l|}
\hline \multicolumn{1}{|c|}{ von Thünen } & \multicolumn{1}{c|}{ Current situation } \\
\hline Transport is uniform & $\begin{array}{l}\text { Transport is not uniform } \\
\text { Different modes of transport } \\
\text { Different cost of transportation }\end{array}$ \\
\hline Single dominant market & $\begin{array}{l}\text { More than one market } \\
\text { Dominant market may be located further away from the region }\end{array}$ \\
\hline $\begin{array}{l}\text { Specialisation (one commodity) i.e. } \\
\text { farmer }\end{array}$ & $\begin{array}{l}\text { Multiple commodity: } \\
\text { Including skills and labour, and not just farm products } \\
\text { Knowledge worker and not just farmers }\end{array}$ \\
\hline $\begin{array}{l}\text { Farmer - working as an individual } \\
\text { entity }\end{array}$ & $\begin{array}{l}\text { Household working together - and income comes from } \\
\text { diversified sources (not just farm-based) }\end{array}$ \\
\hline Land Rent & Limited conventional market for NCR land \\
\hline
\end{tabular}

Adapted from Anderson, 2012; Atkins, 1987; Grotewold, 1959; Hite, 1997; Ozkul, 2015; and von Thünen \& Hall, 1966.

\subsubsection{Multiple transport modes}

von Thünen assumed that transportation costs (dollar per kilometre) were uniform across the plain. This assumption, as briefly described above, is no longer valid in the present day. As I show in Chapter Five transporting commodities to the market depends very much on the mode of transport, and the cost can be categorised as monetary or non-monetary (i.e. time taken to reach destination). Because of this departure from von Thünen's assumption, the land rent for the same commodity may vary dependent on its transport option as illustrated in Figure 3.4 below. If a farmer chose transport option $P_{1} B$, he/she gains higher net revenue but the land has to be located nearer to the market (i.e. between $A$ and $B$ ) compared to transport options of $P_{2} C$ and $P_{3} D$. 
Figure 3.4: von Thünen model with changes in mode of transport

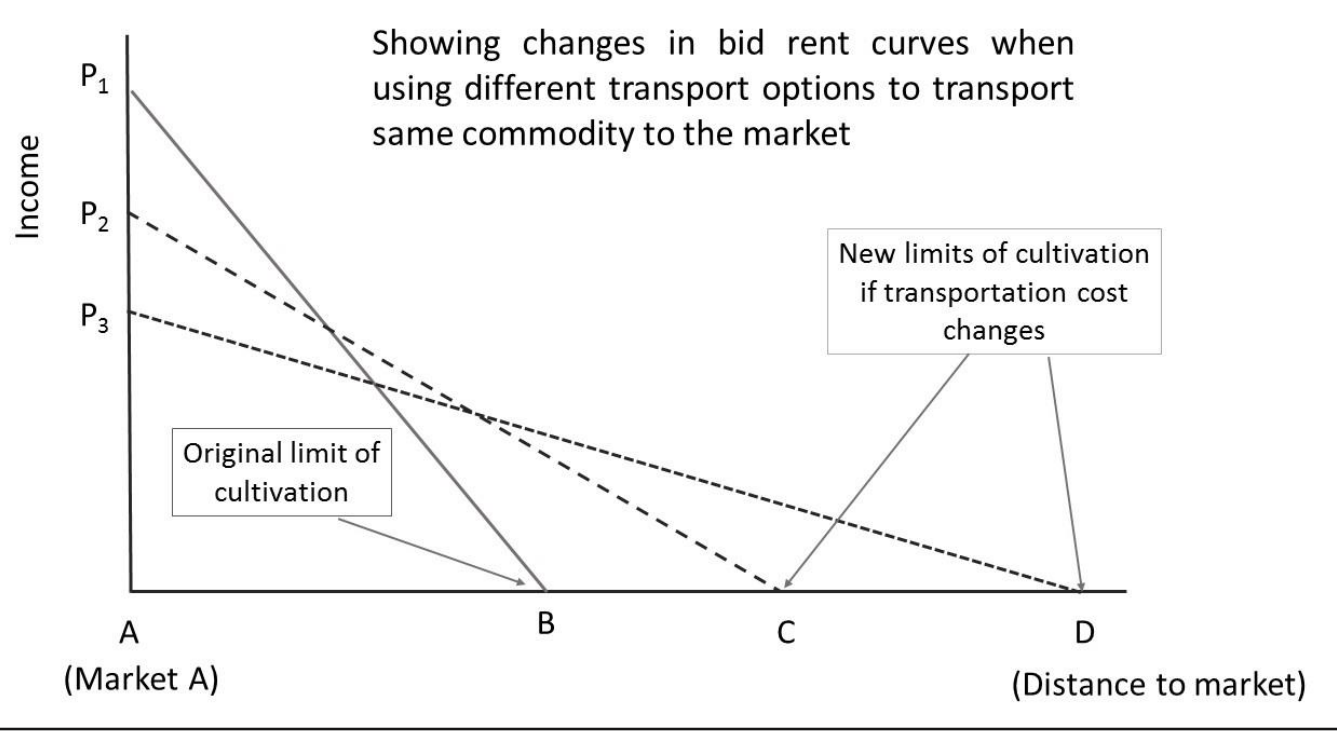

The above diagram can also be used to explain how road construction in a previously non-accessible rural area can influence land use. A new road lowers average transportation cost. Let $P_{1} B$ reflect the cost of transport using river transportation and $P_{3} D$ as the cost of transport after a new road has been constructed in the area. It shows that road construction opens up more land for development (i.e. from $A B$ to $A D$ ) and, thereby, changes the limit of cultivation. ${ }^{40}$

Instead of a single mode of transport as envisaged by von Thünen, my case study area has multiple modes of transport. Not only that, the transportation costs are not uniform across my 'plain' (i.e. across Batang Baleh and its tributaries). Unlike von Thünen's model, the costs of transportation varies (i.e. is not stable) as they are dependent on local factors. For example, the cost of travel to Kapit Town using longboat is higher during low river level compared to when the river level is high ${ }^{41}$. In the same

\footnotetext{
${ }^{40}$ As I show below, Chapter Six, this is significant especially in Baleh, which is currently inaccessible due to no road connection, but the area has already been earmarked for two major development projects in the very near future. The two major infrastructure projects are road construction, which will eventually linked Kapit Town to Sibu, and a hydro-electricity dam in upper Baleh. Both of these projects will result in improved road connection from Kapit Town and its rural hinterlands, thus affecting a large number of settlements and rural dwellers in the region. This also poses the question of how these new development projects will affect the accessibilitydevelopment equation in the area, and what are the implications to the community, households and individuals. ${ }^{41}$ The cost is higher during low water level because the longboat will be slower in navigating the rivers, and, therefore, uses more petrol. It is also more time consuming.
} 
vein, the cost of transport varies depending on where one is located along the accessibility continuum $^{42}$, as well as on the mode of transport used ${ }^{43}$.

Another assumption made by von Thünen, that is no longer applicable in the present day, is that transport, in the form of roads, was available anywhere farmers wanted them. In the real world the provision of a 'road' network is not uniform, and when 'roads' are not available anywhere, farmers with road access accrue advantages that others do not have.

\subsubsection{More than one market}

One of von Thünen's key assumptions is that there is only one market, where farmers sell their commodities. In Sarawak, or most places for that matter, farmers have access to more than just one market but these markets differ substantially in size. A farmer may also have more than one commodity to sell in the market, which highlights another departure from von Thünen's assumptions, namely that farmers only produce one type of agricultural product for sale, or at least all commodities bear the same production and transportation costs and realise the same prices.

Figure 3.5 below shows a situation whereby an individual (Person A) is selling two commodities (Commodity \#1 and \#2) at two different markets, and both commodities fetch different prices. If, for example, the cost of transportation to market A increases, and income from Commodity \#1 decreases from $\mathrm{P}_{\mathrm{a}}$ to $\mathrm{P}_{\mathrm{a} 1}$, Person A may decide to rethink whether to stop cultivating Commodity \#1. However, if the income from Commodity \#1 drops further to $\mathrm{P}_{\mathrm{a} 2}$, Person $\mathrm{A}$ is now better off focusing solely on Commodity \#2. Continuing with Commodity \#1 in that situation would only means that Person A will incur some losses in his/her income.

\footnotetext{
${ }^{42}$ The cost of using express boat to Kapit Town ranges from RM15 to RM30 (equivalent to NZD7.80 to NZD11.50), but once all the cheaper seats are taken, other passengers have no choice but to pay for the more expensive fare. In other words, the level of accessibility to 'cheaper seats' influence the cost of travel.

${ }^{43}$ Different mode of transport also influence accessibility to market. Using own transport could costs more than using express boat, depending on location.
} 
Figure 3.5: von Thünen model with multiple markets

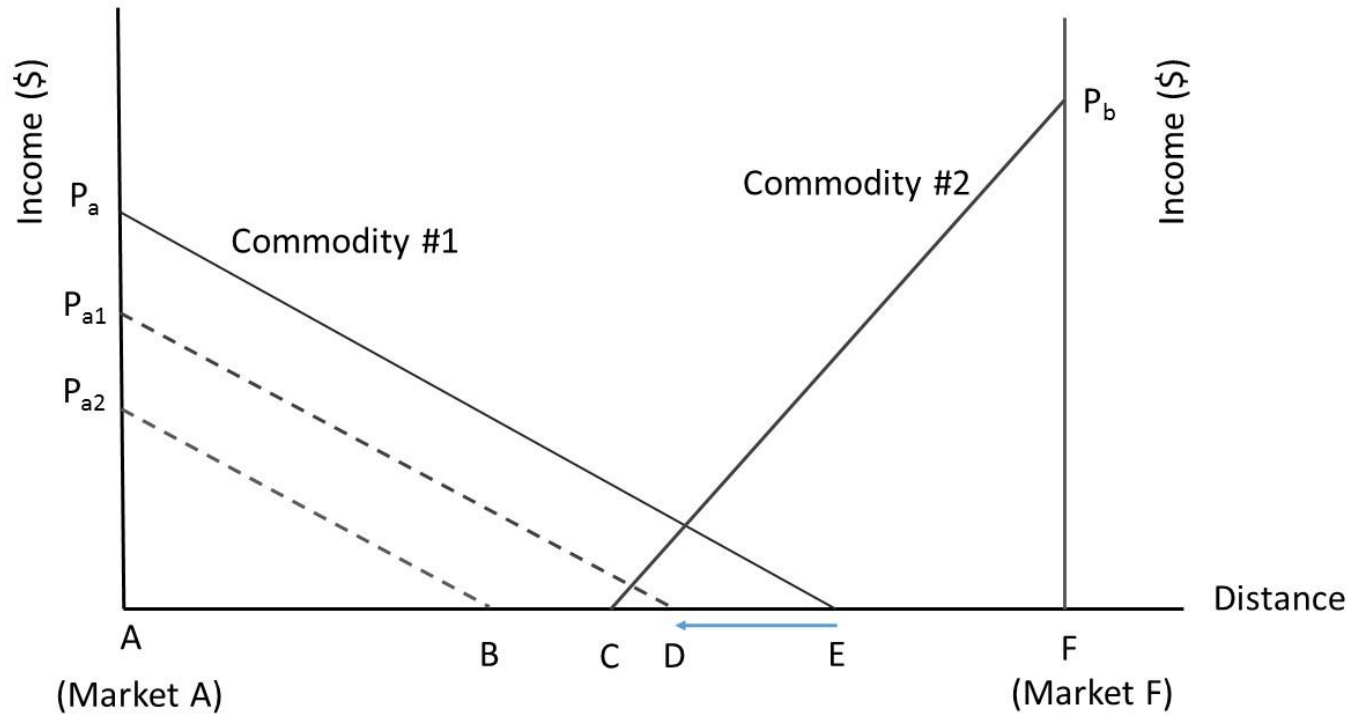

In present day Baleh, this explains how an individual is selling two commodities at different market places. In translating this thinking to the Kapit economy it is useful to extend the notion of a commodity beyond the agricultural and away from products in general to the sale of labour. In this context the dwelling and family become an environment for the growing of labour power, for the reproduction of labour on a daily basis. This labour power can then be sold on local markets.

As farming is no longer the lynchpin of Kapit's economy, Person A could be a civil servant, selling his/her skills at Market F and earns a fixed salary. At the same time, Person A is also involves in other economic activity (e.g. part-time farming, fishing or another type of employment) and sells his/her product at Market A. If the cost of transportation in his/her part-time economic activity fluctuates, it would affect his/her income ${ }^{44}$. Person A might have to rethink whether to continue with both activities or to just focus on one activity.

\footnotetext{
${ }^{44}$ E.g. An increase in travel cost, or a hike in transport fare, would means he/she will have to pay more for transport, and consequently, reduces his/her income from that activity.
} 


\subsubsection{Land Ownership}

In order to make the model tractable, von Thünen turns all farmers into tenants who bid periodically for parcels of land in the vicinity of the market. Those who bid highest for any given parcel earn the rights to farm. The implicit assumption therefore is that there is a market for rural land. Rights to use land among farmers in Baleh derive not from the market but from historical occupancy based on cultivation of primary forest. They farm on their ancestral land and do not pay rent as such but nor do they have title, only Native Customary Rights $(\mathrm{NCR})^{45}$. Their rights to sell are, therefore, limited except to other NCR holders, other Iban in effect. I speculate on the implications of this departure in the study's conclusion.

In summary, there are clear differences between the assumptions von Thünen introduced in order to explain rent variations across the rural landscape and the realities of the Baleh Iban landscape, just as there are with most real world landscapes. The important property of the von Thünen model, however, lies in its ability to abstract from any such detail to expose the economic forces which underlie differences in the income farmers can earn from their land. This application of particular interest is the role of market size, transportation cost, the farmers who income aspirations and role which the limit of cultivation plays in the search for alternative markets for both commodities but particularly for labour.

\subsection{Relationship between development and accessibility}

In the absence of no other conditions and all the von Thünen assumptions we can expect income to rises with accessibility to the market, as depicted in Figure 3.1. In economies where there is no market for land and where allocation of rights of occupancy are the result of something akin to an historical lottery, those who happen to be located closer to the market are able to pocket the income differences which result.

A central feature of the von Thünen model is the size of the market. However when it comes to development more generally the size of the market plays a role which extends further than simply moderating $p$, the price received for the commodity. The town is also a supplier and, as such, proximity alters the costs of production, a. Other less tangible benefits of being close to town, also apply, for example, production techniques and market knowledge. More importantly, as Adam Smith observed,

\footnotetext{
${ }^{45}$ Or if the farmer owns the land, the rent accrues to him/her.
} 
the division of labour is also a function of the size of the market. From that division follows specialisation, higher productivity and higher incomes. For these reasons average incomes tend to rise with city size.

The greater opportunities cities offer for labour mean a wider distributions of incomes. Those accessing urban markets to sell labour as well as commodities will typically exhibit greater income disparity certainly than those practicing subsistence agriculture. Spatial concentration of population in a market means the combination of labour, capital and land are focused in one location, which benefits in terms of having a potentially specialised environment which are central to economic growth (World Bank, 2009). Economic growth display unevenness and usually places close to large markets prosper more than places more distant (World Bank, 2009, p. 5).

Therefore, while accessibility to larger markets can increase average incomes, it also creates opportunities for greater income inequality. In the developing economy context these disparities can manifest between villages, but also between households within a village, and between individuals in the same households. For example, an individual who is employed in higher paying job in urban area would have higher income compared to his/her siblings, or relatives in different households, who live and work in the villages. As the World Bank (2009, p. 1) noted, "the best predictor of income in the world today is not what or whom you know, but where you work."

The World Bank Report was referring to how different countries have different income per capita and that different markets (locations) offer different income potential ${ }^{46}$. Individuals may be awarded the opportunities to work in urban area due to their education, access to employment market or their skills, all of which are personal attributes of an individual. Inequality arises when the uneven access to both markets and services exist, and can be exacerbated by the perpetuation of advantages (and disadvantages) peculiar to individuals and households. In response to inequality, individuals and households might, therefore, be tempted to change their household strategies, and to take more risks, in order to improve their standard of living. Their responses may involve spatially separating their household in order to take economic risks and opportunities. As Ellis (1998, pp. 12-13) points out "risk is often cited as primary motive for income diversification as it implies a trade-off between a higher total income involving greater probability of income failure and a lower total income involving smaller probability of income failure".

\footnotetext{
${ }^{46}$ The Report uses the examples of how a Bolivian man with nine years of schooling earns an average of USD460 a month, but the same person would earn about three times as much in the United States to illustrate 'place premium' that occurs throughout the world (World Bank, 2009, p. 1).
} 


\subsection{Summary}

The aim of this chapter has been to introduce a conceptual framework to help order and interpret the complexity presented by the multiple livelihood strategies being used by the Baleh Iban in 2014, some seven generations from their initial settlement in the region in the 1800s. The conditions I describe out of fieldwork in 2014 differ vastly from those experienced by the shifting cultivators whose eastward advance was halted by Brooke in 1874. They also differ substantially from the detailed description offered by anthropologist Derek Freeman some ninety years later as a result of his field work in the Baleh in the mid-1950s.

Taking a human geography approach I have used the von Thünen model to guide my interpretation of spatial patterns of livelihood during what is a late phase in the process of de-agrarianisation in rural Sarawak. My aim has been to draw on the insights offered by the model to understand the relationship between development and accessibility.

The primary insights I carry forward are threefold: firstly, that access to markets affects incomes through all three parameters of the model (equation 3.1): $p$, the prices received for commodities (and labour in my extension of the model), a, the costs of production which importantly include the producers own evaluation of their own required rate of return, and $f$, the costs of transport. Of particular interest is the limit of cultivation derived from the model and the livelihood strategies adopted by those living beyond that agricultural margin. Each of these considerations is built into the research design I introduce in Chapter Four. 


\section{Chapter 4}

\section{Research Design and Methodology}

Following from a conceptual overview of the relationship between accessibility and development in the previous chapter, I now discuss the research design and methodology that I used in this thesis.

This chapter details my research design and methodological approach. I describe five key elements of my research methodology, which are the multi-level research design, the case study area, data preparation and analysis, the survey instruments, and the indicators developed to measure both accessibility and development. These indicators include measures of physical development, income, personal (individual) development, subjective measures of development and accessibility, physical accessibility, and, what I refer to as, contemporary accessibility.

\subsection{Research design}

The main purpose of any research design is to connect the conceptualisation of the problem and underlying processes with the empirical evidence. In my case, the aim is to test two broad hypotheses: (a) whether and under what circumstances, a greater level of accessibility is associated with higher level of development, (b) and the degree to which greater accessibility is also associated with increased inequality, at the level of the community, the households and the individuals.

Development is a process, influenced at different stages by levels of accessibility to markets and services. An ideal research design would therefore be one in which both variables, development and accessibility, are observed over time. However, since I did not have the luxury of time to monitor both over the several decades required, I had to substitute time with space. Since I could not look at low into high accessibility eras, I choose to compare low and high accessibility areas and relate them to spatial variations in levels of development.

The substitution of space for time in the research design introduces both opportunities and imposes certain limitations. The result is a cross-sectional study, which according to Babbie (2008, p. 111), involves observations of a sample of areas with different levels of accessibility to a central market. The market of interest is Kapit Town (population of 18,000 in 2013), the primary means of transport is by river and, therefore, I divided the hinterland of the town into three mutually exclusive accessibility 
zones as detailed in Map 4.1: a relatively high accessibility zone (I), A1, a middle (II), A2, and the less accessible zone (III), A3. This design allowed me to test my principal hypothesis which was that different levels of development would be associated with different levels of accessibility, namely that development levels would be ranked $\mathrm{A} 1>\mathrm{A} 2>\mathrm{A} 3$.

Map 4.1: Accessibility zones and settlement locations within Kapit District study area, Sarawak, Malaysia, 2014

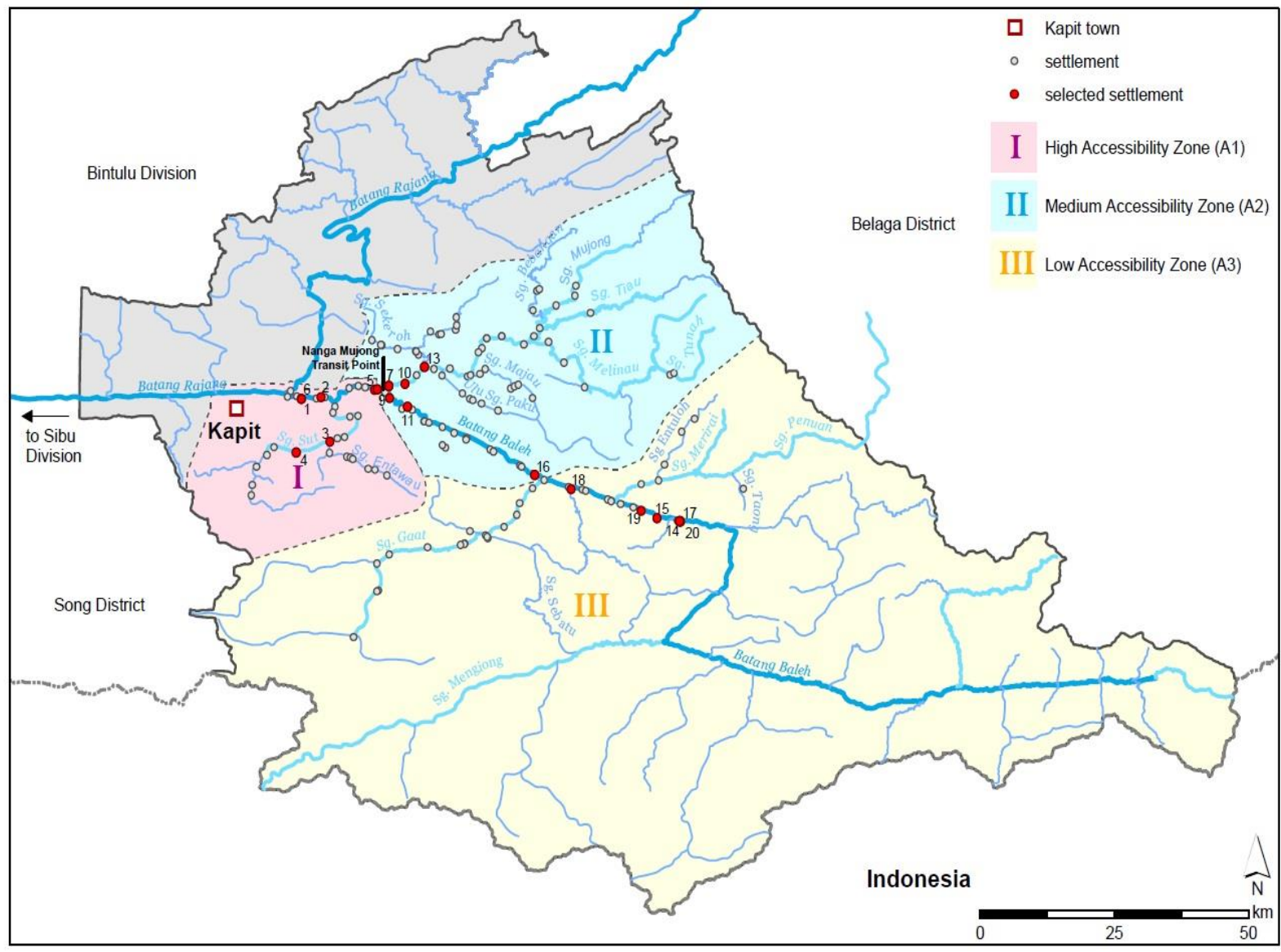

Source of base map: Series MY91001R, Edition 1-PPNM, Department of Survey and Mapping Malaysia, 2010

\subsection{Case study area: selection method}

Map 4.1 details the location of the primary river of interest, Batang (River) Baleh, the main tributary of Batang Rajang, Sarawak's longest river which flows from the Iran Mountains in the Borneo Highlands for 563 kilometres to Kapit Town, and then into South China Sea through the Sibu Division. The Batang Baleh itself has several tributaries including Sungai Mujong, Sungai Sut, Sungai Gaat, and Sungai Merirai. 
At the time of the fieldwork (May-July 2014), there were approximately 154 Iban longhouses along Batang Baleh and its tributaries, with an estimated total of 3,444 bilik-families (Kapit District Office, 2014). These longhouses varied in size with an average of 22 doors (bilik-family) per longhouse. Their locations are indicated by small circles in Map 4.1 (both open and filled).

For the purpose of sampling, these 154 longhouses were assigned to one of the three mutually exclusive accessibility zones. Their level of physical accessibility was based on the distance to Kapit Town and the mode of transportation used. Each of the 154 settlements (longhouses) was assigned to one of three accessibility zones: High Accessibility Zone (A1), Medium Accessibility Zone (A2) and Low Accessibility Zone (A3) as detailed in Figure 4.1.

Figure 4.1: Categorisation of accessibility zones

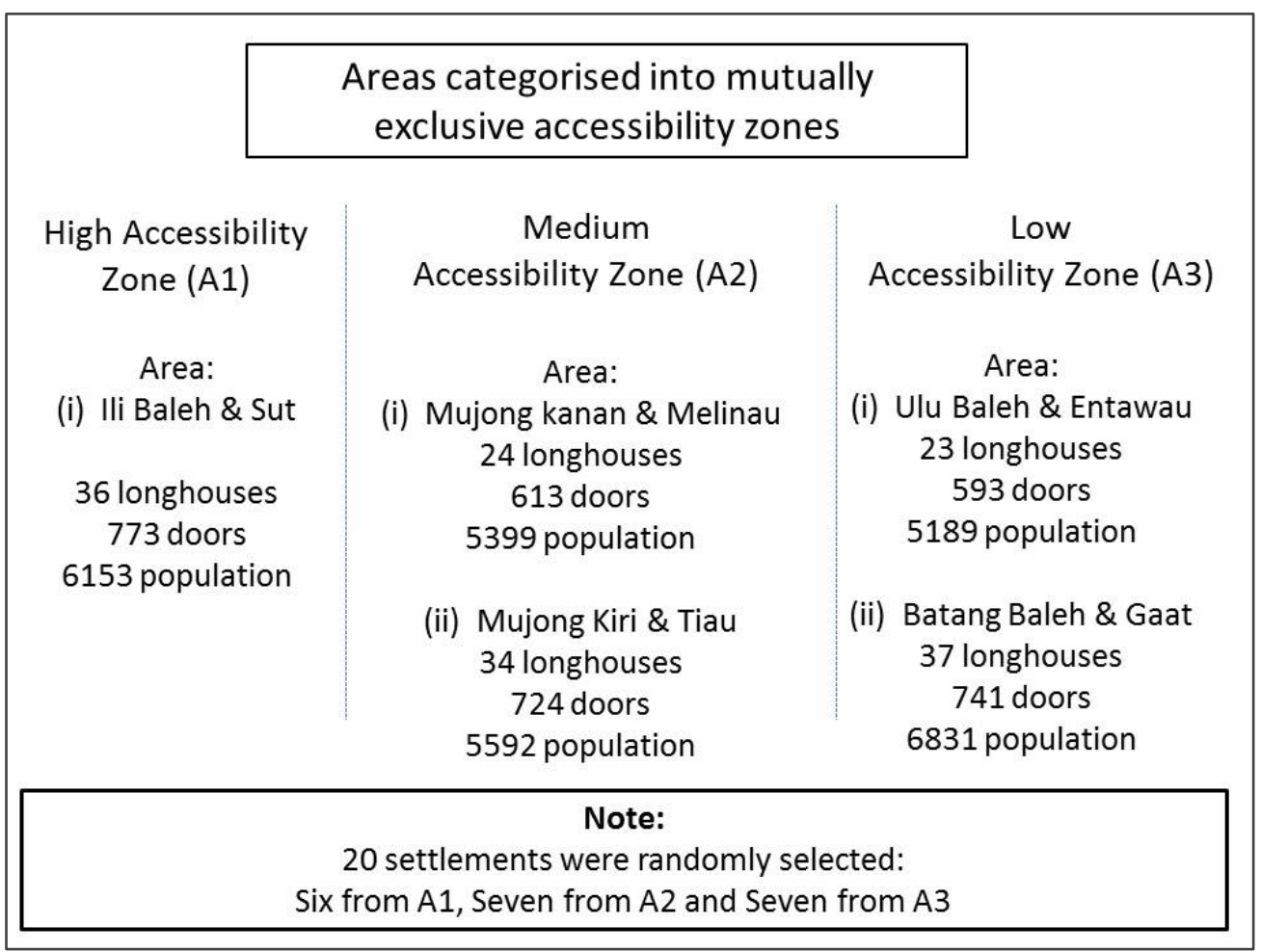

I used a three-stage cluster technique to sample my participants. The first stage was the longhouses (also referred to as the settlement or community) where a total of 20 longhouses were randomly selected within Baleh river basin ${ }^{47}$. Each longhouse typically has a population of about 25 bilik-families, which with an average household size of eight implies an average of approximately 200 residents per longhouse.

\footnotetext{
${ }^{47}$ I used the random number generator function in Microsoft Excel to select my sample.
} 
Stage two of the selection process involved randomly selecting households within each of the selected longhouses. This unit of analysis is referred to as the bilik-family, an Iban household containing an independent domestic family units whose members may consists up to four generations (see Glossary).

The third stage involved a random selection of one adult (minimum age of 18 years) member from each selected bilik-family. Not all members of a bilik-family were residing under the same roof as the head of household in May-July 2014 and the selected individual bilik-member had to be chosen from those in residence (in-situ).

Figure 4.2 is a graphical summary of the sample selection process: interviewed individuals were sampled from within sampled households from within sampled longhouses.

\section{Figure 4.2: Sampling procedure}

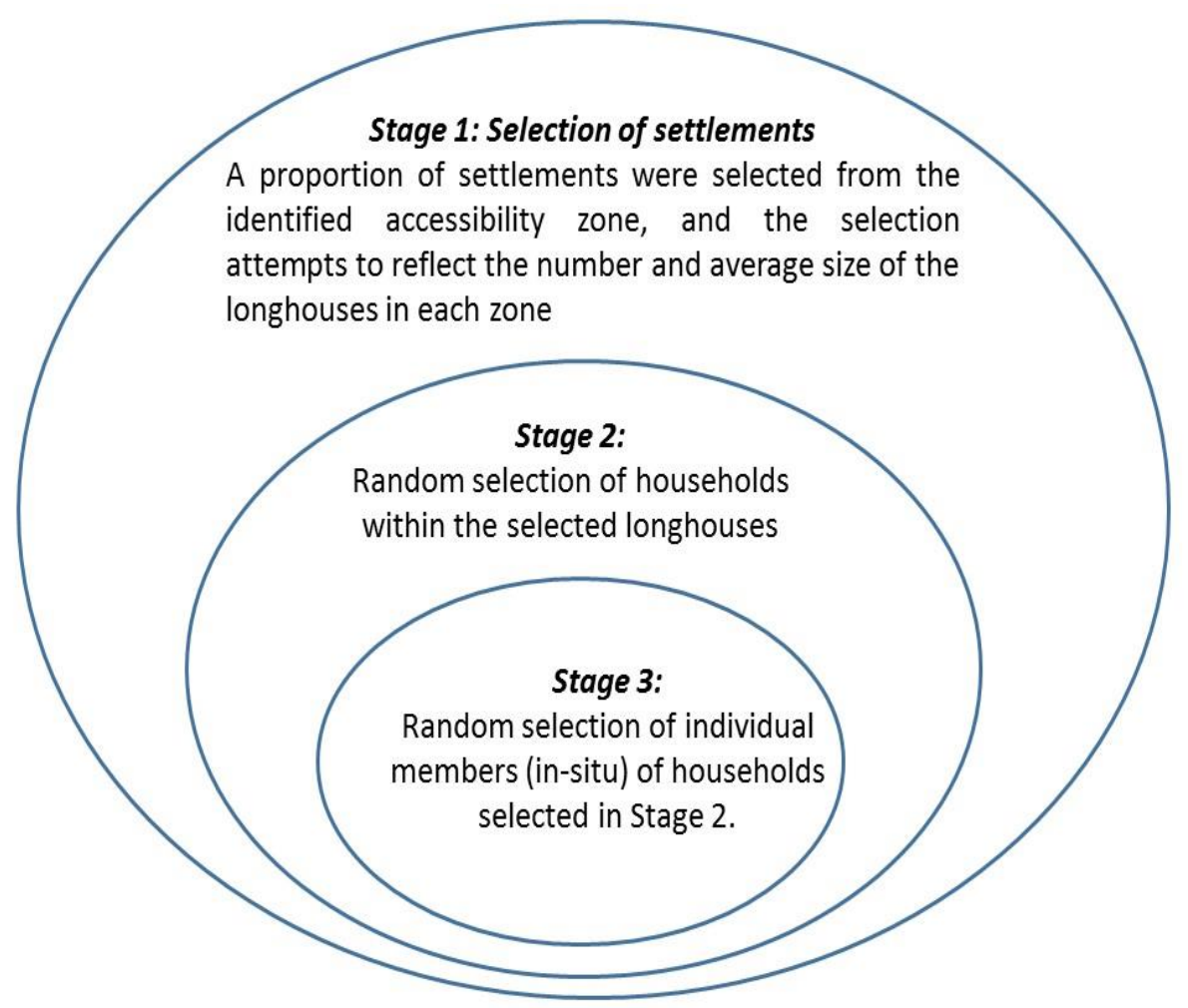

I carried out a total of 184 face-to-face interviews between May and July 2014 as detailed in Table 4.1 below; 20 at the level of the longhouse, 82 with the head of the bilik-family and 82 with a randomly selected individual within the bilik. 
Table 4.1: Number of interviews conducted, Kapit District, Sarawak, May-July 2014

\begin{tabular}{|l|c|c|c|c|}
\hline & Zone A1 & Zone A2 & Zone A3 & Total \\
\hline Longhouse & 6 & 7 & 7 & 20 \\
\hline Bilik-family & 25 & 18 & 39 & 82 \\
\hline Individual & 25 & 18 & 39 & 82 \\
\hline & 56 & 43 & 85 & 184 \\
\hline
\end{tabular}

Source: Based on fieldwork, May-July 2014

\subsubsection{Unit of analysis}

Past studies of rural change in Sarawak have tended to focus on the changes that have taken place at either the level of community (longhouse) or the bilik-family. Responses are usually obtained from interviews with the tuai rumah and heads of bilik-family (Cramb, 2012; Morrison, 1993; Ngidang, 2012; Padoch, 1982; Soda, 2001; J Windle \& Cramb, 1997). While these studies report views on how communities and households have reacted to rural change, they may not necessarily include the perspectives of the community members or the members of the households themselves.

The literature suggests that most household decisions are gender-biased and dominated by a few leaders whose views are then portrayed as collective (Folbre, 1986; Rigg, 2003, 2007). Scholars who glean information primarily based on the viewpoints of heads of community and heads of household tend to gloss over the existence of frictions, contradictions and inequalities within a household (Rigg, 2007). As such their interpretation may neglect the individual views and needs of other members of the households. As argued by Rigg (2007, p. 45) individual needs are not taken into consideration, particularly when household is treated as a single, welfare maximising decision-making unit.

My field work was based on a belief that rural studies should also incorporate the voices of the less heard' members of the community. Generalisations based on interviews with those who head groups of others run the danger of missing much of the variation that occurs at individual level, especially since de-agrarianisation involves a release from much of the cooperative pressure which the ricebased agricultural regime imposes. Given the structural change which de-agrarianisation implies, it is important to understand and to be able to, then, trace the variety of ways that individuals, bilikfamilies and communities respond to changes that have resulted from a shift from farm to non-farm activities. Moreover, differences in levels of development by level of accessibility to market and services may vary according to these different levels of analysis. Therefore, in addition to randomly selected households within the longhouse (to interview the head of household), I also randomly select 
another individual member of the household - irrespective of gender, age (over 18 years), occupation and education.

Three separate questionnaires were prepared for each unit of analysis: the (head of the) longhouse (see Appendix 1), the (head of the) bilik-family (Appendix 2) and the selected individual within the bilik-family (Appendix 3). The effect of differences in accessibility to market and services described in the chapters to follow was based on comparison of these multi-layered responses with each predetermined accessibility zone. At the community level, for example, I asked questions that would enable me to understand how the community at a given accessibility zone behaved. Similarly, questions for the heads of household and individual members of household were designed to provide information on how households and individuals from different accessibility zones behaved and reflected on their level of accessibility to markets and services.

\subsection{Data preparation and analysis}

Responses obtained from the three different questionnaires were collated and organised into four different datasets: tuai rumah ${ }^{48}$, head of bilik-family, the sampled individual and secondary information on other, non-resident, bilik members. The first three datasets reflect the chosen units of analysis for this research while the last dataset (Bilik-member dataset) is an additional layer of information on absent members of the bilik-family obtained from the resident family head. The dataset organisation is summarised in Figure 4.3.

\footnotetext{
${ }^{48}$ Tuai rumah is the Iban village headman, whose position in his/her community is to act as the leader of a village, and in modern days, as an intermediary between his longhouse and the administrative system (Freeman, 1970, p. 110).
} 


\section{Figure 4.3: Description of survey datasets}

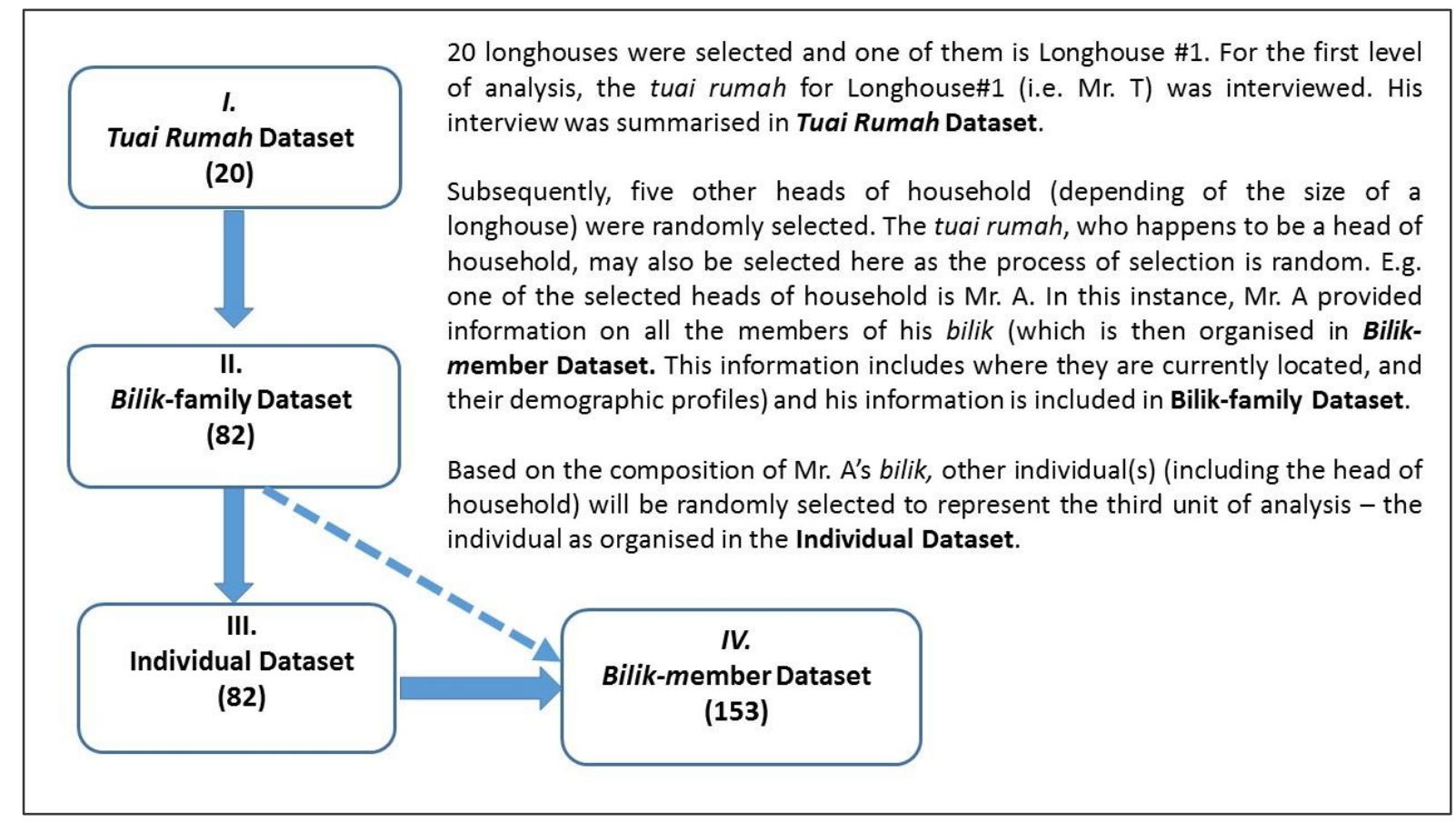

The datasets were organised so that I could analyse relationships within each level as well as between them. With this structure in place, I was able to compare responses at the village level (say Longhouse \#1) with those of the other longhouses in the same accessibility zone as well as between the three accessibility zones. I was also able to see how the different households in Longhouse \#1 responded in any given question to those of other longhouses. I was also able to see the 'other-side' of the household's story by comparing responses by the head of the bilik and that of the randomly selected individual within the household. The content of each of these files will now be described in more detail.

\subsubsection{Tuai Rumah Dataset}

A tuai rumah is an Iban village headman whose position in his/her community is to act as their leader. $\mathrm{He} / \mathrm{she}$ has jural status within their own longhouse - as the custodian of adat, its juridical warden and principal arbiter (Freeman, 1970, p. 114). The tuai rumah usually act as intermediary between the community and the administrative system (Freeman, 1970, pg.110) and that description of tuai rumah's role still holds true today. What is different, however, is that there are now tuai rumah who are practicing dual residency. Soda, for examples, points out that the tuai rumah, 
"... does not necessarily stay in their longhouse all the time. The key qualities of a leader are not only the leader's ability to maintain harmony within the community but to maintain close connections to the outside society, especially to the parties in power ... longhouse communities do not necessarily choose their leaders from among longhouse dwellers. Rather they tend to support leaders - regardless of their current place of residence - who can link the rural to the urban, or the longhouse community to local assemblymen."

(Soda, 2003, p. 478)

As a result of this contemporary practice there are several tuai rumah in my sample longhouses who were practicing dual residency and were not available for interviews. In such cases, I interviewed their sapit (deputy) or representative instead.

The Tuai Rumah dataset represents the responses from my first unit of analysis: the community level. This file contains the profiles of the longhouse - from the perspective of the tuai rumah, with consensus view from his anak biak. Anak biak (or sometimes spelled as anembiak) refers to the other members of the longhouse.

The term community carries different meanings to different people (Kepe, 1999). The most common characteristics are homogeneity, and the presence of recognised social and geographical boundaries. In the same vein, Bernard (1973, in Kepe, 1999, p.418) lists three basic characteristics of a community: shared locale, common ties and social interaction. These characteristics view a community as a spatial unit, an economic unit and as a unit consisting of a web of kinship, social and cultural relations (Kepe, 1999, p. 418). In this research, the term community refers to the people who are members of the longhouses in the case study area. It includes both in-situ members and those who are living elsewhere but remain as acknowledged members of the longhouse community.

Longhouses are also synonymous with traditional Iban settlements and, in this research, I use the term community and longhouse interchangeably. They have a physical structure, which accommodates separate bilik-families (refer Photo 4.1). They usually have between 15 to 60 individual households in a longhouse who are usually bound by kinship and affinity. Acknowledged members of the longhouse can actually reside within or outside of the longhouse, as long as they continue their membership by meeting the conditions imposed by the tuai rumah and/or by remaining a member of a household that still remain largely in the village. 


\section{Photo 4.1: Examples of longhouses in the case study area}
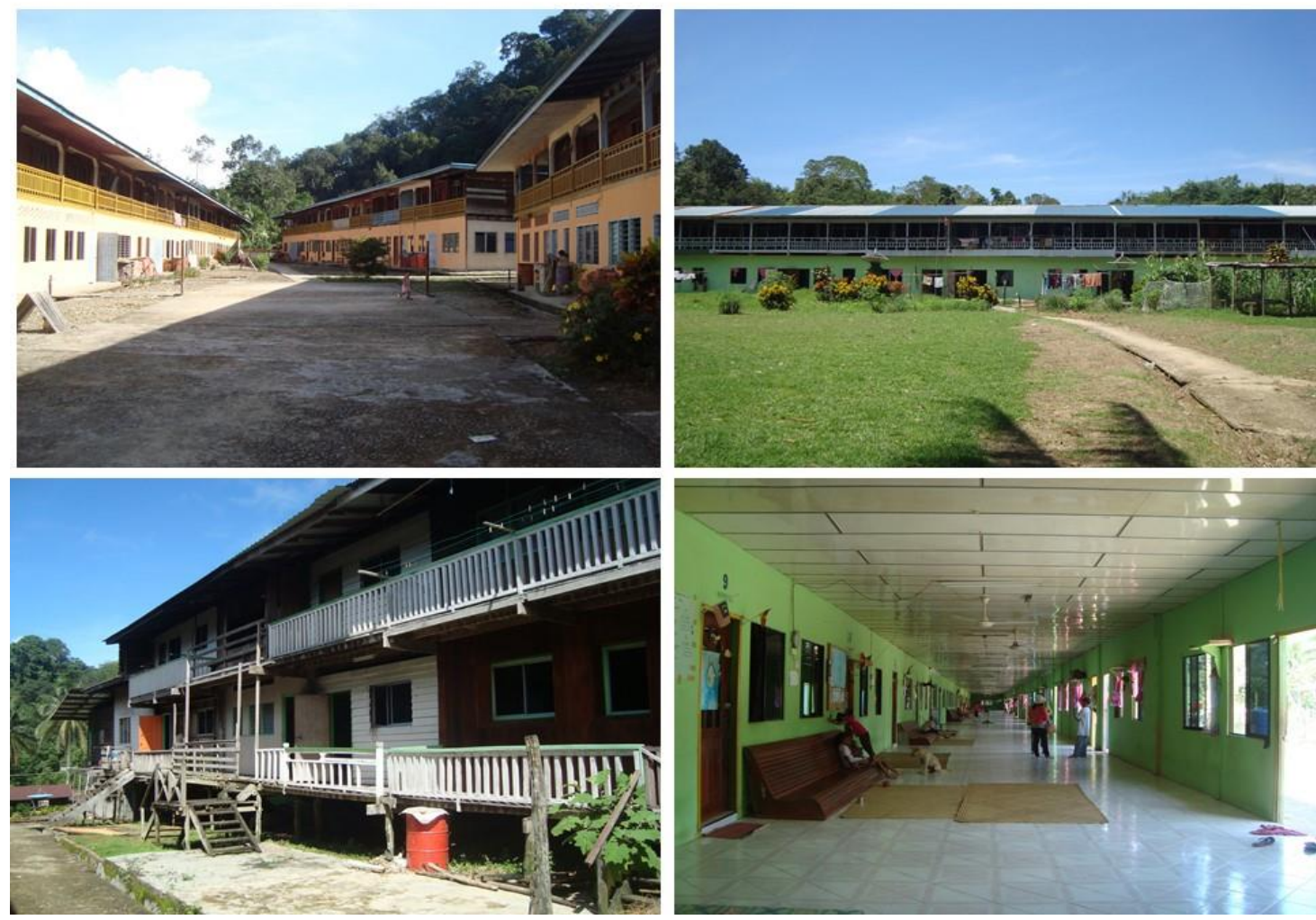

Source: Author. Field work, May-July 2014

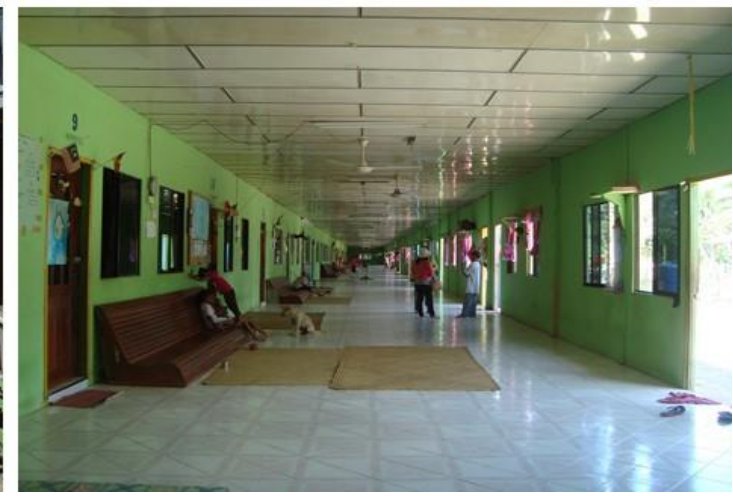

Source: Author. Field work, May-July 2014

\subsubsection{Bilik-family Dataset}

The second dataset contains information obtained from the interviews with the heads of the sampled bilik-families (households) or in cases where the head of household was unavailable, with his/her spouse or other bilik-members who were at least 18 years old. Bilik-family refers to Iban domestic family units, whose members may consists of up to four generations, and constitute a single household. They share resources and act as an allodial unit possessing both land and property in its own right (Freeman, 1970, p. 9) ${ }^{49}$. There are four ways for an Iban to become a member of a bilikfamily; by birth, marriage, adoption or incorporation. It is a custom that each bilik is headed by a senior member of the family, regardless of gender, and decisions are often made by the head of the bilikfamily with or without consultation with the other members.

Heads of bilik-family were interviewed to create a profile of the whole household (see Appendix 2). This includes a socio-economic profile of those bilik-members who did not reside under the same roof as the head of household in the longhouse. I therefore obtained information on the current

${ }^{49}$ Allodial means free and not subjected to the rights of any lord or superior; an opposite of feudal. 
whereabouts of the absent bilik-members as well as their socio-economic profiles. This information helped me to understand how accessibility to market and services affected the level of development of a bilik-family, and, to some extent, whether accessibility influenced bilik's choices of livelihood strategy. This information provided a better understanding of the difference in household strategies adopted both within longhouses and between longhouses, and those in different accessibility zones.

\subsubsection{Individual Dataset}

The third dataset is based on the responses from randomly selected individual bilik-members (based on questions in Appendix 3). These individuals were randomly selected from sampled households. I am mindful that households consist of a group of individuals, and that each individual has different needs, and may be driven by different motives and desires. Including individuals as my third unit of analysis allowed this diversity to be explored.

My aim was to investigate individuals' responses to the different levels of accessibility to market and services. By selecting individuals from the same bilik-family I was to examine the way different personal attributes such as gender, age and education level related to their own level of accessibility and personal development.

\subsubsection{Bilik-member Dataset}

This dataset contains information on every member of the selected household. One of the sections in the head of household questionnaire asked for detailed socio-demographic profiles of acknowledged members of the bilik-household (refer Appendix 3$)^{50}$. I use this dataset to track the bilik-members and how they contribute to their household development.

\subsubsection{Handling missing data}

During data cleaning I found that my datasets contained missing data, particularly when it came to income-related questions. Approximately 28 percent (or equivalent to 23 respondents) did not

\footnotetext{
${ }^{50}$ Acknowledged member of a household here refers to its bilik-members who are identified as part of the bilik-family, and could be living under the same roof as the head of household or anywhere else. This excludes those members who have set up their own household (bilik) in accordance to the Iban custom and those who opted to choose to live with the spouse's side of the family.
} 
provide income data. ${ }^{51} \mathrm{I}$ could have opted to ignore the missing values and only analyse the dataset based on the available responses. This deletion technique is the de-facto method to handle missing data in most research (Myers, 2011). It is a straightforward method and easy to use as most statistical packages incorporate default setting for such deletion..$^{52}$

However, deleting missing cases has been widely criticised because it usually introduces bias into the analysis as well as affected the effectiveness of sample size and statistical power (Fox-Wasylyshyn \& El-Masri, 2005; Graham, 2009; Horton \& Lipsitz, 2001; Myers, 2011). Graham (2009, p. 554), for example, points out how a significant loss of power can occur in deletion method, and may occur even though the missing data involves only a few cases (e.g. less than five percent). Fortunately, there are methods that can be used to address these shortcomings. ${ }^{53}$

Due to my small sample size, I cannot afford to ignore the missing data and I therefore opted to use a Multiple Imputation method by which the missing value is replaced by a set of imputed values. Myers (2011) suggests that Multiple Imputation is the most applicable method to deal with data with over 10 percent missing values.

The imputation method replaces the missing income data with its pooled estimate, which is derived from multiple imputation procedure conducted in the SPSS software that I used. Graham (2009, p. 559) states that, whilst imputation can be generally described as a process of plugging in plausible values where none exist, the values used as substitute (e.g. estimated mean from the imputation process) should be close to the true population value of the mean. This is because the imputation process is repeatedly run and the pooled parameter estimates are averaged across these separate analyses (Myers, 2011, p. 303). Sinharay et al. (2001, p. 320) also suggests that, in most cases, just three to five imputations are sufficient to obtain the efficiency for the results. In this research, ten imputation results were used to obtain the pooled parameter estimates. This ensures that I am able to preserve my sample size and analyse all cases using estimated values to replace the missing values.

\footnotetext{
${ }^{51}$ This type of missing data is categorised as Missing Not At Random (MNAR), which according to Myers (2011, p.300), happens when data is missing due to the value being considered and that individuals choose not to provide a response because of the true value of the variable in question. Myers (2011) and Sinharay, Stern, and Russell (2001) state that income variable, which is dependent upon the value of an individual's income, maybe categorised as MNAR because individuals may not want to disclose their income value to researchers.

${ }^{52}$ E.g. Listwise or pairwise deletion in SPSS.

${ }^{53}$ The commonly used methods include Mean Substitution method, Single Imputation method and Multiple Imputation method.
} 
Aside from the handling missing data and preserving my sample size, I also need to handle subjective responses to the measures of accessibility and development.

\subsubsection{Subjective responses to measuring accessibility and development}

I also discovered the need to address the problem of 'subjectivity' arising from the use of subjective measures for both development and accessibility. When a participant is asked for his/her self-rated response, his/her response differs from that of another participant as how one perceives thing is highly subjective. Their expectation of a service or topic may differ, and, therefore, tend to vary in terms of intensity. When this occurs, the accuracy of the findings may be questioned.

I believe that the discrepancy of the subjective responses in this research has been minimised by ensuring that responses are arrived at through consensus. My initial interviews with tuai rumah were done out in the open with members of his community, where his anak biak can interject at any point and add to our discussions. Thus, the responses from the tuai rumah interviews are not just his view but also reflect that of his anak biak. This can be seen as a response from the voice of many, instead of just one person. At the same time, I acknowledge that there is a danger of peer pressure from the anak biak which may constrain the tuai rumah's responses. In order to balance this, I also set up another private interview with the tuai rumah - at their convenience - and clarified their answers from the previous session. In the same vein, I also conducted private, one-on-one interviews with members of the household to clarify their responses. This way I was able to get the individual participants to talk freely without having another members of their household present and, possibly, influencing the individual's responses to my questions.

I have tried my best to ensure the responses were grounded i.e. that the questions asked were timespecific and known to all respondents. For example, when asking them about their perception of changes in the last five years, I phrased the question in such a way that it was tied to specific timeframe such as the last five years.

\subsection{Survey Instruments}

My surveys involved face-to-face structured interviews, group interviews and direct observation. The structured interview is the main instrument used in this study. The construction of the questionnaires took into consideration both objective and subjective measures of development which were used to 
create the index for measuring development (as will be explained later in this chapter). These questionnaires, according to McGuirk and O'Neill (2010, p. 191), pose standardised, structured questions to the participants, proved adequate in obtaining contemporary data about my respondents, their behaviour, experiences and social interaction.

Pilot testing of my questionnaires was conducted in March 2014. Questionnaires were sent to several researchers who have conducted research in rural areas and/or in Sarawak. Feedback from the pretesting exercises was used in their revision. Pre-testing of questionnaires, as stated by McGuirk and O'Neill $(2010$, p. 206), is an essential step in the methodology, to assess the merits of the research design, its appropriateness to the audience, and whether or not it can achieve the research aims. Similarly, Kitchin and Tate (2000) argues that testing allows a researcher to identify ambiguous or confusing questions, to see if the questions are asked in logical sequence, to assess the level of difficulty of each questions, and to estimate how long it would take to complete one questionnaire ${ }^{54}$.

A Human Ethics application was submitted to the Victoria University of Wellington's Human Ethics Committee in February 2014. The key issue I highlighted in the application was my rationale for using verbal consent, rather than the usual written consent form (will be explained later in this chapter). The application was approved on 3rd May 2014, and I started my fieldwork soon after.

Upon my arrival in Kuching, Sarawak in mid-April 2014, I started to prepare for my trip to Kapit. This includes getting the maps and updated list of villages in the area from relevant agencies, as well as meeting researchers from Universiti Malaysia Sarawak who have conducted research in the area. I also obtained an introductory letter from the Dean of the Faculty of Social Sciences, University Malaysia Sarawak, which is my workplace, to bring to meetings with Kapit District Officer and other government officials.

Scheyvens (2014) points out that establishing contact is one of the key tasks in fieldwork preparation especially if the researcher is not familiar with the field area. I spent a week after my arrival in Kapit Town in May 2014 enhancing my network and making local contacts. By then I already had my list of longhouses I wanted to visit and was planning my foray up Batang Baleh. As suggested by my hosts in Kapit Town, I went to popular local meeting places, such as Kapit Town square, Kapit market, and various coffee shops in town, to make myself known and to find out how I could get to the different

\footnotetext{
${ }^{54}$ As Kitchin and Tate $(2000$, p. 53$)$ points out some questions may never have occurred to the interviewee, or simply too complex and difficult to answer.
} 
longhouses along Batang Baleh and its tributaries of Sungai Mujong and Sungai Sut. As a result of these new contacts, I was informed that the fare for travelling upriver in the district varied greatly, and was advised not to travel on my own as I would be charged a flat-rate which is equivalent to renting the whole longboat to myself. For example, a one way trip to cross Batang Baleh into Sungai Mujong is usually RM6-8 per person. However, if I travelled alone, the fare could be as high as RM50 for the same trip.

My field work and data collection took place between May to July 2014. I personally conducted all the face-to-face interviews with the participants. The process was costly and time consuming, but proved an effective data collection option. Through the personal interviews I was able to build rapport with the participants, and most importantly, face-to-face interviews allowed me to have the opportunity to clarify questions, minimise vague responses, as well as to spend time at the longhouses as an observer. The interviews with the participants were conducted in the Iban language as the participants were not well-versed in other languages.

My own Iban dialect is slightly different from the Kapit Iban dialect. This difference, although not a major issue, did result in some miscommunication. For instance, the word 'ila' means tomorrow in my Batang Lupar Iban dialect, but in Kapit Iban dialect the same term means sometime in the future (i.e. no specific time). A number of times I found myself arriving at the participants' home only to find the persons I was supposed to meet not there. I was informed that I had yet to set any time for our meeting as I was using the term 'ila' when making the arrangement.

One other issue I faced in using the Iban language was in translating specific words and terminology from English to Iban because certain terms used in the questionnaire and during interviews had no direct Iban equivalent. This posed some difficulties in trying to get my point across so that the respondents knew exactly what I was trying to convey.

'Subsistence activity' is one of the terms that is difficult to translate. I used the term betanam betupi in my interviews to describe subsistence activities. I found out later that the term did not convey quite the same meaning as the one I intended. The term betanam betupi, which literally means planting and rearing, caused the participants who are doing other subsistence activities, such as collecting jungle products and fishing, to report that they were not involved in any subsistence activity. I only realised my mistakes during my data entry stage (which I conducted at the field during my fieldwork). 
Nonetheless, I managed to resolve this problem as I have follow-up questions in the questionnaire that asked the respondents to list their daily activities.

I also realised that my understanding of farming, which is mainly based on literature and prior understanding was not quite the same as that of the respondents. The Iban use specific terms such as 'bumai' and 'bekebun' instead of the general term of farming that I used. Bumai refers to rice planting and bekebun generally means other planting activities. The latter comprises of, but is not exclusive to, vegetable gardening and pepper planting. This ambiguity was identified at the end of my first phase of data collection and was rectified during the second stage of data collection. I went back to the longhouses that I visited during the first stage of data collection and clarified their farming activities with the respondents. In hindsight, I should have explained to the participants what I meant by both terms with more detailed examples, but at that point in time I was not completely aware that what I understood and what I translated to the respondents do not carry the same meaning.

\subsubsection{Negotiating the cultural maze}

Fieldwork experience can be exhilarating and eye opening, but it can also be frustrating, time consuming and complicated (Chacko, 2004; Hammett, Twyman, \& Graham, 2014; Scheyvens, 2014; Scott, Miller, \& Lloyd, 2006). Scott et al. (2006, p. 28), for instance, state that fieldwork, which involves the negotiation of complex relations, interests, situations and logistics, is a part of research that offers insights to researchers and may even force a researcher to think about his/her research in new ways. Undoubtedly, fieldwork is a challenging process that necessitates a negotiated, adaptive and flexible approach. The key to thrive in the fieldwork environment, according to Scheyvens (2014), is preparing well, being open-minded and flexible.

I was aware of the Iban custom of seeking permission from the tuai rumah before proceeding with any request for interviews. When negotiating permission to conduct interview at longhouses, I approached the selected tuai rumah informally at first and informed them of my intention. If they agreed to be interviewed, they would invite me over to the longhouse for the next step in this process i.e. to meet their anak biak and to inform everyone of the purpose of my visit.

It is a custom in Iban longhouses for a visitor to explain the purpose of the visit in front of the tuai rumah and its anak biak (a process known as madah ka penatai). The men and women who are at the 
longhouse at the time of the visit usually congregates at the ruai (common varandah) of the tuai rumah to hear a visitor explaining the purpose of his/her visit (see Photo 4.2).

Photo 4.2: Assembled anak biak during my first visit at several longhouses, 2014
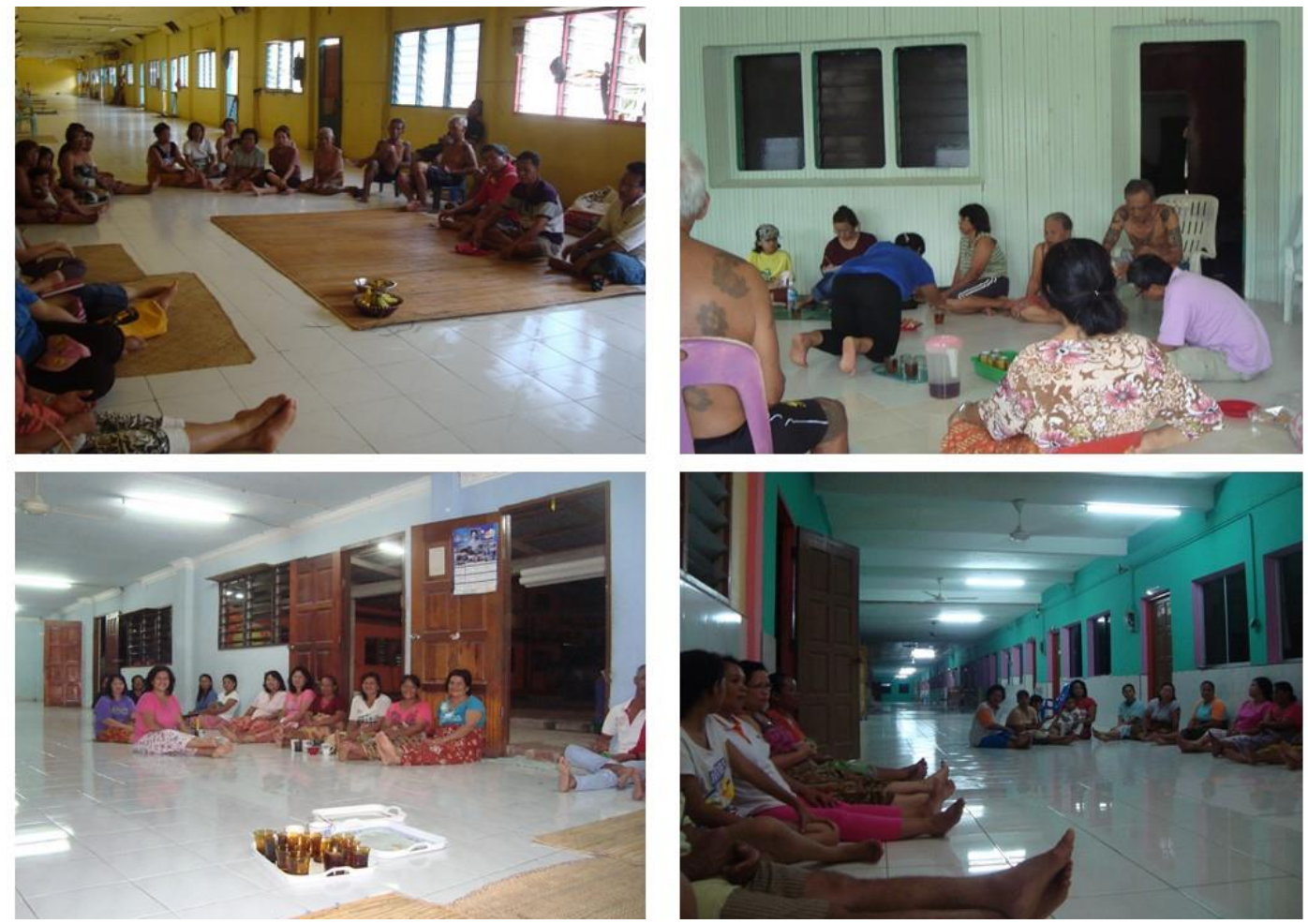

Source: Author. Field work, 2014

Note: Verbal permission obtained from participants to use these photographs in the thesis.

Being city raised I was not well versed in this custom and to avoid any disrespect on my part my introduction was facilitated by a family friend (Mr. Meringai). He began by thanking everyone present and explained the purpose of my visit. I then introduced myself, my research and what I hoped to learn. I also explained about informed consent, the confidentiality of their responses and the fact that they could opt out from participating in my research if they wish to do so. I also mentioned the units of analysis I was covering and how I selected the respondents. Then the tuai rumah reciprocated by introducing himself and his views on my request. At this point I would know whether or not I would be granted permission to interview him and his anak biak, and if there were any other conditions that he wished to share with me. At the end of this introductory session, I usually took time to clearly explain the purpose of research and allocated time for participants who wished to clarify the process and their involvement. I believe that my taking time to explain the process helped alleviate different expectations of myself and the participants. 
Overall, I did not have many problems with the introduction and request for permission because the process was largely facilitated by my family friends: Mr Meringai and his wife, and Aya Masing. I was briefed by them about what I should and should not do before I went into any longhouses. This is particularly important as I wanted to avoid offending the tuai rumah and his anak biak through my ignorance of the customs and practices in this area. I also found that different longhouses tended to have slight variations in the ways they receive their visitors.

\subsubsection{Informed consent and confidentiality}

Since the majority of my respondents are illiterate or have only limited educational background, I decided not to use written consent in this research. Instead, I opted for verbal informed consent. As Dowling (2010, p. 29) explains, this was not simply acquiring a, 'yes, you can interview me' response, but ensuring the participants knew exactly what they were consenting to. In this case, I used verbal consent to inform the participants, in the Iban language, of the aims and purposes of my research, how they were selected as my respondents, and that they were free to participate in the research. I also informed them that they had the right to refuse to participate or to withdraw from participating at any time. This was done at the first meeting I had with them (as a group) and again before I started my face-to-face interviews with them individually.

The reason for using verbal consent was to ensure that the participants were willing to talk freely with me, for in my view the use of written consent forms might have intimidated many of them. In some parts of remote rural areas in Sarawak, the community tend to be intimidated by the sight of signing (or the act of signing) any documents. Since a majority of the participants are illiterate and do not understand the meaning of written consent forms, asking them to sign such document could be perceived as an underhand tactic for obtaining information. They were not familiar with the process of asking for research consent as it is not a norm and if I insisted on a written consent they may have refused to grant me an interview.

I was always careful to ensure that the participants' confidentiality was protected. However, I constantly found that respondents did not want to be interviewed alone. They preferred to have someone, usually family members, with them during the interview. This was a way of them having someone validate what they were saying to me. 
In light of the above it is important to make a clear distinction between what is included in this examination copy of the thesis and what will appear as a public document. Names of longhouses, respondents and photographs in this examination copy have not been anonymised. In order to address the issues of confidentiality and anonymity in any public document, I will use a numbering system to denote the name of the longhouses and name of the respondents. This will ensure that the community and their tuai rumah are not identifiable.

I now turn to how to develop measures for both accessibility and development - which will be the basis for my analysis and discussions in the following thesis chapters.

\subsection{Measuring development and accessibility}

One of the key steps in my analysis has been to develop measures of both accessibility and development. Both are broad and ambiguous concepts. What is meant by development and accessibility is very much dependent on the perception and stand point of individuals or organisations, and is very much at the 'eyes of the beholder'. Therefore, in addition to objective measures, such as building construction material or electricity supply, I attempt to explore what both development and accessibility mean to the participants personally. The term 'pemansang' has been used in Sarawak, amongst the Iban, to (loosely) describe development. However, the origin of the term is unknown and, like its Western counterpart, the term is relatively ambiguous. The participants were asked what does the term pemansang meant to them, in an attempt to define pemansang from the perspectives of the local Iban. It should be noted that the term 'mansang' means going forward in Iban.

The respondents were also asked to list up to three key elements that they feel a developed longhouse/village should have, i.e. three key priorities of development (e.g. refer Appendix 3: Section 4). The reason for this question was to identify what participants considered important to them in order to 'progress'. In order to ensure that I took into account of the participants' view of development, I used their identified elements as indicators when I measured development, thus incorporating both objective and subjective elements into the measure. These measures will be used in discussions in Chapter Five and Chapter Six.

Objective measures here refers to the standard measures used in measuring development such as standard of living, income, education and health. I also used the elements of development identified by the respondents (refer Appendix 3: Section 4). These include provision of facilities and 
infrastructure such as electricity, water supply, school and clinic provision. I also include road connection and mobile coverage, elements often identified by respondents.

\subsubsection{Physical development indicators}

My overall goal was to come up with an overall development score for each units of analysis: the community, the households and the individuals. The overall score was obtained by combining a number of 'development' elements, as illustrated in Table 4.2 below. Other than obtaining an overall score for development (which appears at the end of the table), the different elements incorporated in the table can be broken up into sections as required in the analysis. 
Table 4.2: Measuring physical development at village level

\begin{tabular}{|c|c|c|c|}
\hline Variables & Justification & Description & Coding \\
\hline $\begin{array}{l}\text { SESCO- } \\
\text { provided } \\
\text { electricity } \\
\text { [electricity1] } \\
\left(\mathbf{E}_{1}\right)\end{array}$ & $\begin{array}{l}\text { SESCO is the main state } \\
\text { electricity provider. There are } \\
\text { two types of services: } 12 \text {-hours } \\
\text { and } 24 \text {-hours of electricity }\end{array}$ & $\begin{array}{l}\text { It is assumed that if an area is provided } \\
\text { with electricity from SESCO - it is 'more } \\
\text { developed' than areas which are not } \\
\text { having electricity. } \\
\text { It is also assumed that those with } 24 \\
\text { hours of electricity are "more } \\
\text { developed" than those with 12-hours. }\end{array}$ & $\begin{array}{l}0=\text { no electricity } \\
1=12 \text { hours of electricity } \\
2=24 \text { hours of electricity }\end{array}$ \\
\hline $\begin{array}{l}\text { Other provider } \\
\text { of electricity } \\
\text { [electricity2] } \\
\left(\mathbf{E}_{2}\right)\end{array}$ & $\begin{array}{l}\text { Besides SESCO, several saw } \\
\text { mills (timber companies) also } \\
\text { provide electricity to villages } \\
\text { (usually villages adjacent to } \\
\text { their camps) }\end{array}$ & $\begin{array}{l}\text { It is assumed that other types of } \\
\text { electricity providers are an indicator of } \\
\text { "development". }\end{array}$ & $\begin{array}{l}0=\text { no } \\
1=\text { yes }\end{array}$ \\
\hline Electricity (E) & $=E_{1}+E_{2}$ & Denotes the combined electricity score & \\
\hline $\begin{array}{l}\text { Water supply } \\
\text { (W) }\end{array}$ & $\begin{array}{l}\text { There are two types of 'water } \\
\text { supply' in the area: treated } \\
\text { water (from Sarawak Water } \\
\text { Board) and gravity feed water } \\
\text { (sourced from various rivers in } \\
\text { the locality) }\end{array}$ & $\begin{array}{l}\text { It is assumed that those having treated } \\
\text { water supply are more "developed" } \\
\text { compared to those with gravity feed } \\
\text { water (i.e. treated water supply is } \\
\text { 'safer' as drinking water) }\end{array}$ & $\begin{array}{l}2=\text { treated water supply } \\
1=\text { gravity feed }\end{array}$ \\
\hline Water (W) & $=\mathrm{W}$ & & \\
\hline $\begin{array}{l}\text { Primary school } \\
\left(S_{p}\right)\end{array}$ & $\begin{array}{l}\text { Education is one of the } \\
\text { commonly used indicators of } \\
\text { development. }\end{array}$ & $\begin{array}{l}\text { This indicator shows how far an } \\
\text { individual is from the nearest primary } \\
\text { school. }\end{array}$ & $\begin{array}{l}1=\text { more than one hour } \\
2=30 \text { minutes to } 1 \text { hour } \\
3=\text { less than } 30 \text { minutes by } \\
\text { transport } \\
4=\text { walking distance (less } \\
\text { than } 20 \text { minute walk) }\end{array}$ \\
\hline $\begin{array}{l}\text { Secondary } \\
\text { school } \\
\left(\mathbf{S}_{\mathbf{s}}\right)\end{array}$ & $\begin{array}{l}\text { Secondary school education is } \\
\text { one of the commonly used } \\
\text { indicators of development. }\end{array}$ & $\begin{array}{l}\text { This indicator shows how far an } \\
\text { individual is located in relation to the } \\
\text { nearest secondary school in the } \\
\text { locality. }\end{array}$ & $\begin{array}{l}1=\text { more than one hour } \\
2=30 \text { minutes to } 1 \text { hour } \\
3=\text { less than } 30 \text { minutes by } \\
\text { transport } \\
4=\text { walking distance (less } \\
\text { than } 20 \text { minute walk) }\end{array}$ \\
\hline $\begin{array}{l}\text { Education score } \\
\text { (S) }\end{array}$ & $S=S_{p}+S_{s}$ & $\begin{array}{l}\text { Denotes the combined score for } \\
\text { education }\end{array}$ & \\
\hline $\begin{array}{l}\text { Health score } \\
\text { (C) }\end{array}$ & $\begin{array}{l}\text { Health service is another } \\
\text { indicator frequently used to } \\
\text { measure 'development' }\end{array}$ & $\begin{array}{l}\text { It is assumed that an area is more } \\
\text { 'developed' when it has access to } \\
\text { health services. } \\
\text { Note: this does not take into } \\
\text { consideration the number of personnel, } \\
\text { and services offered by the health } \\
\text { service. }\end{array}$ & $\begin{array}{l}1=\text { more than one hour } \\
2=30 \text { minutes to } 1 \text { hour } \\
3=\text { less than } 30 \text { minutes by } \\
\text { transport } \\
4=\text { walking distance (less } \\
\text { than } 20 \text { minute walk) }\end{array}$ \\
\hline $\begin{array}{l}\text { Road } \\
\text { connection } \\
\left(\mathbf{R}_{\mathbf{c}}\right)\end{array}$ & $\begin{array}{l}\text { Road connection has also been } \\
\text { widely used as an indicator of } \\
\text { how "developed" an area is } \\
\text { comparative to other areas } \\
\text { without road connection. }\end{array}$ & $\begin{array}{l}\text { Having direct road connection or } \\
\text { partial road connection might have } \\
\text { different effects on an individual's (or } \\
\text { household's) level of development }\end{array}$ & $\begin{array}{l}0=\text { no road connection } \\
1=\text { partial road } \\
\text { connection } \\
2=\text { direct road connection }\end{array}$ \\
\hline $\begin{array}{l}\text { Mobile } \\
\text { connection } \\
\left(\mathbf{M}_{\mathbf{c}}\right)\end{array}$ & $\begin{array}{l}\text { Availability of mobile coverage } \\
\text { can be used as an indicator of } \\
\text { "development" - especially in } \\
\text { today's society whereby the use } \\
\text { of mobile phones is quite } \\
\text { significant in daily life. }\end{array}$ & $\begin{array}{l}\text { To see if the respondent can get } \\
\text { "signal" for the mobile phone without } \\
\text { leaving the longhouse or not }\end{array}$ & $\begin{array}{l}3=\text { getting "signal" at the } \\
\text { house } \\
2=\text { have to go elsewhere } \\
\text { (near LH) for "signal" } \\
1=\text { only using mobile } \\
\text { phone when in town } \\
0=\text { no mobile coverage }\end{array}$ \\
\hline Facilities score & $=E+W+S+C$ & & \\
\hline $\begin{array}{l}\text { Total } \\
\text { development } \\
\text { score }\end{array}$ & $=E+W+S+C+R_{c}+M_{c}$ & $\begin{array}{l}\text { Total village physical development } \\
\text { score }\end{array}$ & \\
\hline
\end{tabular}


The development score above works on the presumption that a developed village is better equipped with basic facilities and infrastructure than its less developed counterparts. The World Bank defines basic needs, in its various basic needs strategies, to include not just food, clean water and shelter, but also access to health and education ${ }^{55}$. Streeten and Burki $(1978$, p. 413) elaborate that basic needs, as per the World Bank's definition, may be defined as those that have to be met for continued survival and comprise a minimum of food and water, protection from fatal diseases and adequate shelter. They also explain that basic needs should be more than just meeting the needs to survive, and, therefore, should include education and health services; and other non-material needs such as participation in decision-making for continued productive survival. I tried to incorporate those indicators in my measures of development of a village/community (see Table 4.3), a household and individual (see Table 4.4).

\subsubsection{Income indicators}

Income is one of the most commonly used objective indicators of development. However, it is clearly focused on looking at how an individual, a household, a village or even a region develops economically over time. In this research, I use a few variations of income and income sources (refer Table 4.3) as indicators of economic development at household and individual levels.

These different variations of income are in recognition of the increasing dependence of individuals and/or households on multi income sources in today's society, especially during the period of deagrarianisation. Past studies, particularly those looking at rural change, acknowledged that diversification of income sources are parts of individual or households survival strategies (Ellis, 1998; Hussein \& Nelson, 1998; Rigg, 2006) and remittance is fast becoming one of the key income sources in many parts of rural Asia (Kelly, 2011; McKay, 2003, 2005; Posel, 2001; Rigg, 2003).

\footnotetext{
55 Basic Needs approach is predominantly used in the World Banks' strategy to eradicate absolute poverty. Streeten and Burki $(1978$, p. 413) state that the aim of a basic needs strategy is to increase and redistribute production so as to eradicate deprivation that arises from lack of basic goods and services.
} 
Table 4.3: Measuring economic development via income at the household level

\begin{tabular}{|c|c|c|c|}
\hline Variables & Justification & Description & Coding \\
\hline $\begin{array}{l}\text { Individual } \\
\text { (monthly) } \\
\text { income } \\
{\left[Y_{\text {ind }}\right]^{56}}\end{array}$ & $\begin{array}{l}\text { Average individual monthly income, } \\
\text { from each member of the household } \\
\text { ( } 18 \text { years and above), in order to } \\
\text { identify both individual and } \\
\text { household's total income and in-situ } \\
\text { income. }\end{array}$ & $\begin{array}{l}\text { It is assumed that the higher the } \\
\text { income, the potential for individual } \\
\text { and household development is } \\
\text { greater. }\end{array}$ & $\begin{array}{l}0=\text { no income } \\
1=\text { RM1 }- \text { RM942 } \\
2=\text { RM943 }- \text { RM1952 } \\
3=\text { more than RM1952 }\end{array}$ \\
\hline $\begin{array}{l}\text { Income from } \\
\text { commodity } \\
\text { sales }{ }^{57} \\
{\left[\mathbf{Y}_{\text {comm }}\right]}\end{array}$ & $\begin{array}{l}\text { To identify income obtained from } \\
\text { commodity sales (to separate income } \\
\text { from wage/salary) - at household } \\
\text { level }\end{array}$ & $\begin{array}{l}\text { It is assumed that during de- } \\
\text { agrarianisation period, income } \\
\text { from commodity sales will } \\
\text { decrease over time. }\end{array}$ & $\begin{array}{l}0=\text { no income } \\
1=\text { RM1 }- \text { RM286 } \\
2=\text { RM287 }- \text { RM597 } \\
3=\text { more than RM597 }\end{array}$ \\
\hline $\begin{array}{l}\text { In-situ income } \\
{\left[\mathbf{Y}_{\text {insitu }}\right]^{58}}\end{array}$ & $\begin{array}{l}\text { To measure how much average } \\
\text { income a household earn in a month } \\
\text { (i.e. total income from every } \\
\text { household member who live under } \\
\text { the same roof at the longhouse) }\end{array}$ & This excludes remittance. & $\begin{array}{l}0=\text { no income } \\
1=\text { RM1 }- \text { RM1381 } \\
2=\text { RM1382 }- \text { RM2945 } \\
3=\text { more than RM2945 }\end{array}$ \\
\hline $\begin{array}{l}\text { Total In-situ } \\
\text { income } \\
{\left[\mathrm{Y}_{\text {totinsitu }}\right]^{59}}\end{array}$ & $\begin{array}{l}\text { Including remittances, and this is to } \\
\text { identify the various sources of income } \\
\text { for a household } \\
\text { (Note: similar to above but includes } \\
\text { remittance received by the household } \\
\text { members) }\end{array}$ & $\begin{array}{l}\text { Remittance and other income } \\
\text { source is included as they also } \\
\text { contribute to household income. } \\
\text { Also to identify household's income } \\
\text { sources. }\end{array}$ & $\begin{array}{l}0=\text { no income } \\
1=\text { RM1 }- \text { RM153 } \\
2=\text { RM154 }- \text { RM1775 } \\
3=\text { RM1778 }- \text { RM3398 } \\
4=\text { more than RM3398 }\end{array}$ \\
\hline $\begin{array}{l}\text { Remittances } \\
{[\mathbf{R}]^{60}}\end{array}$ & $\begin{array}{l}\text { To see how much (if applicable) are } \\
\text { remitted by household members who } \\
\text { are practicing multi-local living. }\end{array}$ & $\begin{array}{l}\text { To see how remittance play a role } \\
\text { in household development. }\end{array}$ & $\begin{array}{l}0=\text { no income } \\
1=\text { RM1 }- \text { RM316 } \\
2=\text { RM317 }- \text { RM933 } \\
3=\text { more than RM933 }\end{array}$ \\
\hline $\begin{array}{l}\text { Total } \\
\text { household } \\
\text { income } \\
{\left[\mathrm{Y}_{\text {totHH }}\right]^{61}}\end{array}$ & $\begin{array}{l}\text { This includes income from in-situ } \\
\text { members and members who are } \\
\text { practicing multi-local living. The idea } \\
\text { is to see the 'potential' (pooled) } \\
\text { income for the household as a whole. }\end{array}$ & $\begin{array}{l}\text { To see the total household income } \\
\text { i.e. including incomes of those who } \\
\text { are practicing multi-local living. }\end{array}$ & $\begin{array}{l}0=\text { no income } \\
1=\mathrm{RM} 1-\mathrm{RM} 376 \\
2=\mathrm{RM} 377-\mathrm{RM} 3944 \\
3=\mathrm{RM} 3945-\mathrm{RM} 7510 \\
4=\text { more than RM7510 }\end{array}$ \\
\hline $\begin{array}{l}\text { Diversification } \\
\text { of income } \\
\text { source } \\
{\left[\mathbf{Y}_{\text {sou }}\right]}\end{array}$ & $\begin{array}{l}\text { Diversification of income is the trend } \\
\text { in Southeast Asian rural economy and } \\
\text { often used to measure development. }\end{array}$ & $\begin{array}{l}\text { It is assumed that a more } \\
\text { 'developed' household or } \\
\text { individual moves away from single } \\
\text { income source. }\end{array}$ & $\begin{array}{l}0=\text { no income } \\
1=1 \text { income source } \\
2=2 \text { income sources } \\
3=3 \text { income sources }\end{array}$ \\
\hline $\begin{array}{l}\text { Income score } \\
\text { (individual) }\end{array}$ & $=Y_{\text {ind }}+R+Y_{\text {sou }}$ & Individual (income) development & \\
\hline $\begin{array}{l}\text { Income score } \\
\text { (household) }\end{array}$ & $=Y_{\text {ind }}+Y_{\text {comm }}+Y_{\text {insitu }}+R+Y_{\text {totHH }}+Y_{\text {sou }}$ & $\begin{array}{l}\text { Overall score for household } \\
\text { (income) development }\end{array}$ & \\
\hline
\end{tabular}

Figure 4.4 illustrates how I developed the coding boundary points for the income variables in Table

4.3. The coding helps identify the proportion of respondents within certain income categories.

\footnotetext{
${ }^{56}$ Individual income (head of household): mean value is RM942.44 and standard deviation is RM1009.484

57 Income from commodity sales: mean value is RM286.10, and standard deviation is RM310.594

58 In-situ income (excluding remittance): mean value is RM1381.46 and standard deviation is RM2944.862

${ }^{59}$ Total in-situ income: mean value is RM1775.37 and standard deviation is RM1622.468

${ }^{60}$ Remittance: mean value is RM316.46 and standard deviation is RM616.694

${ }^{61}$ Total household income: mean value is RM3943.50 and standard deviation is RM3566.178
} 
Figure 4.4: Steps in coding income variables

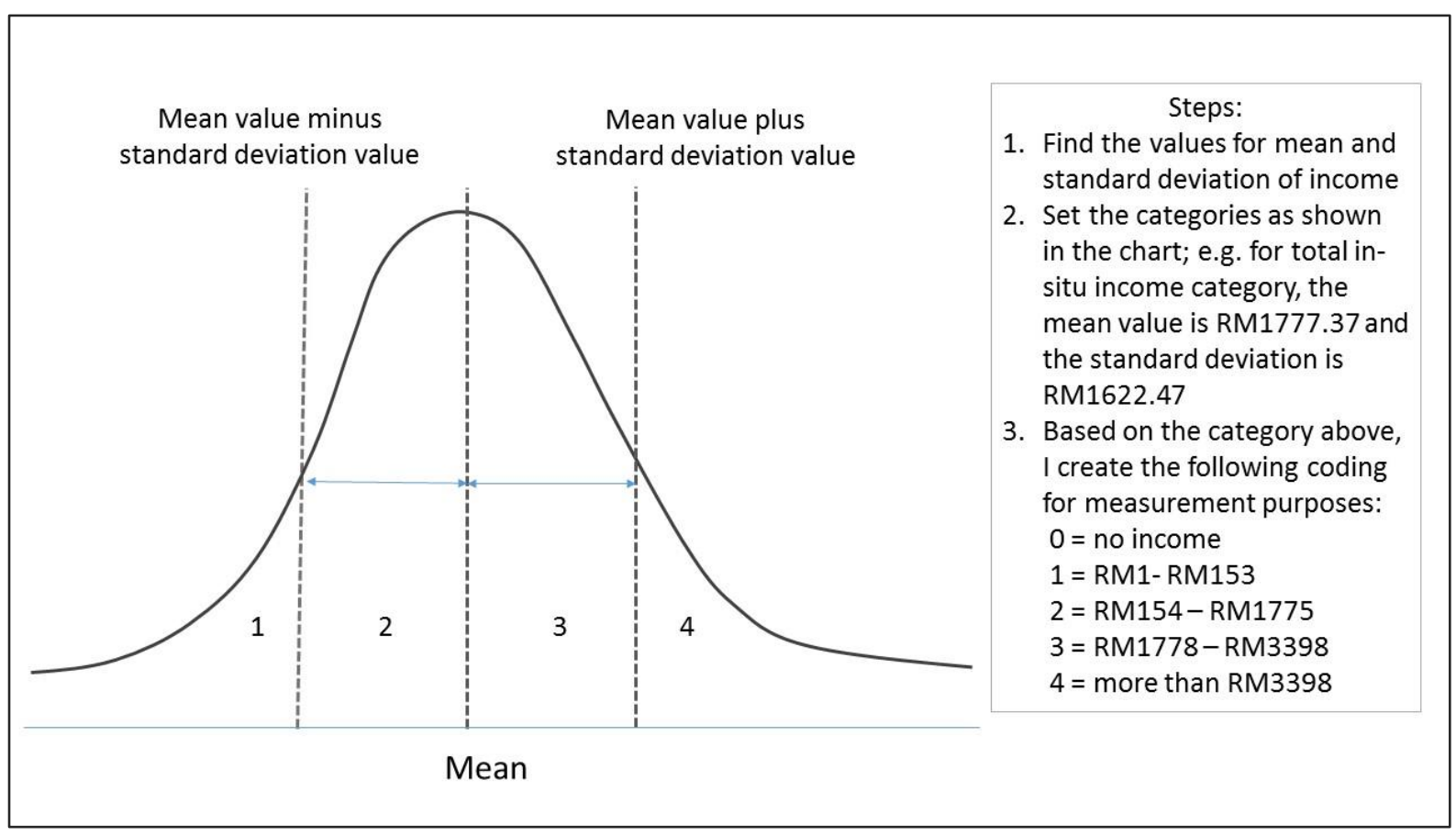

Using income to measure development has always been problematic (Bradburn, 1983; Hicks \& Streeten, 1979; Posel, 2001). It is often criticised as an indicator which does not reflect the true economic ability, be it of an individual, a household, a region or even a country. For example, there is a tendency for respondents to give inaccurate accounts of their income (Bradburn, 1983; Posel, 2001) or to refuse to answer any questions related to income and income sources (van Melis-Wright, Stone, \& Miller, 1993). Bradburn, for example, states that;

"...problem of asking about family income during the past year... first, respondents might deliberately omit some types of income that they do not want anyone to know about, such as income from illegal sources or income not reported on their income tax forms. They may forget about some income (e.g., dividends or interest on a saving account) or report faulty estimates of income for which good records are not readily available. A third problem may arise from their misunderstanding the question or not defining the concept of income the same way as the investigator does... Respondents may also include income from the wrong time period... Finally, some respondents may deliberately inflate their income reports to impress the interviewer or to make themselves look better off than they in fact are."

Bradburn (1983, p. 290)

In this research, I also experienced some of the problem Bradburn refers to. From the start, I acknowledged that asking about one's individual and household income, spending patterns and saving behaviours may be quite sensitive for most people. As explained by van Melis-Wright et al. (1993, p. 
422), respondents are often reluctant to discuss direct references to their money, financial matters or status and this often results in a relatively high non-response or incomplete responses to incomerelated questions in survey research. Several respondents in my study were reluctant to answer questions relating to their income and household earning. During my interviews with the respondents, I observed that their reluctance to answer the income question was the results of various factors and not actually an outright refusal to answer.

The main reason for their reluctance over income questions was due to the uncertainty of income itself. Several respondents indicated that they actually have no idea how much they (the individual) earned and, therefore were unable to answer the question. In this case, I assigned his/her responses as 'don't know'. This was mainly due to the nature of household structure and organisation whereby most (if not all) proceeds, particularly from farming activities, are pooled together as one (household) income. It should be noted that, while this practice of sharing still prevails when it comes to income from agriculture, it does not apply to other income where individuals are not culturally bound to share.

Another reason why the respondents were unable to answer the income question is because of income uncertainty. They do not earn a fixed amount every month. Their income may differ from time to time due to circumstances such as the fruit season (where income will be higher as they are able to sell surplus fruits), farming season (they have less time to fish or gather jungle products for sales), drought season (more fishing activities and log-rafting tasks are conducted when the river level is low) and rainy season (not much can be done during the prolonged rainy season and high river level). Such fluctuations in income make it harder for the respondent to give a fixed answer and, sometimes, end up with a non-response from the participants.

Since the income from agriculture activity might be less than income from other sources, income among rural families is now quite individualised. Furthermore, the sales of farm commodity are often conducted by only one or two household members even though every member of the households may work on the same family farm. This is particularly widespread amongst farming households. The wives and/or children of the head of household are often unsure of how much they, as an individual, earn a month from their farming activities. This is in contrast to those who earn fixed hourly rates or a monthly salary.

Problems of reporting also arise when principal respondents are reporting on the income of the other household members, and he/she may not know the income of his family members (Posel, 2001). 
Nonetheless, in this study I asked the head of households for the socio-demographic details (including income) of each of his/her bilik-member. In most instances, the head of household tended to validate his/her responses by having the other family members present during the interviews to confirm his responses. I also found that most of the head of households did not know the income of their family members but they did know how much (if relevant) were the remittances. ${ }^{62}$

It should be noted that the measures illustrated in Table 4.2 and Table 4.3 are for both group and individual scores. To recap, Table 4.2 contains measures of physical development at village (community) level, and also used to measure physical development at both household and individual levels. The income measures, however, are not applicable for village level as I only interviewed selected participants from each village (even though they were randomly selected, the number is not enough to be representative). I did not have enough data to estimate income at community level with sufficient precision. However, the income measures in Table 4.3 are applicable for measuring development (income) at both the individual and household levels.

\subsubsection{Personal (Individual) development indicators}

Apart from the community and household development indicators, I also explore personal development in this research and include education, literacy, health and decision making as key indicators (see Table 4.4).

\footnotetext{
62 This is my justification for including remittances as an indicator of development. The amount may not be accurate but the fact that the in-situ households have other sources of income which come from places other than their longhouse can be construed as an indicator of how developed a household is in comparison to those households that do not receive any remittance.
} 
Table 4.4: Individual development indicators

\begin{tabular}{|c|c|c|c|}
\hline Variables & Justification & Description & Coding \\
\hline $\begin{array}{l}\text { Highest level } \\
\text { of education } \\
{\left[\mathrm{ED}_{1}\right]}\end{array}$ & To see the level of education attainment & $\begin{array}{l}\text { It is assumed that an } \\
\text { individual with education is } \\
\text { more 'developed' } \\
\text { individually than those who } \\
\text { do not have formal } \\
\text { education }\end{array}$ & $\begin{array}{l}0=\text { no formal education } \\
1=\text { not finishing primary school } \\
2=\text { primary school } \\
3=\text { not finishing secondary school } \\
4=\text { SRP } \\
5=\text { SPM } \\
6=\text { STPM } \\
7=\text { Post school certificate } / \text { Diploma } \\
8=\text { Degree }\end{array}$ \\
\hline $\begin{array}{l}\text { Literacy } \\
{\left[\mathrm{ED}_{2}\right]}\end{array}$ & $\begin{array}{l}\text { To see individual's ability to read and } \\
\text { write }\end{array}$ & $\begin{array}{l}\text { It is assumed that an } \\
\text { individual who is literate is } \\
\text { 'more developed' compared } \\
\text { to those who are illiterate }\end{array}$ & $\begin{array}{l}1=\text { yes } \\
0=\text { no }\end{array}$ \\
\hline $\begin{array}{l}\text { IT Literacy } \\
{\left[\mathrm{ED}_{3}\right]}\end{array}$ & $\begin{array}{l}\text { This is significant in discussion related to } \\
\text { contemporary accessibility and } \\
\text { development }\end{array}$ & $\begin{array}{l}\text { It is assumed that an } \\
\text { individual who is IT literate is } \\
\text { 'more developed' compared } \\
\text { to those who is IT illiterate }\end{array}$ & $\begin{array}{l}1=\text { yes } \\
0=\text { no }\end{array}$ \\
\hline $\begin{array}{l}\text { Participation } \\
\text { in household } \\
\text { decision } \\
\text { making } \\
{\left[\mathrm{DM}_{1}\right]}\end{array}$ & $\begin{array}{l}\text { Streeten \& Burki (1978) states that } \\
\text { involvement in decision making is } \\
\text { categorised as non-material basic need. }\end{array}$ & $\begin{array}{l}\text { More "developed" } \\
\text { individuals are empowered - } \\
\text { and in this case should be } \\
\text { actively involved in decision- } \\
\text { making }\end{array}$ & $\begin{array}{l}0=\text { no participation } \\
1=\text { very poor participation } \\
2=\text { poor participation } \\
3=\text { neutral } \\
4=\text { involved } \\
5=\text { very involved }\end{array}$ \\
\hline $\begin{array}{l}\text { Participation } \\
\text { in longhouse } \\
\text { decision- } \\
\text { making } \\
{\left[\mathrm{DM}_{2}\right]}\end{array}$ & $\begin{array}{l}\text { Same as above - to see whether an } \\
\text { individual participates in decision- } \\
\text { making outside of his/her household }\end{array}$ & $\begin{array}{l}\text { Individuals who are actively } \\
\text { involved in decision-making } \\
\text { are assumed to be 'more } \\
\text { developed'. }\end{array}$ & $\begin{array}{l}0=\text { no participation } \\
1=\text { very poor participation } \\
2=\text { poor participation } \\
3=\text { neutral } \\
4=\text { involved } \\
5=\text { very involved }\end{array}$ \\
\hline $\begin{array}{l}\text { Health } \\
{[\mathrm{H}]}\end{array}$ & $\begin{array}{l}\text { Health is one of the key (objective) } \\
\text { indicators of personal development [e.g. } \\
\text { Hicks \& Streeten, 1979) }\end{array}$ & $\begin{array}{l}\text { This is based on the self- } \\
\text { rated response obtained } \\
\text { from respondent on their } \\
\text { health status }\end{array}$ & $\begin{array}{l}1=\text { poor } \\
2=\text { fair } \\
3=\text { good } \\
4=\text { very good } \\
5=\text { excellent }\end{array}$ \\
\hline $\begin{array}{l}\text { Personal } \\
\text { development } \\
\text { Score }\end{array}$ & $=\left(E_{1}+E D_{2}+E D_{3}\right)+(D M 1+D M 2)+H$ & & \\
\hline
\end{tabular}

Education, health and decision-making elements are included in the individual development score as these elements are deemed significant in influencing individual's development (Burki \& Haq, 1981; Hawley, 2004; Hicks \& Streeten, 1979; Rigg \& Nattapoolwat, 2001; Rungmanee, 2014). Burki and Haq (1981, p. 168), for example, states that education and health are as important as land, credit and machinery when it comes to factors that can contribute to a higher level of productivity. Similarly, literacy can be used as an indicator of an individual's progress in education (Hicks \& Streeten, 1979) and IT literacy is relevant in the light of the increased significance of technology in today's society. Participation in decision-making is also a mark of personal development and is considered nonmaterial basic needs by Hicks and Streeten (1979). 


\subsubsection{Subjective measures of development}

I also used a subjective approach to measure development at all three levels: the community, the household and the individual. One way to measure development (and accessibility) in a subjective manner is to ask for respondents' self-rated assessment and/or ranking regarding a point or category. I asked respondents, at all three units of analysis, to rate their level of satisfaction, and their views on the changes (in both development and accessibility variables) that have occurred in their respective longhouses in the last five years (refer Appendix 1: Section 4; Appendix 2: various questions in Section 3, e.g. Questions 3.9, 3.14, 3.15, 3.18 and 3.23; and Appendix 3: Section 4). I assumed that, for the purpose of measuring development, changes for the better, or progress, indicate development. This exercise provided me with self-rated responses based on the performance of the longhouse as viewed by the tuai rumah or their representatives, and changes as perceived by heads of household and individual members of a household. The responses for the longhouse level were validated by the respective anak biak (who agreed on the responses given by their tuai rumah) who were present during the group interviews.

I use the indicators listed in Table 4.5 as subjective measures - being levels of satisfaction and perception of services available to the participants. Once I was able to determine the total score for perception of access to service, I then used that score to explore its relation to my pre-determined measures of development (e.g. perception of overall development, infrastructure provision or level of education). 
Table 4.5: Subjective measure - respondents' satisfaction and perception of services

\begin{tabular}{|c|c|c|c|}
\hline Variables & Justification & Description & Coding \\
\hline $\begin{array}{l}\text { Access to } \\
\text { education } \\
{[\mathrm{AE}]}\end{array}$ & $\begin{array}{l}\text { Perception of education } \\
\text { services for the area }\end{array}$ & $\begin{array}{l}\text { This refers to respondents' perceptions on the } \\
\text { ease of which their bilik members (or they } \\
\text { themselves) access education i.e. pre-school, } \\
\text { primary school, secondary school and post school } \\
\text { education }\end{array}$ & $\begin{array}{l}1=\text { very unsatisfied } \\
2=\text { unsatisfied } \\
3=\text { neutral } \\
4=\text { satisfied } \\
5=\text { very satisfied }\end{array}$ \\
\hline $\begin{array}{l}\text { Access to health } \\
\text { services } \\
\text { [AH] }\end{array}$ & $\begin{array}{l}\text { Satisfaction of, as users of, } \\
\text { health services in the area }\end{array}$ & $\begin{array}{l}\text { This refers to respondents' self-rated level of } \\
\text { satisfaction regarding their access to health } \\
\text { services in the area }\end{array}$ & $\begin{array}{l}1=\text { very unsatisfied } \\
2=\text { unsatisfied } \\
3=\text { neutral } \\
4=\text { satisfied } \\
5=\text { very satisfied }\end{array}$ \\
\hline $\begin{array}{l}\text { Access to job } \\
\text { [AJ] }\end{array}$ & Perception of access to job & $\begin{array}{l}\text { This refers to respondents' perception of access to } \\
\text { job in the locality. }\end{array}$ & $\begin{array}{l}1=\text { very unsatisfied } \\
2=\text { unsatisfied } \\
3=\text { neutral } \\
4=\text { satisfied } \\
5=\text { very satisfied }\end{array}$ \\
\hline $\begin{array}{l}\text { Access to credit } \\
\text { [AC] }\end{array}$ & Perception of access to credit & $\begin{array}{l}\text { This refers to respondents' perception on the ease } \\
\text { at which they gain access to credit and finances }\end{array}$ & $\begin{array}{l}1=\text { very unsatisfied } \\
2=\text { unsatisfied } \\
3=\text { neutral } \\
4=\text { satisfied } \\
5=\text { very satisfied }\end{array}$ \\
\hline $\begin{array}{l}\text { Access to } \\
\text { transport } \\
\text { [AT] }\end{array}$ & Perception of transport & $\begin{array}{l}\text { This refers to respondents' perception regarding } \\
\text { the ease at which they travel from one place to } \\
\text { another }\end{array}$ & $\begin{array}{l}1=\text { very unsatisfied } \\
2=\text { unsatisfied } \\
3=\text { neutral } \\
4=\text { satisfied } \\
5=\text { very satisfied }\end{array}$ \\
\hline $\begin{array}{l}\text { Total score for } \\
\text { perception }\end{array}$ & $=A E+A H+A J+A C+A T$ & & \\
\hline
\end{tabular}

I turn now to objective and subjective measures of accessibility.

\subsubsection{Measuring accessibility}

The concept of accessibility has been used in past studies on rural change to evaluate performances of rural areas as well as the rural economy in Sarawak (Jill Windle, 2002; J Windle \& Cramb, 1997). Similar concepts have been used by other scholars working in the Philippines (Olsson, 2009) and Africa (Ogunsanya, 1987). For example, Ogunsanya investigate the role of rural transport (and its accessibility problems) in influencing rural development in Nigerian villages; while Olsson explored the effects of improved road accessibility on socio-economic development of fishing community in rural Philippines.

The term accessibility in this research refers to accessibility to market and services, unless stated otherwise. The term refers not just to accessibility to commodity markets, but also includes markets for labour services and accessibility to supplies for both production and consumption. Accessibility refers to the ease with which one can obtain desired opportunities and it includes not just the 
necessary travel (physical accessibility) but also contemporary means of obtaining desired goods, services, and information (e.g. internet). This inclusion of contemporary accessibility is hoped to provide a more comprehensive perspective regarding the level of actual and perceived accessibility to market and services in the case study area.

\subsubsection{Measuring physical accessibility}

In conventional discourse, the notion of 'accessibility' refers to 'physical accessibility'. This view of accessibility is usually measured in terms of economic distance, in terms of both financial cost and travel time, depending on the mode of transport, and availability of land-based transport infrastructure.

As a starting point, accessibility is examined in terms of its pre-determined mutually exclusive accessibility zones and the different types of accessibility based on the adopted operational definition. The former has been discussed in detailed (refer Map 4.1) and is basically referring to proximity of the areas in its hinterlands, to local market, i.e. Kapit Town. Kapit Town is only accessible via river transport from its nearest town, Sibu, which is approximately 126 kilometres away, and the rest of the state. The road network within the district is limited to its town centre and the immediate periphery. Therefore, the majority of the selected sample longhouses in my study still rely very much on river transportation, as illustrated in Table 4.6 and 4.7 below $^{63}$.

Table 4.6: Mode of transportation used by members of the sampled longhouses,

Kapit District, 2014

\begin{tabular}{|l|c|c|}
\hline & Number of longhouses & Percentage (\%) \\
\hline Mixed mode of transportation & 9 & 45 \\
\hline Land transportation & 3 & 15 \\
\hline Express boat ${ }^{64}$ & 8 & 40 \\
\hline
\end{tabular}

Based on interview with tuai rumah, June 2014

\footnotetext{
${ }^{63}$ At the time of the fieldwork, there is no direct road connection from Nanga Mujong transit point to the mid and upper Baleh areas. Residents and visitors alike have to cross Batang Baleh at Nanga Mujong transit point (refer Map 4.1). Settlements further along Batang Baleh, and its tributaries still rely completely on river transportation.

${ }^{64}$ Along this particular stretch of the river, express boats can be described as the riverine version of 'public buses'. They stop at settlements along Batang Baleh to pick up and drop off passengers and goods. The express boat charges between two to three types of fares depending on the boat operators. The most common fare ranges from RM15 to RM20 and RM30 depending on the seat chosen.
} 
Table 4.7: Number of longhouses in the sample that are still dependent on river transportation, Kapit District, 2014

\begin{tabular}{|l|c|c|}
\hline & $\begin{array}{c}\text { Number of longhouses chosen in } \\
\text { the study }\end{array}$ & $\begin{array}{c}\text { Number of longhouses dependent } \\
\text { on river transportation }\end{array}$ \\
\hline High Accessibility Zone (A1) & 6 & $3^{65}$ \\
\hline Medium Accessibility Zone (A2) & 7 & 7 \\
\hline Low Accessibility Zone (A3) & 7 & 7 \\
\hline
\end{tabular}

Based on interview with tuai rumah, June 2014

In this research, I chose to measure accessibility in terms of the average time taken to travel and the cost of travel from the longhouses to Kapit Town. Map 4.2 below shows the estimated average travel time (and cost) from the longhouses to Kapit Town using longboat. Six main routes were highlighted in the map, and the estimated travel time were made based on using a 15 and 40 horse power engines. The Nanga Mujong transit point, which is the main transit point for switching to/from river-land mode transport for rural residents along mid-Baleh area, is located at Point 2 on Map 4.2. Meanwhile Point 7 is one of the pala menoa, which signifies the last Iban settlement on Batang Baleh, and is the furthest settlements in terms of distance, as well as travel time, from Kapit Town.

65 Three longhouses with direct road access to Kapit town are LH1, LH4 and LH6, all of which are located within A1. LH1 and LH6 are adjacent to each other and both have had road access to town since early 1980s. At that time, it was an unsealed dirt road, before it was upgraded to gravel road in the 1990s. In 2000, the road, which now serves those settlements from Kapit town to Nanga Mujong transit point, was upgraded to a tar-sealed road. 
Map 4.2: Estimated cost and travel time to Kapit Town using longboat, Kapit District, 2014

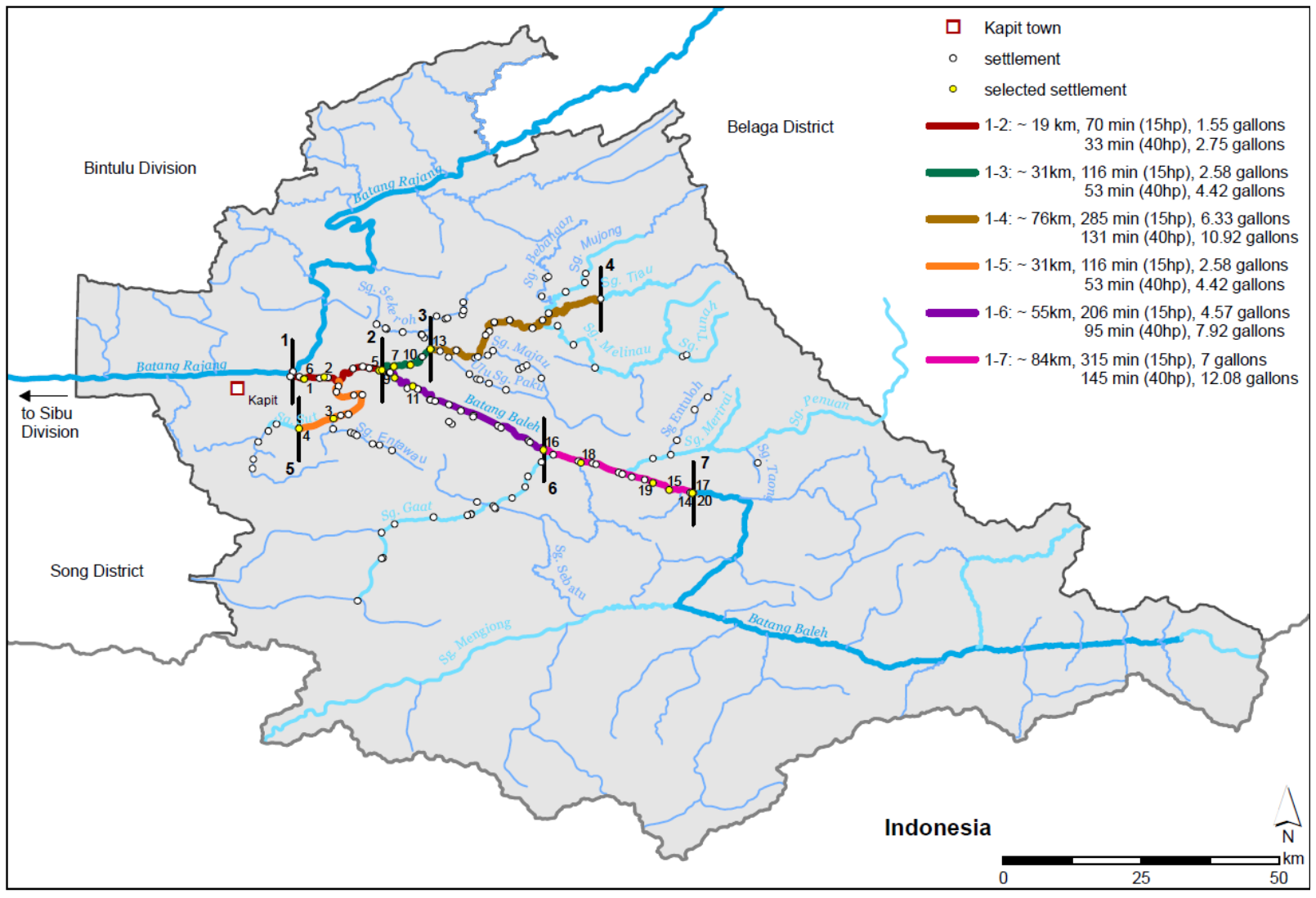

Source of base map: Series MY91001R, Edition 1-PPNM, Department of Survey and Mapping Malaysia, 2010

Settlements at the pala menoa (using route 1-7 in the map) would have to purchase approximately 12.08 gallons of petrol for a one way trip to Kapit Town. At the time of the fieldwork, a gallon of petrol costs approximately RM12, and, therefore, the total cost for the return visit would approximately be RM300 (per boat). This is relatively high compared to the cost, for example, incurred by residents along route 1-3 (Nanga Mujong) or route 1-5 (Sungai Sut), which cost approximately RM100 for a return trip using longboat.

However, as illustrated in Table 4.8 below, there are other modes of transport from sampled longhouses to Kapit Town. These different modes of transport have different travel time and cost, than illustrated in Map 4.2 above. The cost ranges from RM4 to RM18 per person for a one way trip to town. The cheapest, at RM4, is from settlements near Point 1 (see Map 4.2) using a van to travel to town. For settlements in upper Baleh (Point 6 to 7 on the map), the express boats charge a fixed fare of a minimum of RM15 regardless of their distance to Kapit Town. The difference in cost is notable particularly between settlements in areas between Point 1 to Point 2 (using land transportation) and 
Point 6 to Point 7 (using express boat). Respondents attribute the cheaper cost of travelling to the existence of road, either direct access or partial connection, linking them to town.

Table 4.8: Cost and average travel time, using different modes of transport, from sampled longhouses to Kapit Town, Kapit District, 2014

\begin{tabular}{|c|c|c|c|c|}
\hline Longhouse & $\begin{array}{l}\text { Accessibility } \\
\text { Zone }\end{array}$ & Type of transport & $\begin{array}{l}\text { Minimum Cost - } \\
\text { single trip (RM) }\end{array}$ & $\begin{array}{l}\text { Average travel time - single } \\
\text { trip (time taken in minutes) }\end{array}$ \\
\hline 1 & A1 & Land & 4 & 40 \\
\hline 2 & $\mathrm{~A} 1$ & Mixed & 9 & 40 \\
\hline 3 & $\mathrm{~A} 1$ & Mixed & 10 & 90 \\
\hline 4 & A1 & Land & 8 & 60 \\
\hline 5 & A1 & Mixed & 11 & 50 \\
\hline 6 & A1 & Land & 4 & 40 \\
\hline 7 & $\mathrm{~A} 2$ & Mixed & 15 & 80 \\
\hline 8 & $\mathrm{~A} 2$ & Mixed & 13 & 90 \\
\hline 9 & $\mathrm{~A} 2$ & Mixed & 11 & 40 \\
\hline 10 & $\mathrm{~A} 2$ & Mixed & 13 & 90 \\
\hline 11 & $\mathrm{~A} 2$ & River & 10 & 120 \\
\hline 12 & $\mathrm{~A} 2$ & Mixed & 14 & 80 \\
\hline 13 & $\mathrm{~A} 2$ & Mixed & 18 & 120 \\
\hline 14 & A3 & River & 15 & 220 \\
\hline 15 & A3 & River & 15 & 200 \\
\hline 16 & $\mathrm{~A} 3$ & River & 15 & 140 \\
\hline 17 & A3 & River & 15 & 220 \\
\hline 18 & A3 & River & 15 & 160 \\
\hline 19 & A3 & River & 15 & 180 \\
\hline 20 & A3 & River & 15 & 220 \\
\hline
\end{tabular}

Based on interview with tuai rumah, June 2014

Essentially, my measures of physical accessibility are focused on these two criteria: average travel time and monetary cost to travel from the longhouses to Kapit Town. The above table has measured accessibility in a conventional manner, namely by estimating the average travel time and cost. Furthermore, I have confined the discussion only to accessibility to the main commodity market, Kapit Town. There are other, smaller markets elsewhere, a wide variety of markets for labour and a range of accessibilities to different types of services and the locational resources associated with political patronage and social networks more generally. I will cover these in Chapters Six and Seven. In addition, there are alternative, contemporary forms of accessibility which have a bearing on the relationship between development and accessibility.

\subsubsection{Measuring contemporary accessibility}

The notion of contemporary accessibility addresses other non-conventional transport forms of accessibility. In particular, despite residing in a remote area with limited physical accessibility, one can 
be categorised as having a greater level of accessibility if he/she has access to information and communication technology. Kwan and Weber (2003, p. 342), for example, argue that the conventional measures of accessibility is less suitable in the present day as it does not take into account the increasing importance of ICTs in people's everyday life. Just as ownership of a boat or motor transport or access via kin or friends alters accessibility levels and can alter effective accessibility levels among individuals even in the same household, so too can the ownership of a mobile phone, computer or other related device.

Indicators of contemporary accessibility include ownership and/or access to mobile phone, accessing the internet via mobile phone, ownership and/or of laptop or personal computer. Just as skills are required to operate a long boat, specific skills are required to operate a laptop or personal computer, and the coverage for mobile communication (refer Table 4.9 below). In both cases, individual differences in these skill sets create a difference in person specific accessibility.

For the above reasons I include elements of contemporary accessibility in the index of accessibility because of their growing significance in today's society. 
Table 4.9: Elements of contemporary accessibility

\begin{tabular}{|c|c|c|c|}
\hline Variables & Justification & Description & Coding \\
\hline $\begin{array}{l}\text { Mobile phone } \\
\text { ownership }\left(M_{0}\right)\end{array}$ & $\begin{array}{l}\text { To see if the respondent own } \\
\text { a mobile phone }\end{array}$ & $\begin{array}{l}\text { Owning a mobile phone means } \\
\text { 'better accessibility' to market }\end{array}$ & $\begin{array}{l}1=\text { own a mobile phone } \\
0=\text { not owning a mobile phone }\end{array}$ \\
\hline $\begin{array}{l}\text { Access to mobile } \\
\text { phone }{ }^{66}\left(M_{a}\right)\end{array}$ & $\begin{array}{l}\text { To see if respondents have } \\
\text { access to phone despite not } \\
\text { owning one him/herself }\end{array}$ & $\begin{array}{l}\text { Access to mobile phone means } \\
\text { better accessibility to market } \\
\text { compared to not having access } \\
\text { to one }\end{array}$ & $\begin{array}{l}2=\text { own a phone (full access) } \\
1=\text { have access to mobile phone } \\
0=\text { no access to mobile phone }\end{array}$ \\
\hline $\begin{array}{l}\text { Using mobile } \\
\text { phone to access } \\
\text { internet }\left(\mathrm{M}_{\mathrm{i}}\right)\end{array}$ & $\begin{array}{l}\text { To see if respondents are } \\
\text { using their mobile phone to } \\
\text { improve their "accessibility" } \\
\text { to market via internet }\end{array}$ & $\begin{array}{l}\text { Using mobile phone to access } \\
\text { internet means the } \\
\text { respondents have 'better } \\
\text { access' to market for } \\
\text { communication and obtaining } \\
\text { information }\end{array}$ & $\begin{array}{l}1=\text { yes } \\
0=\text { no }\end{array}$ \\
\hline $\begin{array}{l}\text { Mobile phone } \\
\text { coverage }\left(\mathrm{M}_{\mathrm{c}}\right)\end{array}$ & $\begin{array}{l}\text { In order to work, mobile } \\
\text { phones depend on } \\
\text { telecommunication coverage }\end{array}$ & $\begin{array}{l}\text { To see if the respondent can } \\
\text { get 'signal' for the mobile } \\
\text { phone without leaving the } \\
\text { longhouse or not }\end{array}$ & $\begin{array}{l}3=\text { getting 'signal' at the } \\
\text { longhouse } \\
2=\text { have to go elsewhere (near } \\
\text { longhouse) for 'signal' } \\
1=\text { only using mobile phone } \\
\text { when in town } \\
0=\text { no mobile coverage }\end{array}$ \\
\hline $\begin{array}{l}\text { Mobile } \\
\text { Accessibility }\end{array}$ & $=M_{0}+M_{a}+M_{i}+M_{c}$ & & \\
\hline $\begin{array}{l}\text { Laptop/ computer } \\
\text { ownership }\left(\mathrm{L}_{\mathrm{o}}\right)\end{array}$ & $\begin{array}{l}\text { To see if the respondent } \\
\text { owns a computer or laptop }\end{array}$ & $\begin{array}{l}\text { Owning a laptop or computer } \\
\text { may indicate 'better } \\
\text { accessibility' to market }\end{array}$ & $\begin{array}{l}1=\text { own a computer/laptop } \\
0=\text { not } \text { owning }\end{array}$ \\
\hline $\begin{array}{l}\text { Access to laptop/ } \\
\text { computer }^{67}\left(\mathrm{~L}_{\mathrm{a}}\right)\end{array}$ & $\begin{array}{l}\text { To see if respondents have } \\
\text { access to computer or laptop } \\
\text { despite not owning one } \\
\text { him/herself }\end{array}$ & $\begin{array}{l}\text { Access to laptop/computer - } \\
\text { better accessibility to market } \\
\text { compared to not having access } \\
\text { to one }\end{array}$ & $\begin{array}{l}2=\text { own a laptop/ computer (full } \\
\text { access) } \\
1=\text { have access to laptop/ } \\
\text { computer } \\
0=\text { no access to laptop/ } \\
\text { computer }\end{array}$ \\
\hline $\begin{array}{l}\text { Know how to use } \\
\text { laptop/ computer } \\
\left(L_{s}\right)\end{array}$ & $\begin{array}{l}\text { To see if the respondents - } \\
\text { who own and have access to } \\
\text { laptop/ computer - know } \\
\text { how to use it }\end{array}$ & $\begin{array}{l}\text { Having access to laptop/ } \\
\text { computer does not mean } \\
\text { "better access" to information } \\
\text { and communication if the } \\
\text { respondents do not know how } \\
\text { to use it }\end{array}$ & $\begin{array}{l}1=\text { yes } \\
0=\text { no }\end{array}$ \\
\hline $\begin{array}{l}\text { Laptop } \\
\text { Accessibility }\end{array}$ & $=L_{o}+L_{a}+L_{s}$ & & \\
\hline $\begin{array}{l}\text { Contemporary } \\
\text { Accessibility }\end{array}$ & $\begin{array}{l}\text { = mobile accessibility + } \\
\text { laptop accessibility } \\
\text { This is applicable for } \\
\text { measuring contemporary } \\
\text { accessibility at individual and } \\
\text { household levels. }\end{array}$ & $\begin{array}{l}\text { For community level, mobile } \\
\text { coverage }\left(M_{c}\right) \text { is a more } \\
\text { suitable indicator to measure } \\
\text { its contemporary accessibility. }\end{array}$ & \\
\hline
\end{tabular}

According to Warren (2007, p. 385), internet is becoming embedded in society so rapidly that it is becoming a default medium for anyone wishing to provide information, to perform transactions, or to create civic engagement. That statement may be true in the western society and/or in urban centres

${ }^{66}$ Only talking about access to mobile phone owned by bilik-member.

67 This indicator is only referring to the respondents' access to laptop/ computer from his/her other bilikmembers. 
but it is not yet a reflection of rural areas in Sarawak. Rural dwellers are involuntarily excluded from digital accessibility as a result of a number of factors. I attempted to reflect this issue in my analysis.

\subsection{Summary}

In this chapter I have explained five key methodological elements of my research: the research design, study area, respondent selection method, data preparation and my mode of analysis. I also introduced the survey instruments and the indicators that I have developed to measure both development and accessibility. I have explained how my sample was chosen, the rationale behind the selection of the units of analysis, and who my research participants are. I then explained how I will study the relationship between accessibility and development, at the level of the community, the household and the individual. My point of departure from the existing work on this field is to explicitly recognise this multi-level response.

I have also introduced different definitions of accessibility and development as indicators to measure the relationship between accessibility and the market. In order to clearly see the implications of different levels of accessibility on development at these three levels, I begin in Chapter Three with a conceptual overview of the relationship between accessibility and development and then draw on the von Thünen model as a conceptual framework which to confront the evidence in Chapter Five and Chapter Six. 


\section{Chapter 5}

\section{Accessibility and Income}

The central argument of this thesis is that an increase in accessibility to markets and public services is associated with a higher level of development, but paradoxically, greater inequality. In this chapter, I will focus on the market to explain the different forms of the relationship between accessibility and development when explored using different income variables. The units of analysis are the village and the household. In Chapter Six, I turn to the role of services (in the form of electricity, water supply, schools and health facilities) play in determining this accessibility-development relationship.

The relationship between development and accessibility in the case study area is not as straight forward as the von Thünen's model of the market would suggest. There are many different possible measures of development and accessibility. This chapter begins by seeking empirical evidence for von Thünen's proposition about the geography of land rent - namely that the income from farming commodities marketed in the town declines with distance from the market. In other words, income (in this context, income is a proxy for development) rises with accessibility.

I begin with the simple case of vegetables before I include all other commodities. Nowadays most rural families receive most of their income from wages earned off the farm. Therefore, secondly I will look at the relationship between accessibility and other non-vegetable commodities. Then I will proceed to examine in-situ income, which refers to the income of everyone who resides under the same roof as the head of household, but it excludes remittances sent by bilik-members living elsewhere. My fourth type of development measure is total in-situ income, which includes remittances sent by bilik members to the head of household as well as any other financial assistance that he/she receives plus income from commodity sales, and income from non-farm activities. Total household income is, therefore, the combined income for the bilik-family that includes income from those who are practicing multi-local living. As I add in these different income sources, the conventional measures of accessibility diminish in importance - to the point where in the Baleh case, higher incomes are earned beyond the agricultural margin. 


\subsection{Measure of accessibility}

Proximity to Kapit Town is measured in terms of travel time in minutes ${ }^{68}$. The average travel time market from the selected longhouses in zones A1, A2 and A3 are 53.3 minutes, 120 minutes, and 220 minutes respectively. The average distance for A3 is approximately double of that of A2. Table 5.1 below shows the time taken (in minutes) from my sample longhouses to Kapit Town, and the preferred form of transport in the respective area. It should be noted that in this research, I am only looking at the distance from longhouses (in minutes), regardless of the form of transport, to measure accessibility to market, unless stated otherwise.

Table 5.1: Average travel time to Kapit Town (in minutes) by sampled settlements, Kapit District, 2014

\begin{tabular}{|c|c|c|c|}
\hline Longhouse & Accessibility Zone & Type of transport & $\begin{array}{c}\text { time taken in minutes } \\
\text { (single trip) }\end{array}$ \\
\hline 1 & A1 & Land & 40 \\
\hline 2 & A1 & Mixed & 40 \\
\hline 3 & A1 & Mixed & 90 \\
\hline 4 & A1 & Land & 60 \\
\hline 5 & A1 & Mixed & 50 \\
\hline 6 & A1 & Land & 40 \\
\hline 7 & A2 & Mixed & 80 \\
\hline 8 & A2 & Mixed & 90 \\
\hline 9 & A2 & Mixed & 40 \\
\hline 10 & A2 & Mixed & 90 \\
\hline 11 & A2 & River & 120 \\
\hline 12 & A2 & Mixed & 80 \\
\hline 13 & A2 & Mixed & 120 \\
\hline 14 & A3 & River & 220 \\
\hline 15 & A3 & River & 200 \\
\hline 16 & A3 & River & 140 \\
\hline 17 & A3 & River & 220 \\
\hline 18 & A3 & River & 160 \\
\hline 19 & A3 & River & 180 \\
\hline 20 & A3 & River & 220 \\
\hline
\end{tabular}

Based on interviews with tuai rumah and head of households, June 2014

There are noticable variations between settlements even in the same accessibility zones. In most cases, the differences arise from the different modes of transport used. For example, in A1, there are respondents who completely rely on land transport. Other villages still rely on a mixed transport option (refer Table 5.1 above). The variations are greater between longhouses within A3 and as shown in Map 5.1 settlements in A3 are located at the upper reaches of Baleh, from Nanga Gaat towards Entawau (from Point Six to Point Seven in Map 5.1). The differences in travel time are due to a combination of the type of transport and the location of settlements in relation to Kapit Town. The ${ }^{68}$ The time measure was obtained from interviews with the tuai rumah, and verified by their anak biak. I also
observed the time taken to travel from each settlement to Kapit Town when I visited the longhouses. 
comparative distance between the three accessibility zones as well as their locations are shown in the following Map 5.1 and Figure 5.1.

Map 5.1: Approximate distance to Kapit Town by longboat, 2014

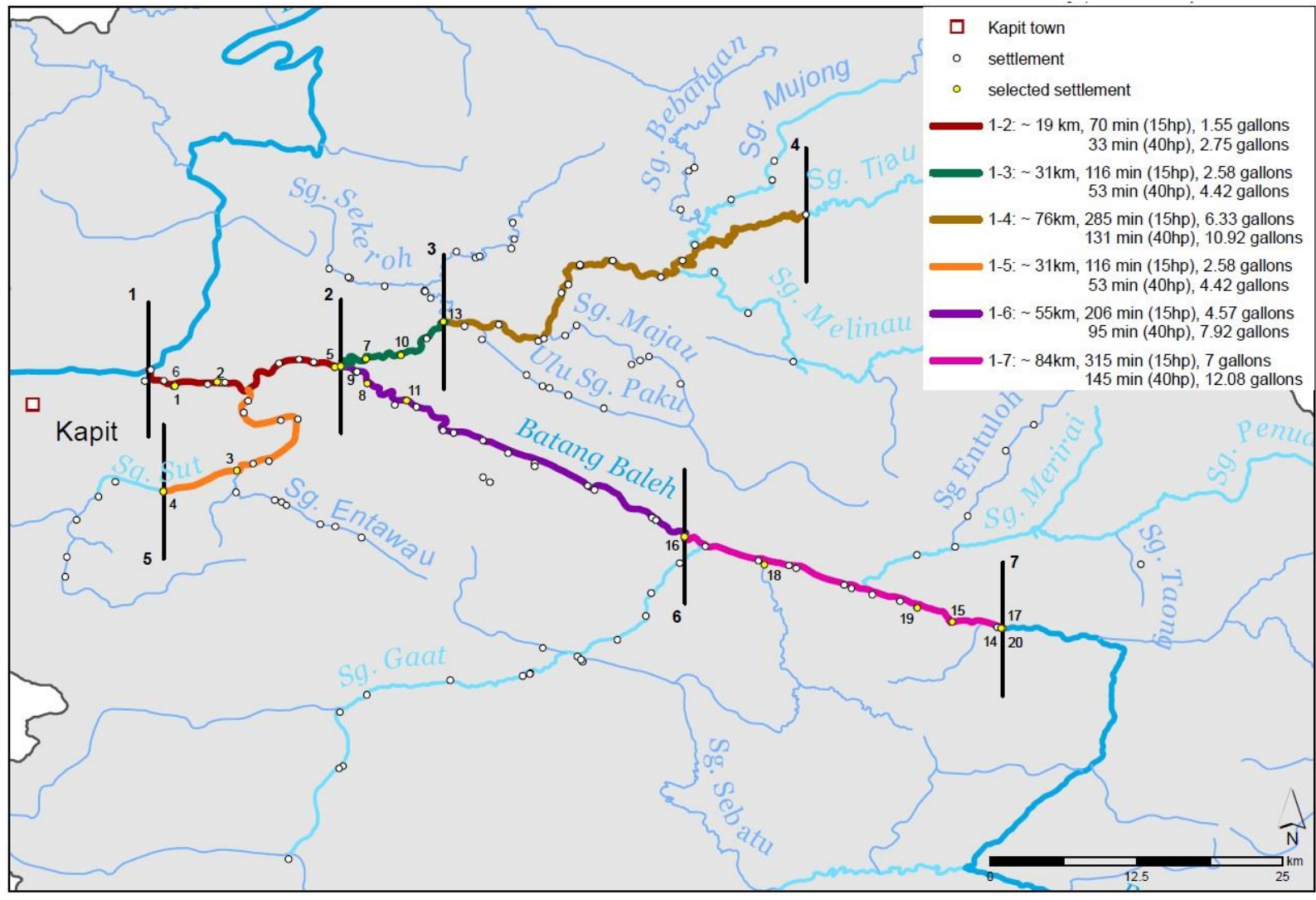

Note: The average travel time shown in this map is based on the following: using a 40 horsepower engine, a longboat can travel $7 \mathrm{~km}$, using a gallon of fuel; or $12 \mathrm{~km}$ and a gallon of fuel if using a 15 horsepower engine. The exact amount of fuel or the time taken also depends on other factors, e.g. water level, or the direction of travel. Travelling downriver takes less time than travelling upriver.

Figure 5.1: Proximity to Kapit Town (in minutes), by accessibility zone, 2014

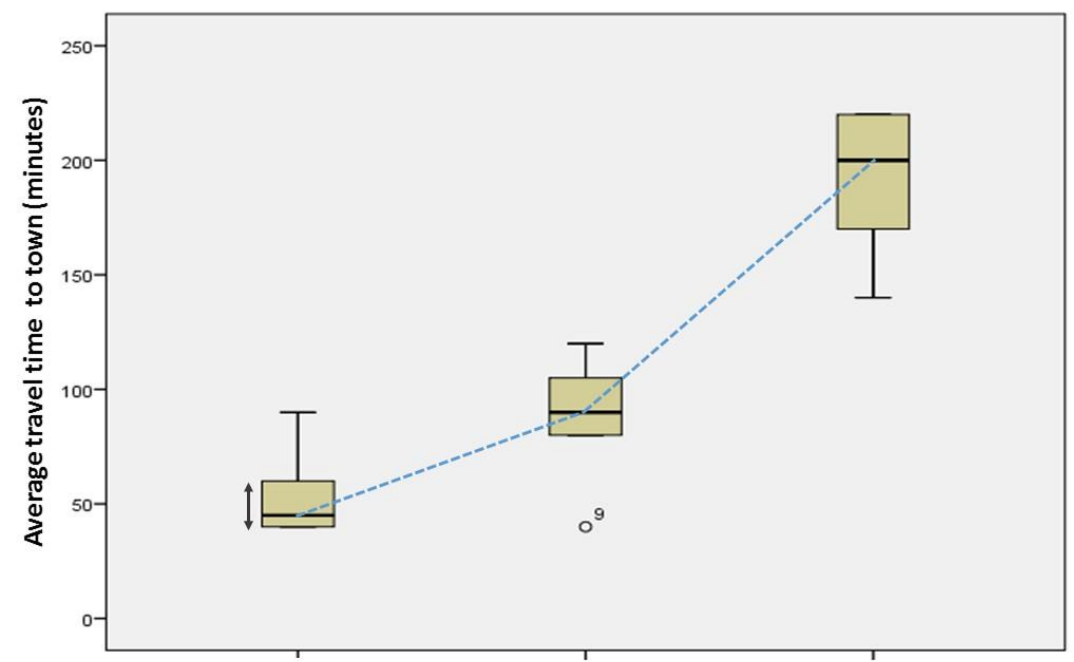

High accessibility zone (A1) Medium accessibility zone (A2) Low accessibility zone (A3) Accessibility zone 


\subsection{Income and Accessibility}

The hypothesis derived from von Thünen's model is that an increase in accessbility to the main market (i.e. Kapit Town) will be accompanied by a rise in income - an indicator for development. Income is one of the most commonly used measures of development (Costanza, Hart, Talberth, \& Posner, 2009; Willis, 2005), ranging in scale from Gross Domestic Product per capita (GDP/C) at the national level to disposable income per person as captured in survey research. I will use different types of income which includes income from commodity sales, in-situ income (both with and without remittance), remittances, and total household income.

I begin with income from commodity sales - the income a household earns from selling one or more commodities at the local market such as rubber, vegetables and seasonal fruits as well as jungle-based products. Because the main agricultural commodity produced based in the Baleh river basin is vegetables, I firstly focus on the relationship between accessibility and income from vegetable sales.

\subsubsection{Relationship between income from agricultural commodity sales and proximity to Kapit} Town

The main commodities my respondents sell are vegetables from their market gardens. Later I will include jungle-based commodities as most respondents are still practicing hunting-gathering and fishing as part of their income generation strategy along with rubber tapping. By far, the most important cash income earner is market gardening (see Figure 5.2).

Figure 5.2: Types of commodity by accessibility zone, at household level, 2014

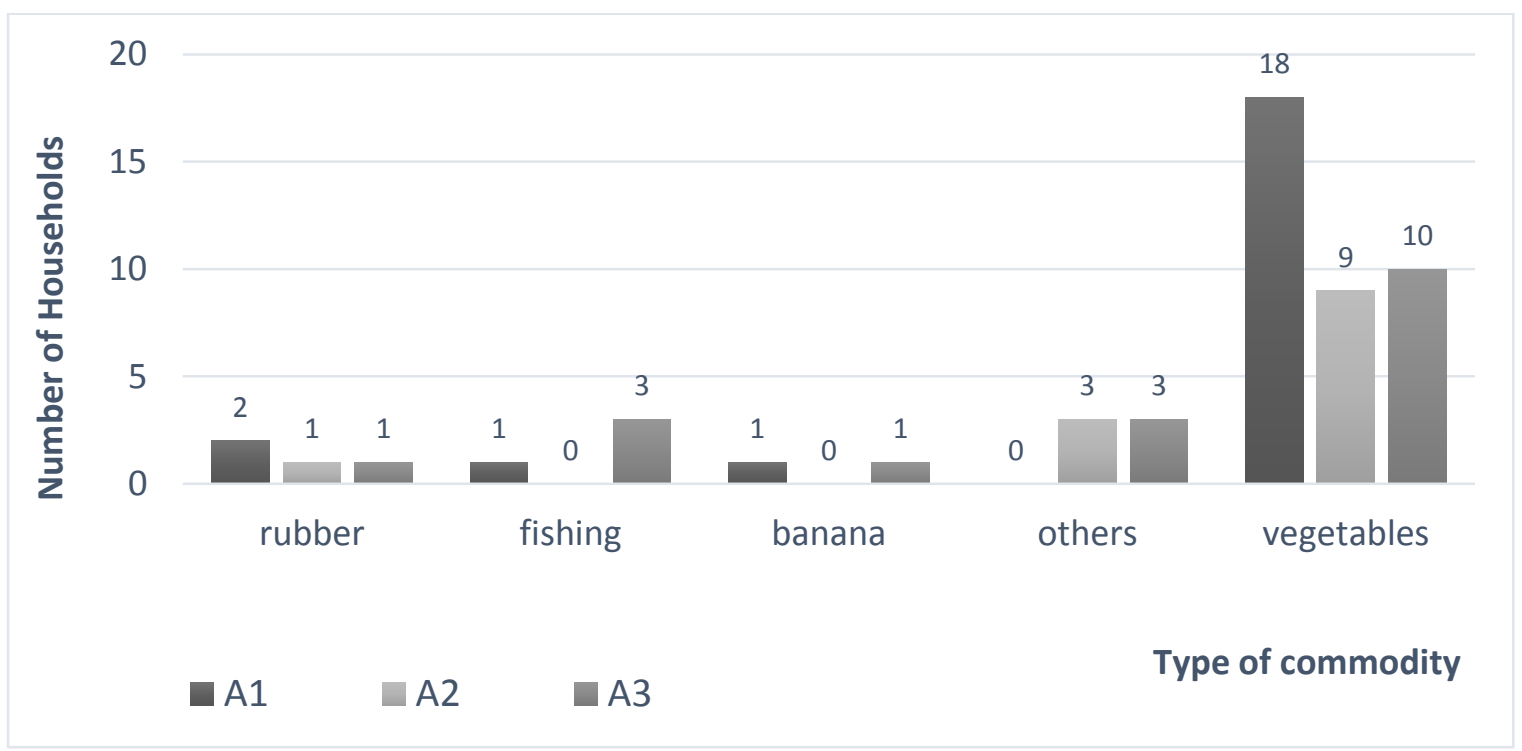

Note: others include jungle-based products; e.g. from hunting and gathering activities. 
Figure 5.3 shows that (gross) income from vegetable sales decline with travel time to Kapit Town. The result is true if every household selling vegetables sells produce at Kapit Town. However, only 14 households (out of 82 households) sell their vegetables in Kapit Town. Another 23 sell their vegetable produce at smaller local markets.

Figure 5.3: Relationship between income from vegetable sales and average travel time to Kapit Town, at household level, Baleh river basin, 2014

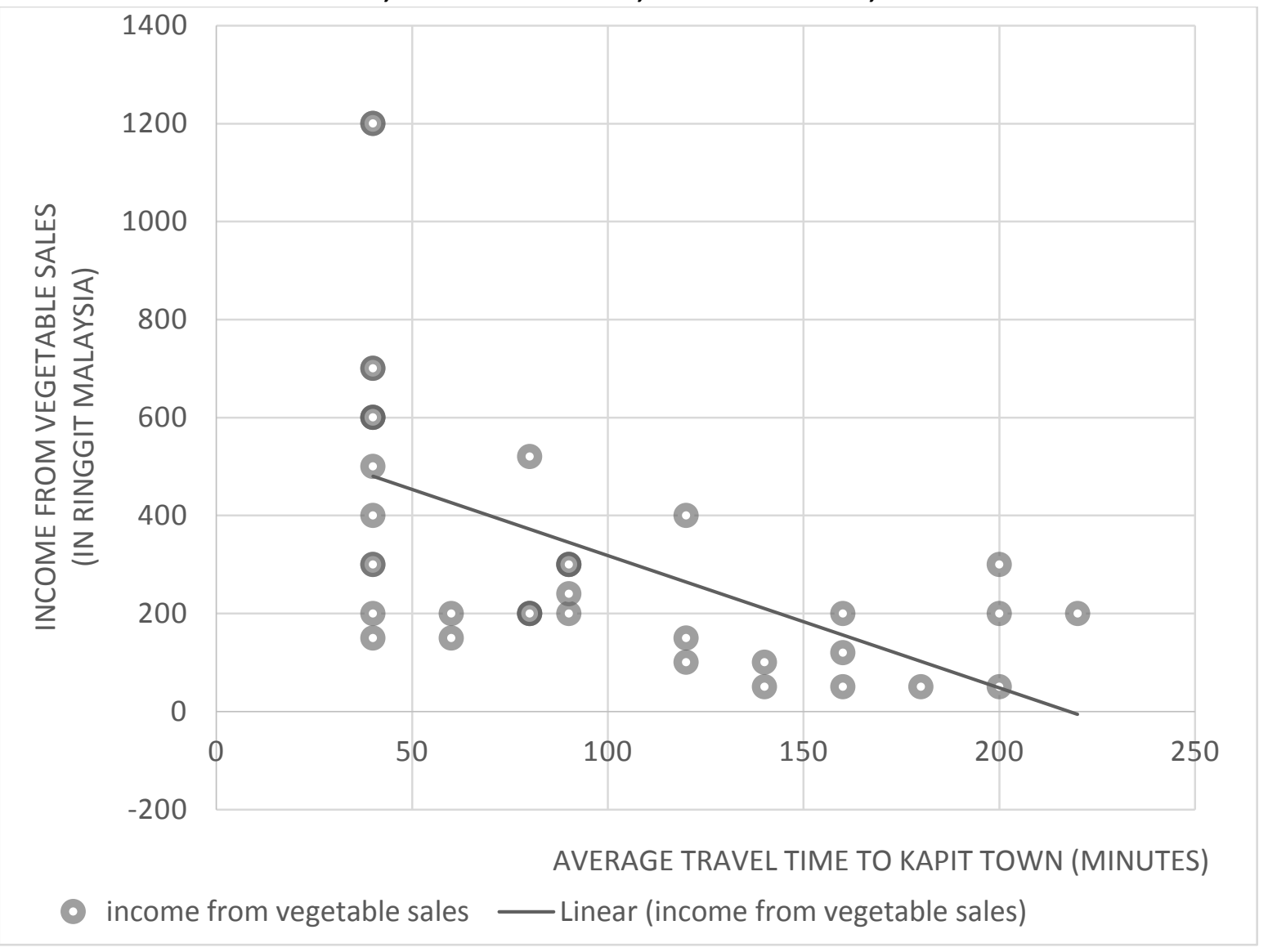

Source: Field notes

Note: Fitted linear line is $y=-2.697 x+587.85$, and $R^{2}=0.304$

The respondents from $A 1$, for instance, claimed that they have been selling vegetables from their market gardens for decades. In fact, for a majority of respondents in A1, market gardening and selling vegetable produce is a main part of their household income strategy, and they proudly call themselves the pioneers of market gardening in the area. The income of market gardeners ranges from RM 800 to RM1200 a month from vegetable sales. According to the respondents who make a living out of selling vegetables, direct road access really benefits them as they are able to reach the market in a short time. Time is significant due the perishability nature of the vegetables. 
By contrast, interviews with both tuai rumah and head of households in the most distant zone, $A 3$, indicated that selling vegetables or other perishable products at Kapit Town was not an option due to their inaccessibility. One of the respondents commented that,

"...because we do not have direct road access to town and rely on river transportation, it is not feasible for us to sell our surplus vegetables ... the (return) trip alone costs us RM30 and it is not even profitable for us to do so."

(Respondent No.51, A3, June 2014).

This effects of travel time is quite apparent from the estimated probability that a household located at a given travel time (in logs) falls with travel time from Kapit Town. The probability is post estimated from a logit regression of $1=$ selling vegetables, $0=$ otherwise on the log of travel time to Kapit Town. The bars are confidence intervals. Over 70 percent of those who live within approximately half an hour travel time (3.5 in log time) from Kapit Town sell vegetables at the market at Kapit Town. As the travel time increases, however, the likelihood of farmer selling at Kapit Town decreases, with an estimated drop to under 33 percent within an hour travel (once the log travel time of 4 is reached, 54.6 minutes). No household living an hour away considers it worthwhile selling vegetables to Kapit Town and, that time threshold effectively delimits the agricultural margin for vegetable sales.

Figure 5.4: The post-estimated probability of vegetable sales to Kapit Town by log average travel time to Kapit, Sarawak, 2014

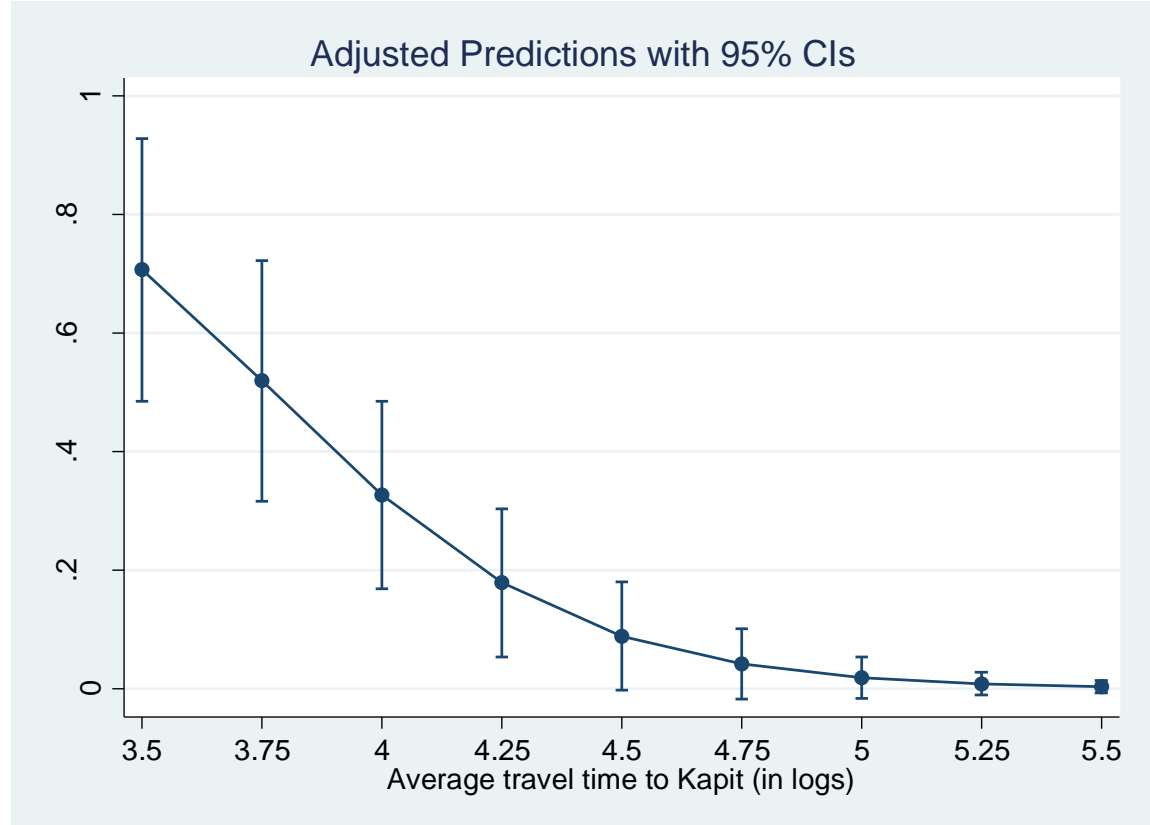

Source: Field notes 
In response to the relative inaccessibility to Kapit Town, a number of households that are located beyond the areas of agricultural margin (i.e. in A2 and $A 3$ ) sell vegetables at markets within the vicinity of their own longhouses. They sell their vegetable produce from longhouse to longhouse, at Nanga Mujong transit point, by the 'roadside', or at schools (while waiting for their children). These 'local' markets are smaller in size and, therefore, the income from vegetable sales is also smaller. Findings reveal that the average income from vegetable sales for those who are less than 30 minutes travel distance to smaller markets is approximately RM20769 (standard deviation of RM154) and the average income for those in $\mathrm{A} 1$ who sell their vegetables at Kapit Town is approximately RM532 ${ }^{70}$ (standard deviation is RM324).The former refers to participating households that sell vegetable at their local markets. Figure 5.5 shows the different markets for vegetable by accessibility zone.

Figure 5.5: Main market place for vegetables as identified by head of households, 2014.

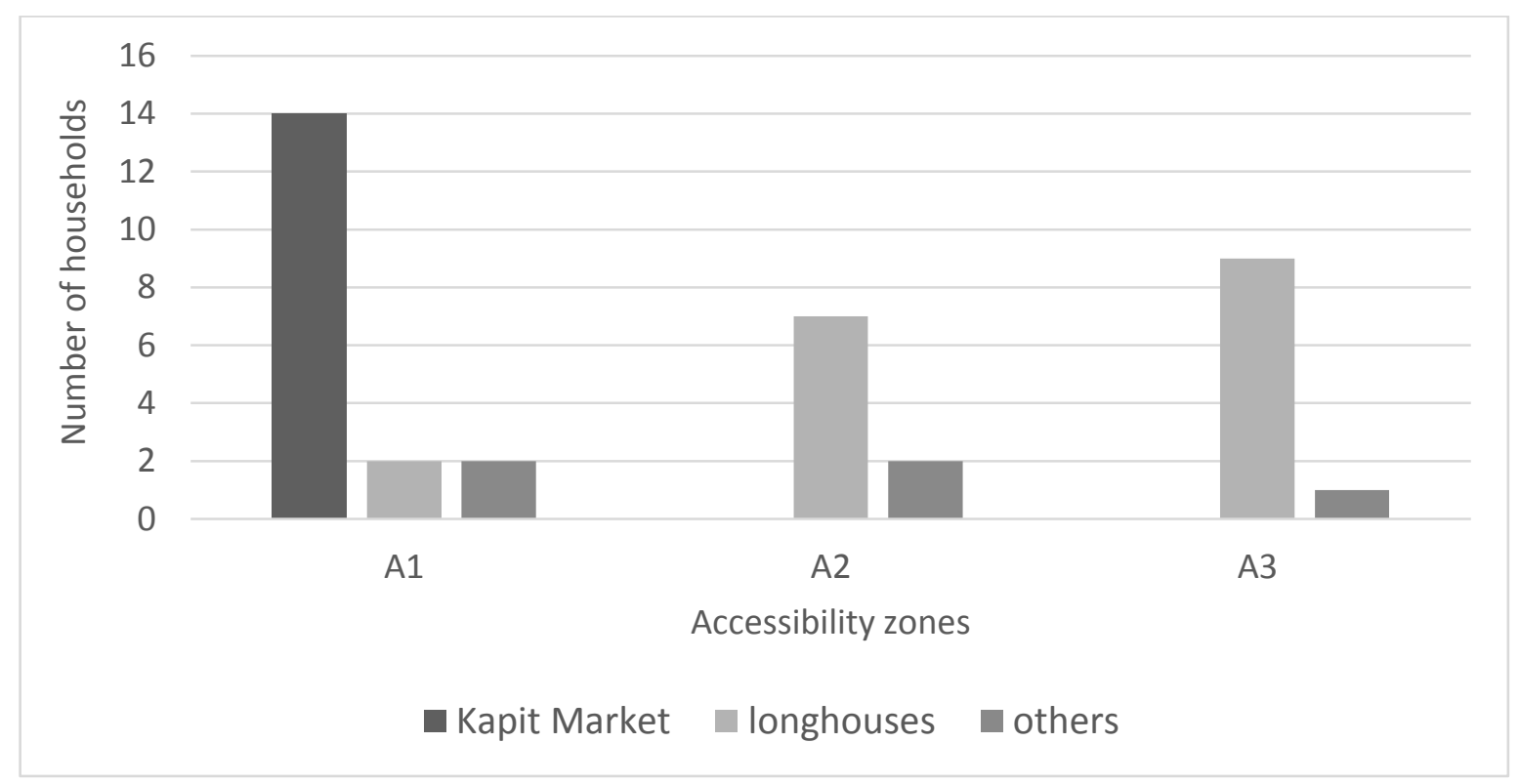

Source: Based on data from fieldwork conducted in 2014

Those who are selling their vegetables in Kapit Town earn more compared to those household who sell their vegetables within the vicinity of their own longhouses. This is due to the difference in volume or supply of vegetables. Those in A1, who are nearer to Kapit Town, farm more intensively than their counterparts in A2 or A3. By contrast, the households in A2 and A3 are less dependent on vegetable sales and sell considerably less by volume. In most circumstances, less proximate households only sell surplus (e.g. okra, sweetcorn, and chillies) and seasonal vegetables (e.g. ensabi (mustard green), and cucumber).

\footnotetext{
${ }^{69}$ Minimum income is RM50 and maximum income is RM700.

${ }^{70}$ Minimum income is 150 and maximum income is RM1200.
} 
Photo 5.1: Market scene at the 'other vegetable market', Baleh river basin, Sarawak, 2014
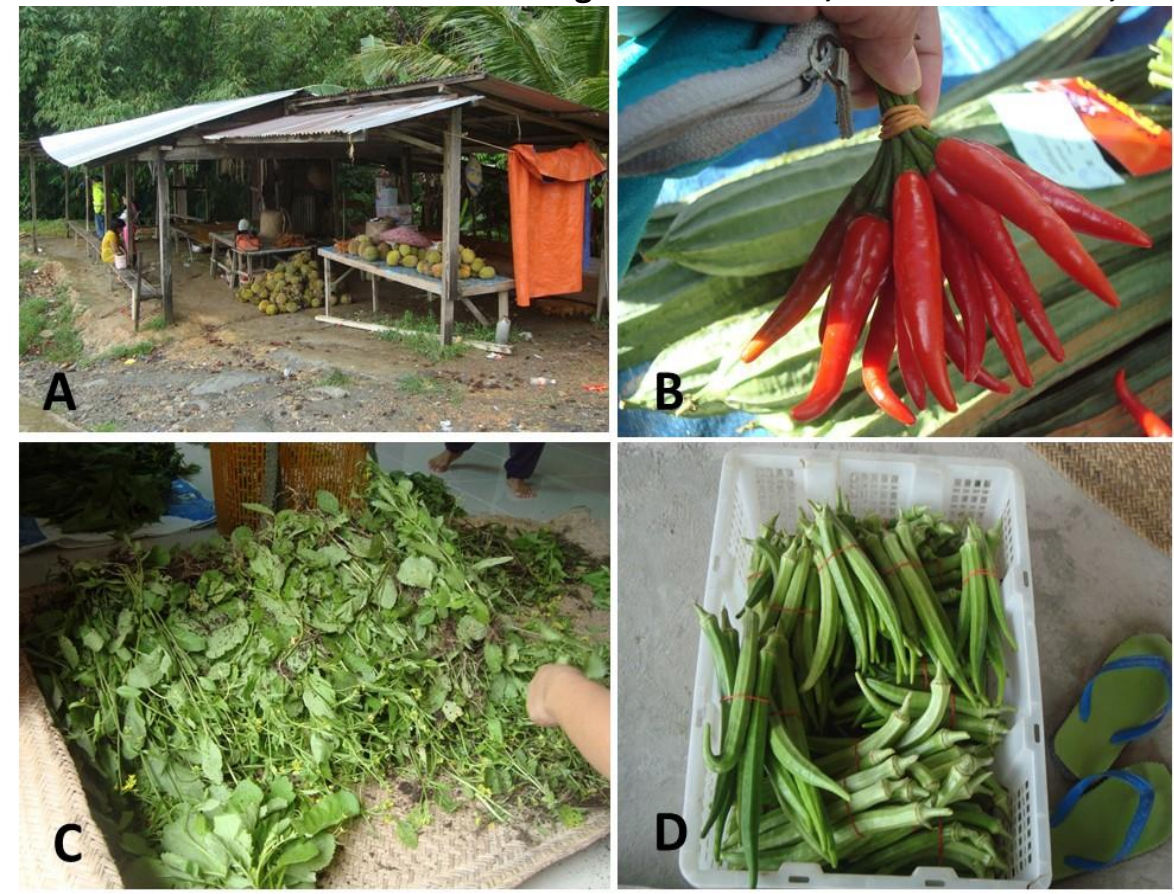

Photo A: Vegetable stalls at Nanga Mujong transit point. Photo was taken late in the day when the vegetable sellers have gone home.

Photo B: Fresh chillies

Photo C: Freshly picked ensabi to be sold at one of the longhouses

Photo D: Okra for sale at one of the longhouses that I visited.

In summary, the purpose of this initial exploration of vegetable sales has been to demonstrate the fundamental role of accessibility in agricultural commodity production and to verify von Thünen's essential point that travel cost matters in determining agricultural incomes - all other things being equal. Next I am going to explore the relationship between accessibility and sales of these other (nonvegetable) commodities. The sampled households also sell commodities other than vegetables. This includes produce from their hunting and gathering (17 households), fishing (7 households), rubbertapping ( 5 households), farming ( 2 household), and poultry rearing ( 2 households) activities ${ }^{71}$. Due to the nature and demand for these commodities (e.g. rubber, fish, wild boars), participants usually sell them at Kapit Town. These commodities fetch higher prices if sold in a larger market. For example, at the time of the interview, two fish species Empurau (Tor tambroides species) from Batang Baleh can fetch up to RM130 a kilogram, and semah (Tor duoronensis) is between RM50-RM100 per kilogram. Both are among the most expensive, but highly sought after fish species, which are indigenous to the

\footnotetext{
${ }^{71}$ If they are unable to sell their catch in Kapit Town themselves, there are no shortage of middlemen who would buy the fish from them ${ }^{71}$.
} 
area. Respondents who were fishermen reported that they can catch between 20 to 30 kilogrammes of fish per trip, and usually sell up to 400 kilogrammes a month.

Figure 5.6 shows the relationship between proximity to Kapit Town and the income from the sales of commodities - which shows there is indeed a negative relationship between accessibility to Kapit Town and income from commodity sales. Households that are located further away from the market, tend to have lower income from commodity sales.

Figure 5.6: Relationship between income from commodity sales and accessibility to Kapit Town, at household level, 2014

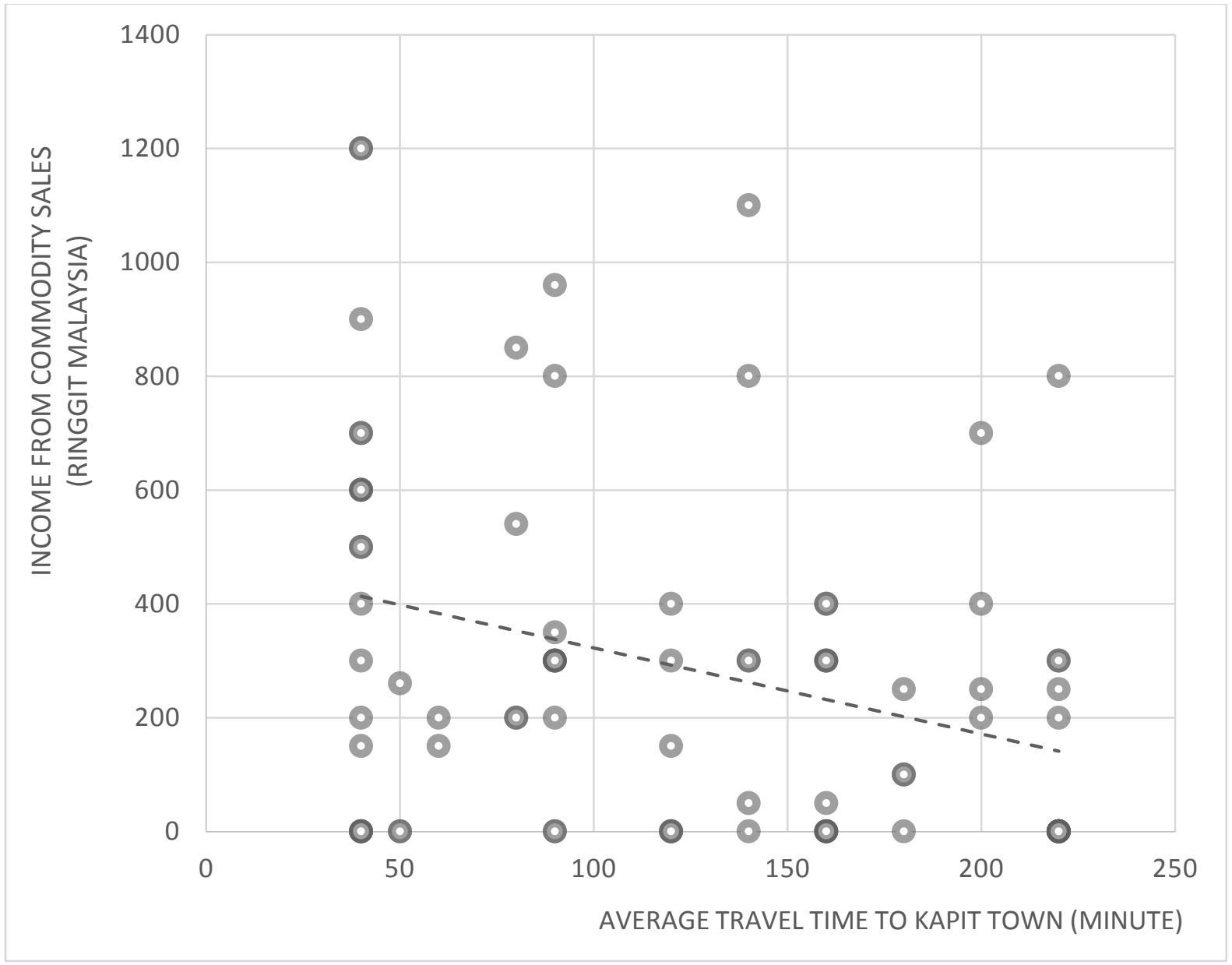

Source: Field notes

Note: Fitted regression line is $y=-1.5115 x+473.93$, and $R^{2}=0.1051$

In this instance, the average monthly income from commodity sales in the three accessibility zones, A1, A2 and A3 was RM430, RM206 and RM208 respectively. Therefore, the average income from commodity sales in $\mathrm{A} 1$ was nearly double that of $\mathrm{A} 2$ or $\mathrm{A} 3$ due to their proximity to Kapit Town. Unlike those in $A 1$, the participants in $A 2$ and $A 3$ lamented the fact that their limited access to Kapit Town 
made it more difficult for them to sell commodities. Express boat operators, for example, charge them higher fare if they are bringing commodities to market (e.g. extra charge of RM1-5 depending on item brought by passengers or RM5 per box of item regardless of weight). A number of respondents in both zones explained how limited access to market (coupled with fluctuating commodity prices in the case of rubber) had discouraged them from active involvement in commodity cultivation.

If we look at the relationship between average travel time to Kapit Town and income from commodity sales alone, we might miss the variations that might exist in the relationship between commodity income and accessibility. The income variation across households is due largely to the types of commodities the household sells, the volume of commodity sold, their chosen market and their accessibility to Kapit Town. Bilik-members of a household sell different types of commodity, and the commodities are also sold at different markets (not necessarily Kapit Town). Nonetheless, all are subjected to the price accessibility effects.
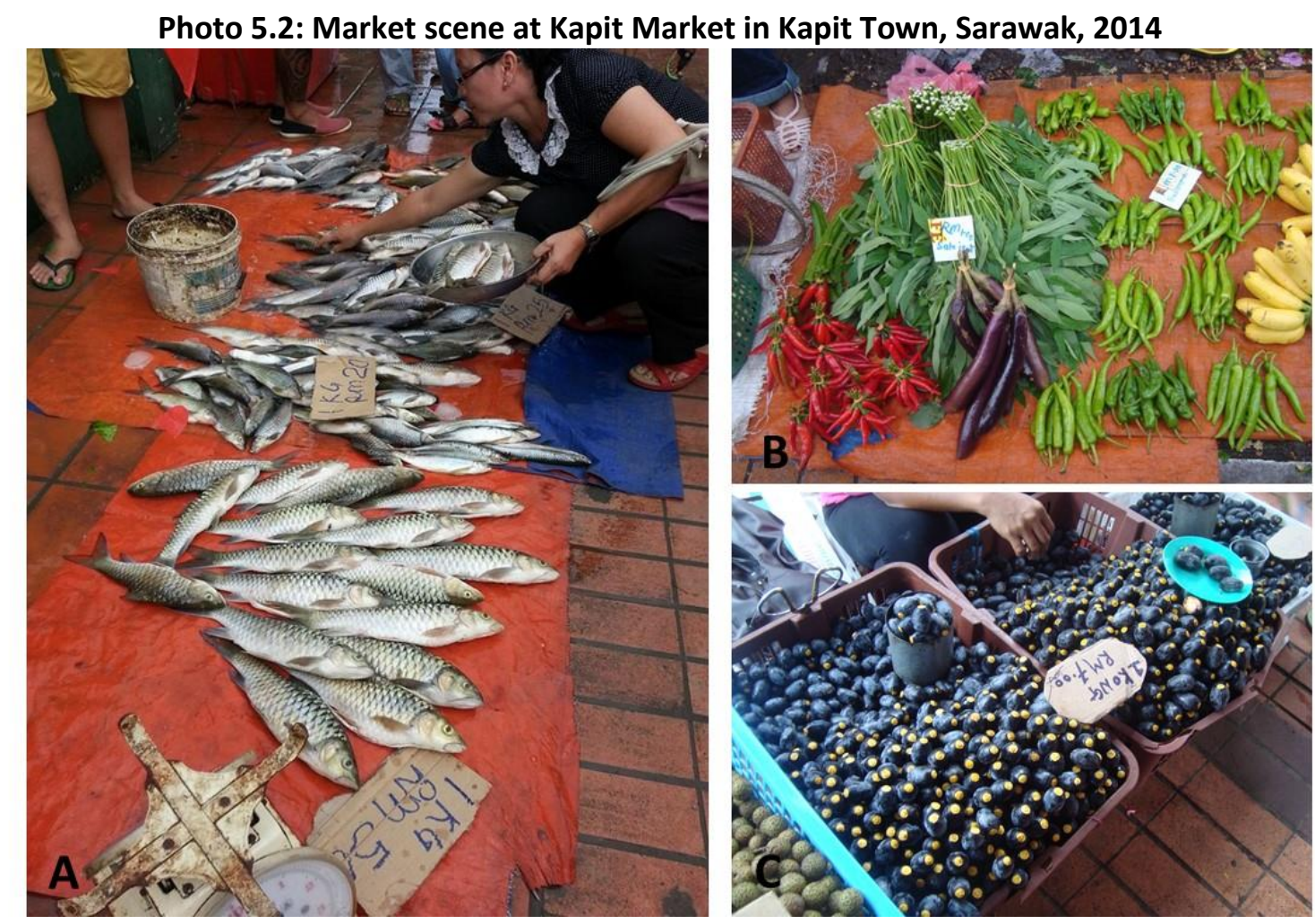

Photo A: Semah fish (selling price RM50 per kilo) Photo B: Various vegetables sold at Kapit Market Photo C: Dabai (Canarium odontophyllum), a seasonal fruit native to Sarawak, is one of the highly sought after delicacy. 
In summary, as the von Thünen model was designed to demonstrate, earnings from market gardening respond to market access. Respondents who participate in market gardening do so because of their proximity and comparative ease of access to Kapit Town. By contrast, respondents from A2 and A3 face higher costs of travel (both financially and in time taken to travel), which render market gardening unprofitable. These results were consistent with J Windle and Cramb (1997, p. 50) who observe how the size of the market and proximity to access road influence food crop production, and consequently family income in their case study of a few villages in Betong and Padawan in Sarawak. A similar conclusion was reached by Wong (2005) in her research into market gardening as a livelihood strategy in Kapit (Wong, 2005).

Clearly if commodity sales were a household's only source of livelihood, few households could live beyond the agricultural margin - and certainly not at standards that they aspire to. This raises the questions as to how such households do survive in areas beyond the agricultural margin.

\subsubsection{Relationship between in-situ income and proximity to Kapit town}

Income from commodity sales is not sufficient to support most households at any distance from Kapit Town. Therefore, the households' sources of income had to be diversified. Rural households are forced to obtain income from several sources. Similar observations were made by Morrison (1993) in his study of Iban households in the Kemena basin, in Bintulu District, where he identified five income sources that made up a household's total income: food production, off-farm work, remittances, rent (from land) and cash cropping. In Kapit District, however, there is a noticable absence of cash-cropping (i.e. pepper) and rental of land, largely due to its inaccessibility.

In order to be reflective of the current economic situation in Baleh river basin, I employed in-situ income as a development indicator. In-situ income refers to combined income earned by members of the household residing in their ancestral home (i.e. at the longhouse). By using the term in-situ, I am deliberately excluding remittance and income of non-resident bilik members.

Figure 5.7 below shows the pattern of household in-situ income by average travel time to Kapit Town and, for comparison purposes, income from commodity sales. The relationship is no longer negative but positive implying that the further away the settlements are from Kapit Town, the higher their level of in-situ income. This pattern is quite opposite to the relationship between commodity income and accessibility. 
Figure 5.7: Relationship between average travel time to market, income from commodity sales, and in-situ income at village level, Baleh river basin, Sarawak, 2014

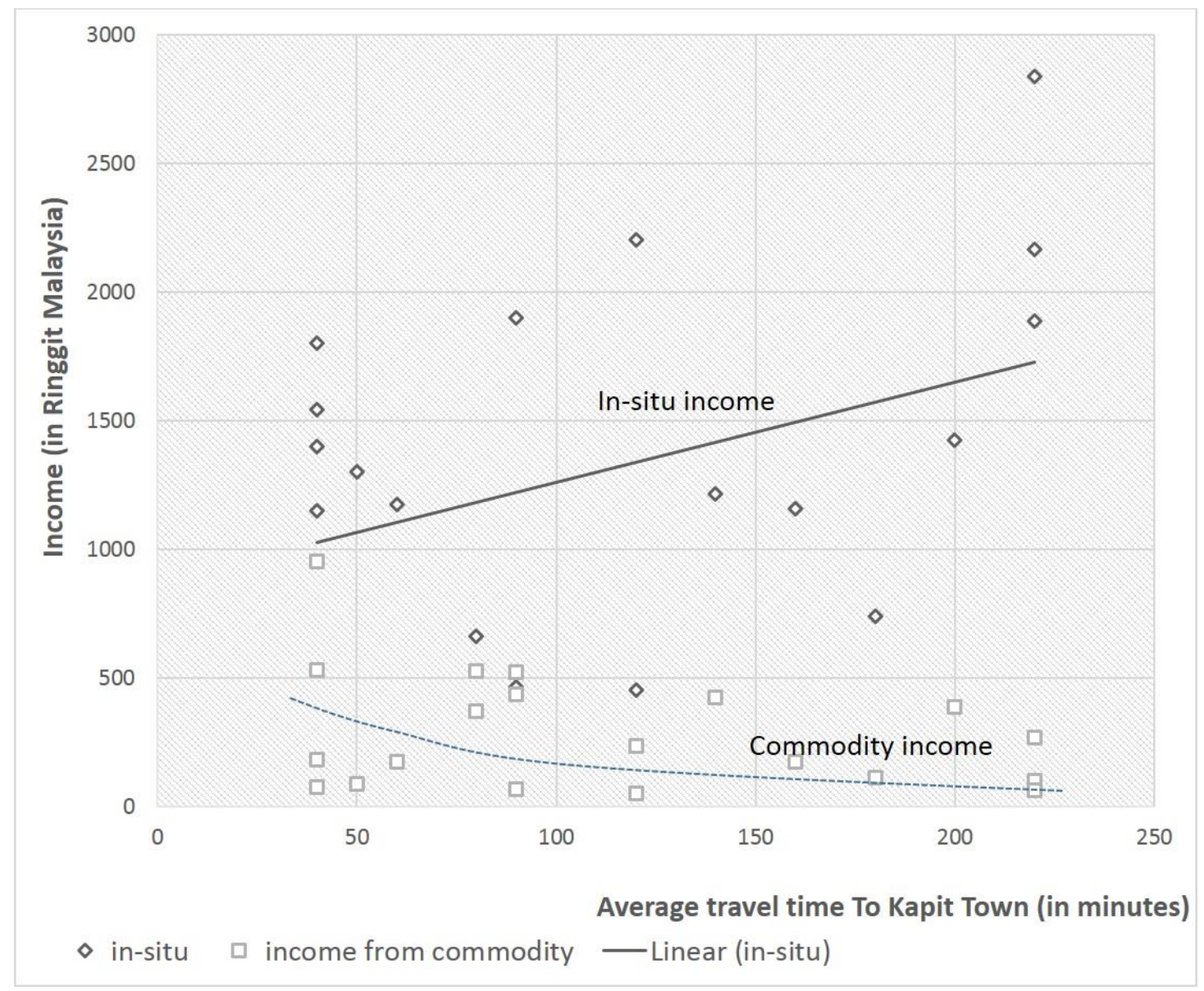

When it comes to in-situ income, households in the low accessibility zone (A3) have a higher average in-situ income level than those in A1 and A2; approximately RM1550 in A3 compared to an average of RM1317 and RM1106 in A1 and A2 respectively.

According to interviews with the tuai rumahs, the primary non-commodity source of income is wage and/or salary (45\%) and hill rice (40\%). Clearly settlements which are located further away from town were more dependent on wages and salaries. Six (out of seven) settlements in A3 indicated their main income source was wage and salary compared to only one settlement in A1 and two in A2. The respondents in $\mathrm{A} 3$ are mainly wage earners because they are mostly employed in timber industries located at close proximity to their longhouses. 
There is also greater variation between settlements in average in-situ income in A3 than the other two zones, as shown in Figure 5.8. This variation exists due to the different combinations of incomegenerating strategies adoped by the different households in different settlements within the same zone. In $\mathrm{A} 3$, there are households which consist of only two or three elder members and only one person breadwinner in the family. At the same time, there are larger size and younger households with several family members earning income for the bilik. Differences in household size and age of individuals, therefore, play a role in determining the variation in in-situ household income within the accessibility zones.

Figure 5.8: Average in-situ income by accessibility zone, Baleh river basin, Sarawak, 2014

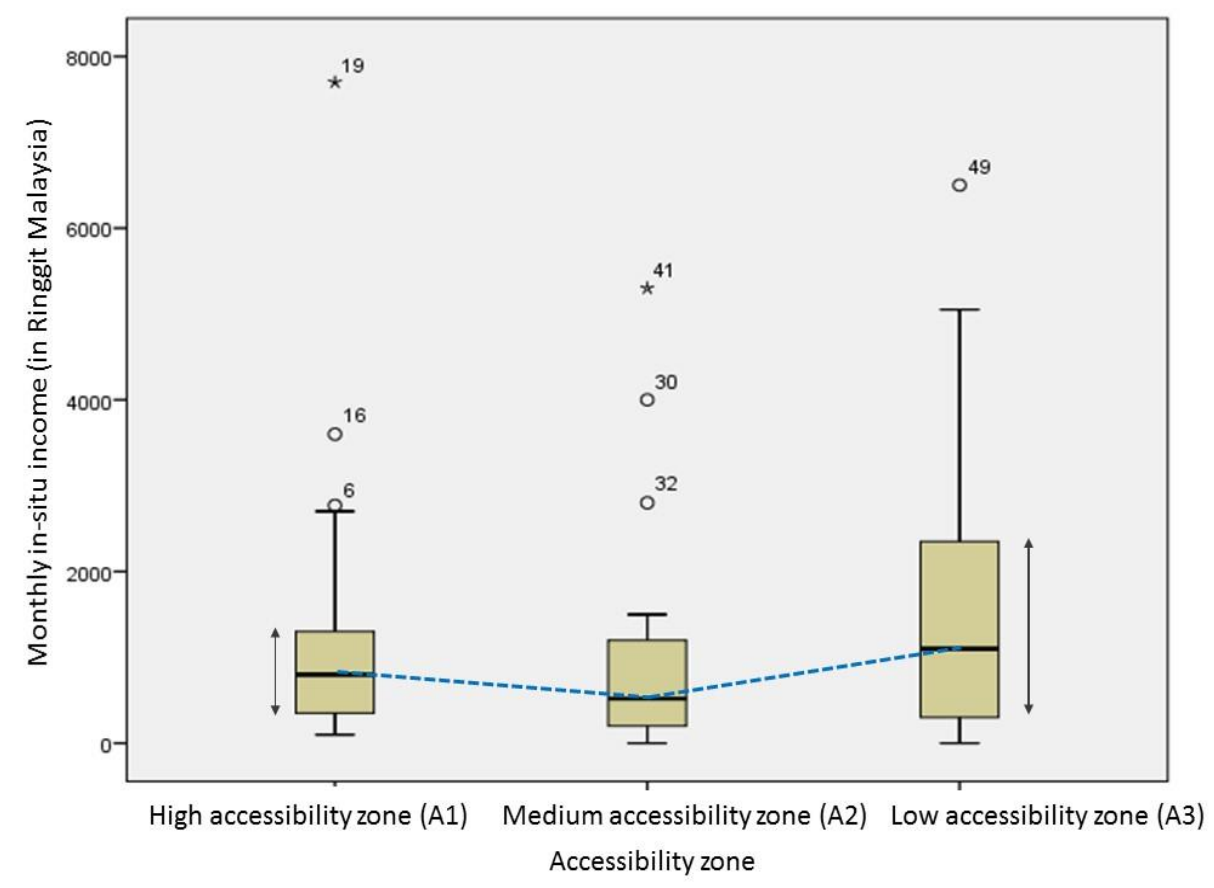

Notes: In-situ income is a combined income earned by members of the household residing in their ancestral home (i.e. at the longhouse) and it excludes remittances.

Number refers to the household numbers as mapped in Figure 5.9

Figure 5.9 extents the analysis of in-situ income by plotting in-situ income against accessibility. As accessibility to Kapit Town increases, the level of in-situ a household's income decreases. The reason is that most settlements in $\mathrm{A} 3$ are located closer to logging camps, which have been in operation since late 1960s and early 1970s. These logging camps offer continuous employment opportunities to mainly man from local longhouses. This source of income is not available in the medium accessibility zone (A2). 
Figure 5.9: Relationship between in-situ income and accessibility to market at household level, Baleh river basin, Sarawak, 2014

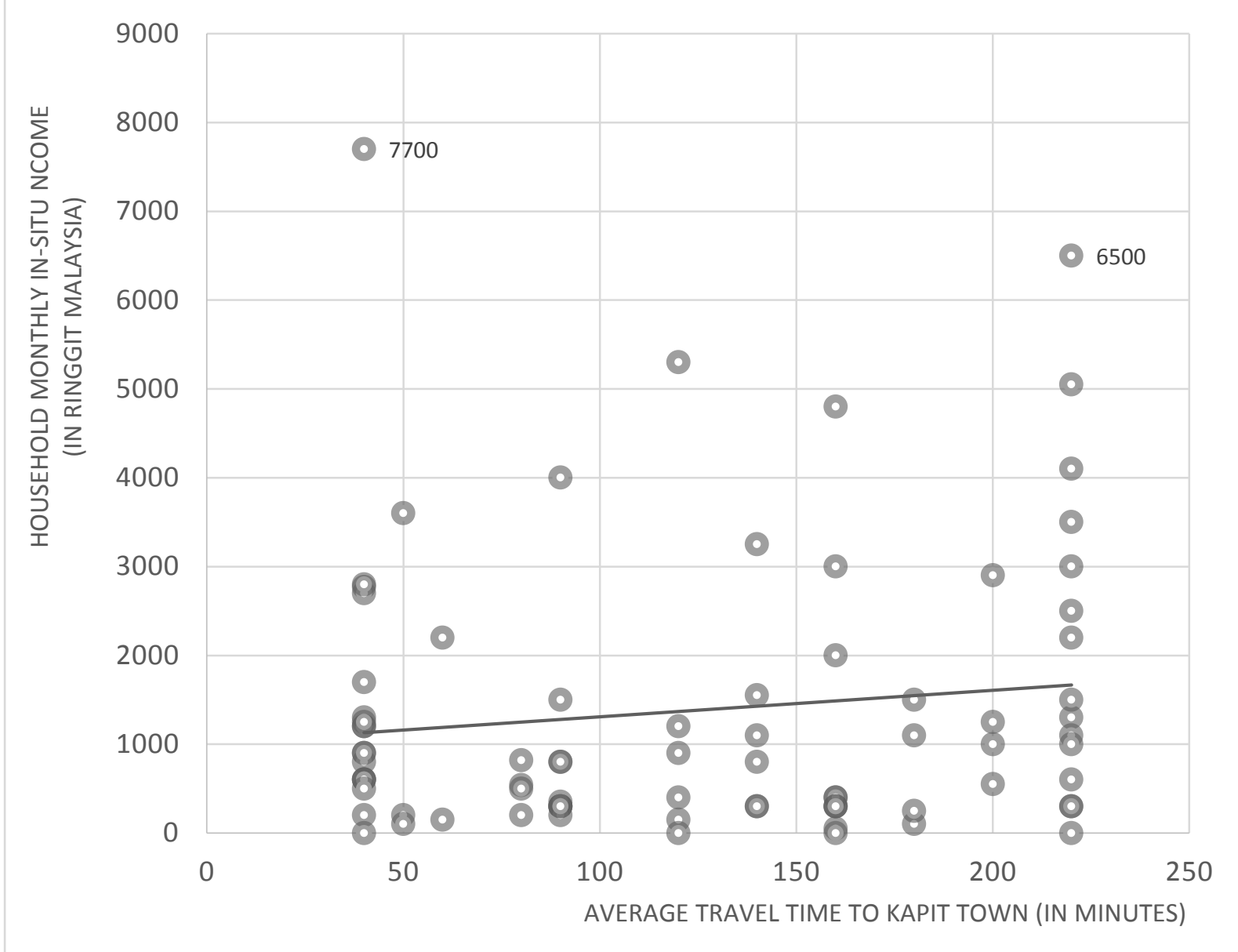

Source: Field notes

Note: Fitted regression line is $y y=2.9854 x+1010.5$, and $R^{2}=0.0162$

Of the 82 households, 14 heads of households indicated timber-related job as their main source of income. A total of 38 households have bilik-member(s) working in timber industry as their main occupation. A great majority of the individuals who worked in the timber industry hailed from A3, where approximately 64 percent of heads of household in A3 indicated that their main income came from timber-related employment. About 45 percent of households in A3 has bilik-member(s) working in similar capacity.

The outliers shown households with higher than average income. For example, Household No.49 in A3 has an average monthly in-situ income of RM6500, derived from three income sources, while Household No.19 has a monthly in-situ income of RM7700, which is the combination of monthly income from three different bilik members. Both outliers were between four to six times higher than their zone's average. 
A number of respondents also indicated they were also involved in part-time employment, in various capacities, with timber companies in their locality. One of these jobs is known as 'log rafting' (transporting logs to town via the river when the river level is too low for the barge to go upriver). Their pay is based on the tonnage of logs they transport to Kapit Town where the barges are waiting to transport the logs outside the District. This activity is only carried out when the water level is too low for a barge to go upriver to upper Baleh. The task is usually carried out by two to three individuals, and they can earn an average between RM800 - RM1200 per trip (a trip that usually takes two days). This type of job is demand-based and seasonal, and the timber companies usually offer them to those who are experienced and live within close proximity to the camps.

Other markets can take many forms, and do not necessarily involve selling products. In this example, settlements in A3 draw higher income due to the proximity of labour markets. Morrison (1993), in his study of rural Iban community in Kemena, Sarawak found that, in early 1990s, there was a substantial allocation of household labour force from farm to non-agricultural work. He argued that his participants were increasingly relying on off-farm employment (including in logging operations) as they were not able to rely on just agricultural sources. Thus, surplus farm labour was diverted into non-farm activities - similar to what is experienced in Baleh river basin.

I analysed the different relationships between accessibility to Kapit Town and the average in-situ income per worker in a household, i.e. that is the in-situ income of a household divided by the number of working bilik-members. The results shown in the following Table 5.2 and Figure 5.10 show that there are differences between average in-situ income per household and in-situ income per worker. 
Table 5.2: Average monthly in-situ income per household and per worker at household level, by accessibility zone, Baleh river basin, Sarawak, 2014

\begin{tabular}{|c|c|c|c|}
\hline Longhouse & $\begin{array}{l}\text { Accessibility } \\
\text { Zone }\end{array}$ & $\begin{array}{c}\text { Average in-situ income per } \\
\text { household (in Ringgit Malaysia) }\end{array}$ & $\begin{array}{l}\text { Average in-situ income per } \\
\text { worker (in Ringgit Malaysia) }\end{array}$ \\
\hline 1 & $\mathrm{~A} 1$ & 1150 & 725 \\
\hline 2 & A1 & 1544 & 469 \\
\hline 3 & A1 & 438 & 300 \\
\hline 4 & A1 & 1175 & 588 \\
\hline 5 & A1 & 1300 & 1267 \\
\hline 6 & A1 & 1800 & 676 \\
\hline 7 & $\mathrm{~A} 2$ & 370 & 185 \\
\hline 8 & $\mathrm{~A} 2$ & 1900 & 1233 \\
\hline 9 & $\mathrm{~A} 2$ & 1400 & 2325 \\
\hline 10 & $A 2$ & 467 & 283 \\
\hline 11 & $\mathrm{~A} 2$ & 450 & 250 \\
\hline 12 & $\mathrm{~A} 2$ & 660 & 262 \\
\hline 13 & $A 2$ & 2200 & 1100 \\
\hline 14 & $\mathrm{~A} 3$ & 1888 & 1075 \\
\hline 15 & A3 & 1425 & 712 \\
\hline 16 & A3 & 1217 & 725 \\
\hline 17 & $\mathrm{A3}$ & 2167 & 1750 \\
\hline 18 & A3 & 1155 & 795 \\
\hline 19 & A3 & 738 & 600 \\
\hline 20 & A3 & 2838 & 1138 \\
\hline
\end{tabular}

Based on interview with head of households, June 2014

When it comes to individuals, there is a negative relationship between accessibility to Kapit Town and the average incomes. Average in-situ incomes per worker rise from RM646 to RM786 to RM923 in A1, $A 2$ and $A 3$ respectively. What is equally striking, however, is the variation among individuals within households. In A1, the average household in-situ income per worker ranges from RM185 to RM2325, while average in-situ income per household ranges between RM370 to RM2832. This result implies a greater difference in income between individuals compared to households. One finds the same patterns in all three zones. 
Figure 5.10: Relationship between in-situ income per worker and accessibility to Kapit Town, at household level, Baleh river basin, Sarawak, 2014

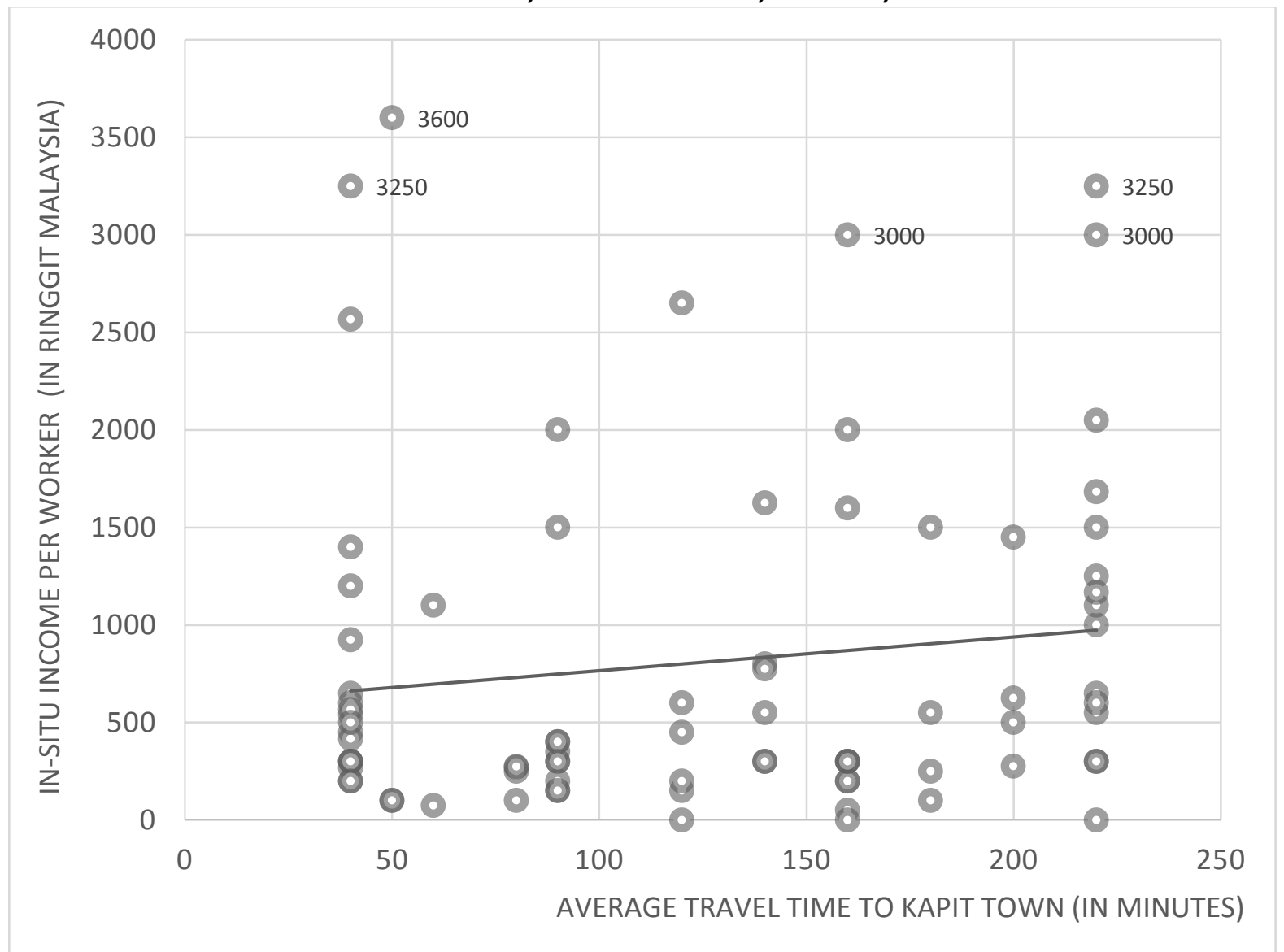

Source: Field notes

Note: Fitted regression line is $y=1.7226 x+593.85$, and $R^{2}=0.0177$

Based on the above chart, there are five households with an average income per worker of RM3000 or more. Three out of the five are households with only one worker (with a monthly income of RM3600 in $\mathrm{A}^{72}, \mathrm{RM} 3000$ in $\mathrm{A}^{73}$, and another RM3000 of a dual residency status ${ }^{74}$ ). Meanwhile the other two households with an average in-situ income per worker of RM3250 has two workers per household (one each in $\mathrm{A} 2$ and $\mathrm{A} 3$ ).

In summary, these descriptions highlight the role that non-commodity markets play in terms of influencing 'development', and also showing how development levels vary between, and within, households. However it is not just income from the local labour markets that make a difference.

\footnotetext{
72 This individual receives a monthly pension as well as additional income from his current salaried job.

${ }^{73} \mathrm{He}$ works two jobs, on as a timber camp worker and as a part-time fisherman (earning between RM1000-1500 a month from fishing.

${ }^{74}$ She was a farmer before practicing dual residency in Kapit Town. She earns RM3000 a month from running her own tailoring business, which, according to her, is a great improvement from her income from farming (before practicing dual residency).
} 
Beyond that, there are people who are working at more distant location who remit some of their earnings back to the family. These addition further qualifies the role of accessibility.

\subsubsection{Relationship between remittances and proximity to Kapit town}

Another type of income source in the case study area, which is common in households with elderly parent(s) and/or families left-behind by migrating spouse, is remittances. Approximately 59 percent of the households in the case study area receive remittances from bilik members who are working and/or living away from the longhouses. Sixty eight percent, 41 percent and 62 percent of households receives remittance in $A 1, A 2$ and $A 3$ respectively.

Figure 5.11 shows that there is a negative relationship between accessibility to Kapit Town and the monthly remittances received by bilik-members at household level. Remittances received in areas nearer to Kapit Town are higher than that of the areas located further along into the interior of Baleh. However there is no theoretical reason for expecting this pattern and I addressed the two outliers. The first outlier is LH2 (in A1) with an average monthly cash remittance of RM1100 and the second outlier is LH11 (in A2) with an average remittance of RM733. These outliers exist because of a single household in these two longhouses receives a particularly large amount of monthly remittance. The head of household in A1, for instance, receives a total monthly remittance of RM3500 a month from his two sons - one working in Republic of Congo and the other within Sarawak.

Figure 5.11: Relationship between remittance and accessibility to market, at village level, Baleh river basin, Sarawak, 2014

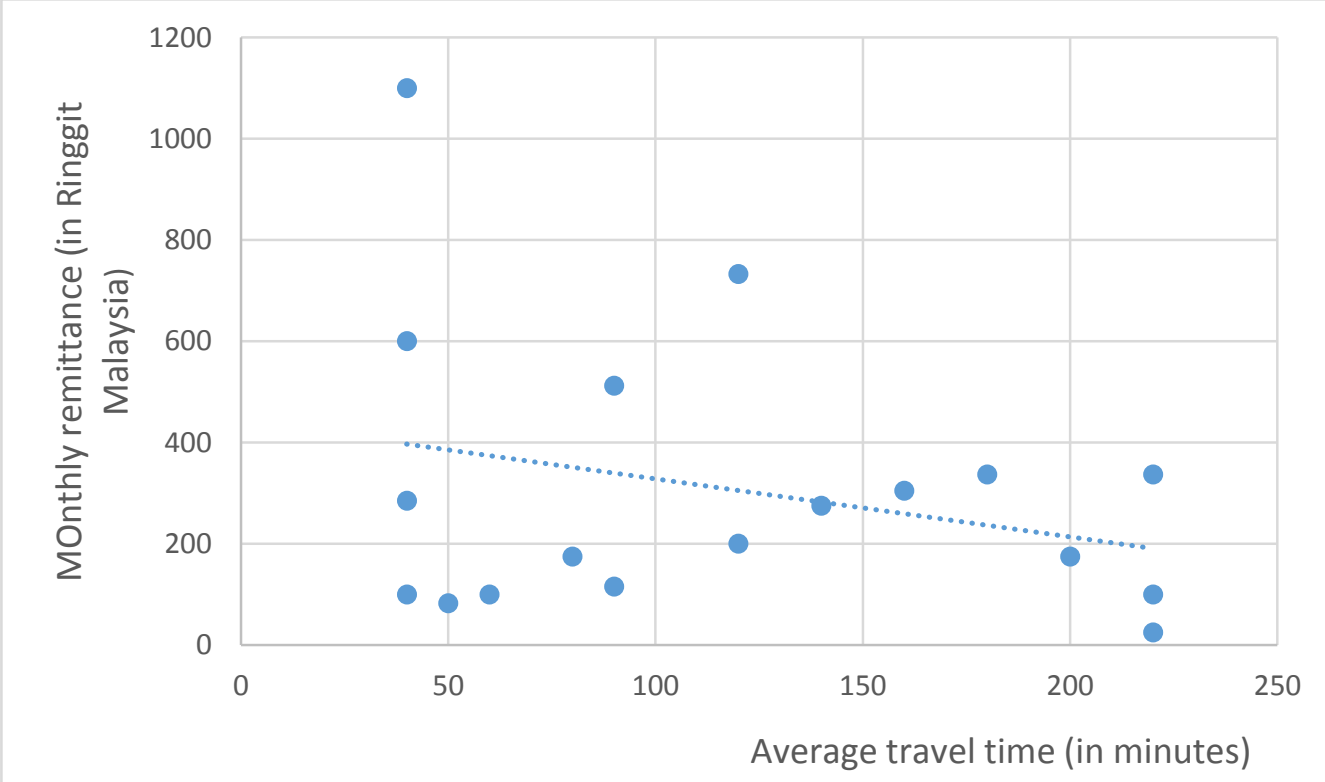

Source: Field notes

Note: fitted linear regression line is $y=-1.1453 x+443.03$, and $R^{2}=0.0812 ; n=18$ 
The same relationships between accessibility to Kapit Town and remittance at village level, but without the two outliers still show a downward slope but the negative relationship is weak and nonsignificant.

Not surprisingly, longhouses which receive higher average monthly remittances have a higher number of individuals working outside of Malaysia. For example, there are five households in A1 who are working outside of Malaysia, with a minimum monthly remittance of RM1000 and a maximum of RM2000. In A3, a total of four households have bilik-members working overseas, and sending a minimum of RM200 and a maximum of RM2000 of cash remittance a month. Those who have families (i.e. wife and children) left behind in the longhouses tend to remit more (i.e. higher value) as well as more frequently.

In Figure 5.12 below shows the relationship between proximity to town with monthly cash remittance at household levels. I have taken out the five outliers, which are households with bilik-members working overseas (e.g. Republic of Congo, United Arab Emirates, and Solomon Island). Four of the five individual identified are sole remitters to their households, and each of them have families left behind in their longhouses. They send between RM200 to RM2400 to their families each month. The other outlier is a household which receives remittance totalling RM3500 from three different sources. 
Figure 5.12: Relationship between remittance and accessibility to market, at household level (outliers removed), Baleh river basin, Sarawak, 2014

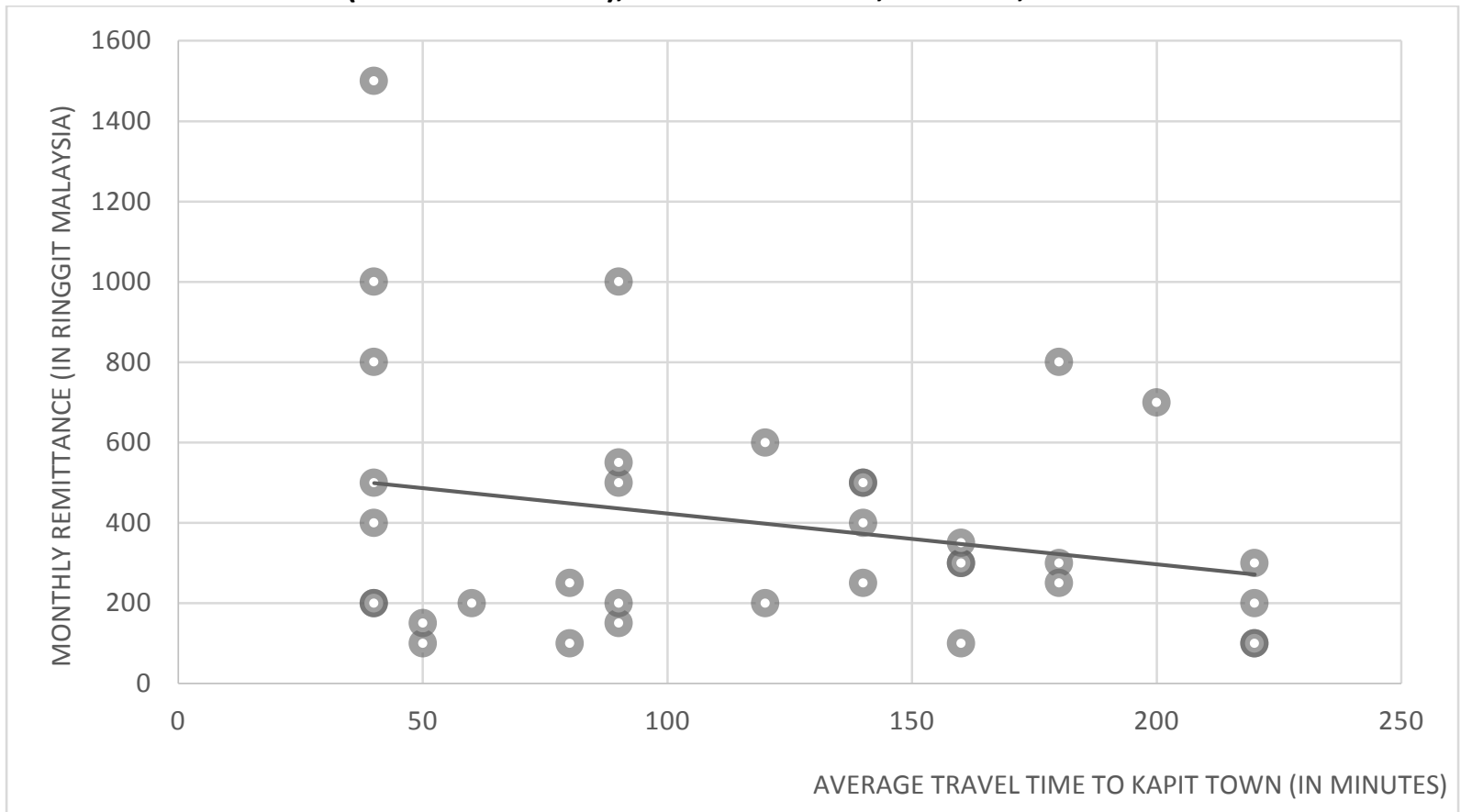

Note: Fitted regression line is $y=-1.2636 x+549.82$, and $R^{2}=0.0621$

Source: Head of Household Dataset, $N=35$

This time the figures show that as the average travel time to Kapit Town increases, the amount of cash remittance received by household decreases ${ }^{75}$. A total of 40 (out of 82 ) households receive monthly cash remittance. The number of bilik members sending remittances ranges from one to four person, with 22 households indicating one remitter and 16 household with two remitters ${ }^{76}$. The frequency of remittance tend to vary between households as well as between remitters from the same household. Twenty nine of the 40 households said that they receive monthly remittance from their bilik members, which is mainly in the form of cash banked in into their bank accounts (73\%) and cash brought home (12\%). The rest is in the form of 'in-kind' contribution and a mix of 'in-kind and cash' respectively. The number of those sending remittance via cash and in-kind seems to be similar for all three zones.

It is hard to determine the exact amount remitted. Unless it is a fixed monthly cash remittance, the head of households are not sure how much their household members are remitting especially when it is irregular or based on the number of visits made. The number of visits made is linked with accessibility, e.g. easier to go back to village to visit parents or the number of time the parents visit their children in towns are determine by their ease of movement, affordability, and needs.

\footnotetext{
${ }^{75}$ I used cash remittance for my analysis as it is difficult to calculate the value of 'in-kind' remittance.

${ }^{76}$ No difference between the number of bilik members sending remittance by accessibility zone.
} 
Analysis indicates that the average cash amount remitted monthly is approximately RM770.97, with a minimum of RM50. Nearly 58 percent of households with remittance claimed to receive up to RM500 a month, while 21 percent received between RM500 to RM1000 monthly. Most of the receiving households consist of elderly parents and/or family with young children. The family member(s) who send remittances are usually male, and working elsewhere and leaving behind parents and/or spouse at the villages. Similar finding was observed by Osaki (2003) who stated that migrants with spouse or children left behind are likely to remit more because of their families' immediate consumption needs. Migration reduces the uncertainty of a family income, provides investment funds, and contributes to livelihood for those with small plots (Osaki, 2003). Meanwhile, as noted by Oberai and Singh (1980, p.231) in their study in Indian Punjab, distance from their place of origin does not appear to loosen family ties among the migrants, and that, in general, remittances raise the incomes as well as the living standards of rural households.

Oberai and Singh (1980, p. 229) also state that the net effect of remittances on the rural economy is difficult to determine, and its effects in the level and distribution of income depend on the size and frequency of remittance. The size and frequency of remittance are influenced by factors such as type of jobs, education, and location and unequal access to opportunities. Not everyone has to the opportunities to migrate or seek work outside their place of origin. For these reasons, migration of family members can increase the level of inequality within communities, households and across individuals within households. The effects, however, vary depending on which scale of analysis is conducted. Even if remittances are relatively less important for the rich, they may still contribute to increasing inequality (A. De Haan \& Rogaly, 2002).

With that argument in mind, I made a comparison of the relationship between accessibility and in-situ income with (Figure 5.13) and without remittances (Figure 5.14). The results, as shown below, indicated that remittances do make a difference in terms of 'levelling out' the average in-situ income in Baleh river basin. If remittances are excluded from the in-situ income calculation, those in A3 seem to enjoy higher level of in-situ income than those nearer to Kapit Town. By contrast, if remittances are included in the calculation, they off-set the differences in A1 and A2. The average cash remittances received in A1, A2 and $A 3$ are RM496, RM206 and RM253 respectively. 
Figure 5.13: Average in-situ income (without remittance) at household level, 2014

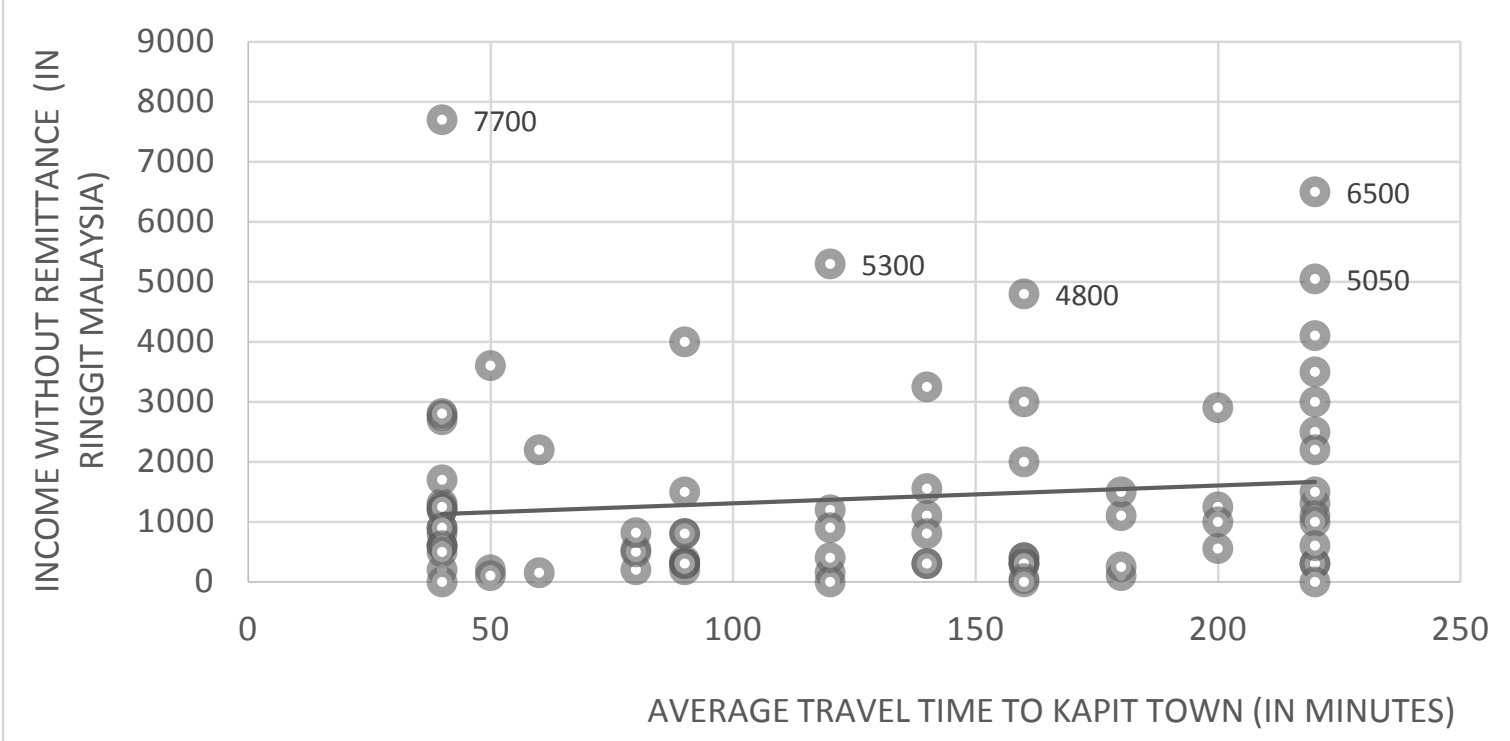

Note: Fitted linear regression line is $y=2.9854 x+1010.5$, and $R^{2}=0.0162$

Figure 5.14: Average in-situ income (including remittance) at household level, Baleh river basin, Sarawak, 2014

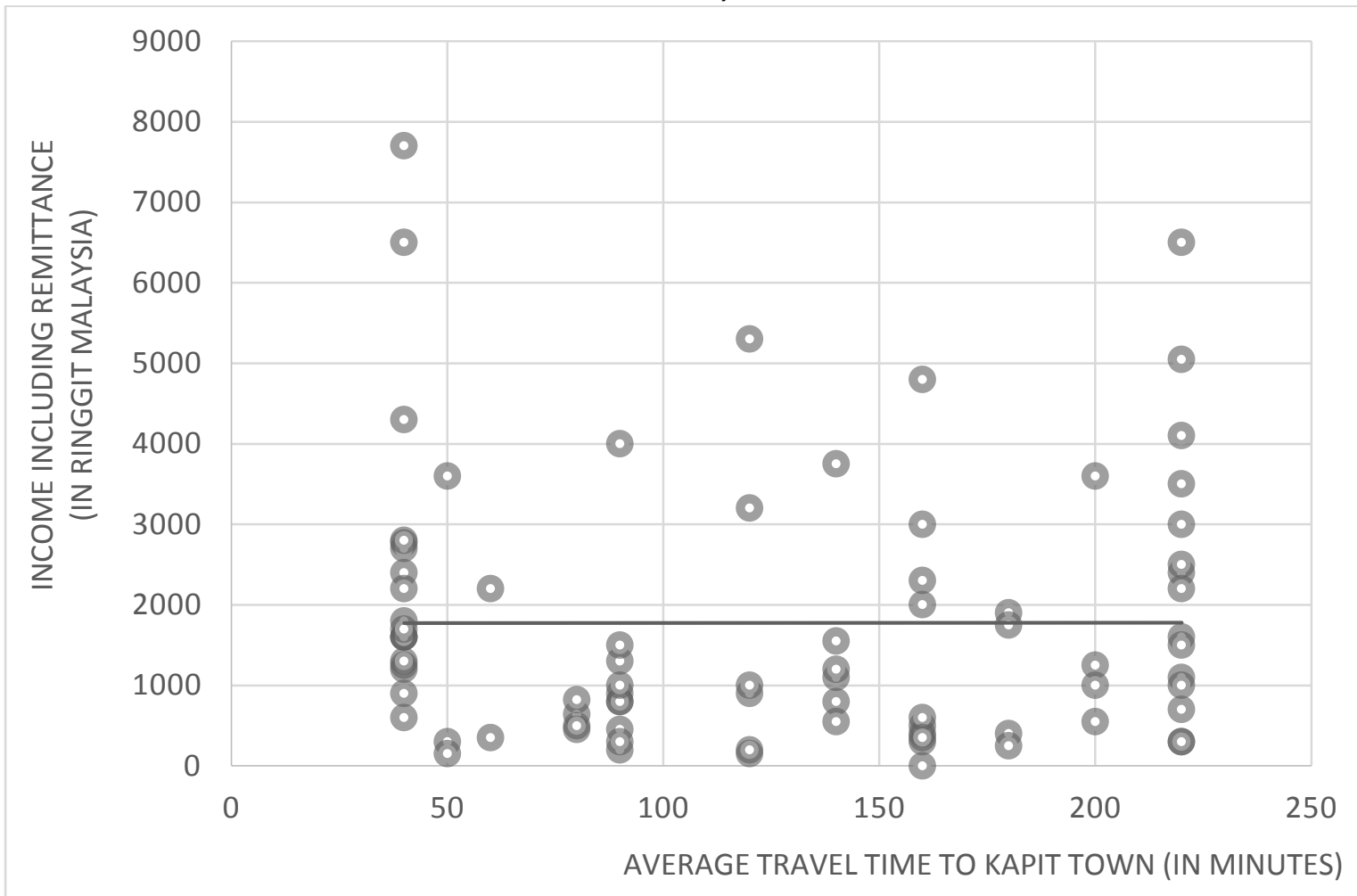

Note: Fitted regression line is $y=0.024 x+1772.4$, and $R^{2}=1 E-06$ 
The above discussions on remittances have highlighted that accessibility to one market does not necessarily influence accessibility to outliers although inaccessibility precipitate a search for other markets as is clearly the case in Baleh. It means that labour markets, which facilitate remittances, can be located anywhere outside of the longhouse boundary or outside of Kapit District. Recognising that households have members working and living outside of their villages, it is worth looking at the relationship between accessibility and development as measured by the households' total income.

\subsubsection{Relationship between total household income and proximity to Kapit Town}

Total household income refers to the combined income from all sources and all acknowledged bilikmembers regardless of their current residence. The relationship between total household income and accessibility is illustrated in Figure 5.15. It should be noted that there appear to be no relationship between these two variables.

Many family members who under 'normal' circumstances would be living in the same place are in actuality living in separate places (Fan et al., 2011, p. 2166) due to various reasons and chief among them is to gain access to employment opportunities. This discussion will be further expanded in the following Chapter Six.

Figure 5.15: Relationship between total household income and proximity to Kapit Town, at household level, Baleh river basin, Sarawak, 2014

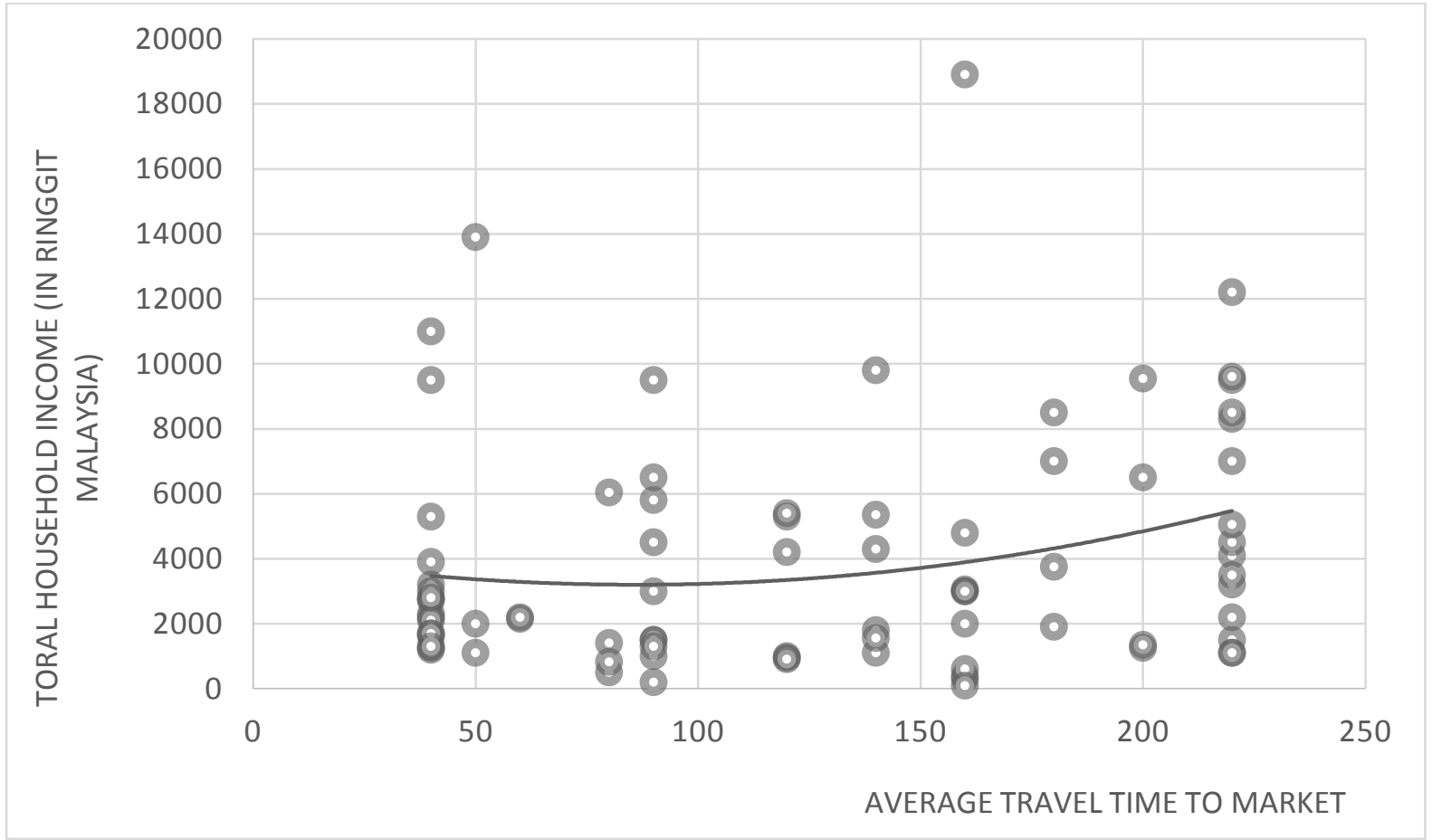

Note: Polynomial regression line is $y=0.1271 x^{2}-21.911 x+4146.7$, and $R^{2}=0.054$ 
A total of 77 households (out of 82 ) have at least one household member practicing multi-local living. The average per household is much higher in in A3. An average of eight individuals per household in $\mathrm{A} 3$ are practicing multi-local living, five in $\mathrm{A} 2$ and seven in $\mathrm{A} 1$ respectively. The figures are high as they include adult children living with their nuclear families in urban areas. A household's average level of development (i.e. total household income) is, therefore, tied up with their families' ability to access other types of markets beyond Kapit Town and Kapit District. It implies that household income is not just influenced by the availability and proximity of its local markets.

The existence of these non-local markets are, therefore, a crucial factor in retaining residents in the Baleh and Kapit District more generally and slowing down the rate of migration from the area. This point was made by Ngidang (2012) who states that employment opportunities in the logging camps provided the much needed alternative source of livelihood to the rural dwellers in the area. Instead of moving out of the District entirely in search of employment, they were able to stay in the area. This situation could change in the next few years as timber industry in the area is coming to an end and the current logging site is expected to be displaced by the proposed Baleh Hydroelectricity dam project. The implication for local families dependent on this income are as yet unclear.

\subsection{Summary}

Unlike the von Thünen model, there is more than one dominant market available to the residents of Baleh. The markets of choice or the market that is accessible to the residents vary depending on a number of factors. One of the factors is the uneven access to market at an individual, household and community level.

The situation in Baleh river basin is, therefore, quite different from the von Thünen's deliberately abstracted landscape. Those located in areas beyond the agricultural margin, which von Thünen deemed as not profitable, have in the Baleh case found smaller, local markets. Selling labour directly (e.g. to timber camps) has also been a survival strategy. So has having family members living elsewhere in larger urban centres for they remit income.

The hypothesis of this thesis was the accessibility to market would raise the level of development of the community, household and individual. I showed this was the case for vegetable sales. However most did not sell vegetables. In fact, most lived beyond von Thünen's limits of cultivation - more than an hour travel from Kapit Town. If there were no commodity sales or no income from employment at 
timber companies, life along Batang Baleh and its tributaries would be almost impossible. In order to cope with these very limited opportunities for development, at household and individual levels, the people in the area have moved to markets elsewhere. In doing so, they demonstrated that multi-local living is significant. Multi-local living is a strategy that allows outside markets to be accessed, thereby, presenting rural residence in otherwise market deficient areas like the Baleh river basin.

At the same time, as income rises and development rises, so does the level of inequality particularly among individuals and households. This is because despite having similar level of accessibility to market, household and/or individual development can vary for other reasons including their gender, age, educational attainment and socio-economic status.

However, it should be noted that income is not the only dimension of development. I only use income as a proxy for development in this chapter as income is the most measurable indicator. Furthermore, the participants themselves had identified income as one of the measure for development. However, there is a lack of statistically significant relationships between income and accessibility to market as illustrated in this chapter. This finding highlighted the existence of other significant 'factors' in the development-accessibility relationship. These factors will be explored further in the following chapters. 


\section{CHAPTER 6}

\section{Accessibility, Physical Development and Human Capital}

Aside from accessibility to market, which includes both traditional and contemporary markets, as described in the previous chapter, accessibility to services is also vital for generating higher levels of development. Accessibility to services enables communities, households and individuals to be equipped with basic inputs, e.g. skills, education and good health, which they use to produce outputs for the market. These output can be in various forms including commodities for the traditional agriculture market, labour with relevant skills for the employment market, and willing and healthy students for the education market.

This chapter explores the relationship between accessibility to services and development in Baleh river basin. In particular, the chapter will address the relationships between accessibility and three development measures: physical infrastructure development, road and telecommunication connectivity and human capital. Physical infrastructure development indicators include the availability of electricity supply and water supply, as well as proximity and availability of schools and health clinics. Description of the chosen indicators will be elaborated on later in the chapter. This explanation will be followed by discussion on inequality as a consequence of higher levels of development and accessibility.

\subsection{Accessibility to market and basic infrastructure provision}

The term 'basic infrastructure' refers to facilities and infrastructure that are considered fundamental for an area's level of development, and are the frequently mentioned elements of development in Malaysian policy on infrastructure development (Economic Planning Unit Malaysia, 2006; Naidu, 2008; PEMANDU, 2013). The following discussion covers aspects of electricity, water supply, schools, health clinics, and road and telecommunication infrastructure provision, which are among the indicators used to measure the level of development of a locality (Economic Planning Unit Malaysia, 2006; PEMANDU, 2013). The Malaysian Government recognises that infrastructure is vital for the economic development. The key aim is to provide infrastructure to promote development of the less developed regions including rural areas (Naidu, 2008, p. 208). 
In this section the aim is to test the hypothesis that there is a positive relationship between development and accessibility. Specifically the physical development score combines the presence of electricity, water supply, schools and health facilities (refer Table 4.2 in Chapter 4). The time taken to travel from settlements to Kapit Town, is used to measure accessibility to market.

The physical development score shows how well equipped one longhouse is compared to other longhouses in the study. A higher physical score means a longhouse, and by extension its community (households and individuals within the longhouse), has better access to basic infrastructure. Having electricity indicates higher levels of development, as longhouse dwellers are not restricted by daylight for their household or individual activities. As Calderón and Servén (2004) observe in their study that improved access to electricity can potentially result in better educational attainment as a consequence of increased study time.

Treated water supply is specifically used as an indicator because it denotes a higher level of development than its gravity-feed counterparts. In the Baleh river basin, very few settlements have access to treated water supply. Gravity feed water is the main water supply option for a majority of the settlements. Treated water supply means water that has been treated at one of the Sarawak Water Board's treatment plants. Therefore, it is a safer source of water.

Similarly, access to schools and health clinics is included in the physical development score, as education and good health are commonly identified contributors to human capital development. Burki and Haq (1981) in their report for the World Bank, for example, highlight how education and health are among the key elements of basic needs and that both elements play a crucial role in improving livelihood. Furthermore, a number of scholars describe human capital measures including both education and health (Nafukho et al., 2004; Ranis et al., 2000; Son, 2010). Therefore, access to both schools and health clinics are crucial indicators of development.

In summary, the physical development score that I use in this section is a combined scores for electricity, water supply, school and access to health clinic, all of which are essential indicators of development. 


\subsubsection{Accessibility and market}

I expect accessibility to markets to be positively correlated with physical development. However, a scatterplot of the two variables, does not support this simple linear hypothesis. Instead, development scores fall then rise with travel time (Figure 6.1). What was not expected was the fact that $A 3$, which is the low accessibility zone, would have to have a higher physical development score than A2 and A1. This implies that, despites its distance from the primary market, settlements in A3 enjoys better physical development than its counterparts located nearer to market.

Figure 6.1: Relationship between physical development score and travel time to market, at village (longhouses) level in Baleh river basin, Sarawak, 2014

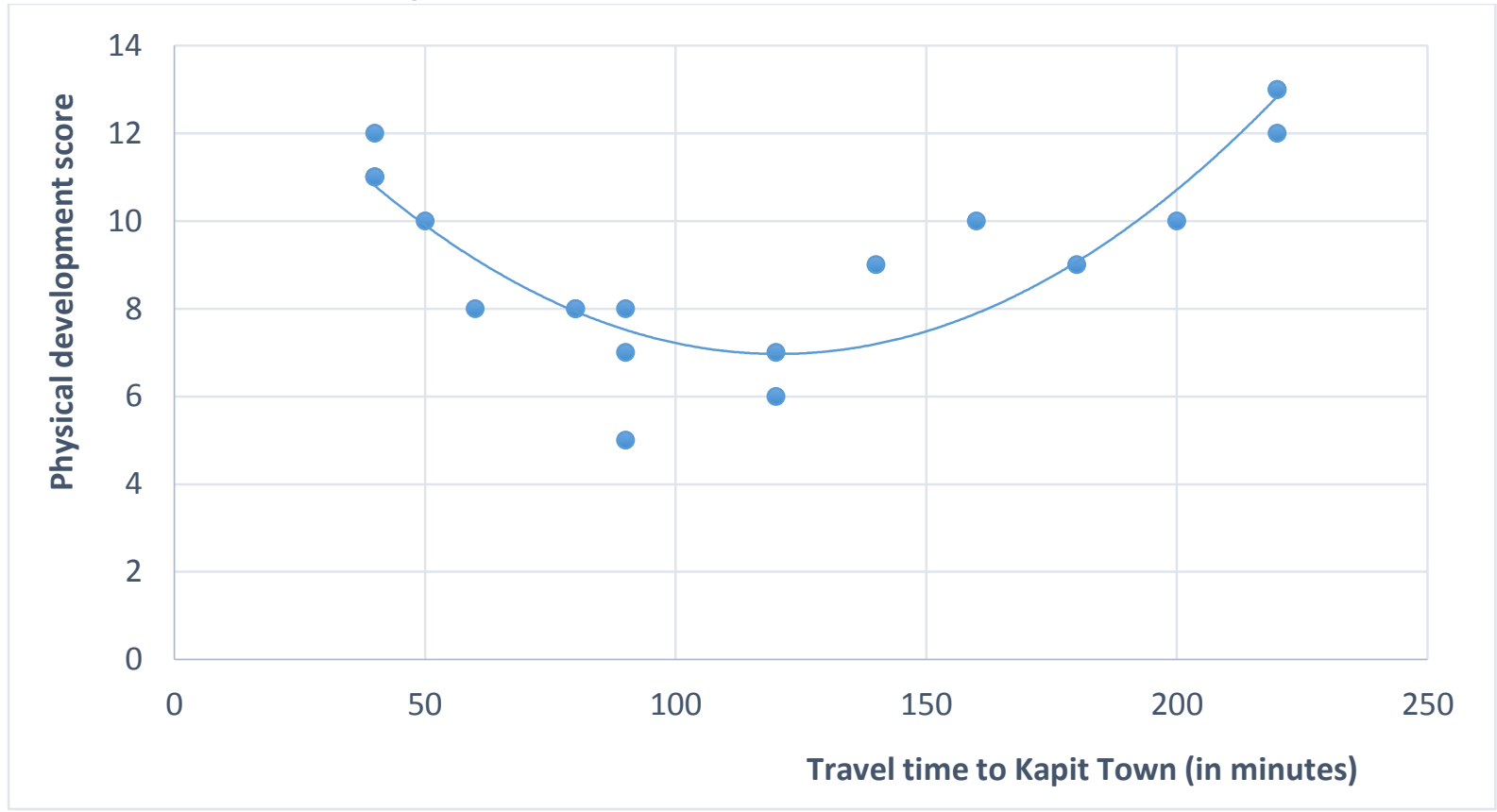

Source: Field notes

Note: Polynomial trendline, with $y=0.0006 x^{2}-0.1426 x+15.561$ and $R 2=0.8017 ; n=20$

The reason for this result lies primarily in government policy and intervention, specifically in relation to provision of rural (primary) schools and clinics. Healthcare in Sarawak, for instance, is a two-tier system which consist of a health centre, for a population of 8,000 to 10,000; and a klinik desa (rural clinic) for an area with 1,500 to 2,000 people (Chen \& Tan, 1982, p. 26). The distribution of schools is also based on the size of the population in an area. This explains why the physical development score for $A 3$, the least accessible zone, is higher than $A 2$, the medium accessibility zone. Those in $A 2$ have lower physical development score mainly because of their location - in an intermediate area between high and low accessibility zones - and, in most cases, they are categorised as being located at the periphery of the infrastructure provision margin. 
The von Thünen agricultural model describes how any changes in accessibility (transport cost) has a greater impact on land rent on the periphery (refer Chapter 3). Land rent is based on a model of the way the market works. Public provision of services is based on completely different criteria. In this case, despite their proximity to Kapit Town, compared to $A 3$, the community in $A 2$ seems to be at a disadvantage with regards to basic infrastructure development. Provision of electricity, treated water supply, schools and rural clinics is more comprehensive in A3 despite being located at the lower end of the accessibility continuum. This discrepancy can be seen clearly when we discuss the individual types of infrastructure provision later on in this chapter (refer Section 6.3).

The boxplots in Figure 6.2 show that the average physical development score higher in A1. This is expected as the settlements in a high accessibility zone often enjoy the advantage due to their proximity to the market. Nonetheless there is also some variation between settlements, e.g. in A3 more settlements have a physical development score that is lower than the zone's average score, while in A3 more settlements have higher than the zone's average physical development score. This implies that there is a wide variation within $\mathrm{A} 1$ and $\mathrm{A} 3$.

\section{Figure 6.2: Relationship between physical development score and accessibility to market, by accessibility zone in Baleh river basin, Kapit District, 2014}

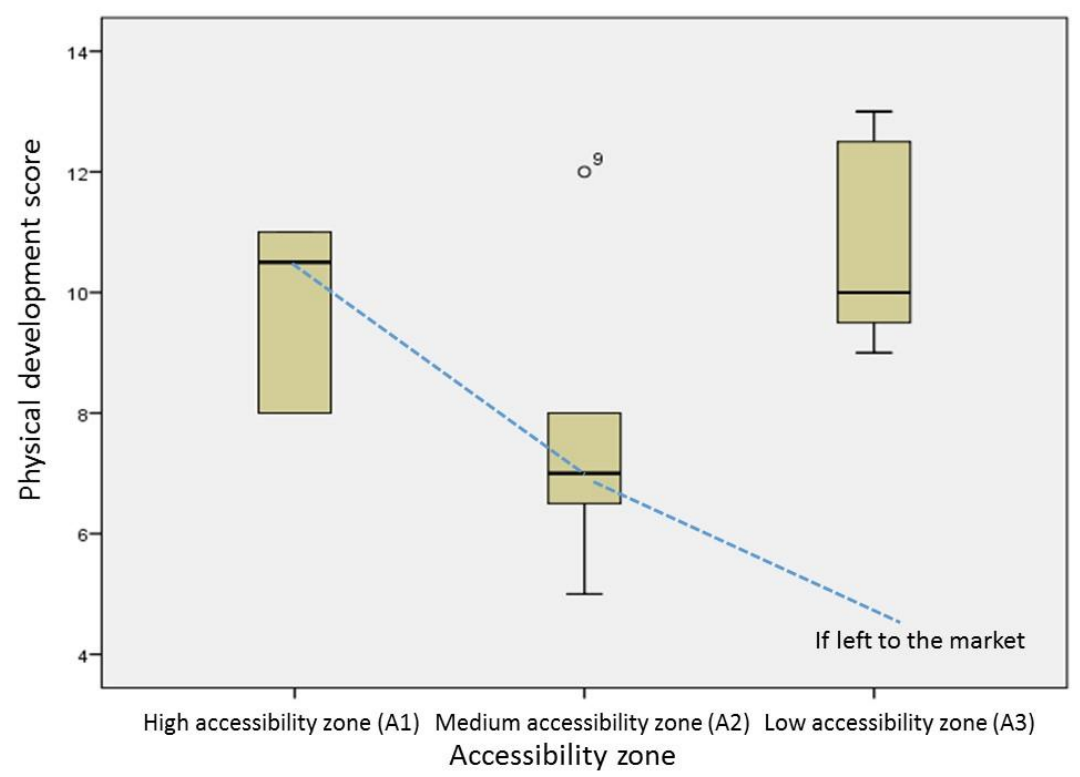

These variations indicate inequality and, to some extent, it can be argued that, if the basic provision is left to the market, the level of inequality would be bigger than portrayed below. On the other hand, 
one would expect an even development score if the provision of basic infrastructure is provided through government policy. In reality, the most remotely located longhouses are well equipped with electricity and treated water supply. The rest of the villages in the same accessibility zone, however, do not enjoy the same level of service. This difference in the provision of basic facilities creates a disparity between the physical scores of longhouses in the same accessibility zone (as illustrated in Figure 6.2 above).

In A1, a significant differences exists between villages due to the closure of a clinic at one of its tributaries. The clinic at Nanga Bena, which is approximately 30 minutes to most settlements in its area, was closed in 2010 due to soil erosion and has not been re-opened. This closure means that villagers in the surrounding area have to go to Bletih Polyclinic in Kapit Town for their medical needs. The travel time for villagers in Sungai Sut area to Kapit Town is between 50 minutes to one hour and half hour, depending on their location and mode of transport. The location of the clinic at Nanga Bena and its approximation of service area is highlighted in Map 6.1.

\section{Map 6.1: Location of clinic facilities in Baleh river basin, Kapit District, Sarawak, 2014}

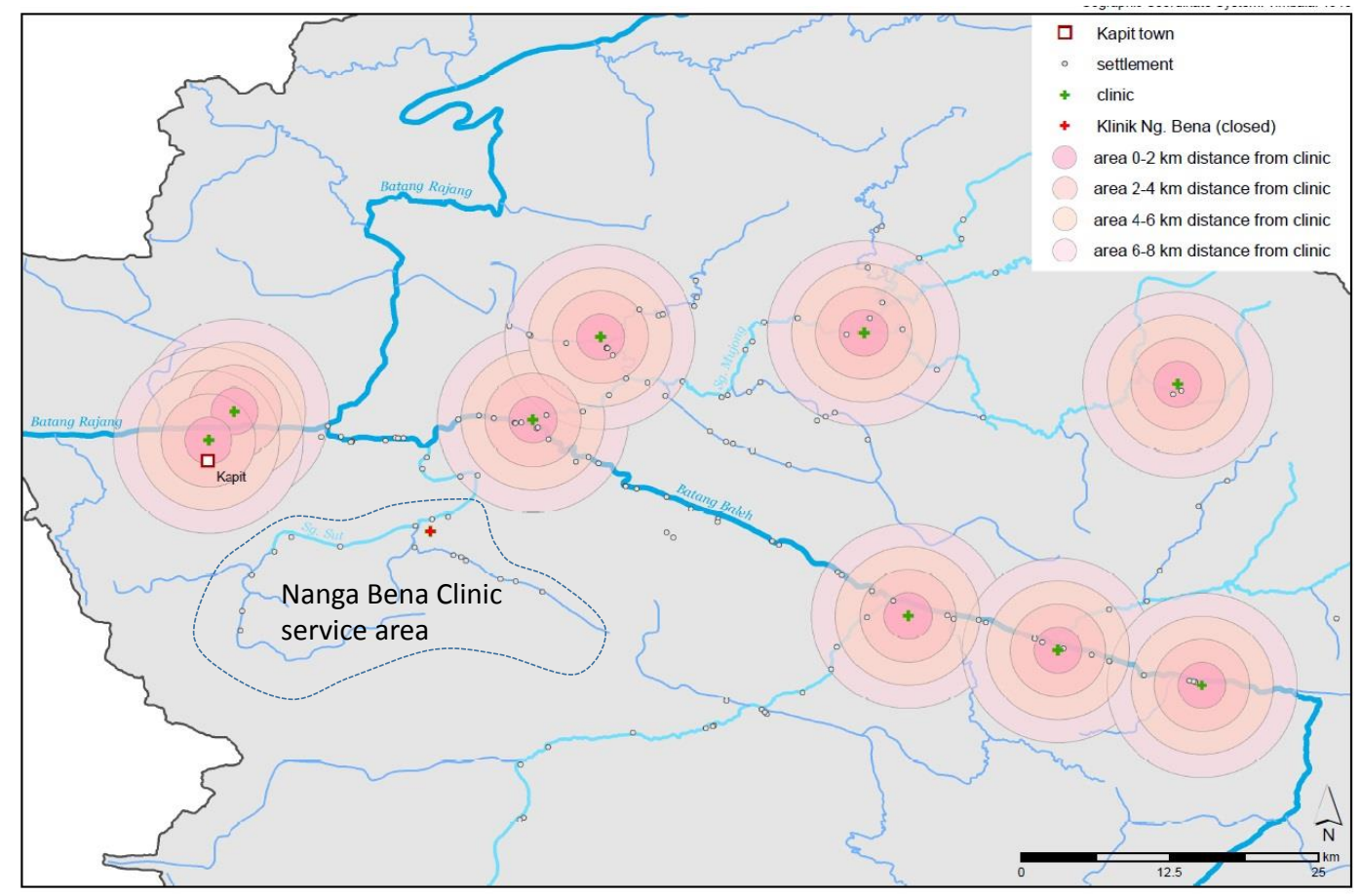

Source of base map: Series MY91001R, Edition 1-PPNM, Department of Survey and Mapping Malaysia, 2010

Note: Euclidean (straight-line) distance is used in the map in order to standardise the data. The complexity surrounding accessibility and mode of travel makes it hard to model the distance individually (i.e. real distance), and, therefore, l opt to use this method instead. 
In summary, variations do exist between settlements in the same zone as well as within the different accessibility zones in terms of basic infrastructure provision despite State's intervention. I now turn to discuss the relationship between accessibility with another indicator of development which is more comprehensive.

\subsection{Accessibility to market, basic infrastructures and connectivity}

A more comprehensive development indicator combines the scores of road connection and mobile coverage with the physical development score. I categorised road connection and mobile coverage separately from the other four facilities (identified in Section 6.1 above) because electricity, water supply, schools and health clinics, have been identified by respondents themselves as the key elements in their definition of physical development (refer Appendix 3: Section 4). Furthermore, those four facilities have consistently been 'packaged' together in both State and Federal policies and plans. The connectivity elements, which refer to facilities that enable connection between zones or locations, although they are important, are not perceived as the top priority by a majority of the older respondents but the younger respondents argue that road connection and mobile coverage were significant and should be considered. I tried to reflect their perceptions on 'what is development' by separating these variables in my analysis.

The augmented physical development score, combines the basic infrastructure (electricity, water supply, school, health clinic) with road connection and mobile coverage. Road connection is widely used as an indicator of how 'developed' an area is. Having direct road connection or partial road connection is expected to have different effects on development at community, household and the individual level as covered in the literature review, Chapter Two. Mobile coverage is a new infrastructural element which needs to be accounted for when considering levels of rural development (Kwan \& Weber, 2003; Warren, 2007). This is because information and communication technologies, including mobile phones, now play a significant role in rural life, and, in many cases, can be an income generating asset for the rural household and the community.

The scatterplot in Figure 6.3, which shows the relationship between the augmented development score and accessibility has a similar pattern to Figure 6.2. Both development scores (augmented and non-augmented) of the two variables, do not support the simple proposition that development falls with accessibility. Figure 6.3 shows how the development score falls then rise with average travel time to Kapit Town, as well as how settlements in the high accessibility zone, A1, are now showing almost 
similar augmented scores to the low accessibility zone, A3. This rise in score for A1 is attributed to road connection and mobile coverage, which is available in A1 but not in A3. This implies that the nearer to market (i.e. Kapit Town), the higher the connectivity scores, that is, the two aspects of accessibility are interrelated.

Figure 6.3: Relationship between the augmented score for physical development and average travel time to Kapit Town, by villages (longhouses) in Baleh river basin, Sarawak, 2014

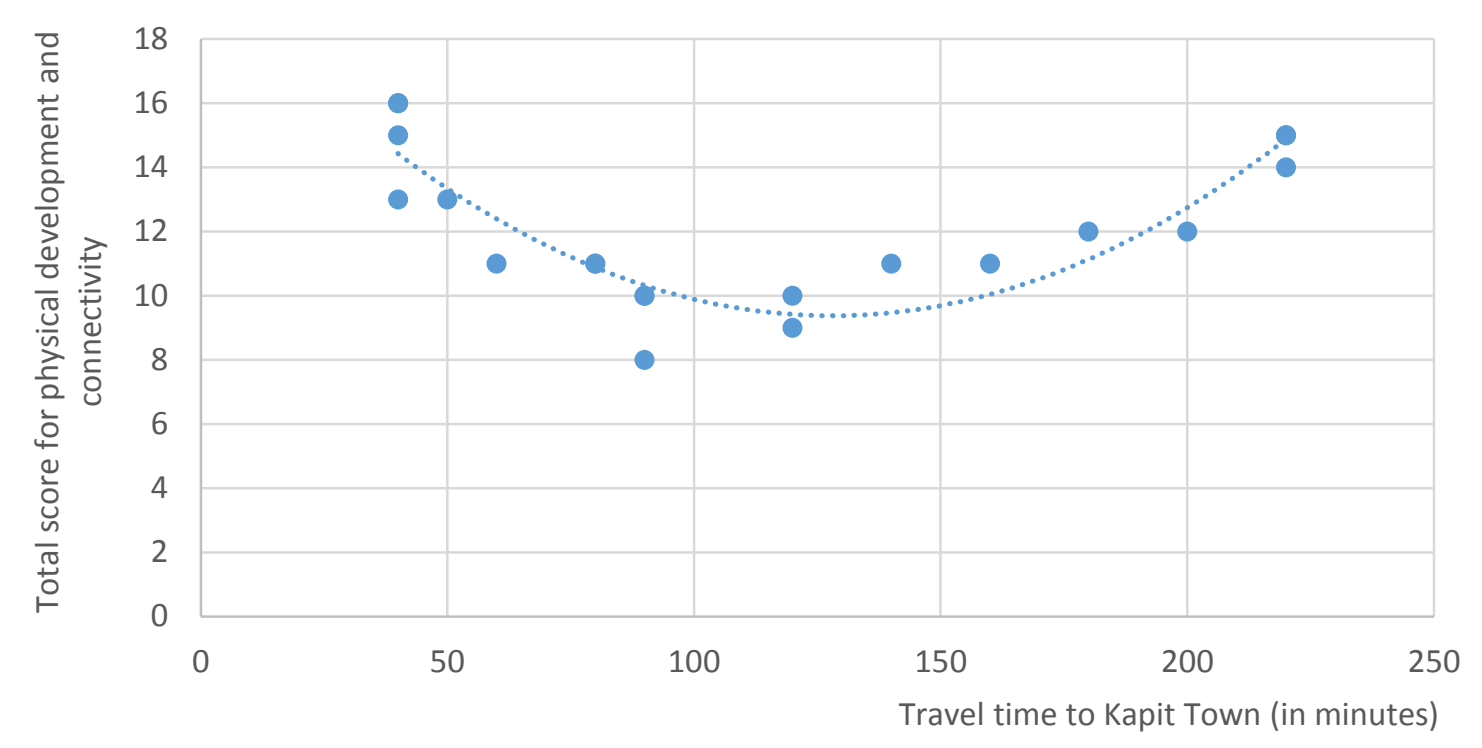

Source: Field notes

Note: Polynomial trendline, with $y=0.0007 x^{2}-0.1667 x+20.048$ and $R^{2}=0.804 ; n=20$

The relationship between the augmented score for physical development and average travel time to market is clearer in the boxplots in Figure 6.4. As expected, settlements in A1 enjoy the highest average augmented development score compared to the other two accessibility zones. Its proximity to market (i.e. Kapit Town) means that settlements within this zone are able to enjoy the infrastructure, especially road connection and mobile coverage, earlier than the rest of Baleh. Bearing in mind that the road connection and mobile coverage are being developed in stages, outwards from Kapit Town, means that settlements further away from Kapit Town will get to enjoy these facilities later than those settlements nearer to town. 
Figure 6.4: Relationship between the augmented development score and accessibility to market, by accessibility zone, Baleh river basin, Sarawak, 2014

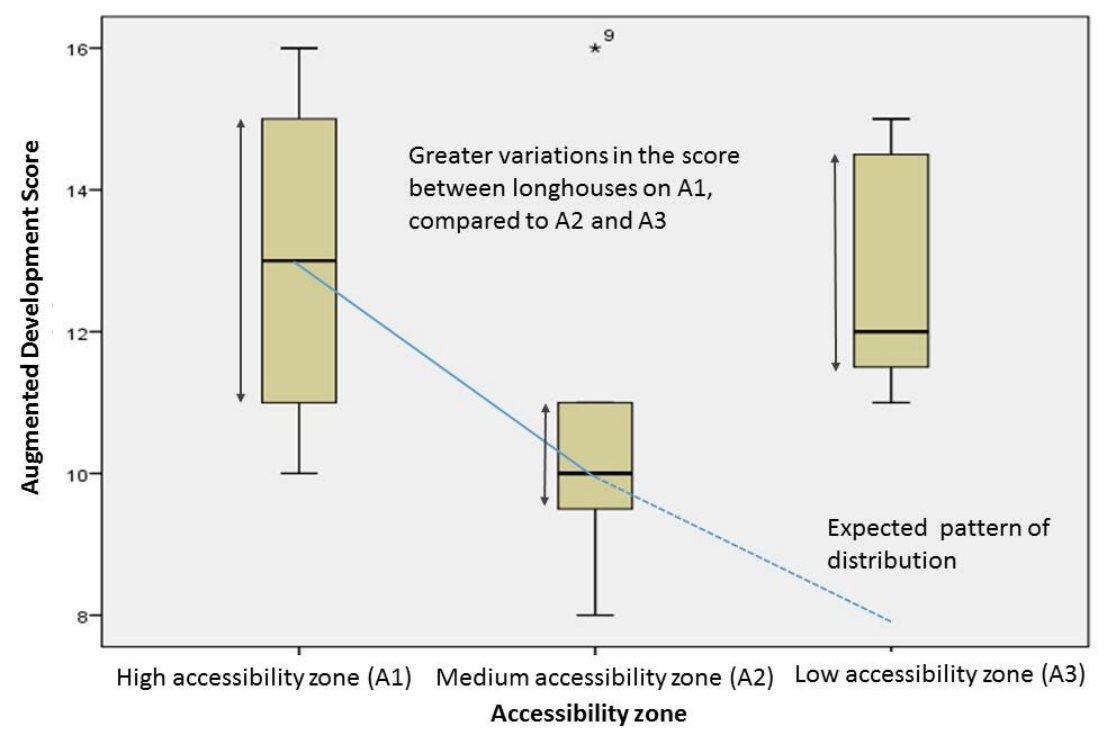

Figure 6.4 shows that settlements in $\mathrm{A} 2$ have the lowest augmented development score of the three accessibility zones, echoing the previous result. Although settlements in A2 have a slight advantage in terms of their partial road connection compared to $A 3$, they lack other basic infrastructure services.

The boxplots also show that the settlements in the same accessibility zone experience vary considerably in their augmented scores. The difference is more pronounced between settlements in the high accessibility zone as shown in Figure 6.4. This difference arises from the fact that there are three longhouses that have direct road connection to Kapit Town, which give them the highest augmented development score, compared to the other longhouses (along Sungai Sut and towards Nanga Mujong) that still rely, albeit a partial reliance, on river transportation. As noted above, the longhouses along Sungai Sut are also at a disadvantage due to the closure of their nearest rural clinic. This closure means that the residents in these longhouses have to travel up to an hour and a half to Kapit Town for their medical needs (instead of the 20 minutes trip to the clinic at Nanga Bena which was closed). It is this clinic closure together with partial reliance on river transportation that create a large variation in the augmented development score between settlements in A1. Conversation with staffs from Kapit General Hospital indicates that the clinic closure could be permanent unless new site for the clinic can be identified. 


\subsection{Infrastructure development: an elaboration}

The above results were based on the total scores from a number of development indicators. These aggregate measures may, however, be 'hiding' alternative individual relationships with accessibility. As described in the previous sections, the relationships between accessibility and development exhibit a U-shape relationship when both physical development score and augmented development score to measure development. Therefore, this section will describe the condition of each of the facilities, and provide contextual narratives on their availability in each of the accessibility zones. This provides us with a better context with which to account for the unexpected U-shaped relationships with accessibility as measured above. To recap, the initial expectation is that both development scores fall with accessibility but the analysis shows otherwise.

\subsubsection{Electricity and water supply}

Table 6.1 shows the distribution of electricity and water supply provision in the case study area. It also shows that, contrary to expectation, settlements nearer to town are not as well equipped as those further away.

Table 6.1: Electricity and water supply provision in sampled settlements, Kapit District, 2014

\begin{tabular}{|c|c|c|c|c|c|c|c|}
\hline \multirow[t]{2}{*}{ Accessibility Zone } & \multirow[t]{2}{*}{ Settlement } & \multicolumn{2}{|c|}{ Electricity } & \multicolumn{2}{|c|}{$\begin{array}{c}\text { Treated Water } \\
\text { Supply }\end{array}$} & \multicolumn{2}{|c|}{ Gravity-fed Water Supply } \\
\hline & & Yes & No & Yes & No & Yes & No \\
\hline \multirow{6}{*}{$\begin{array}{c}\text { High Accessibility } \\
\text { Zone (A1) }\end{array}$} & LH1 & $*$ & & & $*$ & $*$ & \\
\hline & $\mathrm{LH} 2$ & $*$ & & & $*$ & $*$ & \\
\hline & LH3 & $*$ & & & $*$ & $*$ & \\
\hline & LH4 & $*$ & & & $*$ & $*$ & \\
\hline & LH5 & $*$ & & & $*$ & $*$ & \\
\hline & LH6 & $*$ & & & $*$ & $*$ & \\
\hline \multirow{7}{*}{$\begin{array}{c}\text { Medium } \\
\text { Accessibility Zone } \\
\text { (A2) }\end{array}$} & LH7 & & $*$ & & $*$ & $*$ & \\
\hline & LH8 & & $*$ & & $*$ & * & \\
\hline & LH9 & $*$ & & & $*$ & $*$ & \\
\hline & LH10 & & $*$ & & $*$ & $*$ & \\
\hline & LH11 & & $*$ & & $*$ & $*$ & \\
\hline & LH12 & & $*$ & & $*$ & $*$ & \\
\hline & LH13 & & $*$ & & $*$ & $*$ & \\
\hline \multirow{7}{*}{$\begin{array}{c}\text { Low } \\
\text { Accessibility Zone } \\
\text { (A3) }\end{array}$} & LH14 & $*$ & & $*$ & & & $*$ \\
\hline & LH15 & & $*$ & & $*$ & $*$ & \\
\hline & LH16 & & $*$ & & $*$ & * & \\
\hline & LH17 & $*$ & & $*$ & & & $*$ \\
\hline & LH18 & & $*$ & & $*$ & $*$ & \\
\hline & LH19 & $*$ & & & $*$ & $*$ & \\
\hline & LH2O & $*$ & & $*$ & & & $*$ \\
\hline
\end{tabular}

Based on interviews with tuai rumahs, May-July 2014 
All of the settlements in A1, and half in A3 have electricity, provided by Sarawak Energy (formerly known as SESCO) as part of its rural electrification project. This is a recent development for settlements in A1 as the project was only completed in 2012. The settlements in A3, however, have had electricity since 1995.

By contrast, none of the settlements in A2, except LH9, have electricity supply and their residents still rely on kerosene lamps or their own fuel-powered generators. The only settlement in A2 that has access to electricity is the LH9, which is located at the mouth of Nanga Mujong on the borders with A1. Rural electrification in Kapit District is being implemented in stages, and LH9 happens to be located within the area of rural electrification, unlike the other settlements in A2 which are located further into Sungai Mujong than LH9. It is expected that the next phases will eventually cover all the other settlements in A2 and A3. However, it is not known when the next phase of the project will start or when the entire Baleh river basin will have electricity.

Ideally the water supply should be from the Sarawak Water Board, treated at its water treatment plant prior to distribution to individual homes. However, as Table 6.1 illustrates a majority of the sampled settlements do not yet have treated water supply. Instead, they rely on gravity feed water sources for their daily needs, i.e. water from streams and rivers located near the settlement which is channelled into individual biliks via pipes. According to the definition used by Kiyu and Hardin (1992, p. 126) households were considered to have access to water supply if they have an outlet tap in their own bilik.

Neither A1 nor A2 settlements have treated water supply despite their higher level of accessibility to Kapit Town. Fourteen villages mentioned the lack of treated water supply as the development element that is still lacking in their area. Ironically, the only villages with treated water supply are the three longhouses located at the very end of the accessibility continuum, in zone A3. They have had treated water supply since 2001. Allocation of water supply (as well as electricity) is based on public/government allocation decisions and not the market. Therefore, a market demand based model is inadequate to explain this difference. The same, I will show now, also applies to the provision of education facilities. 


\subsubsection{Schools and primary education}

Education is another frequently used indicator of development. Development policies almost always incorporate provisions for education, especially primary school and its related facilities to be provided even in remote rural locations (e.g. as per policies in the Malaysia plans). The government sees investment in education as a public responsibility which, in this case, is devolved to the State Government of Sarawak. As a result, all 20 settlements have access to primary schools and secondary schools as detailed in Table 6.2.

Table 6.2: Schools and their distances from sampled settlements, Kapit District, 2014

\begin{tabular}{|c|c|c|c|c|}
\hline Accessibility Zone & Settlement & Primary School & $\begin{array}{c}\text { Distance (in } \\
\text { mins) to primary } \\
\text { school (mode of } \\
\text { transport) }\end{array}$ & Secondary School \\
\hline \multirow{6}{*}{$\begin{array}{c}\text { High } \\
\text { Accessibility } \\
\text { Zone (A1) } \\
\text { (average 9.17 } \\
\text { mins) } \\
\end{array}$} & LH1 & SK Lepong Baleh & 5 (van) & Secondary schools in town \\
\hline & $\mathrm{LH} 2$ & SK Ng. Bawai & 5 (boat) & Secondary schools in town \\
\hline & LH3 & SK Ng. Bena & 10 (boat) & Secondary schools in town \\
\hline & LH4 & Sk. Ng. Antaroh & 15 (van) & Secondary schools in town \\
\hline & LH5 & SK Ng. Mujong & 15 (walking) & Secondary schools in town \\
\hline & LH6 & SK Lepong Baleh & 5 (van) & Secondary schools in town \\
\hline \multirow{7}{*}{$\begin{array}{c}\text { Medium } \\
\text { Accessibility } \\
\text { Zone (A2) } \\
\text { (average 19.29 } \\
\text { mins) }\end{array}$} & LH7 & SK Ng. Mujong & 20 (boat) & Secondary schools in town \\
\hline & LH8 & SK Ng. Mujong & 35 (boat) & Secondary schools in town \\
\hline & LH9 & SK Ng. Mujong & 5 (foot) & Secondary schools in town \\
\hline & LH10 & SK Ng. Oyan & 10 (boat) & Secondary schools in town \\
\hline & LH11 & SK Ng. Mujong & 40 (boat) & Secondary schools in town \\
\hline & LH12 & SK Ng. Mujong & 20 (boat) & Secondary schools in town \\
\hline & LH13 & SK Ng. Oyan & 5 (boat) & Secondary schools in town \\
\hline \multirow{7}{*}{$\begin{array}{c}\text { Low } \\
\text { Accessibility } \\
\text { Zone (A3) } \\
\text { (average } 13.57 \\
\text { mins) }\end{array}$} & LH14 & SK Temenggong Koh & 10 (walking) & SMK Baleh \\
\hline & LH15 & SK Temenggong Koh & 10 (walking) & SMK Baleh \\
\hline & LH16 & SK Lepong Gaat & 30 (boat) & SMK Baleh \\
\hline & LH17 & SK Temenggong Koh & 5 (foot) & SMK Baleh \\
\hline & LH18 & SK Ng. Sempili & 10 (boat) & SMK Baleh \\
\hline & LH19 & SK Temenggong Koh & 20 (boat) & SMK Baleh \\
\hline & $\mathrm{LH} 20$ & SK Temenggong Koh & 10 (walking) & SMK Baleh \\
\hline
\end{tabular}

Based on interviews with tuai rumahs, May-July 2014

For the most part, primary schools are located within five to 40 minutes travel time of longhouses, with an average travel time of 14.25 minutes, depending on the mode of transport. Travel time to school ranges from five to 15 minutes in A1 (average of 9.17 minutes), five to 40 minutes in A2 (average of 19.29 minutes) and five to 30 minutes in A3 (13.57 minutes). Map 6.2 below shows that all but one of the settlements selected for my study are located within the eight kilometres distance from the nearest primary school. 
Map 6.2: Distribution of schools in Baleh river basin, Kapit District, Sarawak, 2014

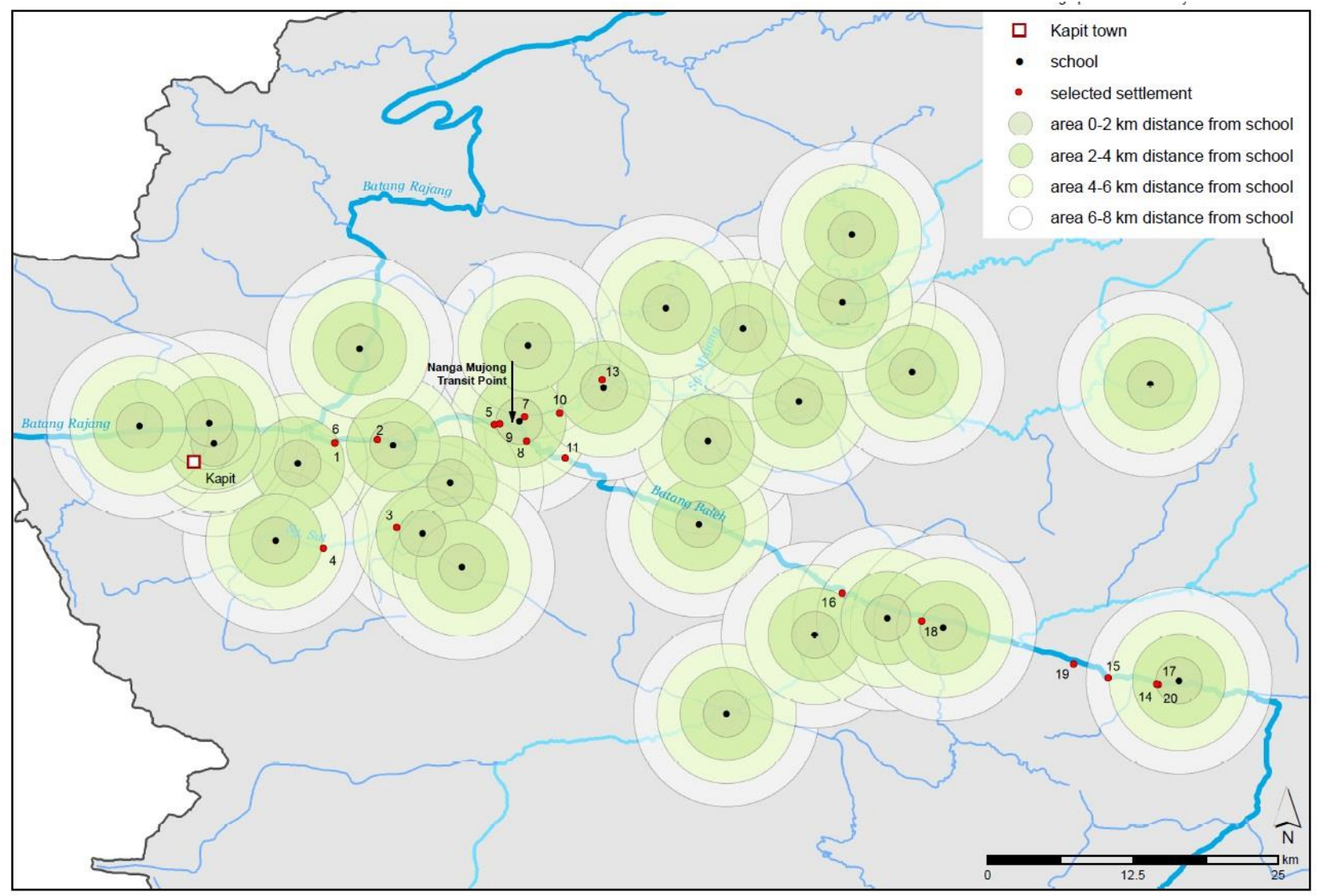

Source of base map: Series MY91001R, Edition 1-PPNM, Department of Survey and Mapping Malaysia, 201077

Twelve out of 20 longhouses (60 percent) are within 10 minutes from the nearest primary school and only 15 percent are located 30 minutes or more away. This proximity indicates 'ease of access' to school by the community and households in the case study area. Proximity to schools, especially primary school, means that residents' school going children have a greater chance at getting basic education, improving their literacy skills and, thereby, contribute to the human capital of their household and community. Rigg and Nattapoolwat (2001), in their case study of rural Thai villages for instance, find that education had become an important determinant of the urban-based economic opportunities open to rural dwellers. Taylor and Yunez-Naude (2000, p. 296) also observe that, in Mexico, schooling influences households' choices of income activities as well as their incomes given these choices. Similarly, Olaniyan and Okemakinde (2008, p. 481) argue that, in Pakistan, education

77 In this research, Euclidean (straight-line) distance is used in the maps in order to standardise the data. The complexity surrounding accessibility and mode of travel makes it hard to model the distance individually (i.e. real distance), and, therefore, I opt to use this method instead. 
played a significant role in augmenting individual's human capital, enhances chances of employment and opportunities for job mobility.

All the longhouses in Baleh river basin have access to secondary schools, either in Kapit town or SMK Baleh, which is located in zone A3. There are three secondary schools located in Kapit town, and students from zones $A 1$ and $A 2$ continue their education at these schools. The students from $A 3$, on the other hand, usually go to SMK Baleh (located opposite LH16 in Map 6.2). Again, the distribution of secondary schools in Kapit District reflects how government intervenes to ensure that those living in remote locations, such as those settlements in A3, also have access to education.

The presumption above was that schools are built to serve the longhouses, however, the reverse can also be the case. A few tuai rumahs mentioned that they specifically choose the location of their longhouses in order to be near school (refer Figure 6.1 for illustration). It should be noted that Iban longhouses, and their community, often re-locate to different locations - usually within their communal longhouse area. There are also instances where community split from their longhouses (for various reasons ranging from overcrowding to conflicts) and forms new ones. Those without land sometimes purchase land from other community to build their longhouses.

Figure 6.5: Example of longhouse relocation

Longhouse \#9

This 15-door longhouse is located at the mouth of Sungai Mujong in zone A2. It was built in 1989 and was set up by 'pioneering bilik-families' who consist mainly of young couples splitting from their main ancestral bilik. They moved out from their ancestral bilik and set up their own bilik-families at a newly established longhouse. The location was chosen because they wanted to be near the school (SK Nanga Mujong) and clinic (Klink Kesihatan Nanga Mujong), both of which were already operational by then. At present, both the school and the clinic are adjacent to the longhouse. School children from the longhouse walk to school (five minutes) and so do those who visit the clinic.

Other facilities that are available at the longhouse are electricity, which has been available since 1990 (but only available 12 hours a day), and a gravity-feed water supply. The longhouse is approximately five to ten minutes boat ride away from the Nanga Mujong transit point, so the area is served by partial road connection to town. The tuai rumah said that the road connection has been a major advantage to the residents of the longhouse as they now have more opportunities to "develop", either at individual or bilik level. A majority of the anak biak are no longer farming. When they initially moved to this site, farming (hill paddy) was the main activity for every family. Nowadays, nearly every family in the longhouse has members who are practicing multi-local living, including the tuai rumah himself (the tuai rumah works in oil and gas industry and is based in other parts of Sarawak but his wife remains at the longhouse.)

The residents here pointed out that their relocation into the area has paid off as they now experience higher level of development than other longhouses which are located further up along Sungai Mujong (where they originally came from). 
In this instance, the move, according to them, enables their children to go to school easily, without having to travel far and ensure that their children do not drop out of school. The respondents often added that they recognised the crucial role of education in relation to individual and household development, and that encouraging their children to get education is seen as a way forward. Having schools nearby is, therefore, considered an important indicator for their development as a community.

In summary, most tuai rumah and their anak biak agreed that education is one factor that can influence their future development. This was repeated numerous times during the interviews as well as during informal discussions with respondents. They regarded education as the key to their human capital development, a response to reduce poverty and inequality (Olaniyan \& Okemakinde, 2008), enhancing employability and earnings (Blaug, 1976; Nafukho et al., 2004; Son, 2010) and the chances for migration and better standard of living (Fafchamps \& Quisumbing, 1999; Neelsen, 1975). Fafchamps and Quisumbing, for example, find that the effect of schooling and education is strong in rural Pakistan, whereby an additional year of schooling for all adult males raises household incomes by 8.9 percent.

\subsubsection{Health services}

The provision of health facilities follows a similar pattern to that of the education facilities: health, like education, is seen as a public responsibility and is provided by the State government. Therefore, all the settlements in the area are provided with basic health facilities regardless of their level of accessibility to Kapit Town. 
Map 6.3: Distribution of rural clinics and the locations of sampled longhouses, Baleh river basin, Kapit District, Sarawak, 2014

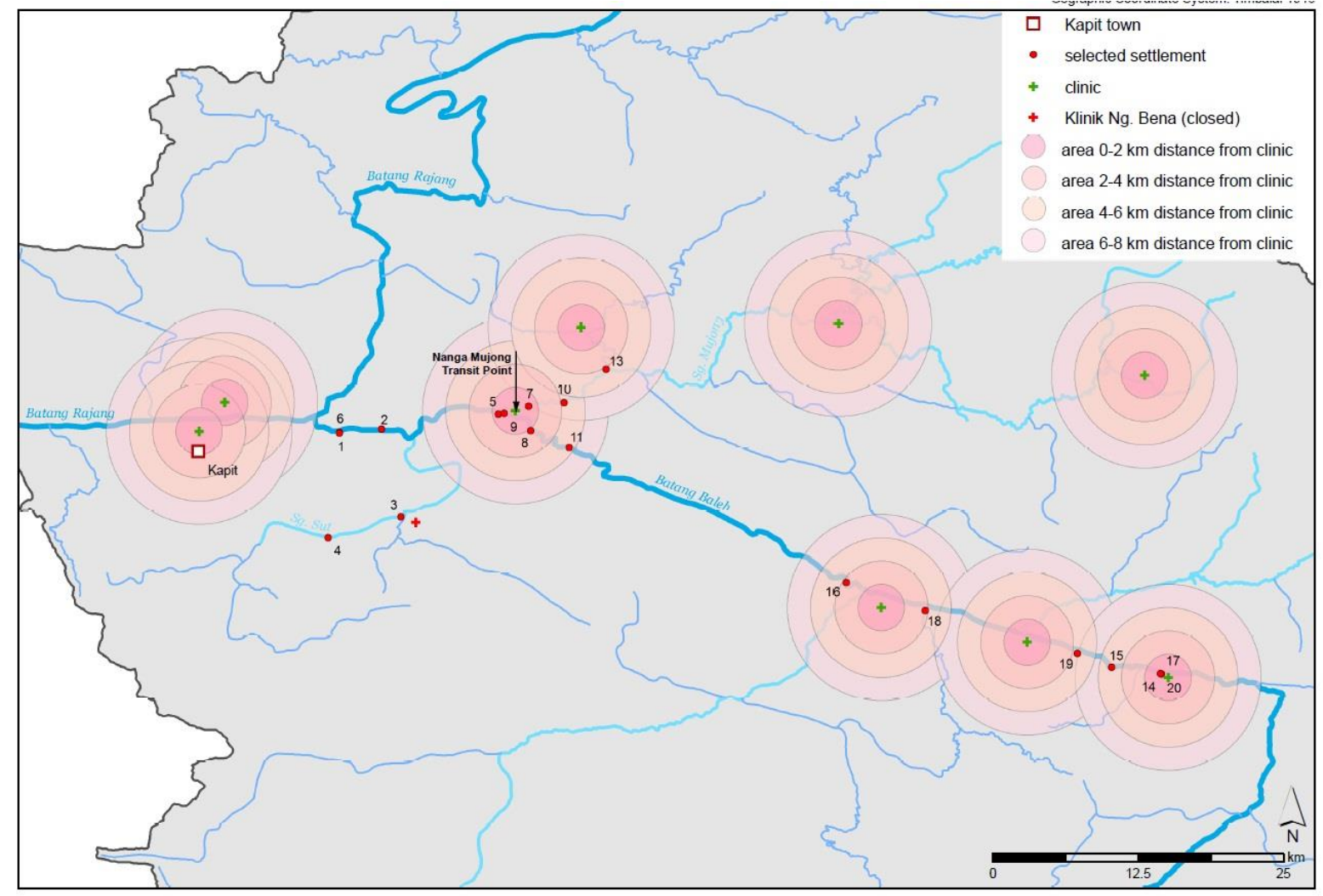

Source of base map: Series MY91001R, Edition 1-PPNM, Department of Survey and Mapping Malaysia, 2010

All 20 longhouses in the case study area have access to clinics, whether it is one of the rural clinics (klinik desa) near to the longhouse and/or to Poliklinik Bletih, the main health centre located in Kapit Town. Rural clinics are located near most settlements with an average of 25 minutes travel time from settlements. The exception, as Map 6.4 shows, are the villages in Sungai Sut tributary in A1, which do not have access to their nearest clinic for reasons mentioned earlier.

Table 6.3 below shows that the settlements in A3 seem to have better development scores in terms of the distribution of health facilities too. Analysis indicates that most rural clinics are within an average of 10.7 minutes from the longhouses in A3. Meanwhile, the average distance for zone A1 and A2 are 36.7 and 27.9 minutes respectively. 
Table 6.3: Distance of rural clinic from sampled settlements and the mode of transport to clinic, Kapit District, 2014

\begin{tabular}{|c|c|c|c|c|}
\hline Accessibility Zone & Settlement & Clinic & $\begin{array}{l}\text { Distance to nearest } \\
\text { clinic (in minutes) }\end{array}$ & $\begin{array}{l}\text { Mode of } \\
\text { transport }\end{array}$ \\
\hline \multirow{6}{*}{$\begin{array}{c}\text { High } \\
\text { Accessibility } \\
\text { Zone (A1) } \\
\text { (average: } 36.67 \text { mins) }\end{array}$} & LH1 & Poliklinik Bletih & 25 & Land transport \\
\hline & $\mathrm{LH} 2$ & Poliklinik Bletih & 30 & Mixed transport \\
\hline & LH3 & Poliklinik Bletih & 80 & Mixed transport \\
\hline & LH4 & Poliklinik Bletih & 50 & Land transport \\
\hline & LH5 & Klinik Ng. Mujong & 10 & Walking \\
\hline & LH6 & Poliklinik Bletih & 25 & Land transport \\
\hline \multirow{7}{*}{$\begin{array}{c}\text { Medium } \\
\text { Accessibility } \\
\text { Zone (A2) } \\
\text { (average: } 27.86 \text { mins) }\end{array}$} & LH7 & Klinik Ng. Mujong & 20 & Boat \\
\hline & LH8 & Klinik Ng. Mujong & 35 & Boat \\
\hline & LH9 & Klinik Ng. Mujong & 5 & Walking \\
\hline & LH10 & Klinik Ng. Mujong & 30 & Boat \\
\hline & LH11 & Klinik Ng. Mujong & 40 & Boat \\
\hline & LH12 & Klinik Ng. Mujong & 20 & Boat \\
\hline & LH13 & $\begin{array}{l}\text { Klinik Ng. Mujong } \\
\text { Klinik Sekeroh }\end{array}$ & $\begin{array}{l}45 \\
70\end{array}$ & $\begin{array}{l}\text { Boat } \\
\text { Boat }\end{array}$ \\
\hline \multirow{7}{*}{$\begin{array}{c}\text { Low } \\
\text { Accessibility } \\
\text { Zone (A3) } \\
\text { (average: } 10.71 \text { mins) }\end{array}$} & LH14 & Klinik Entawau & 5 & Walking \\
\hline & LH15 & Klinik Entawau & 10 & Boat \\
\hline & LH16 & Klinik Ng. Gaat & 10 & Boat \\
\hline & LH17 & Klinik Entawau & 10 & Walking \\
\hline & LH18 & Klinik Ng. Gaat & 20 & Boat \\
\hline & LH19 & Klinik Merirai & 15 & Boat \\
\hline & LH20 & Klinik Entawau & 5 & Walking \\
\hline
\end{tabular}

Based on interviews with tuai rumahs, May-July 2014

While the provision of health clinics is a State responsibility, access can still vary by longhouse and household. The reason is that the average time taken to reach health facilities varies depending on the mode of transport (which can vary by household). For example, the average walking time to clinic is seven minutes and using river transportation takes approximately an average of 24.5 minutes. Using land transport and mixed transport takes longer to reach the health centre or rural clinics with an average time of 33.33 and 55 minutes respectively. Those who are able to use a car and, therefore, mixed mode are usually from settlements in $A 1$, near Kapit town. The other settlements in $A 2$ and $A 3$ use river transportation to reach their nearest rural clinic. Only five out of 20 longhouses are located near enough to a rural health clinic for the residents to walk to the clinic (one in $A 1$, one in $A 2$ and three in A3).

Boxplots in Figure 6.5 show the average travel time to clinics by accessibility zones. It clearly shows that the settlements in low accessibility zone, i.e. those that are located at the far end of the accessibility continuum from the market, have better access to their health facilities - meaning that they will score higher in terms of development. 
Figure 6.6: Average travel time to rural clinic facilities at sampled longhouses, by accessibility zone, Kapit District, 2014

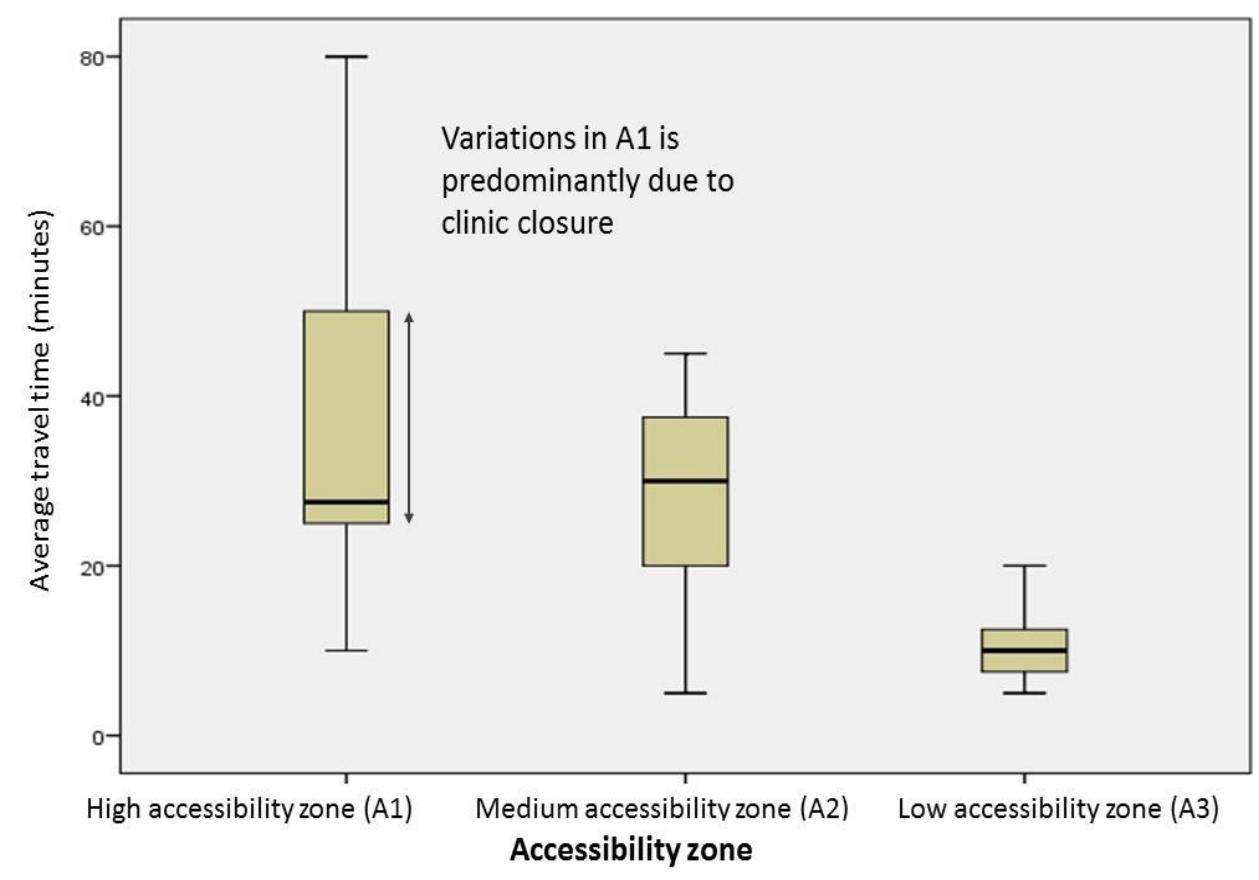

The great variation experienced by settlements in A1 in Figure 6.6 is attributed to the closure of the clinic at Nanga Bena (refer Map 6.1). It has not been re-opened and the closure might be permanent. Although, there were mobile medical units providing health services in the area immediately after the clinic closure, this service had been stopped at the time of the interviews. The residents in this area now have to go to Poliklinik Bletih, which is approximately one to one and a half hour away, for their medical needs. Several respondents have commented that they felt their condition is less favourable than the other longhouses in Baleh region.

Access to, and availability of health clinics is a significant indicators of development (Chen \& Tan, 1982; PEMANDU, 2013). Study by Chen \& Tan (1983) found that the quicker a resident can access health clinic, the quicker they will be treated and, therefore, reducing the number of patients with serious illness. This finding is based on Chen and Tan's study in isolated Sarawak villages, and they came up with an indicator of '30 minutes travel time' to assert areas served by rural clinic. Those beyond the 30-minutes zone were considered as 'unserved areas'.

In summary, the State's intervention ensures that rural health clinics are available in rural areas. What made the situation differ, in this case, is the clinic closure, which affects the development scores of those villages tremendously. 


\subsubsection{Road connection and mobile coverage}

Only three settlements, all in $\mathrm{A} 1$, have direct road connection to Kapit town while the remaining settlements in A1 and all those in A2 have partial connection (Table 6.4). In contrast, none of the settlement in $\mathrm{A} 3$ have a road connection, and they, therefore, rely completely on river transportation.

Table 6.4: Road connection and mobile coverage in case study area, Kapit District, 2014

\begin{tabular}{|c|c|c|c|c|c|c|c|}
\hline \multirow[t]{2}{*}{ Accessibility Zone } & \multirow[t]{2}{*}{ Settlements } & \multicolumn{2}{|c|}{$\begin{array}{l}\text { Direct road } \\
\text { connection }\end{array}$} & \multicolumn{2}{|c|}{$\begin{array}{c}\text { Partial Road } \\
\text { Connection }\end{array}$} & \multicolumn{2}{|c|}{$\begin{array}{l}\text { Full mobile } \\
\text { coverage }^{78}\end{array}$} \\
\hline & & Yes & No & Yes & No & Yes & No \\
\hline & LH1 & $*$ & & $*$ & & $*$ & \\
\hline & $\mathrm{LH} 2$ & & $*$ & & $*$ & & $*$ \\
\hline High Accessibility & LH3 & & $*$ & & $*$ & & $*$ \\
\hline \multirow[t]{5}{*}{ Zone (A1) } & LH4 & $*$ & & $*$ & & & $*$ \\
\hline & LH5 & & $*$ & & $*$ & $*$ & \\
\hline & LH6 & $*$ & & $*$ & & $*$ & \\
\hline & $\mathrm{LH} 7$ & & $*$ & & $*$ & & $*$ \\
\hline & LH8 & & $*$ & & $*$ & & $*$ \\
\hline Medium & LH9 & & $*$ & & $*$ & $*$ & \\
\hline Accessibility Zone & LH10 & & $*$ & & $*$ & & $*$ \\
\hline \multirow[t]{5}{*}{$(\mathrm{A} 2)$} & LH11 & & $*$ & & $*$ & & $*$ \\
\hline & LH12 & & $*$ & & $*$ & & $*$ \\
\hline & LH13 & & $*$ & & $*$ & & $*$ \\
\hline & LH14 & & $*$ & & $*$ & & $*$ \\
\hline & LH15 & & $*$ & & $*$ & & $*$ \\
\hline Low & LH16 & & $*$ & & $*$ & & $*$ \\
\hline Accessibility Zone & LH17 & & $*$ & & $*$ & & $*$ \\
\hline \multirow[t]{3}{*}{ (A3) } & LH18 & & $*$ & & $*$ & & $*$ \\
\hline & LH19 & & $*$ & & $*$ & $*$ & \\
\hline & $\mathrm{LH} 20$ & & $*$ & & $*$ & & $*$ \\
\hline
\end{tabular}

Based on interviews with tuai rumahs, May-July 2014

Having direct or partial road connection to market (i.e. Kapit town) has the potential to improve a community's level of development, as well as that of households, and individuals within the household. During the interviews, the tuai rumahs, and their anak biaks in areas without road connection, agreed that having road connection brings more options for them. They were referring to opportunities for improved standard of living, their children's education, and their health care. While those with partial road connection emphasised that, compared to those settlements without the road connection, their area felt more 'developed', economically and socially, which is a good indicator for their future. Their responses implied that they want more than just physical connectivity, which the road represents, but also via the road connection, they are pursuing their (household and individual) human capital development as well.

${ }^{78}$ Can be accessed from the bilik/longhouse without having to go elsewhere for better coverage. 
Several tuai rumahs expressed their hope for the future development of their area if, and when, the villages are connected to Kapit town by road. One of them states that,

"If we have direct road connection, most of our problems will be solved. We can do market gardening... We can start our own oil palm plantation here ... our land will be fully utilised... road connection means we can send the oil palm to the mill. We cannot do anything about it now because we don't have road. And not just oil palm, we can venture into other activities if we are connected to town. We can go to town as frequent as we want...and not tied up to express boat schedule and am sure it will not be as costly as it is now ..."

(TR of LH11, A2, June 2914)

Similar sentiments were expressed by the tuai rumahs in the other zones. Most, if not all, view road connection to town as the way forward for them as a community, as well as for the bilik-family and individuals, and that only road connection is able to change their current river-dependent lifestyles.

"Road connection is the way forward for us here. In order to spur development, we need to be connected by road. Like those near to town, they can sell vegetables and have diversified income sources... all because of road connection. We want that too, for ourselves, for our children ..."

(TR of LH15, A3, June 2914)

Like road connection, other elements of information and communication technologies are also vital in enabling rural dwellers to pursue higher level of development - at all three levels. Therefore, I have also used mobile coverage as another indicator for development. This form of contemporary connectivity is considered significant in an era where nearly every household owns at least one mobile phone. However, ownership of a mobile phone alone is not enough, as its ability to be utilised for individual and/or household is highly dependent on the mobile coverage.

When I explore the relationship using proximity to Kapit Town (to measure accessibility) and mobile coverage score (to measure development), I found that settlements in A1 had a broad range of scores, whereas the mobile coverage in $A 2$ and $A 3$ is very limited. This is also shown in Table 6.4 above that mobile coverage in the case study area is limited and, at times, unstable. Most areas, from A1 to A3, have unstable and sporadic mobile connection. In many cases, the residents of the longhouses cannot make or receive calls using their mobiles from their own home. They have to go outside their house in order to get signal coverage. 
During the data collection period (May-July 2014), mobile telecommunication coverage in the case study area was limited and unstable in most areas outside of Kapit town. Based on my observation and personal experience, access to mobile network varies according to location. It should be noted that the network coverage is not necessarily better in areas nearer to town. Mobile coverage in the area can be categorised into two types; able to access the mobile coverage without having to go leave the bilik, and able to access the mobile at certain locations outside of the bilik and/or longhouse compound. Residents in most of the sample longhouses have to make a special effort to get mobile coverage. Because they were unable to get any coverage at the site of their own bilik or longhouse compound, the residents of longhouses in zone A3 (e.g. LH14, LH5, LH17 and LH20) had to go upriver, approximately five to ten minutes away, from their longhouses (in a longboat) in order to have a good mobile network and make their phone calls. Similar experiences were described in other longhouses in all three zones;

"...it is common here to see longboats in front of our longhouse with someone paddling up and down the river (Sungai Mujong) to get a better mobile signal ...to make calls and to receive calls ... we also do that because there is no phone coverage at the longhouse itself ..."

(Resident of LH10, A2, June 2014)

"... we cannot get any signal from this longhouse ... have to go in our longboat, either upriver (where MAXIS signal is strong) or down river (CELCOM signal is strong), to get the mobile coverage ... to make urgent calls .."

(Resident of LH15, A3, June 2014)

"... no phone signal here (referring to the longhouse) ... we have our phones but we go elsewhere to use the phone ... I use mine when I am in town only ..."

(Resident of LH2, A1, May 2014)

I also found that many other residents who do not have access to any mobile coverage in their longhouses only use their mobile phones when they are in Kapit Town. They take advantage of the coverage when they are in town to make and receive calls from family members who live outside of Kapit. This limited access and urban-bias coverage of mobile phone services, according to the

\footnotetext{
${ }^{79}$ MAXIS and CELCOM are among the key mobile service providers in Malaysia.
} 
respondents, makes it hard for them to communicate with family members who live elsewhere. Consequently, they resorted to other sources of communication.

The only longhouse that had complete mobile coverage (based on my own experience and results of the analysis) is LH19 zone A3. The residents here have access to mobile coverage without having to leave their bilik or the longhouse (i.e. in-situ coverage). Nonetheless, my observation coupled with interviews indicated that a majority of the residents in this longhouse could not fully utilise the availability of internet coverage due to lack of IT literacy and skills. This observation illustrates how access alone is not enough as skills are also required in order to utilise the available information and communication technologies.

In summary, there are varying degree of access to mobile communication network amongst the selected longhouses in the three accessibility zones. To certain extent, access to mobile communication is limited to their proximity to Kapit town because town area has better signal coverage in the District. Settlements with higher accessibility to market seems to have better connectivity than those further away from Kapit Town. Therefore accessibility to Kapit matters when I am only using connectivity measures of development.

Aside from connectivity, human capital - which I am going to explore next - also matters. This was highlighted earlier when I describe the education aspirations of the respondents as well as the aspiration of the government, through its State-led intervention in providing schools in rural area.

\subsection{Accessibility and human capital development}

Availability of schools and health clinics are pre-requisite for human capital development. Schultz (1961) defined human capital as the knowledge and skills that people acquire through education and training. Other scholars have made similar connection between education and human capital development (Blaug, 1976; Fafchamps \& Quisumbing, 1999; Olaniyan \& Okemakinde, 2008; Son, 2010). For example, Fafchamps and Quisumbing (1999), who analyse human capital using its indirect effects on labour reallocation (from farm to non-farm), find human capital helped rural households in Pakistan improve their livelihood. Olaniyan and Okemakinde (2008) observe that investment in education in Nigeria has positive correlation with economic growth and development. These scholars recognise that education and training are valuable entities as qualification, knowledge and skills 
obtained from education and training enable individuals to obtain access to employment market, and economic market.

Respondents in this case study area recognise the significance of human capital development. The following paragraphs explain their views, concerns and perceptions and the way the development of their human capital is related to accessibility to Kapit Town. Although accessibility to schools is guaranteed government, actual levels of educational attainment and literacy can vary between households in the same longhouse and individuals within the same household. These differences are partly related to their access to Kapit Town.

\subsubsection{Levels of education of heads of households}

I use the Malaysian school qualification to measure the level of educational attainment and assumed that those who did not say they had formal education and/or did not complete their primary education were without basic education. This is similar to the definition adopted by Hawley (2004) in his study in rural Thailand and measured basic education as having completed primary school (or a minimum of six years of formal schooling).

Secondary school consists of two main levels as reflected in the highest qualification obtained. They are Sijil Rendah Malaysia (SRP), and Sijil Pelajaran Malaysia (SPM). Upon the completion of SPM, students who opt for further education can either go on to gain their Sijil Tinggi Pelajaran Malaysia (STPM) qualification, or go on to tertiary education. Those with SRP qualification would have spent nine years in education, and SPM and STPM with 11 years and 13 years respectively. Tertiary level education ranges from Certificate and Diploma to Degrees (university degrees). In this research, education level after completing SPM level is treated as post-school education (i.e. tertiary education).

A large number of the heads of household interviewed had received no formal education $(41.5 \%$, or 34 out of 82 persons). If I include the number of those who did not finish their primary school education, the proportion rise to just over half of all respondents. In summary, 51 percent of the heads of households did not complete primary school education. The distribution of educational attainment across the three zones is shown in Figure 6.7. 
Figure 6.7: Highest level of education of the heads of households in case study area, by accessibility zone, Kapit District, 2014

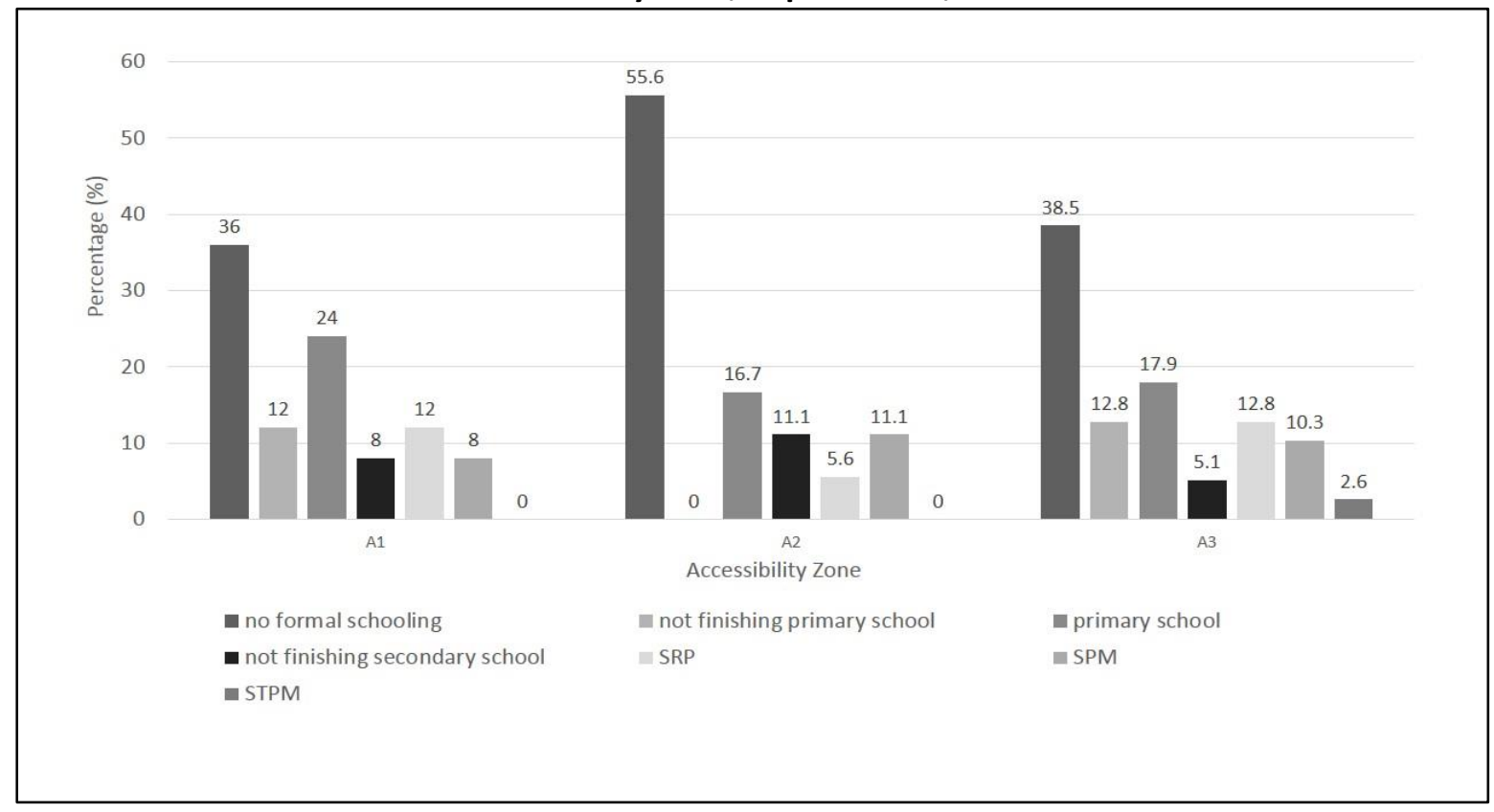

Based on interviews with heads of households, May- July 2014

A further probing on the matter revealed that the head of households who did not have any formal education or dropped out of school before completing their primary school education did so due to the nature of economic opportunities and accessibility to employment market at the time. As previously explained, the timber industry had been providing employment in the area since mid-60s. During the $60 \mathrm{~s}$ and $70 \mathrm{~s}$, the timber industry was at its peak and required a large number of workers and, according to the majority of the heads of households I spoke to, they did not have to finish school or to have secondary schools qualification in order to gain work at the timber camps. Furthermore the wages that they earned by working at timber camps were much higher than that of any type of employment available in the District at that time. Salaried civil servants, who had school qualification, were said to have earned a lower monthly salary than the timber workers. Similar observations were noted by Ngidang (2012), who argued that the employment opportunities offered by the timber industry has actually helped to retain Kapit's rural population otherwise they would have sought employment elsewhere, mainly outside the Division.

However, with the decreasing economic returns from working in the timber industry and diminishing employment opportunities, such perception had waned. The timber industry in Kapit Division is clearly a sunset industry and a number of timber companies which used to be a large employers have now ceased operation. This has been a cause for concern for the residents, especially those whose household income relied on jobs in the industry. 
With timber in decline, heads of household now view education as a significant part of their bilik's future livelihood strategy. They expressed hope that by gaining higher education and academic qualifications than themselves, their children will have a better jobs and better lives than they did. When probed further, they explained that education is a way out of poverty and farm-work, which is not only labour intensive but does not provide stable or sufficient income to feed the family. In other words, education is a way to 'develop' - individually and as a bilik-family.

"Kerja perintah (meaning becoming a civil servant) is way more desirable than working the farm. You avoid the sun and all the hard work that goes with the territory, and you get paid monthly, and able to help the family back in the village... and education can get you there..."

(Head of Household No.59, A3, June 2014)

\subsubsection{Future human capital}

Approximately 62 percent of the households interviewed had in-situ members who were still in school. The in-situ member refers to those bilik-member who still reside in the longhouses in their ancestral bilik (as opposed to the multi-local families living predominantly outside of the longhouse). This figure represents the future human capital for the area, as well as for the household and the community. Approximately 18 percent (i.e. 16 households) have at least one bilik-member studying at post-school level (see Table 6.5).

Table 6.5: Number of households with in-situ members still schooling/studying at post-school level, case study area, Kapit District, 2014

\begin{tabular}{|l|c|c|c|}
\hline & $\begin{array}{c}\text { High Accessibility Zone } \\
\text { (A1) }\end{array}$ & $\begin{array}{c}\text { Medium Accessibility } \\
\text { Zone (A2) }\end{array}$ & $\begin{array}{c}\text { Low Accessibility Zone } \\
\text { (A3) }\end{array}$ \\
\hline Diploma & 2 & 0 & 6 \\
\hline Undergraduate degree & 3 & 1 & 5 \\
\hline Master degree & 0 & 0 & 1 \\
\hline
\end{tabular}

Based on interviews with heads of households, May- July 2014

The majority of heads of households agreed that seeing a member of community going to university and getting jobs in urban areas motivates others to do the same. Households with more than one bilikmember with post school and/or tertiary education were more likely to be better off economically. Their household average in-situ income is approximately RM2862 a month compared to the average in-situ income in the area of approximately RM1758 a month. There is, therefore, a contagion effect. Only 15 percent (i.e. 12 out of 82 ) households have more than one bilik-member with post-school 
and/or tertiary education. This indicates that there is a tendency for a clustering of post-school education within households rather than within settlements, and that demonstration effects within a bilik seem to be a stronger motivational factors.

Respondents value education as future investment for their household and make location decision accordingly. There are families who practice multi-local living primarily in order to be nearer schools and other educational facilities (e.g. tuition centres). For example, a number of households deliberately opted to buy or rent houses in Kapit Town (especially among the bilik-families from A3) so that their children could have access to better education facilities.

There are several reasons for this multi-local living for the purpose of education. Firstly, the quality of rural schools are perceived to be poorer than those in Kapit Town. Secondly, the town offers more education-related choices than their rural counterpart (e.g. availability of Chinese-medium school, kindergarten and pre-schools, and tuition centres). There are also families who re-locate to areas nearer to town or areas near schools so that their children can benefit from having a school nearby and not necessarily because of quality differences (e.g. residents of LH9 chose the current location for their longhouse so that their children can walk to school).

In summary, it is widely believed that better qualifications, through education, can help the Iban household to improve their socio-economic status. This is often interpreted by the respondents as having non-farm employment with a more stable income than is possible through seasonal or waged labour. Apart from educational attainment, they also see income as a measure of both personal and household development. While most are passive recipients of local school services provided by the government, others actively seek greater accessibility to better quality schools and greater choices and proximity which locations in Kapit Town brings.

\subsection{Accessibility, development and inequality}

The central argument of this thesis is that greater accessibility to market results in more development opportunities. The above sections have focused on the various relationships between accessibility to market and the development level of the village (community), household and individual. In the following sections I will discuss how inequality can develop out of these accessibility-development relationships. 
If we compare the relationship between accessibility and development in the context of physical infrastructure provision, we have seen that zones $\mathrm{A} 1$ and $\mathrm{A} 3$ are better developed physically (i.e. in terms of facilities and infrastructure) compared to A2. Non-market, Government intervention can disrupts a purely market-based model and this is one of the primary reasons the State does intervene. Government policy regarding infrastructure provision is usually based on the size of population and the need for the infrastructure as perceived by the State and policy-makers and not on the ability of household to access income.

\subsubsection{Inequality in access to market and services}

Besides accessibility to market and services as measured by the average travel time from the settlements to market (and service), individual residents' level of accessibility to market and services is also influenced by their own individual level of mobility. Mobility refers to an individual's ability to access multimodal level of service, travel speed and connections between modes of travel (Litman, 2003). I will use the term mobility to refer to the ability to move freely and easily, from one place to another.

Mobility can be compromised by a number of factors such as age because mobility reduces as people get older. Apart from that, mobility is also tempered by the growing incidents of disability, which refers to condition(s) that hinders or hampers a person's ability to perform everyday tasks or duties (Alsnih \& Hensher, 2003, p. 905) ${ }^{80}$.

I asked the individual participants how satisfied they were with their own level of mobility (refer Q2.12 in Appendix 3). The finding reveals that all of the male respondents were either satisfied or very satisfied with their level of mobility. By contrast, less than half $(49 \%)$ of the female respondents indicated the same level of satisfaction and another 21 percent expressed dissatisfaction. Among the most commonly cited reasons were their dependence on others for their travel needs (57\%) and that travel is costly (43\%). The respondents who were most dissatisfied with their lack of mobility were females between 23 to 78 years old without their own transport because they had to rely on others for their travel. Others had limited mobility due to old age and health issues (three respondents), and were carers for babies/toddlers (three respondents).

\footnotetext{
${ }^{80}$ This includes temporary disabilities such as pregnancy, and injuries that limit one's mobility.
} 
In general, most of the women in zones A2 and A3 are able to go to farms, clinic, school, and nearby settlements on their own using longboat but they have to rely on other form of transportation to go to town. This, to some extent, corresponds to a situation called 'physical exclusion as described by Delbosc and Currie (2011) whereby the physical nature of the transport system may create both physical and psychological barriers to access for the people.

Women's barrier to mobility and accessibility also arise from the lack of ownership and/or ability to operate family transport and is parallels the findings of past studies on accessibility in rural Peru by Bravo (2002), a study of non-Western immigrant accessibility in Norway by Uteng (2009) and a study of mobility and transport in sub-Saharan Africa by Porter (2007). Different access can be explained by the different levels of ownership of transport (or household assets in general) by gender. Kenyon, Lyons, and Rafferty (2002, p. 212), in their paper on transport and social exclusion, argue that transport difficulties such as this can be a key barrier to employment, constraining the ability to travel to interview and to find out about employment opportunities especially if individuals are located further away from the market.

An inequality by age emerges when the impacts of improved accessibility, specifically from road construction and road access to town, are not evenly distributed. Improved road connection often cost the elderly their independence as they now have to rely on others for transportation whereas formerly they were able to use their own river transportation to travel independently. They do not own land transportation or know how to operate one. The following are two examples of participants' accounts on how road improvement changed their travel and independence.

"We don't use longboat anymore to go to town ... but I cannot drive nor do I own any land transport. I have to rely on the vans or wait for my son to drive me. I used to be able to go anywhere on my own using my boat... now I am relying on others for transportation"

(Respondent No.14, A1, May 2014)

"I go to our farm on my own. I can operate our longboat as long as I am using the 15 horsepower outboard motor engine, which is easy for me to handle... but I cannot go to town or other places on my own in a longboat. I have to rely on my husband or father when I want to go to town. They can take me using the longboat to Nanga Mujong [transit point] then I will take a van to Kapit Town. This is how everyone in my family go to town. We don't own any land transport or have driving license ... we just rely on others when we need to go to town."

(Respondent No.58, A3, June 2014) 
According to Porter (2007), in sub-Saharan Africa, inequality also exists due to inadequate transport i.e. in terms of transport regularity, reliability and cost. These three issues are present in the complex accessibility-related situation in Baleh region. The high cost of transportation and the limited express boat services for those in zones $\mathrm{A} 2$ and $\mathrm{A} 3$, for example, are among the key factors which influence the mobility and accessibility of an individual, a household and a community in general. These become significant as they cover not just the aspect of place-to-place mobility, but also include socio-economic accessibility (e.g. better income generating opportunities, education attainment and health service).

In summary, the main observation that I made in relation to improvement in transport and accessibility is how it affects women more than men. Regardless of transport and accessibility improvement, the men are not as 'confined' to rural areas. The men have greater opportunities to go seek employment outside of the longhouses, thus having more choice in terms of income sources. Their movement is not as heavily influenced by the overall availability of physical accessibility in their place of origin as is the case for women.

\subsection{Does location matter?}

Taking all the measures considered up to this point, does it matter where along the accessibility continuum communities, households and individuals are located?

One way of measuring that question is to ask respondents themselves - namely whether they think that location plays a role in determining their level of development - not just to the market (i.e. Kapit Town) but to other markets (different types of market and at other locations) as well. Approximately 88 percent said that when it comes to accessibility - particularly to the job market - location does matter. They argued that distance influences accessibility to job search and job opportunities. One respondent explained that;

"... when you live so far away from town like we do, and the only way to get to town is by express boat, with limited service, you are cut off from job opportunities. You are disadvantaged at the very beginning. There are not many jobs available locally unless you are looking for unskilled, menial job ... and when you are called for interviews, you incur extra expenses to go down to Kapit or Sibu (nearest town) ... costs for travelling and accommodation with no guarantee you get the job. The worst is when the interview letter arrive past the date of the interview itself ... which has happened a few times to our children here ... [note: letter is sent to post box in town]"

(TR of LH15, A3, June 2014) 
When it comes to perception of relative accessibility 40 percent of the tuai rumah ranked their 'ease of movement' (i.e. referring to place-to-place mobility - refer Q3.5a in Appendix 1) as only average and the other 40 percent as above average. Only 20 percent believed that their longhouses ranked as below average in terms of ease of movement if compared to other longhouses along Batang Baleh. These longhouses are mainly in zone $\mathrm{A} 3$ and they argued that their movement is very much restricted and tied up to the express boat schedule. There are only three services offered by the express boat a day, and if the water level is too low, the express boat service may be suspended. When the latter happens, the community in $\mathrm{A} 3$ is cut off from town and other areas in the region.

Therefore, despite Government attempts to even up rural dwellers accessibility to market and facilities, location still matters to the respondents. Where one is located in relation to the different markets help to determine their level of development, not just for the individual but also for his/her household and community.

\subsection{Summary}

The hypothesis of this thesis is that an increase in accessibility to market raises the level of development of communities, households and individuals. The model of agricultural rent clearly shows that transport costs matter and that accessibility raises income and, hence, land rent. However, in an era of de-agrarianisation, where there is a shift of emphasis from farm to non-farm economic activity, people are no longer selling commodities in the market but 'selling' their own labour or skills on the 'labour market'. This is particularly significant in areas beyond the agricultural margin, as exhibited by settlements in zone $\mathrm{A} 2$ and $\mathrm{A} 3$, where accessibility to commodity market is not feasible nor profitable for any farming activities. This shift of economic orientation requires a change of skill sets and, as illustrated in this chapter, accessibility to services - including to school and health facilities - is significant in enhancing the skill set required to pursue higher levels of development at individual, household and community levels.

Consequently, human capital development becomes an important platform for individual and household in their pursuit for improved livelihoods. One of the ways to develop human capital is through education. Participants in this research regard education and schooling as important stepping stones for their household members to obtain opportunities beyond the longhouse. Accessibility to school in the case study area is not a problem, as school (as well as rural clinics) are provided by the 
government. Because its provision is not left purely to the market to determine, remote areas such as that of $A 3$ are well equipped by schools (and health) facilities.

My second hypothesis was that levels of inequality would rise with development. Discussions above describe how inequality - e.g. in mobility - hampers one's level of accessibility, and consequently his/her level of development. Inequality, or rather accessibility to market and services, are dependent on various community, household and individual attributes. Despite having similar level of accessibility to market and services, household and/or individual development may vary according to their attributes, which range from gender, age, educational attainment and socio-economic status. Social and familial constraints may limits one's accessibility: it is not only what people do, but their capability to change what they do is also influenced by their social context (Ellis, 1998, p. 11). The female, for instance, seems to be more prone to facing mobility problem compared to the men in this study.

This study also found that there are strong demonstration effects within households, in relation to educational achievement. There is a tendency for a clustering of post-school education within households than within community. This concentration of better educated individuals in one household may potentially create more inequality between households in the same longhouse in the future.

The participants responded to the obstacles arising from lack of accessibility to their primary commodity market, i.e. Kapit Town, by re-allocating members of their households both spatially, mainly in urban areas and other employment markets, and sectorally (in non-farm sectors). These responses, which will be elaborated in the next chapter, are among the livelihood strategies adopted by the Iban of Baleh in pursuit of greater level of development in spite of their remote location. 


\section{Chapter 7}

\section{Multi-local Living and the Changing Structure of Iban Bilik- family}

This chapter continues the discussion on the contemporary phenomenon arising from the changing nature of accessibility and development relationships in the present day Baleh. The focus of discussion is on the responses, for greater levels of development, adopted by the participants, both at individual and household levels. The participants experienced limited accessibility to market and services due to their unfavourable location along the identified accessibility continuum. As illustrated in Chapter Five, residents in $A 2$ and $A 3$ were limited in their ability to participate in market gardening or other agricultural-based activities due to their location. They are located in areas that are not feasible or profitable for them to be involved in commodity sales. von Thünen called these areas as 'beyond the agricultural margin'.

This chapter is centred on multi-local living as a response to de-agrarianisation, and how a shift in emphasis from farm to non-farm works changes the structure of traditional Iban households and their choice of livelihood strategies. This, in turn, introduces the notion of guardianship role and the issues of land tenure as it relates to development.

\subsection{Implications of de-agrarianisation at household and individual levels}

As I noted in Chapter One, the number of people involved in farming in Sarawak has been declining steadily since the 1970s, from 67.8 percent in 1970 to 56.5 percent in 1980, 45.3 percent in 1991, 27.3 percent in 2007 and 24.6 percent in 2010 (Department of Statistic Malaysia). The category is known as 'Agricultural, animal husbandry and forestry workers, fishermen and hunters'. Correspondingly, the number of people employed in non-farm sector in Sarawak has increased over the same period. Sales workers, for instance, have increased from 3.9 percent in 1970 to 6.9 percent in 1991 and 12.5 percent in 2010; and those in professional and technical category increased from three percent in 1970 to 7.6 percent in 1991 and 10.2 percent in 2010 (Department of Statistic Malaysia) ${ }^{81}$.

\footnotetext{
${ }^{81}$ Appendix 3 shows the percentage distribution of employed population in Sarawak, by occupation, 19702010
} 
However, equivalent figures are unavailable for Kapit Division and District but it is likely that statistics from Department of Agriculture Sarawak (2016) shows the estimated area used for hill rice cultivation in Kapit Division decreased from 18,871 hectare in 2005 to 12,683 hectare in 2010. During my field visit, only half of the households interviewed (53.6\%) were involved in farming, either as their main or secondary household activity. Farming, in their cases, refers to hill rice cultivation, market gardening, and other cash crop cultivation.

De-agrarianisation is an on-going, dynamic process associated with a continued quest for improved accessibility to new markets and higher levels of development. This results in a structural change in employment and an estimated change in the geographic distribution of the working population, and, with a lag, i.e. the non-working population.

In the context of de-agrarianisation, accessibility plays an important role. Poor accessibility pushes rural dwellers out of the rural area, and releasing their labour from farming to non-farm activities. The surplus labour then seeks greater accessibility to non-agricultural occupations and education. At the same time, poor accessibility can potentially slow the rate of development in rural area at all three levels, the individuals, the households and the community, due to limited development opportunities comparative to areas with high level of accessibility. Thus, this limitation tends to lower residents' potential for achieving higher level of development.

In short, I am arguing that accessibility to market plays a dual role in rural settings. On one hand, accessibility to market and services can accelerate development of individuals (and their households) but, on the other hand, limited accessibility at community level can slows down the overall development of the rural area (and thereby affecting the community, households and individuals). Settlements with limited accessibility to market have less options for individual and household development (e.g. economic opportunity) compared to areas with high level of accessibility, e.g. in urban areas.

The central issue is the degree to which greater accessibility to market and services promotes development. In this chapter I explore a pattern of re-location designed to increase accessibility and raise income of families and communities - namely multi-local living.

Cramb $(2012)$ and Soda $(2003,2005)$ have already noted that the present day phenomenon in which Iban households have become multi-sited extended families. Lack of agricultural development in rural 
areas ironically means that while the size of bilik-family continues to grow but fewer and fewer bilikmembers actually lives in the longhouse. These changes to the structure of Iban households is a result of multi-local living, whereby more family members are becoming urban-based but at the same time still maintain their membership to their pun bilik.

\subsubsection{Multi-local living as a result of de-agrarianisation}

Historically, the early Iban settlers along Batang Baleh and its tributaries were subsistence farmers and heavily involved in hill rice cultivation (Freeman, 1970; Pringle, 1970), and later on ventured into cash crops such as rubber, cocoa and pepper. However, cash cropping has not been successful in Kapit District due to a number of factors. Ngidang (2012) states that cash cropping activities failed due to infertile land, while officials from several government departments in Kapit attributed this unsuccessful cash cropping to inaccessibility, remote location and lack of market. In the present day Baleh, farming is not their main economic activity and, in fact, it has not been the main activity for many of the respondents for decades.

Baleh and its hinterlands have been, and continue to, experience de-agrarianisation, i.e. a shift from farming as the sole income-generating activity to more diversified non-farm activities. The statistics which support this view has been laid out earlier (refer page 1). Similarly, discussions in Chapter Five have shown how income from selling agricultural commodity in the case study area is low, compared to income from other non-farm sources. This difference in income, to some extent, reflects why respondents are not depending on income from farming and agriculture as their main income source.

Participants stated that, unlike their pioneering ancestors, their household income is obtained from multiple sources. Their ancestors were focused on a more specialised activity (i.e. farming) and worked the farm as a family unit, while now they are diversified in terms of income-generating activities and more individualistic in terms of their approach. Nowadays, an individual could be doing multiple jobs, and, therefore, having multiple income sources. Different members of one household could also be working in different sectors, thus creates diversification at individual levels within the same household.

At village level, I asked the tuai rumah to specify the main income source of his longhouse (refer Appendix 1: Question 1.7). What I found was that the tuai rumah in all 20 longhouses indicated that their anak biak have multiple income sources. Their responses were summarised in Figure 7.1 below. 
Figure 7.1: Main and secondary sources of income according to tuai rumahs, sample longhouses, Kapit District, 2014

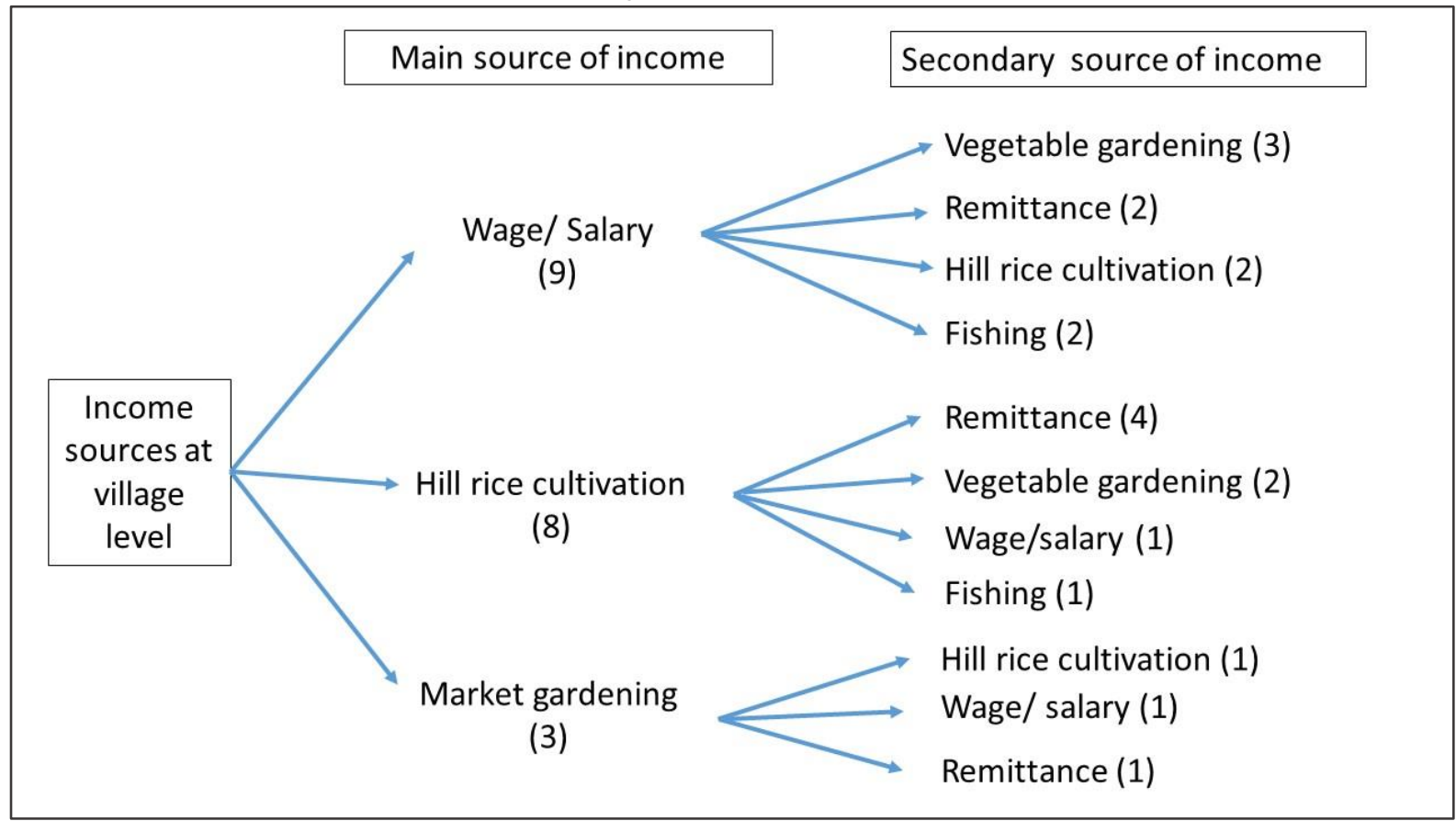

Based on interviews with tuai rumah, May- July 2014

In general, the key income sources at village levels are wage/salary, hill rice cultivation and market gardening. For example, nine tuai rumah identified wage and salary as the main income source for a majority of their anak biak. The same nine tuai rumah then identified the secondary income sources of their longhouses, and of the nine longhouses, three indicated their secondary income sources as coming from vegetable gardening. The other secondary income sources are remittance (two longhouses), hill rice cultivation (two longhouses) and fishing (two longhouses). In this research, the term income includes both monetary rewards and by-products from subsistence activities.

The emergence of wage/salary and remittance as household source of income are the consequence of the de-agrarianisation process in Baleh river basin. In their attempts to seek better living standards, e.g. through better paying jobs or higher income, a number of rural dwellers opt to seek employment outside of their villages. This movement, which, to some extent, is triggered by increased rate of deagrarianisation, has created the phenomenon of spatially dispersed households.

Spatial dispersion of household occurs when members of households are living, and working, in separate geographical locations while still maintaining their household ties. Maintaining the household ties mean maintaining their cultural ties as well as their claims to their household 
inheritance. Fan et al. (2011, p. 2166) describe this as a situation where family members who under 'normal' circumstances would be living in the same place are in actuality living in separate places. This separation includes cases whereby an individual leaves his/her family due to work commitment in different locations during working days/months but returning to the family home on non-working days/months. It also includes couples who are double wage earners with separate homes at their own work-based location and a shared, main residence. This form of spatial dispersion of household is also known by other names in various literature, e.g. dual residency (Soda, 2000, 2003), multi-local living (Dick \& Reuschke, 2012; Greiner, 2012; Schier, Schlinzig, et al., 2015; Schmidt-Kallert, 2009; Weichhart, 2015; Wood et al., 2015), split households (Ellis, 1998; Fan et al., 2011; Greiner, 2012) and multi-sited extended households (Cramb, 2012; Yamanaka, 2005). In this research, I am using the term multi-local living to describe this spatially dispersed household practice ${ }^{82}$, unless stated otherwise.

Multi-local living here refers to a situation where acknowledged member(s) of an Iban household lives separately from their ancestral home, usually the bilik in their longhouse, while at the same time maintaining their membership to the bilik-family through regular visits or meeting the conditions imposed by their respective tuai rumah. In the Iban context, ancestral home (or known as bilik) for the family is located at a longhouse and usually passed down through generations. Being a member of a longhouse is the very essence of being an Iban, and that to be an Iban is to belong to a bilik in a longhouse (Cramb, 2012, p.77). Because of this strong cultural tie, being an acknowledged member of a bilik is important. I am using the term 'acknowledged members' of household here because the Iban household structure is not as straightforward as the meaning of family or household in the western context. Acknowledged member of a household refers to an individual who is acknowledged as being part the household, a fact made known to everyone within the family and longhouse community, and he/she may or may not be living under the same roof as his/her household. In addition, household in this context refers to the independent domestic family unit known as bilik-family whose members may consist of up to four generations. As a single household, they share resources and collectively have rights to bilik's inheritance.

The phenomenon of multi-local living, which resulted in spatially dispersed rural household, is facilitated by improved accessibility to market and improvement in transportation, and information and communication technologies. These improvements have open up opportunities for rural dwellers

\footnotetext{
${ }^{82}$ It should be noted at this juncture that I am also using the term 'dual-residency' in this research. Dual residency is a type of multi-local living, but refers more specifically to a situation where the household members have two main homes, which they divided their times equally to. For example, a home in town and an ancestral home in the longhouse, and the family spend their time between these two residences.
} 
to seek employment and other economic activities outside of their village boundary. Past studies have observed such movement from rural to urban centres, which are parts of rural household livelihood strategies (L. De Haan \& Zoomers, 2003; Ellis, 1998, 2000; Fan et al., 2011; Firman, 1994; Hugo, 1982). This rural-urban movement can be in different forms such as a movement over a short distance (e.g. nearest big town from the village), a long distance (in different states) or even involve movement over regional and national boundaries. Improvements in communication and infrastructure technologies are crucial as they facilitate access to markets, which could well be outside of local or regional boundaries, by individuals, households and communities.

Interviews with head of households revealed that spatial dispersion of members of rural household has been on-going in the District for decades. This is parallel to Ngidang's (2012) discussion on household with bilik-members living separately from their main residences whilst working at timber camps around Baleh ${ }^{83}$. This observation is also similar to that of Cramb (2012), in his case study of the Iban in Batu Lintang, and Soda (2005) in his study of rural Iban in Sibu, Sarawak. The Batu Lintang Iban community is no longer spatially bound to their ancestral longhouse territory nor dependent on landbased livelihoods (Cramb, 2012, p.68-69).

At present, the movement of people is not merely confined to Kapit District, or within Sarawak. Respondents have indicated that their bilik-members are practicing multi-local living in other states in Malaysia, as well as outside of Malaysia. Map 7.1 and 7.2 below illustrate the dispersion of rural households at international, national and local levels.

\footnotetext{
${ }^{83}$ Employment opportunities in timber industry in 1960s drew surplus rural labour from longhouses, and this has prevented out-migration from rural Kapit to urban areas, but instead encouraged rural-rural movement within the District. Expansion of logging in 1980s created greater opportunities when men who work at various timber camps brought along their wives when they worked in the camps, and their wives became entrepreneurs by selling food items at the camps (Ngidang, 2012, p.166). In the 1990s, however, due to decline in timber industry, surplus labours from timber camps were pushed back into the longhouses, but this did not last long. The surplus labours, unable to cope with limited economic options in longhouses soon left to seek employments in other urban centres.
} 
Map 7.1: Dispersion of (sampled) households at national and international level, 2014

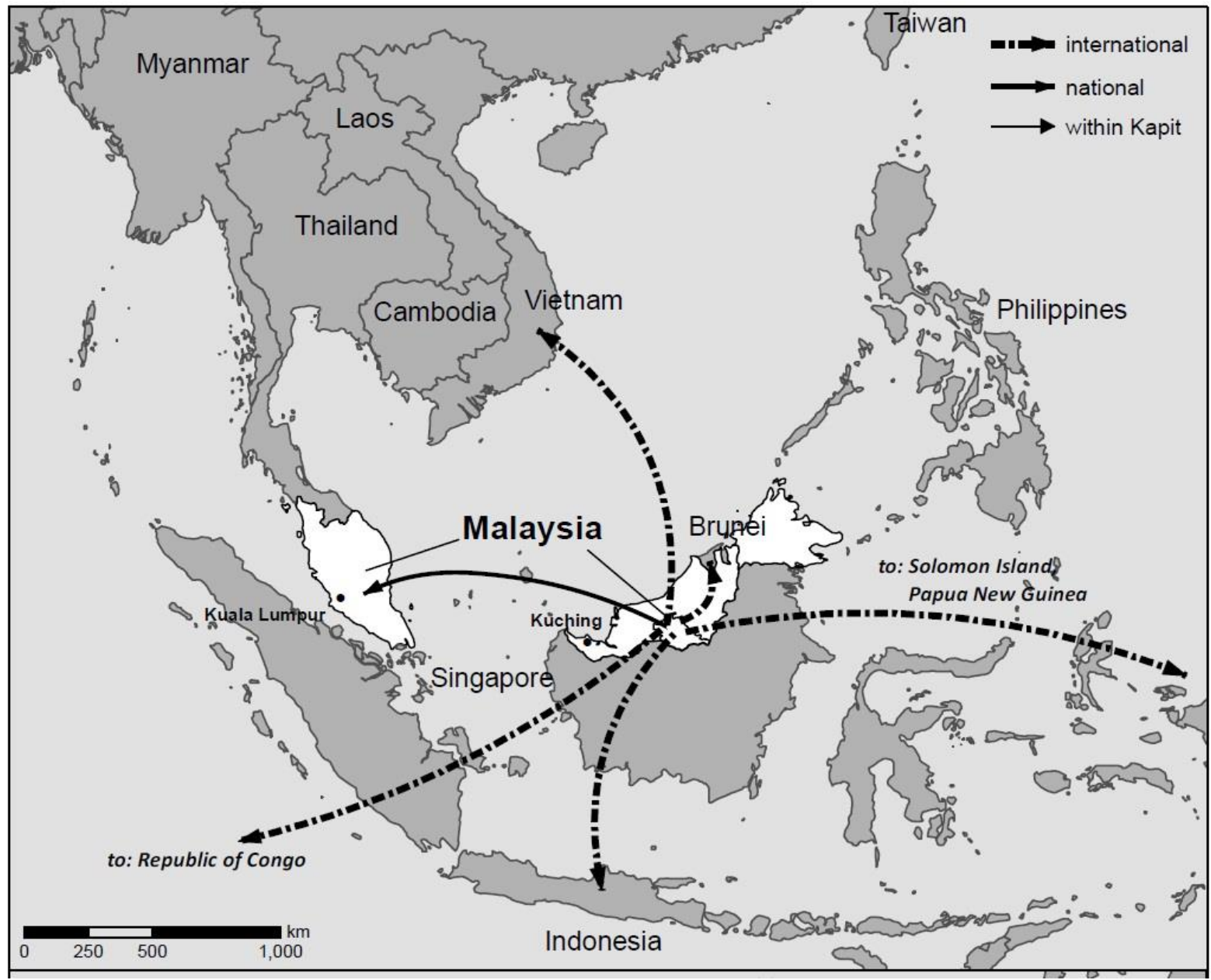

Map 7.2: Dispersion of sampled households within Kapit District, and within Sarawak, 2014

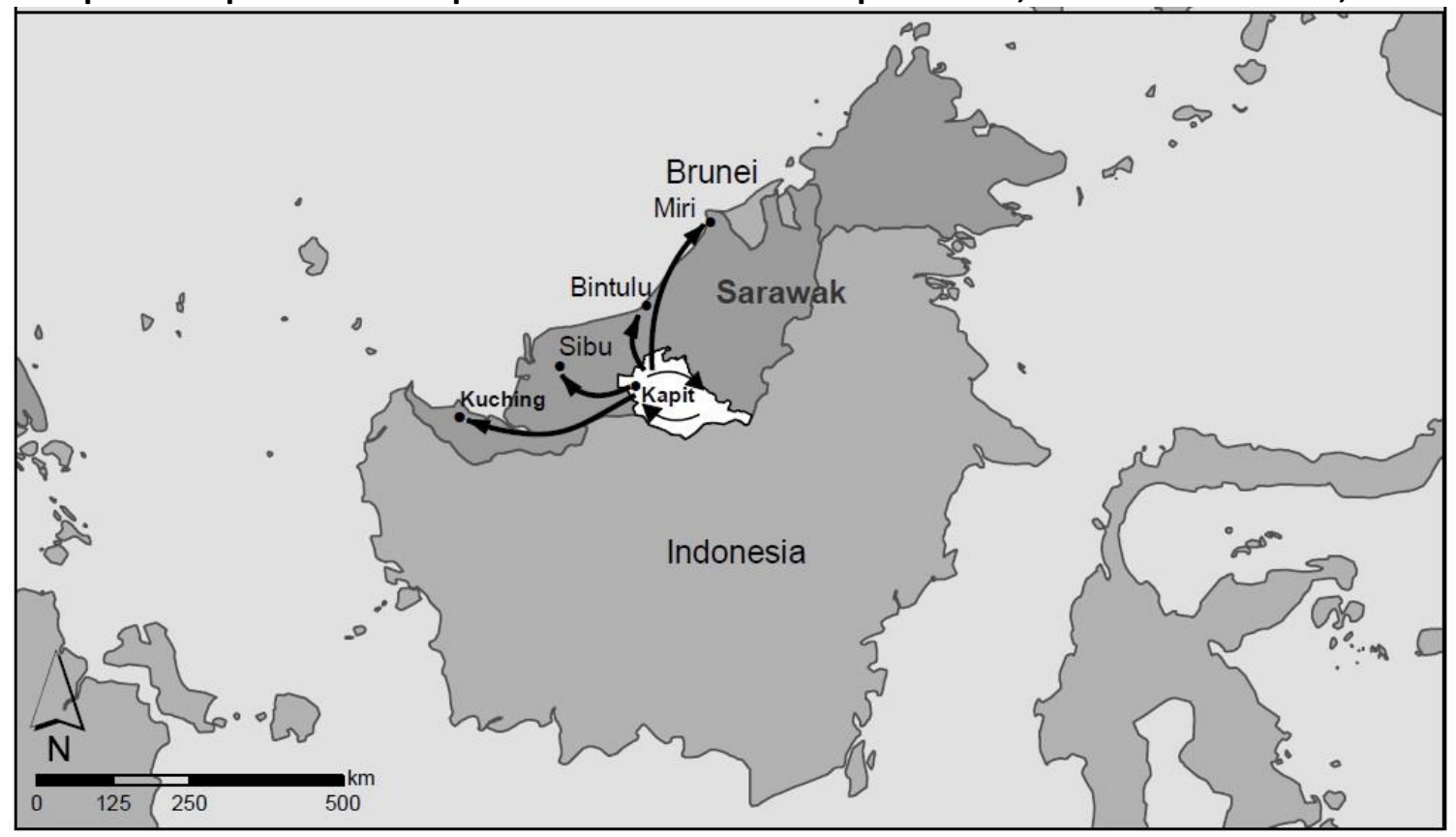


Accessibility to 'outside' opportunities is also aided by education. Cramb (2012, p. 68), his case study of Iban households in Batu Lintang, Sarawak, notes how educated young Iban move permanently to urban-based employment, sending remittances to help support their parents back in the longhouse. Similar situation, which I will elaborate later, is also happening in my case study area. The above maps, for instance, highlight how widely the members of sampled households in Kapit District are geographically dispersed.

\subsubsection{Profiles of bilik-members practicing multi-local living}

Multi-local living is prevalent within the Iban community in my study. Nearly every household that I interviewed has at least one family member practicing multi-local living. This is illustrated in Figure 7.2 below.

Figure 7.2: Distribution of households with bilik-members who are practicing multi-local living, by accessibility zone, 2014

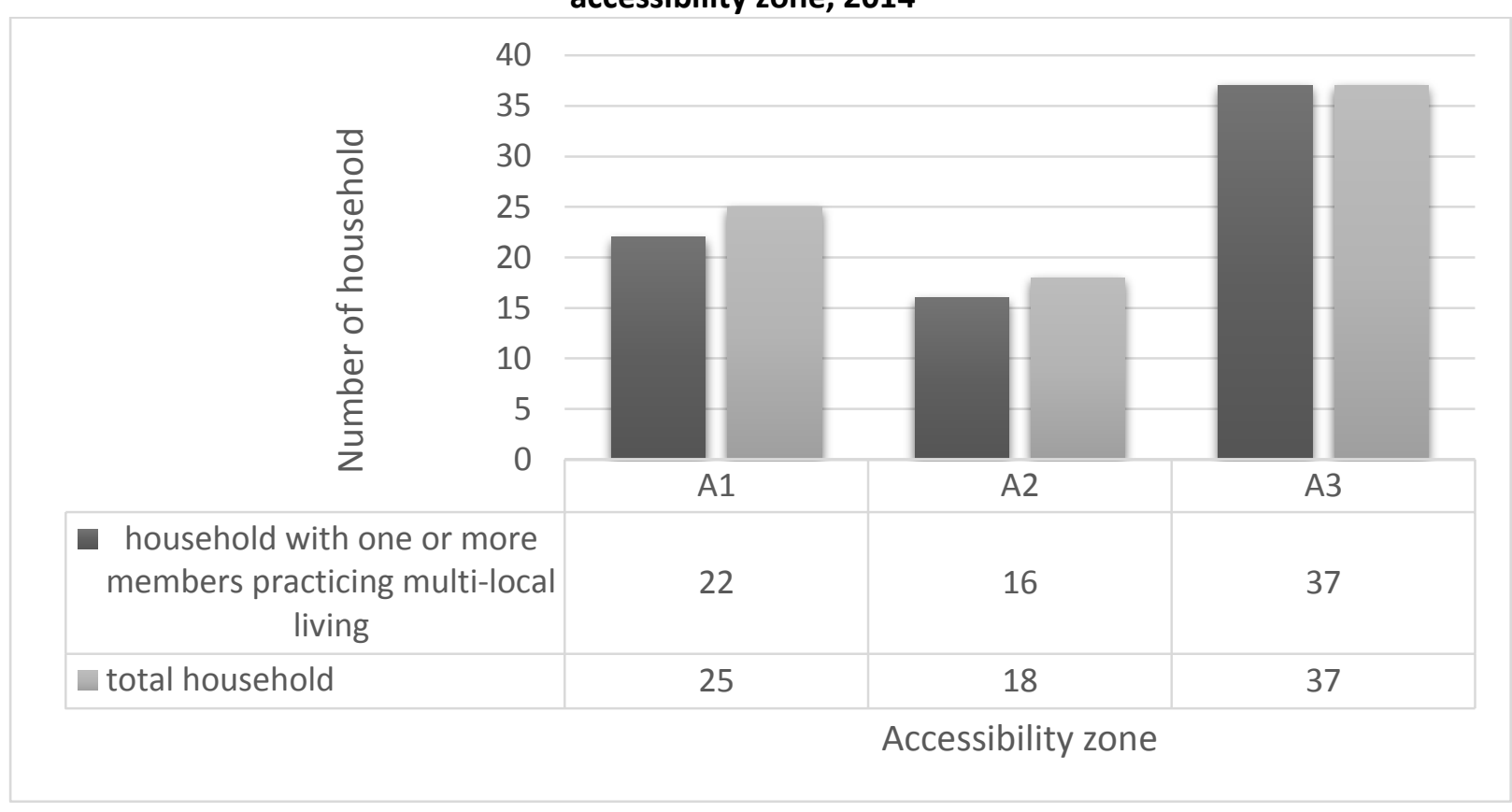

Based on field work, May-July 2014

At the individual (bilik-member) levels, approximate 57 percent of all bilik-members in the sample population are practicing multi-local living. This is equivalent to 302 (out of 531) individuals from 20 longhouses, and from 82 households. Their profiles are shown in the following Table 7.1. 
Table 7.1: Profiles of individuals from sampled households who are practicing multi-local living, by accessibility zone, 2014

\begin{tabular}{|c|c|c|c|}
\hline & $\begin{array}{c}\text { High Accessibility } \\
\text { Zone (A1) }\end{array}$ & $\begin{array}{c}\text { Medium } \\
\text { Accessibility Zone } \\
\text { (A2) }\end{array}$ & $\begin{array}{c}\text { Low Accessibility } \\
\text { Zone (A3) }\end{array}$ \\
\hline Number of respondents & 96 & 60 & 146 \\
\hline Percentage of respondents & 31.8 & 19.9 & 48.3 \\
\hline Age (average) Below 18 years old (\%) & 30.5 & 25.8 & 30.0 \\
Working age - 18-65 years old (\%) & 17.7 & 33.3 & 15.8 \\
Over 65 years old (\%) & 72.9 & 65.0 & 80.8 \\
Fender (\%): Female & 9.4 & 1.7 & 3.4 \\
Male & 39.6 & 50.0 & 46.4 \\
\hline Single & 60.4 & 50.0 & 41.1 \\
Married & 40.6 & 53.3 & 54.8 \\
Divorced & 59.4 & 43.3 & 3.4 \\
Widowed & - & 1.7 & 0.7 \\
\hline
\end{tabular}

Based on Bilik-member Dataset, 2014

As expected the highest proportion of individuals practicing multi-local living is from the working age category (i.e. between 18 to 65 years old ${ }^{84}$ ) and similar pattern can be seen across the accessibility zone. This is parallel to the discussion in the previous chapters, which highlighted the situation whereby more rural dwellers are seeking 'markets' outside of their place of origin in order to improve their levels of 'development' (both individual and household development, e.g. through higher income, remittance, and better education and facilities).

As discussed in Chapter Five, without income from commodity sales, and employment opportunities from the operating timber camps in the area, there is very limited livelihood option for rural dwellers especially from mid to upper Baleh (i.e. A2 and A3). Multi-local living is an obvious response to their poor accessibility to market.

Reasons for practicing, and forms of, multi-local living are varied (see Figure 7.3), but can generally categorised into three purposes: employment, education and family commitment. There are individual who practices for multi-local living alone, together with their family, or opt for dual residency. Those who take their families with them are usually better off financially, or in a more permanent situations compared to those who just started out. Civil servants or individuals who are in higher paid employment, tend to bring their family along. However, if the place of work is further away from the longhouse, or in areas which they are not familiar with, the individuals tend to go alone,

${ }^{84}$ This is the age range for labour force as identified by the Department of Statistics Malaysia. 
at least at first. This situation applies to situations when the type of employment is casual or temporary, i.e. individuals have higher tendency to go alone than bringing his/her family.

Figure 7.3: Reasons for practicing multi-local living, at individual level, by accessibility zone, 2014

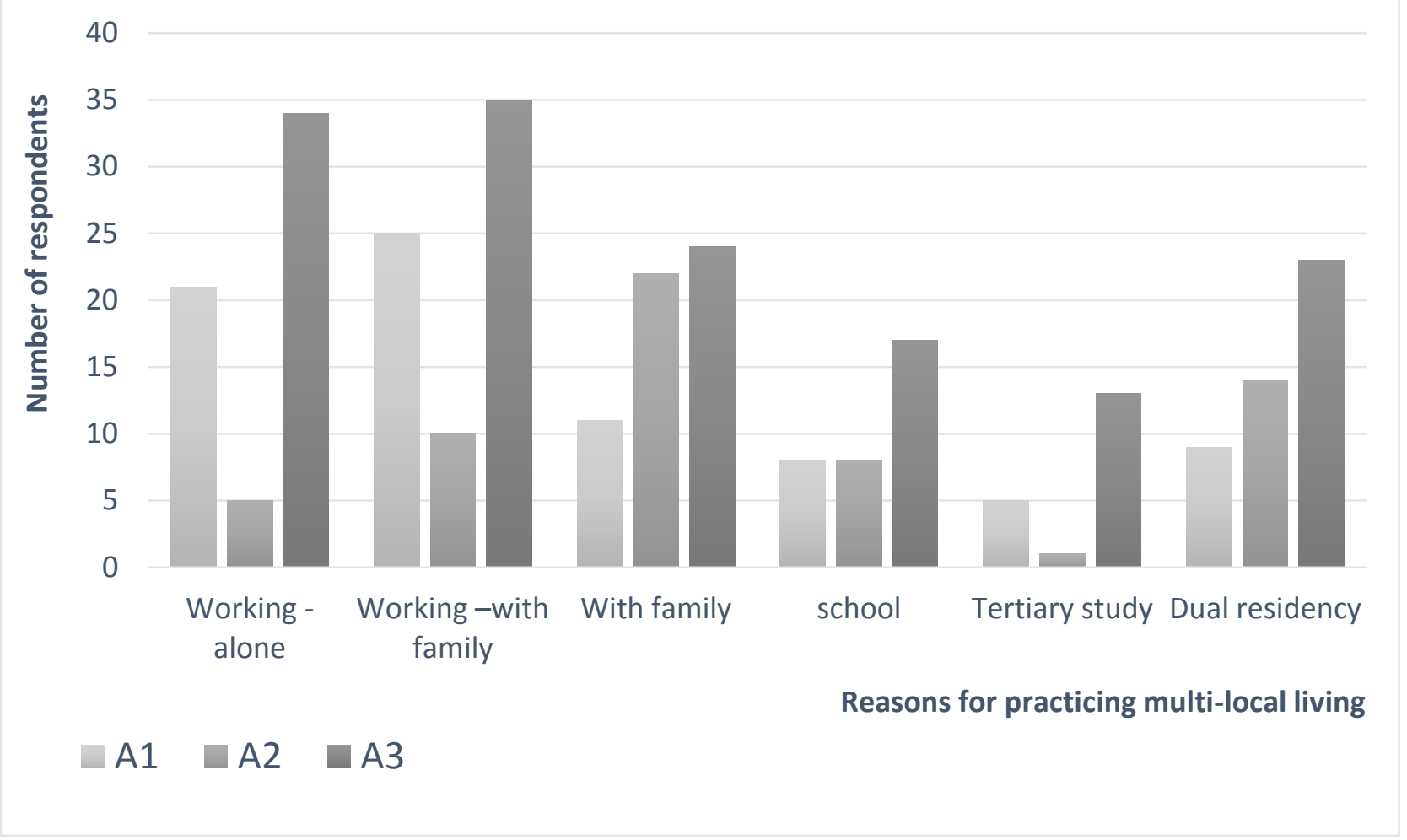

Based on Bilik-member Dataset, 2014

Soda $(2000,139)$, in his study of Iban rural-migrants in Sibu, finds that more females are leaving their villages to accompany their spouses who are employed in urban areas. He also argues that family migration is vital because the likelihood that the family to stay longer in urban areas are higher than that of a single migrant. Similar observation was made by Fan et al. (2011) who identified three types of migrants in their study of rural-urban migrants and split household in China: sole migrant, couple migrant, and family migrant. Sole migrant, according to Fan et al. refers to one member of the family, usually the husband or an adult unmarried child, leaving home for migrant work while other family members stayed behind, while couple migration involve bringing the spouse along, but leaving the children back in the village. The third type of migrant they identified is the family migrant, which involves the migrant couples bringing their children along with them. The latter becomes increasingly common in China, and reflects growing desires to leave the countryside for good (Fan et al., 2011). They further explained that the type of migrants influence whether the migration is likely to be short, temporary or permanent. The Chinese households' migration, however, are restricted by the hukou system, a household registration system in China which officially identifies residents' residency status. 
This system makes it difficult for its rural dwellers to settle permanently in urban centres, and also explains why children (and spouses) are often left behind (Fan et al., 2011). The rural Iban households have no such restriction, and, therefore, the likelihood of settling down permanently in urban centres with families are greater.

Whatever the reasons, or types of multi-local living practiced by respondents, the underlying intention is clear: to seek higher level of development, and not just for themselves as individuals, but also for their bilik-families. However, the implications are not confined to the individuals and households, as any changes to livelihoods and households also affect the longhouse community as a whole.

\subsubsection{Multi-local living and the accessibility-development relationships}

In the context of accessibility-development relationship, multi-local living can be seen as a propeller of development at both individual and household levels from two perspectives. Firstly, multi-local living is a way for an individual, and, to some extent, their household, to expand their income generating potentials. Household members who re-locate to be reap the economic benefits elsewhere by practicing multi-local living contribute to their household via remittance and 'social connection'. The latter refers to how a multi-local individual may help other members of his/her household or village to gain access to markets outside of their villages. Secondly, multi-local living can improve households' overall standard of living via dual residency practice. In contrast with the former, dual residency enables members of the household, as a household unit, to benefit from maintaining two main home. Discussion below uses income as an example to contextualise the relationship between accessibility and multi-local living practices.

\subsubsection{Multi-local living and individual income}

A majority of the respondents who practice multi-local living for employment purpose are male $(77 \%$, $\mathrm{n}=86$ ). They originate from all three accessibility zone; i.e. $40 \%$ from $\mathrm{A} 1,11 \%$ from $\mathrm{A} 2$ and $49 \%$ from A3. In order to get a clearer picture of the distribution patterns of respondents who practice multilocal living, I plotted its accessibility-development relationship using individual income as development measure and average travel time to Kapit Town as accessibility measure. The result is shown in Figure 7.4 below. 
Figure 7.4: Individual income of respondents who practice multi-local living by distance to Kapit Town, 2014

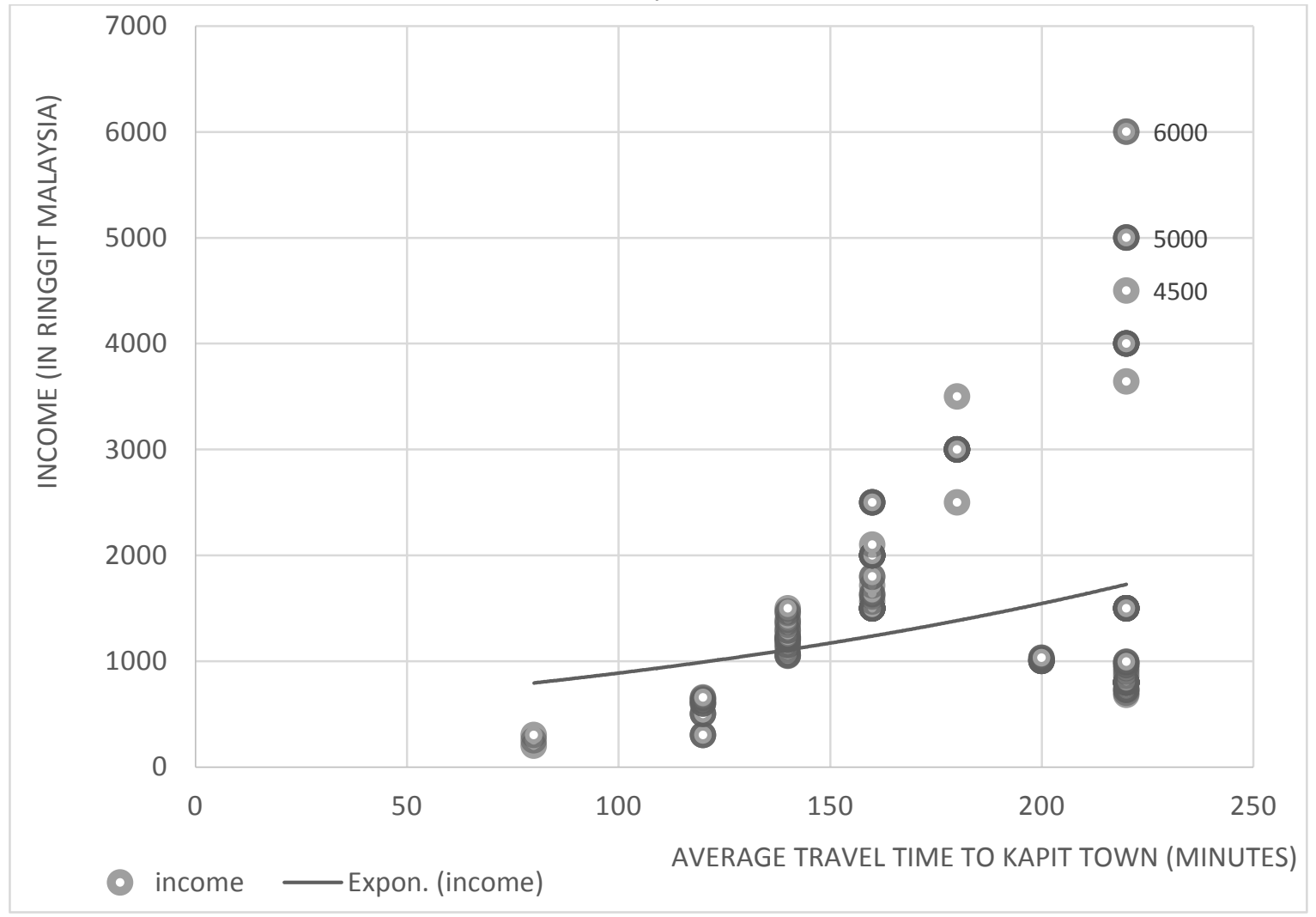

Note: Exponential relationship at $y=510.44 e^{0.0055 x,}$ and $R^{2}=0.1038$

It seems that respondents who practice multi-local living for the purpose of employment $(n=162)$ and originally from longhouses that are located further away from Kapit Town are currently earning higher (individual) income than those who are from areas nearer to Kapit Town. As I have explained in the previous Chapter Five, when I discussed the relationship between accessibility to market with remittance and total household income, a number of households in A3 has bilik-members who work overseas, with considerably higher than average salary compared to those who work within Sarawak and within Malaysia.

Thus, the difference in income can be explained in the context of accessibility to (employment) networks and outside employment opportunities (refers to opportunities beyond Kapit Town and Kapit District). Respondents observed that after the 1997 Asian financial crisis, many workers in timber companies operating in Baleh started to work outside of the country - as they were offered job opportunities by their employer at that time to join the companies' operations overseas. These workers were chosen for their skills and experience in the timber industry, and their access to 'outside employment market' enhances their potential overseas. At the same time, participants observed that 
the 'new' workers in timber camps around Baleh are the 'younger generations' who just entered the employment market and not have experience. My data on respondents who are in the timber industry confirmed this observation. Those who are practicing multi-local living outside of Malaysia are between 40 to 50 years old (average age of 44 years old), and those who are practicing multi-local living within Kapit are between 20 to 67 years old (average age of 42 years old). This situation highlights how accessibility to timber-related employment market, as well as accessibility to network, benefits the older, and more experienced, workers to obtain higher income jobs.

In general, the average individual income by those who practice multi-local living for the purpose of employment varies slightly by their current location. Those who are living and working in other parts of Kapit Division ${ }^{85}$ earn an average monthly income of RM1368 (standard deviation= 995.677), while bilik-members who live and work elsewhere in Sarawak ${ }^{86}$ earn an average of RM 1589 (standard deviation=1020.248). Individuals who work in other parts of Malaysia and outside of Malaysia are earning a higher average income than individuals who opted to live and work within Sarawak and within Kapit Division. They earn an average of RM1825 (standard deviation= 1203) and RM3386 (standard deviation= 3931 ) within Malaysia and outside of Malaysia respectively.

It should be noted that these average incomes are considerably higher than the average individual income of respondents in the longhouses. Therefore, the income differences arising from multi-local living practice have implications on both individuals and households. This difference can be seen as a direct result of different types of accessibility to market experienced by different individuals and their households. This different levels of accessibility, and its related potential for development, vary at (and within) communities, households and individual levels. This difference also attributes to inequality experienced by the different groups of households and individuals within households.

\subsubsection{Dual residency and implication on household development}

The second perspective on this accessibility-development relationship in the context of multi-local living can be explained by exploring 'dual residency' practices among the respondents. Dual residency is a form of multi-local living but it refers specifically to a situation where the bilik-members have two main homes, and they divided their time between these two homes. One of these homes is their

\footnotetext{
${ }^{85}$ Kapit Division comprises of three districts, which area Kapit, Belaga and Song.

${ }^{86}$ Mainly in the main cities and towns in Sarawak, including Kuching, Miri, Bintulu and Sibu.
} 
ancestral bilik at the longhouse. Ngidang (2012, p.176) describes dual residency as crafting a niche in an urban environment while maintaining a bilik-family in a longhouse in the hinterland.

Dual residency is a common practice among respondents who want to take advantage of living both in Kapit Town, as well as the longhouse. Approximately 48 percent of households have bilik-members who are practicing dual-residency (i.e. approximately 40 individuals with dual residency status). It should be noted that this figure is different from that of multi-local individuals (whereby 91.5 percent of households have members who are multi-locals). Respondents who are living further away from Kapit Town are more likely to practice dual residency than those nearer to Kapit Town. Approximately 50 percent of households in A3 are practicing dual residency compared to only 22 percent and 28 percent in $\mathrm{A} 1$ and $\mathrm{A} 2$ respectively.

The reasons behind these figures are, again, largely associated with their level of accessibility to Kapit Town. For example, respondents in $\mathrm{A} 2$ and $\mathrm{A} 3$ comprise of families who live in Kapit Town during weekdays or school terms, but are back at their biliks in the longhouses during weekends and school holidays. In general, most of the dual residency is for the purpose of education and employment, and that having a base (i.e. a home) in Kapit Town helps to increase their accessibility to these different markets (i.e. employment and education markets). Ngidang made similar observation with regards to the advantage of having a base in Kapit Town for individuals and their households,

"In the 1960s, Iban coming from the hinterland slept in the five-foot passageway of Chinese shops with their goods piled up around them if they could not make a day-trip back to their longhouse ... new homes in Kapit served as a convenient accommodation for parents or family members while seeking medical treatment, meeting with government officials, requesting assistance and services from local authorities and, of course, getting their supplies from Kapit, so that they would not have to stay in hotels or lodging houses."

(Ngidang, 2012, pp. 176-177)

In the long run, this practice helps improve their levels of development, at both individual and household levels. As an illustration, $\mathrm{HH} 70, \mathrm{HH} 72$ and $\mathrm{HH} 74$ are three households from the same longhouse in A3 who now have houses in Kapit Town. At the same time, these three households still retain their biliks in the longhouses as their other main residences. These three households are practicing, more specifically, dual residency. They spent time between their two residences and treated them both as their main home. All three head of households explained that their low accessibility level and their disadvantaged position, both spatially and economically, had driven them to make this choice of adopting dual residency. 
"It is hard to improve your family's standard of living if you do not have the same opportunities as other people who live nearer to Kapit Town ... they have all the opportunities to develop themselves and their families ... we cannot do that. After my divorce, I went to town and started my tailoring business ... back at the longhouse I was doing odd-jobs ... farming and selling vegetables ...my small business is doing well and I bought a flat ... I then bring my family (mother and children) with me ... we still stay in longhouses during weekends and school holiday. This (arrangement) is so much better than (my situation) before."

(HH72, A3, June 2014)

\begin{abstract}
"We bought this flat so that we can live in Kapit Town to make it easier for my husband to work, and for my children to go to school. There is not much job opportunity if we stay in our longhouse ... income from farming alone is not sufficient for our family ... and everything is expensive nowadays. Here, my children can go to school easily - no need to use the longboat to go to schools like our relatives back in the longhouse. My two eldest children are doing well and they are now studying in schools in Kuching with scholarship from the government, and another son is still in school here in Kapit. We still go home to the longhouse ...it is still our home, but we only go during school holidays and weekends."
\end{abstract}

(HH74, A3, June 2014)

"We bought this plot of land over ten years ago and build this house. I work at timber camps and couldn't leave my family at the longhouse ... hard for my wife to send our children to school and expensive too. So we moved here, for their education and for them to be nearer facilities - hospital, shops, electricity, clean water ...since then we divided our time between here (house in Kapit Town) and our bilik in the longhouse. Now, my grandson is disabled and need to be near hospital for his monthly treatment ... we cannot have the same access if we were to live in our longhouse ..."

(HH70, A3, June 2014)

Compared to the other people from their longhouse, these three households are doing significantly better in terms of their household socio-economic development (i.e. measured through their household income and educational attainment of bilik-members). Their average monthly household income is RM3300 (HH74), RM4150 ( $\mathrm{HH72}$ ) and RM3220 (HH70), and that amount is significantly higher than the average monthly income of residents at their longhouse in A3 (RM925, with a standard deviation of RM1008.89). Their situations, therefore, highlight how dual-residency practices can improve an individual's and household's overall standard of living.

This practice of dual residency is made possible, firstly, through the improvement in physical accessibility in Kapit District, and, secondly, because of the improvement in the socio-economic standing of the households that practice dual residency living. The former refers to the improvement in transport system and the new Nanga Mujong link road. Both of these improvements, according to the respondents, have made their journeys between Kapit Town and their respective longhouses 
feasible, cheaper and less time consuming than before the link road was constructed. Meanwhile, the latter means that dual residency is possible as those who practice it are in a better socio-economic position, and are able to afford the costs, and frequencies, of travel between these two locations.

In other words, dual residency, which is a form of multi-local living, is another response to the lack of accessibility to market experienced by respondents who are located in areas beyond the agricultural margin. This practice is more prevalent among households who opted to remain within Kapit District and maintain their two residences for their individual and household development instead of practicing multi-local living outside of Kapit District.

\subsubsection{Multi-local living and human capital development}

Besides multi-local living for employment and dual residency, which contribute to increased standard of living for households and individuals, the other frequently cited reason for multi-local living is education. In my sample population, approximately 58 individuals are practicing multi-local living for the purpose of education, both at secondary school and tertiary education level.

Approximately 91 percent of individuals who practice multi-local living for education at school level are living in Kapit District. This is because three of the secondary schools in the District are located in Kapit Town, and the other secondary school is located near Karangan Ara, at upper Baleh in A3. These students practice multi-local living as they stay at the school during school term and only go home to the longhouse during school holidays and selected weekends. Meanwhile, the other eight percent (i.e. two respondents) are living and studying in different divisions (i.e. one in Miri and one in Kuching).

For the tertiary category, 63 percent of the respondents are studying and living in Sarawak's other divisions. They are concentrated mostly in Kuching and Kota Samarahan, which offer a number of postschool and tertiary institutions. Another 25 percent are studying at tertiary institutions in the other Malaysian states while the other 12 percent remains in Kapit Division. The latter includes those who are continuing their studies at STPM level.

As discussed in Chapter Six, household and individual development can be measured by their progress in education and human capital development. In this context, multi-local living for the education purpose can be construed as household's and individual's strategy for development. Accessibility to market - in this case, market might be referring to the educational institution - determines the level 
of development potentially achieved by individuals and households. In other words, households are using the sales of agricultural commodity and labour to 'purchase' education for their household members. Discussions with parents who have children pursuing tertiary education suggested that they - both the parents and children - are aware of the significance of education. Several respondents equate having education as having a passport out of permanent life in the longhouse. This is particularly significant in the period where de-agrarianisation has push rural dwellers to abandon farming for a more diversified, non-farm sources of income. This economic re-orientation put a spotlight on the importance of education as the key link to 'access' other economic opportunities. This move also denotes a societal shifts in focus from physical capital development (i.e. farming and the value of farm land) to the less tangible form of development: its progress in human capital. Similar observation was noted by Rigg and Nattapoolwat (2001) and Rungmanee (2014) in their studies exploring rural mobility in Thailand. For example, Rigg and Nattapoolwat (2001, p. 952) state that rural Thai villagers in their case study area realised how schooling is correlated with income and types of employment and that education can bestow significant added value in an economy that is becoming increasingly knowledge and skill dependent.

Whilst the respondents acknowledge the significance of education in their household development, they also argued that sending their children to pursue tertiary education is expensive. Unlike schools, which are within easy access from their longhouses, the tertiary institutions are often located in major cities throughout Malaysia. The cost of sending their children to study at tertiary level is expensive, and not every family can afford it. The respondents' accessibility to higher education, and, hence, the associated potential household and individual development, is restricted by the cost of tertiary education. I found that, almost all of the individuals who are currently studying at university level come from households with better than average socio-economic background. These households' average in-situ income is approximately RM2862 a month, and the average in-situ income in the area is approximately RM1758 a month.

In other words, the relationship between accessibility and human capital development is influenced, by cost of education and socio-economic status of the household. Practice of multi-local living is seen as a way to bridge this cost and to increase access to education markets. 


\subsection{Implications of multi-local living on household structure}

Iban have a strong cultural attachment to their bilik and longhouse. This can be seen from the way bilik-family is organised and how the sense of belonging (to a longhouse) is rooted within the Iban community. To be an Iban means one has to belong to a longhouse (Cramb, 2012) and that an Iban can only belong to one bilik in one longhouse (Freeman, 1970).

Despite being geographically dispersed from their longhouse and bilik-family, the individuals who are practicing multi-local living still maintain ties with their longhouse and household. This is done in a number of ways, e.g. frequent visits to the longhouse, remittances, and involvement in household decision-making (Hew, 2011; Ngidang, 2012; Soda, 2000, 2005). Cramb (2012) highlights how the Iban community in his case study area are no longer spatially bound to their longhouse or dependent on their land for livelihood but, for them, the longhouse and their ancestral land remain important. Soda $(2001,2005,2007)$ wrote extensively on how urban Iban maintain ties with their longhouse, which he claims are essential as part of the urban Iban's survival strategy. Soda's research also highlights that a majority of urban Iban migrants indicated that they want to maintain the ties with their longhouse community but at the same time reaping the advantage of urban living. This strategy enables them to be part of the longhouse community and, therefore, maintaining and validating their claim to their bilik's assets. As previously mentioned, in Iban society, only acknowledged members of the bilikfamily have the rights to inherit. I use the term 'acknowledged member' to describe an individual who is acknowledged as being part the household, a fact made known to everyone within the family and longhouse community, and he/she may or may not be living under the same roof as his/her household.

While this practice of multi-local living has its advantages to both individual and household development, it has, to some extent, resulted in unavoidable changes to the residential composition of the Iban household. Improvement in accessibility has encourages more and more rural dwellers to participate in multi-local living as a response to de-agrarianisation and to seek better standard of living. This, consequently, affects the traditional household structure of the rural Iban, in particular the functions of household and the roles that each bilik-members play.

\subsubsection{Changes in traditional Iban bilik-family structure}

The widespread multi-local living practice among the rural Iban is one of their responses to overcome problems associated with de-agrarianisation, and a way to 'develop', both at individual and household 
levels. Ngidang summarises how the Iban in Baleh changes over time from their pioneering days till the present time,

"In the 1800s, Iban pioneers were shifting cultivators, hunters and gatherers, mobile people ... In the 1900s, they became sedentary subsistence farmers; they had worked the soil, roamed the jungle, cleared the forest ... Now these pioneers are long gone ... In 2000s, many of their descendants are now migrant workers and wage earners far from their homes; no longer do they subsist by working the land ..."

(Ngidang, 2012, p. 171)

Similarly, Cramb notes that, in Batu Lintang,

"Thirty years ago, most people lived and worked within the longhouse territory and derived their livelihoods from a combination of subsistence and commercial agriculture, supplemented and buffered by periodic off-farm employment. Now most households derive their livelihoods mainly or exclusively from non-agricultural, urban-based employment, and the population resident in the longhouse has declined and aged."

(Cramb, 2012, p. 86)

Soda (2001) finds that the Iban households in Rantau Kemiding village in Kanowit, Sarawak also display changes in the face of de-agrarianisation. He states that an increase in female out-migration was a rather recent trend, which has been accelerated by the relatively stabilised income and improved living conditions of their husbands who are working in urban areas (Soda, 2001, p. 102).

These movements and the practice of multi-local living are influenced largely by the improvement in transport, infrastructure, and information and communication technology. These improvements have enabled rural residents to pursue higher levels of accessibility to different markets, which are often located outside their villages. These changes in technology advancement on accessibility and development can also be seen in terms of how Iban bilik-family structure are changing, or, rather, transitioning into a different form from its traditional agrarian-based structure. Improvement in accessibility, both physical and non-physical, encourages multi-local living, and as Kelly $(2011,494)$ puts it "migration is more than an outcome of agrarian transitions - it is also a driver of change in rural areas". In this context, this change is reflected in the changing structure of traditional Iban household into a more contemporary urban-based multi-local household. The links that bind these spatially dispersed households to their ancestral home in the longhouse is their cultural attachment and Iban custom. 


\subsubsection{Concept of Pun}

Membership to a bilik is of paramount importance in Iban custom, with several scholars even explaining that to be an Iban one has to belong to a bilik in a longhouse (Cramb, 2012; Kedit, 1993; Sutlive, 1992). Freeman also describes similar sentiment, saying that every individual in Iban society is born into one particular bilik, either his/her father's ancestral bilik or his/her mother's natal bilik; and that it is a custom that an Iban can only belong to one bilik at one time. Sutlive (1992, p. 49) explains that under Iban customary law the longhouse into which an Iban is born, marries, or moves is recognised as his/her legal residence even if he/she may work and reside in another area for eleven months out of the year. This relates to the significance of continuity of an Iban bilik. This continuity is very important to Iban society and there should always at least one child, either married or has reach maturity, remains with the parent(s) to maintain the continuity of the ancestral bilik (Cramb, 2012; Freeman, 1970). This explains why couples who do not have children resorted to adoption in order to continue the survival of their biliks, or otherwise the bilik will be wiped out (known as punas).

Concept of Pun was described by Freeman (1970, p. 31), in his explanation of Iban bilik-family, as a term that literally means the root or the foundation of a bilik (Freeman, 1970). It is a concept which is used in the traditional Iban society to describe the notion of continuity of an Iban bilik-family.

"The Iban have a special term to signify the person who is the senior member of a bilikfamily, by right of descent. Such a person is called the pun bilik - literally the root, or the foundation ... it is recognised that there is a person from whom the ownership and inheritance rights of all the other members of the family ultimately stem, irrespective of whether these members be natal, adoptive or affinal."

(Freeman, 1970, p. 31)

Additionally, Sather (2006) explains that,

"... the term pun may convey a notion of group continuity. For example, a pun tusut refers to a 'main-line' genealogy from which branching or collateral lines are said to 'break off' ... Each branching line has a new 'source' and the potential of becoming a main-line itself in the future. The same imagery of 'stem' and 'breaking off' also applies to the bilik-family and is used to describe the processes of succession and partition."

(Sather, 2006, p. 84)

In every bilik-family there is one pun bilik, who is usually the most senior member of the household. $\mathrm{He} / \mathrm{she}$ has either founded the bilik-family or has inherits it from the previous branch of his/her family. A new pun bilik is formed when bilik partition occurs, which happens when one or more siblings 
disaffiliate from the ancestral bilik to form a new and independent household (Freeman, 1955, p. 8). When this happens the new head of household now becomes the new pun bilik for the newly created bilik-family and will lose all rights to inheritance from the previous bilik-family.

The participants in my research still talk about which of their children is inheriting their bilik, or about how their collective family property is still undivided between the siblings as they were still part of the pun bilik. I believed that the participants still, to some extent, put great emphasis on this traditional notion of continuity. However, with the rise of de-agrarianisation and increasingly contemporary lifestyle adopted by the Iban as part of their livelihood survival strategy, what does it mean for the future? How does this modification in accessibility-development relationship affect the Iban family structure?

\subsubsection{Iban bilik-family structure}

Using Freeman's classic study of the pioneering Iban in Baleh as a key point of reference, I will explain how the structure of Iban bilik-family in Kapit District is evolving. Freeman observed that each bilikfamily is a small independent domestic unit, consisting of three to four generations.

"... the Iban bilik-family is essentially based on the simple or elementary family consisting of a father and a mother and their children ... The development of extended families is precluded by a strong tendency towards partition as soon as a bilik-family increases in size and collateral elementary families begin to emerge."

(Freeman, 1970, pp. 11-12)

Sather (2006: 91) also made similar observation in his study of Saribas ${ }^{87}$ Iban, stating that a bilik-family normally consists of three generations - the parents, a son or daughter, and his or her spouse and their dependent children.

During my fieldwork, I observed that a small bilik-family is typically similar to the one described by Freeman and Sather. The bilik-family consists of a small family unit, with head of household and his spouse, and their dependent children. The example of this bilik-family is illustrated in Figure 7.5 below, and it is the simplest form of an Iban bilik-family structure, with the head of household as the pun bilik. It differs, however, from Freeman's observation because of the bilik-members' multi-locality. Freeman observed that every bilik member in an Iban household actually live under the same roof, in the same bilik, as the pun bilik.

${ }^{87}$ Saribas District now known as Layar District, and is approximately 120 miles southeast of Kuching. 
Figure 7.5: Example of small bilik-family unit

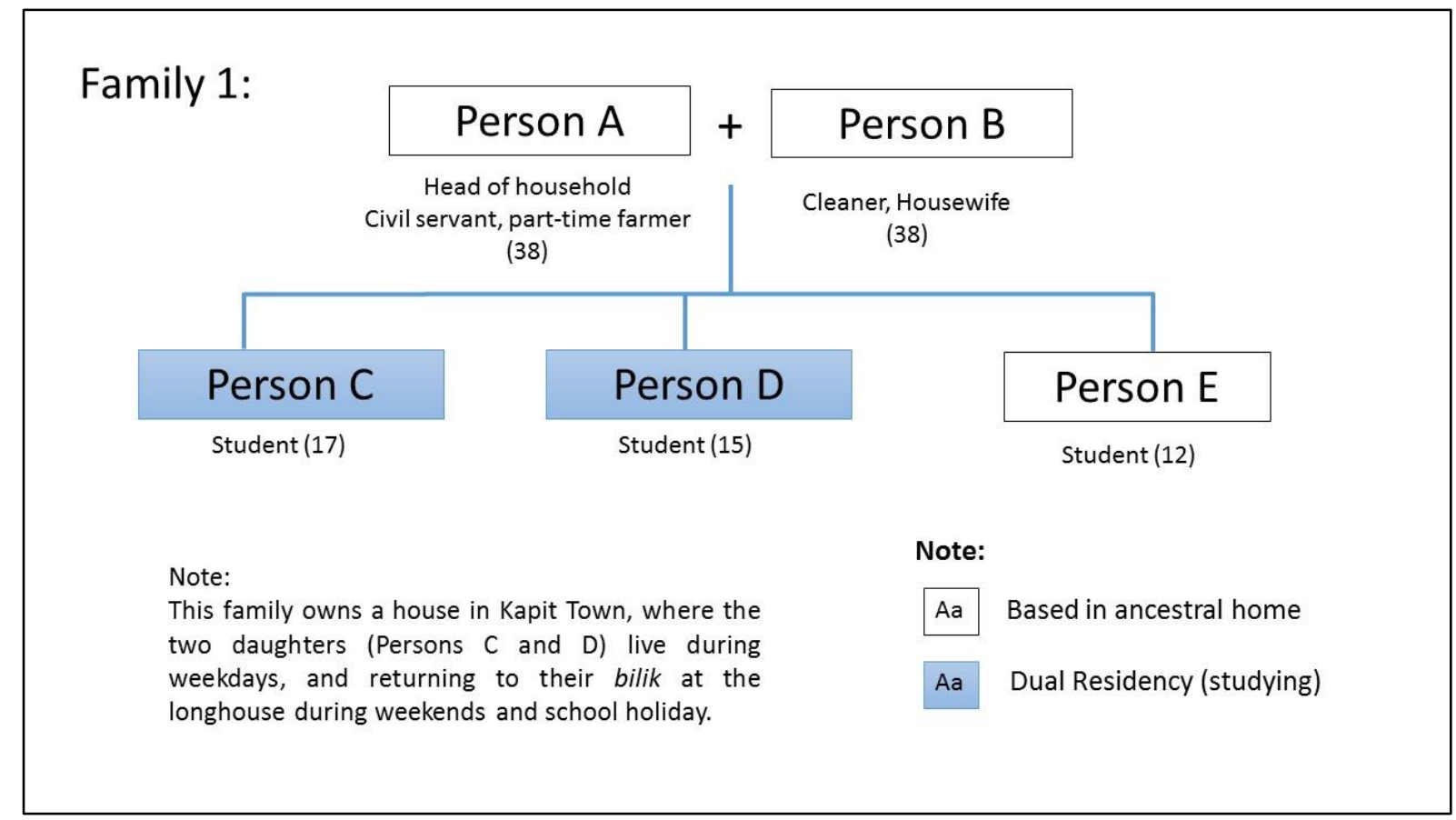

(Note: Names in the diagram have been changed to protect confidentiality)

In the case of Family One above, two of their children (Person C and Person D), who are in secondary school, are practicing dual residency for the education purpose. Since secondary school is only available in Kapit Town, both girls only live with the family at their longhouse during weekends and school holidays. The youngest son (Person E), who is still in primary school, is staying at the longhouse with the parents. This spatial dispersion of school-going children and their family has become an accepted norm for family with school-going children in Kapit District.

Meanwhile, Family Two, as illustrated in Figure 7.6 below differs slightly from the previously described Family One. While Family One is what I categorised as a young family, Family Two is a more mature household. One of the children (i.e. Person C) is married, with two children, and still living in the same bilik at the longhouse with her parents. Her husband (Person G), however, is practicing multi-local living and sending remittance home. The other two children (Person D and Person E) are also practicing multi-local living, as they are both studying for their undergraduate degrees at universities in Kota Samarahan ${ }^{88}$. In this case, the household income comes from multiple sources from different markets in different locations.

\footnotetext{
${ }^{88}$ Approximately 29 kilometres from Kuching (Sarawak's state capital).
} 
Figure 7.6: Example of a contemporary bilik-family

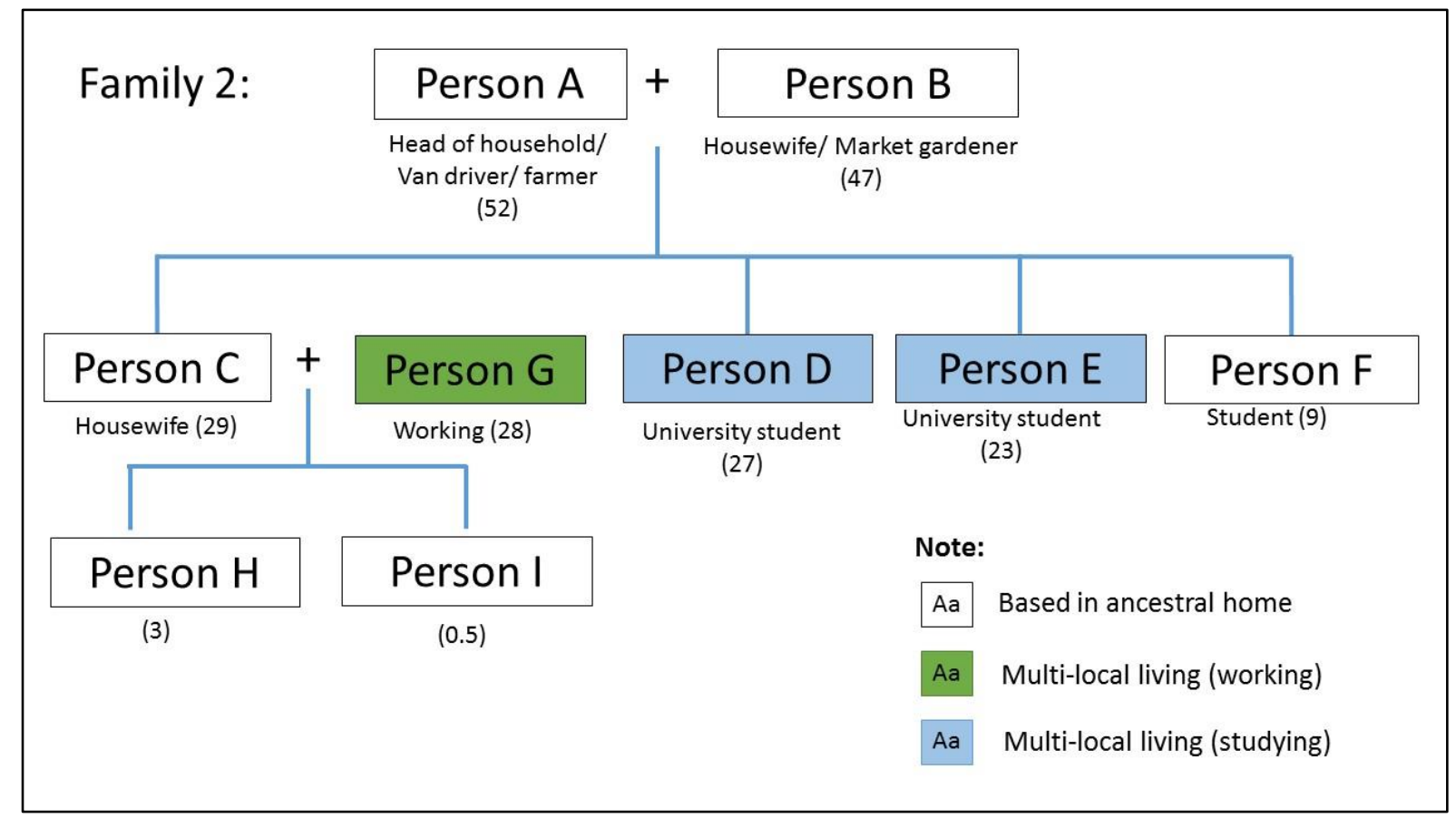

(Note: Names in the diagram have been changed to protect confidentiality)

Conversation with Family Two's head of household reveals that he expects that once the two children (Persons D and E) finish their tertiary studies, they will live and work elsewhere, and will not set up homes in Kapit and certainly not in the longhouse. The head of household acknowledged that employment opportunities within Kapit Town are limited and he supports his children's decision to seek employment elsewhere for their own future development. He stressed, however, that they are still part of his bilik-family, until such a time when the children decide to set up their own bilik-families. As there is no time limit for them to make the decision on this matter, there is a possibility that the status-quo may not change anytime in the future.

Family Two's household structure also differs from Freeman's notion of Iban bilik-family in Baleh in the 1960s. He describes how partition usually occurred after the children are married, and the newlyweds set up their own bilik-family, independent from the pun bilik. This has not happen in Family Two, and conversation with the head of household reveals that the family has not talk about partitioning at all. The fact that his son-in-law, Person G, just started working and earning money means that Person G's nuclear family is not ready to break away from his household yet. 
What I have seen during my field work is that the size of bilik-family is getting larger, as many individuals remain with their respective bilik-family despite having a nuclear family and a separate residence of their own. This is illustrated by Family Three in the following Figure 7.7, where a household consists of a pun bilik (in this case the father-in-law), and his two children (Person B and Person C), who have families of their own. They are still together as members of the same bilik-family, as they have not opt for partition (or set up a separate, independent household). Although they are technically in a larger family (compared to Family One and Family Two), the bilik-members are spatially dispersed. Person B (son) is working in Republic of Congo while his wife and daughter are practicing dual residency (living in Kapit Town during school days and live at the longhouse with the rest of the extended family the rest of the time). Person C (daughter), her husband, her 11 year old son and her father (Person A) live at the longhouse while her two daughters are practicing multi-local living in Kapit Town. Only four (out of ten) bilik-members remain in the longhouse.

Figure 7.7: Example of a (small) contemporary bilik-family

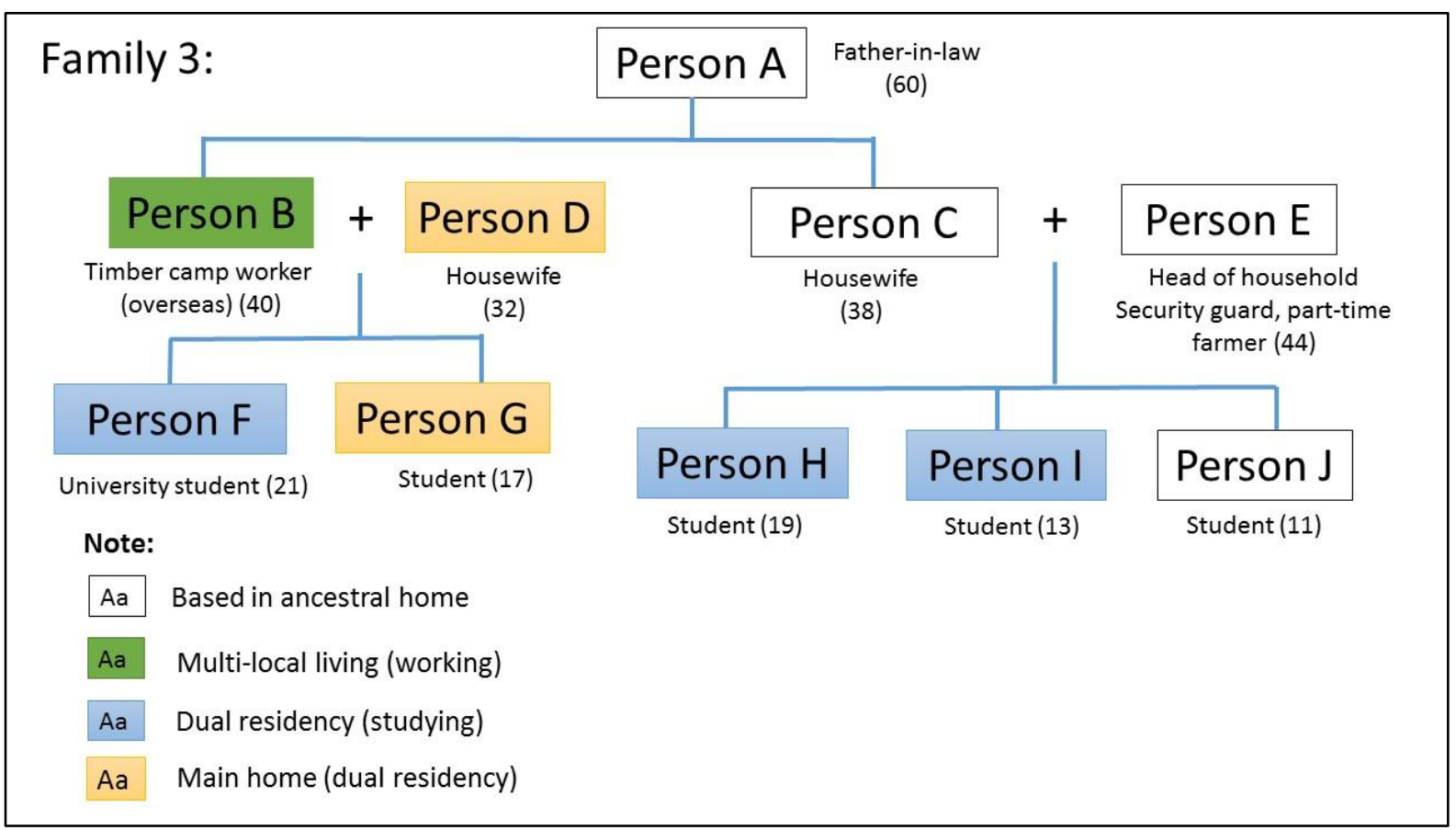

(Note: Names in the diagram have been changed to protect confidentiality)

The above family structure highlights the difference between a typical bilik-family as observed by Freeman in the 1960s and the contemporary family in Baleh in 2014. The above example (Family Three) is of a relatively small size bilik-family (10 bilik-members), compared to that of the following Family Four 
Family Four is a large bilik-family as it consists within it seven 'nuclear families', headed respectively by Person B, Person C, Person D, Person E, Person J, Person K and Person U. Together, their bilik consists of a total of 29 bilik-members. This structure of Iban bilik-family was not a norm in Baleh during Freeman's fieldwork in the 1950s and the 1960s. Freeman $(1955, \mathrm{pg} .8)$ stated that, during his time in Sarawak, he did not encounter siblings - married and having adult children of their own - who are still living together as members of the same bilik. At that time, partitioning usually happened right after the siblings got married. He also noted that partitioning never occurs if a family has only one child, for this individual is then the sole heir. This type of large extended family now exists due to nonpartitioning upon marriage. Similar family structure was observed by Cramb (2012) in his study in Batu Lintang.

Figure 7.8: Example of large extended bilik-family structure

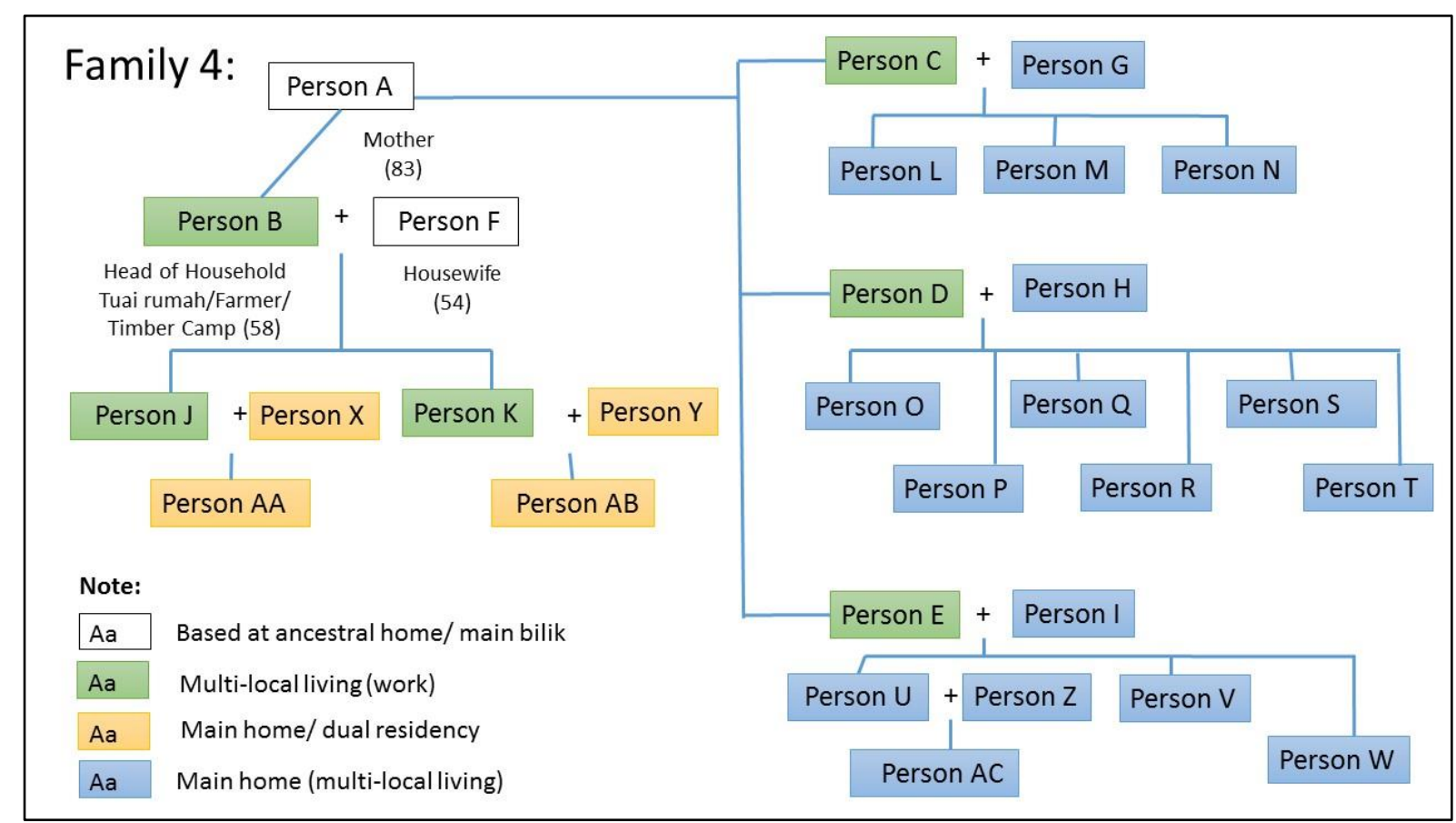

(Note: Names in the diagram have been changed to protect confidentiality)

In the case of Family Four, although all 29 individuals are members of one bilik-family, only one nuclear family (i.e. Person A, Person B and Person F) are residing in the ancestral home at their longhouse. In reality, this bilik-family is scattered spatially, through their multi-local living practices. The oldest member of the family, i.e. the matriarch of the family (Person A), stays at their ancestral home with Person B, their bilik's head of household at the longhouse who practices multi-local living. As the oldest member of the bilik-family, Person A is the pun bilik although it is her eldest son, Person B, who will 
inherit the pun bilik ${ }^{89}$. The other nuclear families (Person B's three brothers) have already established their own homes in Kapit Town, but, at the same time, remain acknowledged members of Family Four as the three brothers have not officially sought to break away from their pun bilik. Other than that, Person B's two sons (Person J and Person K) have their own houses in Kapit Town but both are working elsewhere. Their wives (Person B's daughters-in-law: Person $\mathrm{X}$ and Person $\mathrm{Y}$ ) and his two grandchildren are practicing dual residency and divide their time between living in Kapit Town and at the longhouse.

I am more comfortable using the term setting up or breaking away from pun bilik here instead of the term 'partition' as used by Freeman (and other scholars on Iban households). During Freeman's time in Baleh, when partitioning happened, the newly formed bilik joined the longhouse community by adding a bilik (i.e. individual apartment) to the existing longhouse structure. Nowadays, breaking away from pun bilik does not necessarily mean the new bilik is formed at the same longhouse or another longhouse. In fact, the newly formed bilik can be located anywhere - and in most cases, where families have established homes in urban areas, they might consider their urban-based home as their bilik. This is assuming that they are branching out of their pun bilik at the longhouse and create their own bilik. If, and when, this option is chosen, the newly created bilik is no longer longhouse-based. How the urban-based Iban view this form of bilik-family remains to be seen as Cramb (2012) points out most urban-based Iban who grew up in the longhouse have a desire to return periodically back to their longhouses.

I am using Family Five (Figure 7.9 below) to illustrate a family structure in which members break away from their pun bilik. As can be seen from the diagram, two of Family Five's children (Person C and Person D) have set up their own biliks, which is independent from Family Five. According to Iban custom, these two children (and their subsequent nuclear families) are no longer acknowledged members of this household. When this happens, these former bilik members are no longer officially considered as part of the family and they are not entitled to inherit the bilik and/or any collectively own bilik properties. Their relationship as family members continues as usual but their obligation to the pun bilik and their entitlement to inherit ceased.

\footnotetext{
${ }^{89}$ The decision for the eldest son to inherit the bilik was made known to the other family members as well as the longhouse community.
} 
Figure 7.9: Example of bilik-family with family members breaking away from the pun bilik.

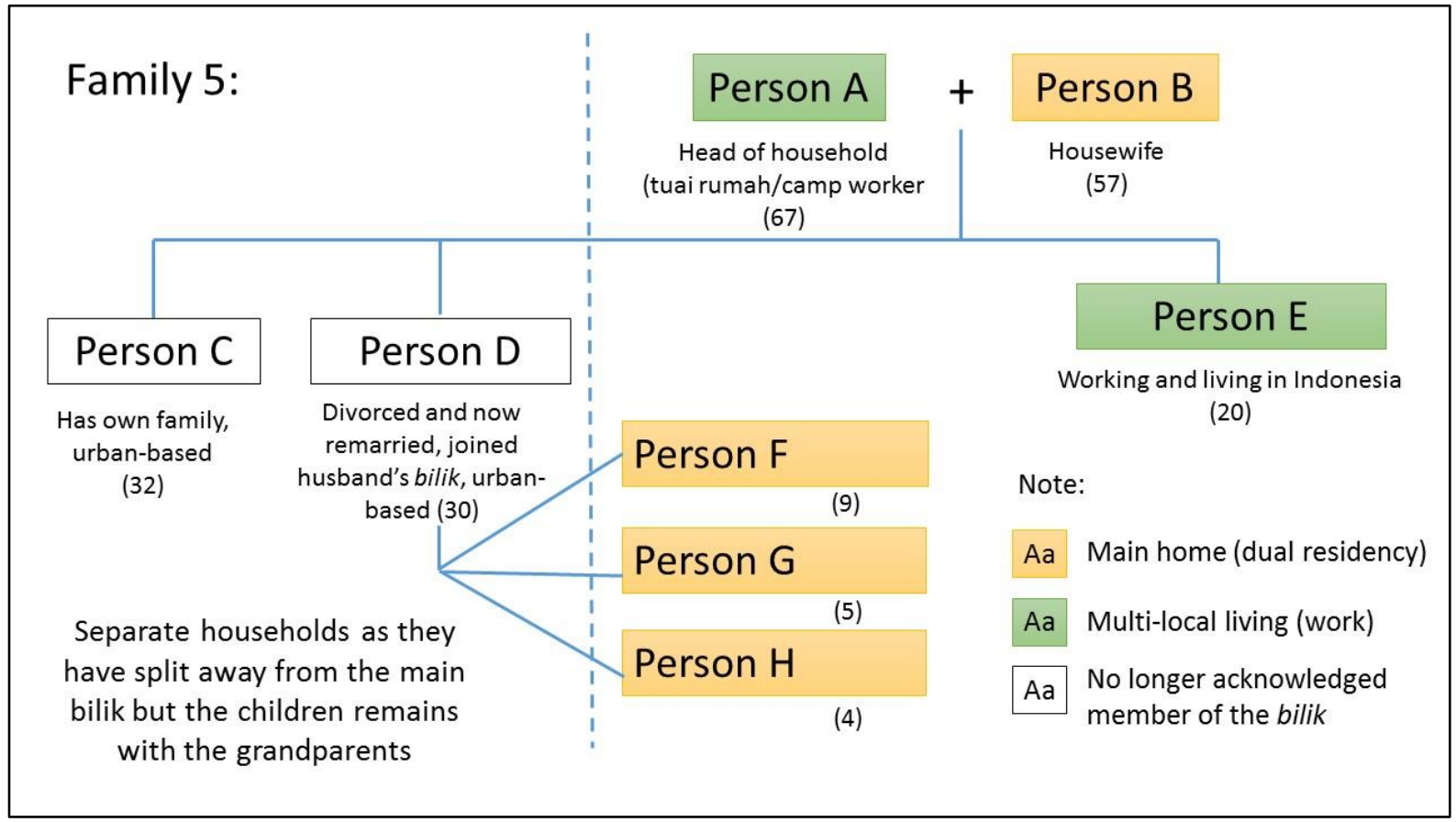

(Note: Names in the diagram have been changed to protect confidentiality)

The bilik-family described in Figure 7.9 above consists of the head of household, his wife, a son and three grandchildren. This household is also an example of a multi-local living bilik-family, with the head of household living at his workplace (timber camp) when working, and alternating between the family home in town and their bilik at the longhouse on his off-days. Meanwhile, his wife and three grandchildren live in Kapit Town, to be near the school for the grandchildren, and they move back to their longhouse during school holidays. They have been practicing this lifestyles for over ten years. In addition, two of their children have broken away from this pun bilik, and set their own independent bilik-family in outside of Kapit District.

\subsubsection{Evolution of the contemporary Iban household in Baleh}

The above narratives on contemporary Iban bilik-family structures highlight the changes experienced by Baleh Iban over time, primarily in their response to de-agrarianisation and improved accessibility to markets. The structure of Iban bilik-family in Kapit District has slowly evolved over the years as explained above. Soda (2000), Cramb (2012), and Ngidang (2012) have all noted the changes to bilikfamily structure amongst the Iban in their studies, particularly in relation to their shift in economic orientation, from farming into non-farming sectors. This change of household structure in Kapit 
District, however, has not been documented or discussed with empirical evidence since Freeman's initial work in 1950s and 1960s. Ngidang (2012, p.164), for example, states that empirical data on the livelihood of Iban living in this frontier region is almost non-existent for the post-independence era.

The structure of Iban families are becoming more complex now as family grows - as there is no rush for bilik-members to break away from their pun bilik. At the same time, less family members are residing at the longhouse as household becomes more spatially dispersed. I believe this was related to de-agrarianisation, improved accessibility and the quest for development, at individual level and as a household unit. Unlike decades ago, individuals in today's situation do not have to stay in the longhouse with their other family members. They can live elsewhere but still maintain their bilik membership. In most cases, only the demise of the matriarch or patriarch would results in the siblings breaking away from pun bilik and set up of their own independent bilik-family unit.

In 1950s, nearly all of Freeman's participants were farmers, and upon marriage, the newlyweds tend to break away from the main household because they could replicate traditional Iban agrarian household structure elsewhere. Household structure as illustrated by Families Three and Four were not common during Freeman's time in Baleh. He noted that:

"... if all families produced two children the tendency would be for one of them to marry out, and the other to be left in possession of the natal bilik. But as soon as the majority of families arise above this level partition is sure to occur ...it is extremely rare for a pair of siblings, each of whom is married, to remain permanent members of their natal bilik. Sooner or later, one couple breaks away to set up a bilik of their own."

(Freeman, 1970, p. 43)

That seems to be no longer the case among my respondents, as illustrated in the above examples (see Figures 7.4 to 7.8). Similar observation was made by Cramb in his study of Iban bilik-families in Batu Lintang. In his example, Cramb noted how a large household consists of elderly parents, and grown up children with their own families. Several of these children have set up their own bilik-families at the same longhouse, or at the spouses' longhouse but there are other children who have not done so. These remaining children have moved permanently to urban locations in Sarawak, but, according to Cramb (2012), they remain formal members of this original household as they have not formed separate bilik in their longhouse or other longhouse. In this context, Cramb noted that,

"The status of those who have permanently settled in town ... as they have not married into another household, nor broken away to set up a new household in the longhouse, nor migrated with a group of households to establish new longhouse in virgin territory, they 
remain members of their natal bilik ... As these urban migrants marry and have children, the size of the household continues to grow and its structure changes from the traditional nuclear or stem family occupying one physical bilik to a large, multi-sited, extended family."

(Cramb, 2012, p. 5)

Cramb's findings strengthen my observation regarding the phenomenon of multi-local living practices amongst the Iban in Baleh. Nearly every households that I interviewed have bilik-members who are living separately from the main household. The kinship diagrams above show how widespread the practice of multi-local living is among the Iban households in the case study area. Cramb also mentions that, in the household that he used as an example, most of the grandchildren of this bilik-family were not born in the longhouse. They are mostly urban-based, and this will, to some extent, influence the future direction of Iban family organisation. I believe that when the time comes for these multi-local families to break away from their pun bilik, these respondents are more likely to end up being urbanbased, as they are already living and working away in urban areas, rather than to set up another bilik in their original longhouse.

The shift from farm to non-farm economic activities is triggering the emergence of different types of family structure. The bilik-members who are still living under the same roof as the head of household in the longhouses are usually the oldest and the younger members of the family. All of these changes can be traced back to de-agrarianisation, which prompted individuals and households to find nontraditional ways to 'develop'. The bottom line is their search for better economic opportunities leads them to geographically separate from their longhouse (and in some case, from their bilik-families). Improvements in accessibility and advancement in infrastructure also facilitate this push towards creating spatially dispersed rural households. The phenomenon of multi-local living has become a common occurrence in rural Baleh. In complete contrast to Freeman's observation, it is now a norm for bilik-members to be located at different places than that of their pun bilik, for various including employment and/or education purposes.

The practice of multi-local living, and, to some extent, the Iban's emphasis on continuity, ensures that despite being geographically separated, these off-site bilik-members are still very much part of the household, and they considered their bilik in the longhouse as their main home. This view, however, is more prevalent when the bilik-family still has its pun bilik, i.e. the elderly parent, staying in the longhouse. When their pun bilik (i.e. the patriarch or matriarch of the family) is no longer at the longhouses, I am anticipating that the structure of these Iban household will change altogether. 
In summary, the above description of the evolution of Iban bilik-family structure is explained in the context of de-agrarianisation framework in Baleh. The structural change that occurred and still occurring in the area has great implications on how the structure of traditional agrarian Iban bilikfamily. Figure 7.9 below shows the de-agrarianisation stages in Baleh since the first pioneers moved into the area in 1800s as well as the corresponding phases of Iban household evolution.

Overall, I identified these three phases of household evolution: (i) traditional phase, (ii) transitional phase, and (iii) contemporary phase of Iban bilik-family structure. The first phase refers to a period when the Iban bilik-family is completely relied on subsistence agriculture as their sole source of livelihood. As explained earlier in this chapter, the main activity of the Iban since 1800 s had been hill rice cultivation.

The second phase is the transitional period which signifies the shift in livelihood strategies from farmbased to non-farm activities. This represents a period when de-agrarianisation started to take place in Baleh and, as Ngidang (2012) explains, the demise of subsistence agriculture. The third phase, which I call the contemporary phase, has yet to fully take place. I expect that in that contemporary phase, the main source of livelihood for Iban bilik-families will come from non-farm activities. It is also a phase where I predict that the majority of Iban household will be urban-based, in their individual biliks in various residential estates rather than the traditional rural-based biliks in longhouses of the traditional phase. This contemporary phase is not just confined to the Iban, but has been experienced by other societies worldwide (Inglehart \& Baker, 2000; Rigg, 2006). In his study, Rigg (2006) mentions how livelihoods in rural areas of Southeast Asia are changing, with its younger generations fervently avoiding future livelihood in farming, but moving towards urban-living as their livelihood goals ${ }^{90}$.

In this section, I have provided a snapshot of bilik-families in Kapit region in 2014. The snapshot showed the presence of families at different stages of this transition from traditional to contemporary phase. A number of bilik-families are still relying completely on farming as their only source of livelihood, but the number is gradually decreasing ${ }^{91}$. In 2014, a majority of the households that I interviewed can be classified as being at the transition stage. This phase is predominantly characterised by household income which is derived from diversified sources from different fields

\footnotetext{
${ }^{90}$ Rigg (2006) cites how the Malays in East Coast of Peninsular Malaysia are moving out in droves from their rural villages, into urban and industrialised cities to join the labour force. Yet, according to Rigg, the literature or statistics continue to identify these (now) urban-based Malay with farming, despite the ever growing numbers migrating out of farming and out of the villages.

${ }^{91}$ Refer to Kapit District Office's figure (in Chapter 5).
} 
(farm and non-farm) in different geographical locations. This transitional phase is also characterised by its prevalent multi-local living and spatially dispersed household. Consequently, a typical Iban household usually involve an elderly couple living in their bilik in the longhouse and their children (with or without their nuclear family) live and work in different towns and cities, and their grandchildren live in different towns or cities for education and/or employment.

I also found that many households have actually moved beyond the transitional stage into the contemporary stage. Evidence from my research suggests that there is a high number of urban-based Iban bilik-families who are, in theory, practicing multi-local living but have been living 'permanently' in major cities and towns outside of Kapit District. The exact number of these households, however, is hard to determine because the pun bilik (head of households at the longhouses) still regards their urban-based members as their acknowledged bilik-members. There are bilik-members who have not lived in the longhouses for over 15 years, have their own nuclear family, bought their own houses in urban areas and have minimal ties with their longhouse. However, their elderly parents still considered them as the acknowledged members of their bilik-family. It will be interesting to investigate, in the future, whether these urban-based members feel the same way as their elderly parents regarding their bilik membership.

These urban-based households also function as contemporary nuclear households. This is particularly more prevalent for bilik-families that are no longer headed for the patriarch or matriarch of the family. Situations like this arise because of individuals' and households' pursuit of a better life, aided by accessibility, education, and communication technologies, and, in the long run, may drastically change the social structure of a traditional Iban bilik-family.

This view may be criticised by those who believe that Iban core adat of continuity and attachment to one's bilik in the longhouse is long lasting. The concept of pun and the idea that a bilik-family will continue through time may well and truly resonates among the generations who have strong ties to longhouses and its way of life. Those who grow up during the transitional phase might be favouring this romanticised idealistic notion of continuity. However, I believe that, for urban-based Iban, especially the generations that were not born in longhouses or familiar with longhouse way of life, the notion of continuity may not resonate too well with their contemporary lifestyles. They may favour the concept, as an idealised concept or a link to the past, but in reality, it is hard to practice or sustain. This is particularly relevant in a period where economic development of individuals and households is very much tied up with accessibility to markets, which, are more likely than not, are urban-based. 
If this does happen, in a larger scale, in the future, i.e. where a majority of the Iban bilik-family are urban-based and working in non-farm, urban sectors, what will it mean to be an Iban and what become of rural land in Baleh?

\subsection{Guardianship role}

Prevalent multi-local living and de-agrarianisation in rural Baleh also have profound effects on the rural farm land. In particular, these rural changes also influence how rural land is now perceived and managed. In this section I will elaborate on how changing household structure are re-defining how farm land is managed and viewed by Iban households in Baleh.

\subsubsection{Disappearing farmers in Baleh?}

The increased number of rural dwellers, together with their families, relocating to urban areas for employment and/or education purposes means that the in-situ rural households comprise of predominantly elderly and families with very young children (pre-school age). This was observed in most of the longhouses that I visited in the area. This change in demographic structure, influenced in part by improved accessibility and availability of different markets, has huge implications for farming practice and land usage.

A majority of the respondents have indicated that they have no intention of farming or extending their current farm, justifying their decisions with reasons such as old age and health issues. These findings are parallel with the other studies on rural and agricultural change in other parts of Sarawak (Cramb, 2012; Hew, 2011; Soda, 2001) and other Southeast Asian countries (D. A. Preston, 1989; Rigg \& Nattapoolwat, 2001). Farming families are no longer farming the way they used to, and in some cases, households have ceased farming activities altogether. Essentially, this leads to idle or underutilised land, and begs the question of land management.

Families in longhouse can afford to leave their land idle (or underutilised) because they are receiving income, in the form of remittances, which contribute towards the total household income (as discussed in Chapter Five). Because of the improved accessibility to different markets, as well as multiple sources of income, intensive farming is no longer being practiced. I found that most of those who are still farming in Baleh are from the older generation (aged 50 years and older). A large majority 
of them only farm a small area (and leave a large area of their farmland uncultivated) just enough to provide for their own consumption. This is because, in most cases, the bilik-families have other income sources in the form of wage/salary from bilik members who work in non-farm sector. The younger generations are more actively involved in non-farm economic venture, leaving their elderly parents behind as guardian of the estate. The notion of guardianship of land is a significant element in rural change in Sarawak, particularly in the context of de-agrarianisation. It rises from the changing nature of the Iban household structure and their ties to ancestral land.

Nearly all (32 out of 34 ) of the households interviewed said they have more farm land available if they want to expand their current farming activities. This implies that land availability is not a barrier for future expansion of farming for these households. However, when asked whether they plan to do more farming in the future, a majority of the respondents in all three accessibility zones indicated that they do not plan to farm or be involved in farming activity in the future. This is equivalent to 50 percent, 75 percent and 100 percent saying no to more farming in zones $A 1, A 2$ and $A 3$ respectively. In this context, farming refers to rice cultivation, market gardening, and other cash crop plantation. Among the major reasons cited by the respondents who said they do not plan to do more farming in the future include old age and/or health reasons (35\%), followed by nobody to farm the land (25\%) and not enough fund to expand farming (15\%). Other reasons given include current capacity is sufficient for households' consumption and land is far away from their longhouses.

The phenomenon of multi-local living has very much curtailed the future of farming in the region. This move takes out the rural labour force from the equation, and leaves behind the older and less productive labour force behind. Hew $(2011$, p. 610) argues that when married women migrated out with their husbands and family, the immediate impact is there are no one left to manage the family farms. Bearing in mind that, in most shifting cultivation societies, the women play central role in the continuity of their farming traditions, and with them moving out from their longhouses the structure of the rural communities is transformed and farming traditions disappearing.

Rice farming, in Iban cultural context, is predominantly the work of their woman folk but men are obliged to assist (Cramb et al., 2009; Freeman, 1970; Kedit, 1993). According to Freeman, rice farming amongst the Iban usually involved sacred rituals and as such, at the present time, are mostly carried out by the older generation. At present, rice farming in the case study area is in decline. Respondents mentioned the older generation are no longer able to carry out hill rice cultivation and the younger generations are said to be lacking the skills and know-how as well as not interested in continuing with 
this farming tradition. Cramb et al. (2009, p. 329) state that the education of young people in modern school systems away from the village not only reduces the availability of household labour for farming but prevents them from acquiring the necessary technical and ritual skills for undertaking farming activity. Similarly, Hew (2011, p. 603) argues that rural children spent most of their adolescent years in boarding schools in towns and away from their families, and they are not initiated into the intricacies of farming. Cramb et al. (2009, p. 329) also argue that these youngsters may be exposed to development ideologies that regard farming as backward, and combined with greater exposure to urban lifestyles and the influence of mass consumerism, may reduce the incentives of young people to engage in farming activities. Similar observations has been highlighted in other farming communities in the Southeast Asian regions (Cramb et al., 2009; Rigg \& Nattapoolwat, 2001).

\subsubsection{Value and meaning of land in Iban culture}

On a different note, it was hard to know whether the respondents actually 'owned' any land. When someone says they owned land, it was difficult to ascertain their level of ownership because land ownership and inheritance system amongst the Iban is complicated. Besides rights of access that are accorded to direct descendants of the bilik-family, provided they are acknowledged member of the bilik-family, there is also what is known as 'shared rights'. It means that any bilik members, who shared the same ancestors, can claim shared rights on communal bilik land. Soda (2005) describes this as 'non-committal sense of belong' or 'flexible belonging'. In his study, Soda $(2005$, p. 39) found that when someone says "I have land back in the village", in most cases they are talking about their parents' land and there is no guarantee that they will inherit the land (although they still have rights to use the land but that is dependent on the decision of the pun bilik). They may also be referring to their grandparents' or ancestors' land.

In this research, I also encountered similar ambiguity in terms of respondents' claim of land ownership. I asked the respondent whether they own any land (refer Appendix 2: Q2.5 and Q2.6; and Appendix 1: Q3.7) and the answer is usually 'yes'. Upon probing with more detailed questions, I found that in most cases where the parent(s) is/are still alive, the land is still under the parents' name. Heads of household who are more than 60 years old, typically still 'own' and manage the biliks' land, and have yet to divide the land amongst his/her siblings and/or children. As a result, a majority of the respondents in this study indicated that their land is still officially undivided (bedau bebagi) and shared (agi kungsi) amongst all acknowledged bilik-members. 
Approximately 91 percent of the households perceived bilik's land as a family asset. They see the land as a family heirloom, an important asset for farming families and to be passed to the next generations. This is despite the fact that they are not keen to farm themselves. Only eight percent (i.e. 7 out of 81 respondents) viewed land as an investable asset, i.e. as an economic asset that can be sold or used to get capital for future uses. These perceptions are parallel to the views of Freeman (1970) and Ngidang (2002) regarding the traditional meaning and value of land among the Iban. Freeman (1970, p. 283) states that land is an important asset to the Iban as their prosperity depended on the land upon which they carry out their subsistence activities. This view implies that land value is associated with its usage value. Along the same reasoning, Ngidang $(2002$, p. 158) states that land is important as Iban depends on land for their source of livelihood and that it governs the whole spectrum of human behaviour pertaining to subsistence farming, fishing, hunting and gathering or harvesting forest products, and the environment as a whole.

However, I believe the above expectation on land value is no longer valid. With changes brought forth by de-agrarianisation, and multi-local living, and aided by improved accessibility to market, the value of land is not as it was when farming was the key activity in rural Baleh. People are no longer entirely dependent on their land for livelihood and this reduces the 'commercial value of the land'. As highlighted in previous chapters, accessibility to market, both local and non-local as well as both traditional and contemporary markets, are more significant in determining people's standard of living than farming in the present day rural Baleh.

Those who view land as family assets argued that their descendants should inherit the land that were obtained by their ancestors. They also value the land in relation to its potential significance as security net in times of economic hardships. This view of farm land as safety nets is similar to what was happening in other Southeast Asian regions (e.g. Thailand, Vietnam and Indonesia). In this context, the bilik-member expects to return to villages and farm the land for their own food security during times of economic hardships. This was highlighted in Soda (2007), Rigg (2003) and D. A. Preston (1989), and their research showed how temporary rural-urban dwellers moved back to their villages when they could not cope with high cost of urban living. A number of respondents mentioned that they have enough land for their children and grandchildren to use if needed in such situations;

"We have enough land for our children and grandchildren ...they all live and work in town but who knows what will happen in the future. If their jobs in town do not work out, they can always come back and farm the land ..."

(HH59, A3, June 2014) 
Other than being a security net in times of economic hardship, it is now common for people to view land as economic assets and a commodity that can be traded for cash and profit (Ngidang, 2012). This perception of land as an exchange value is particularly more attractive in time of hardship if the participants are not into farming. The elderly, however, tend to have more sentimental sense of attachment to ancestral land. Elderly respondents in the study mentioned that they were unable to work the land any more due to old age but had expressed hope that their children will, one day, inherit their ancestral land and keep it in the family as heirloom.

\subsubsection{Guardians of the land}

Against the backdrop of de-agrarianisation and pursuit of improved accessibility and development, the rural Kapit population is getting more mobile and spatially disperse. They are not as attached to the longhouse as their forefathers. Consequently, this changes the nature of land use, how land is perceived and how it is managed. Land is no longer simply an heirloom to be passed down through generations but are seen in different lights as described above.

The guardianship role is an inevitable result from de-agrarianisation process and multi-local living practice. Findings have showed that a majority of people own land (albeit customary in nature) and yet most of the land has been left idle. The aging parents left the land as it is as they are no longer able to farm as intensively as before or the low productivity from farming had dissuaded them from continuing with farming.

As these elderly participants were not able to continue farming as they used to, their roles within the bilik-family also change. Their role now leans more heavily towards the 'guardian of the land'. This guardianship role, in line with the concept of pun described earlier, is often carried out by the elderly members of households until such time the land will be passed down to the next generation. They are basically safeguarding the land for their children/grandchildren who are working and living in urban areas. The question is whether the next generation values the land the same way they do, especially when people are more aware of the economic value of land and the potential opening up of this area in the future as well as the current shift away from rural agrarian economy.

I posit that, as the society is moving towards contemporary phase of Iban household evolution, the way the Iban views their land will also change. I expect that, as farming will not be the key economic income generator in the future, many bilik-families will look on their land as investable assets with 
exchange value rather than idle heirloom. The proposed road construction in the area will also mean that the demand for the land and its economic value will be higher. It will be interesting to see - will they sell or will they keep their land? Will the economic value matters more than its traditional values? I do not know the answer to these questions - but, I forecast that whatever happens, the way land is viewed and managed is no longer the same.

\subsection{Summary}

Development in the sense of standard of living of rural dwellers is no longer simply a function of farmers being able to access local markets, although that remains important, but increasingly it is focusing on accessibility by bilik-members to alternative income generating opportunities at other locations. Such move enables the individuals to now live and work off-farm and remit part of their earnings to their (usually) elderly parents back in the longhouses. These parents are no longer farming in any meaningful way, but are increasingly becoming guardians of the estate, of a farm whose value, in terms of its ability to produce a livelihood is decreasing, while its value as an asset is increasing. Such farm is acknowledged as having high resale value and recognised by all as having the potential to be realised at some future date. This expectation of high resale value is in tandem with the expectations that access road from Kapit Town to the reservoir site of Baleh Hydroelectricity Dam project will increase accessibility and open up the area from mid to upper Baleh.

The perpetuation of the notion of 'farming family' in rural Sarawak is a convenient myth. In reality, the proportion of individuals, from what used to be farming families, now practice multi-local living keeps on increasing. This practice allows former farm families to diversify their earning portfolio by living not as a family in a household as traditionally portrayed but spreading themselves around the globe in order to tap earning opportunities no longer possible 'down on the farm'. In this sense, then accessibility has taken on a much more complex meaning as an agent of development. Modern accessibility is no longer tied to the transportation of produce to market but now allows the family to continue to function as an economic unit but from a quite differently configured household economy, one which has become spatially as well as economically diverse.

Multi-local living practice, coupled with effects from de-agrarianisation, has changed the family structure of a typical Iban bilik-family. Their bilik-members are spatially dispersed albeit still linked together by their bilik memberships. With the practice becoming more widespread, and expected to be more so in the future among rural dwellers, it poses the question of how will the family structure 
change with greater spread of multi-local living? The changing structure is interlinked with the future of farmland in Baleh, particularly in light of on-going de-agrarianisation, as well as the two major projects (i.e. road connection between Sibu and Kapit, and the Baleh Hydroelectric Dam) in the region.

What I attempt to position in this chapter is how multi-local living is very much linked to social change experienced in present day Baleh. The subject of multi-locality has been criticised as a fuzzy concept (Greiner, 2012) which has not been studied extensively in tandem with other relevant concepts such as mobility and migration (Dick \& Reuschke, 2012). Furthermore, in many countries, it has not been explicitly taken into account in official statistics (Firman, 1994; Hugo, 1982; Weichhart, 2015). What I do here is to attempt to discuss multi-local living, in the context of intricate relationships between changing structure of traditional rural Iban households, and its effects of the value and management of rural farm land. 


\section{Chapter 8}

\section{Discussion and Conclusion}

The Iban of the Baleh river basin have been initiating and experiencing the consequences of sustained de-agrarianisation for over three generations with the proportion employed in agriculture falling roughly from $67.8 \%$ in the 1970 s through to under $24 \%$ today. The leaving of the land has taken and continues to take many forms and affects each individual, household and community slightly differently. As a whole, however, it has been accompanied by not only by an emptying out of rural households as younger and often more educated members seek work elsewhere, but also by a movement of whole families and even communities to other more developed parts of the country. The result is a District and Division still without connecting roads, a growing number of underutilised and abandoned farms, unoccupied bilik, and non-resident tuai rumah, whose population continues to fall both absolutely and relative to the rest of Sarawak.

It is in the context of this final phase of de-agrariansation of the Baleh river basin that I began my investigation into the relationship between accessibility and development. I started this thesis with two broad hypotheses: the first asserted that as accessibility to markets and services increases, so will the level of development. The second argued that improved accessibility to markets and services would be accompanied by increased levels of inequality, between communities, households and individuals.

The research turned out to be much more than just exploring the relationships between accessibility and development. What started off as a study of the different implications of accessibility to market and services on the levels of development in remote rural setting, ended up telling a much bigger and more complicated story about the nature of social change among the Iban in the Baleh, i.e. in a remote rural district, and by extension, many other similar river settlements in Sarawak. The accessibilitydevelopment paradigm, therefore, ended up exposing some of the key drivers of social change among contemporary Iban in rural Baleh.

My story reflects how the residents of the Baleh river basin have responded to the sparse and scattered opportunities for higher levels of development, whether measured in terms of income, standard of living, or human capital development, at the level of the individual, household and community. Their pursuit of development is set against the backdrop of their limited accessibility to 
market and services and the development constraints of very low levels of urbanisation in the Division epitomised by the presence of only one small market town.

As I outlined in Chapter One, faced with low, variable and often falling demand for their agricultural commodities, the residents of the Baleh have sought alternative markets for commodities, and their own labour. They have been forced to develop the widespread practice of multi-local living in order to access alternative markets, rural and urban, that exist mainly outside of Kapit District. Both of these responses have major implications for the Iban community as well as on their traditional, agrarian bilik-family structure.

Notwithstanding the uniqueness of the Baleh context, the broad process of de-agrarianisation has been unfolding throughout Southeast Asia at variable rates over the last few decades - and in many other countries much earlier in their history. As a result, there is now a considerable literature on the process which I have been able to draw on in my literature review, Chapter Two. At the same time, the scholarship on rural Sarawak has progressed to the point where we now have multiple studies of rural change. However, most of the research which I reviewed has taken place west of Kapit, in the more developed parts of the country. My field research in Baleh is one of the few undertaken in the less developed central part of the state and most recent addition to the literature on the Kapit District.

\subsection{Key findings}

The relationships between development and accessibility are complex. In order to penetrate that complexity and provide order to my thinking I have drawn on von Thünen's land use model as a starting point. As I outlined in Chapter Three, the model introduces three parameters which govern the relationship between development (proxied by income) and market accessibility: the prices received for commodities, $\mathrm{p}$, the costs of production, $a$, and $f$, the costs of transport. I used each of these to identify the different ways in which market size, the commodity and location interact to generate a distribution of livelihoods across the Baleh catchment.

I introduced my research design in Chapter Four. I divided settlements along Batang Baleh into three zones based on their accessibility to the single local town, Kapit. This way I was able to compare different levels of development across the three accessibility zones. Longhouses, households and individuals were all sampled randomly allowing me to generalise to the population. A distinguishing feature of my study was the decision, taken from the outset, to measure 'development' using three 
different units of analysis, each nested within each other: the longhouse (community or village), the bilik-family, and the individual. This decision was driven by the widespread recognition that development is accompanied by increasing diversity and that average levels of development at a village level may not capture the diversity within the village by household. What has also been recognised but less readily implemented in the fields is the recognition that development is often accompanied by increased opportunities for inequality within the household itself, among the offspring of contemporary pun bilik in the Iban case. Interviews carried out between May and July, 2014 were, therefore, structured to capture data and views of these three different levels, the village, the household and the individual.

Chapter Five is the first of three chapters that detail the results of my field work. It began by testing the basic proposition proposed by the von Thünen model, using the principal agricultural commodity, vegetables. I was able to demonstrate empirically that both the probability of supplying vegetables to the Kapit market (Kapit Town), and the income generated from sales declined with travel time to the market. An important empirical result was the identification of the agricultural margin, the travel time beyond which cultivation of vegetables was no longer viable (less than one hour). This result, in turn, exposed the question as to how those living beyond the margin could make a living.

Several additional points emerged by starting with vegetable production. The first was the presence of other commodities (e.g. fruit, fish and jungle produce) whose marketing to Kapit Town exhibited similar, distance decay properties. The second feature revealed the presence of other, but much smaller commodity markets which allowed some households to generate income from vegetables beyond the Kapit defined agricultural margin.

A third feature was the presence of two types of market for labour, rather than commodities. These answered the question as to how Iban households beyond the agricultural margin were able to generate a living. The first involved the sale of labour to timber camps in what emerges as a sunset industry but which has sustained incomes for over a decade in the least accessible zone of A3 in particular. This way many men in particular have been able to stay residents of their rural dwelling while continuing to earn an off-farm income, raising the in-situ income of their households.

A fourth feature, and possibly the most significant of the study, was the continuing trend towards multi-local living among the Iban of Baleh. Faced with a limited market for both commodities and labour, the majority of Iban households now practice multi-local living. This involves continued 
residency of the ancestral home in what used to be the family base for farming by the now older members of the household, the pun bilik, and those raising pre-school children. At the same time, most of the members of working age live elsewhere, in larger usually more urbanised markets most of the year in order to generate income. Some of this income is then remitted back to the ancestral home.

Out of these four patterns of livelihood emerged two findings. The first was that, in contrast to the fall in agricultural commodity income with distance from the local town when in-situ plus remittances were taken into account, no distance decay effects from Kapit were apparent. De-agrarianisation as manifest in Baleh had effectively removed the effect of local accessibility on the incomes of those resident in Baleh river basin.

However, far from eliminating the effect of accessibility on development, the rise of multi-local living has exposed another way in which accessibility heavily conditions incomes of contemporary rural households. This 'new' accessibility takes two forms. The first is transport cost based but involves the ability to travel from Kapit District to other sites of employment. These are not daily or even weekly travel patterns but those taken far less often including during Gawai, the Iban festive season when most acknowledged bilik-members return home. Unlike the western concept of multi-local living, in my study, most, if not all, of those who practice multi-local living area are doing it out of necessity, as part of their livelihood strategy. Multi-local living is a way for households and individuals to gain greater accessibility to opportunities, beyond their longhouses, for their future development. For example, children as young as ten years old are practicing multi-local living just to gain access to primary education, or family members living separately so that individual(s) in that bilik-family can have greater access to income, a proportion of which can then be remitted to the bilik-family back in the longhouse.

The second form of this 'new' accessibility originates not from transport cost but from the differentiation of human capital. A central feature of this story is the role of the State. The von Thünen model only addresses what happens in a rarefied market environment. Were such an environment to prevail, farmers could only live beyond the agricultural margin at very low levels of living relying mainly on their subsistence ability. Contemporary standards of living are made possible by State investments in three main areas: health, education and public infrastructure. I detail these investments in Chapter Six and show in effect the way the State evens out levels of development that would be highly uneven if market criteria alone prevailed. It is largely as a result of successive investments in public goods that 
the rural population has been sustained. Otherwise, the de-agrarianisation process would have advanced much further by now.

One of the most important investments the State makes is in education and primary school is available within reasonable travel distance for all longhouses along Batang Baleh. For example, eighteen out of twenty sampled longhouses in my study are within 30 minutes travel distance to the nearest primary school, with an average travel time of 14.25 minutes, depending on the mode of travel to school. The State intervention has consistently modified the pure effects of accessibility to local markets (in this case, schools) and, in doing so, ensures that people in the most remote area also have similar accessibility to services as the other longhouses nearer to Kapit Town. What is not apparent from these data, however, are issues of quality and the way in which accessibility in the form of travel time has moderated access to secondary school education.

One of the primary drivers of multi-local living within Kapit District is the desire of many parents to ensure higher than average length and quality of education for their children. As a result, many households now practice dual-residency, with a house in Kapit Town co-existing with the ancestral bilik in the longhouse. It is this investment in education, which parents fully recognise, determines the income their children can earn and remit back to the pun bilik. As I document in Chapter Seven, remittance income now forms a considerable share of incomes of the households that remain in the region.

Therefore, accessibility to services and education, in particular, does matter in terms of contributing to development at individual and household levels. Additionally, the size of the market for the resulting skilled labour matters just as it has done in the simple model of agricultural rent. Larger centres offer greater opportunity for specialisation which is rewarded in general with higher incomes. The price they pay, however, is the spatial separation of the household.

The lesson, therefore, is that accessibility to markets and services means more than just geographical distance, average travel time or cost of travel to the local market. These new markets for skilled labour are characterised by their non-local nature. Accessibility to employment opportunities, where labour is being traded in employment markets, helps household and individual development in two ways. Firstly, it allows labour surplus from de-agrarianisation process to gain employment in non-farm sector, and in exchange of their labour, these residents gain in the forms of wages or salary. 
Level of accessibility (and its associated gain in development) is also dependent on the socio-economic profiles of community, households and individuals. This was apparent in the agricultural commodity market even among those with different access to transport. However, when it comes to the wider, larger markets for labour, we find the role of human capital and acquired wealth and connection to play an enhanced role. I found, for example in Chapter Seven, the way in which households with better than average household incomes had higher likelihood of sending their children to pursue tertiary education, and that those with higher level of education earn higher income than those with lower educational attainment. These examples imply that the enhanced abilities of different households to simultaneously source out various opportunities, especially employment, are rooted at the basic socio-economic level of its household.

These results address my second hypothesis regarding the relationship between development and inequality. They highlight the inequality that can arise between households and between individual within a household, as well as within and between villages. As a result of potential 'development' through better accessibility to education, and subsequently, employment markets the individuals and households who have the advantage will potentially achieve greater level of development. This situation, which stems from unequal access, for example to higher education, effectively raises the level of inequality for the next generations in the community.

These findings highlight how the Baleh Iban are experiencing social change - in their way of life as well as the structure of their households. These change is likely to be more pronounced when Kapit District is experiencing major development in a not so distant future.

\subsection{Future of the Iban in Kapit District}

At the time of the fieldwork in 2014, there were two major development projects proposed in Kapit District. Firstly, there is the planned road construction, which, when completed will link this currently inaccessible Kapit District to the rest of Sarawak. Secondly, the Baleh hydroelectricity power (HEP) dam, which is part of the Sarawak Government's initiative under the Sarawak Corridor of Renewable Energy (SCORE) to capitalise Sarawak's natural resources for generating energy. Under SCORE's 20082030 development plan, the Baleh HEP and the other twelve HEP projects are expected to generate a total capacity of 7,000 megawatt of power (RECODA, 2016b). Essentially, both are major projects, with great consequences on the levels of accessibility and development for the residents in my case study area. Both of these projects are currently underway at the time of writing, July 2016. 
The Sibu-Kapit road project is currently being constructed in stages and, at the present, has yet to reach Kapit District. The expected completion date for this project depends on the availability of funding. Construction is done in stages when funds are made available. What is expected, however, is that road connection at this scale bound to open up Kapit District to a range of investments and development opportunities. For example, studies by Ogunsanya (1987) and Olsson (2009) find that improvement in road transport infrastructure in villages of Africa and the Philippines have led to greater level of development (as measured by income) for the villagers. Olsson also observes that his participants also benefits in terms of having more economic opportunities, both direct and indirect, as a consequence of the new road connection.

Meanwhile the Baleh hydroelectricity project, which starts early this year, is scheduled to complete in 2024 (Sarawak Energy, 2016). As part of the Baleh Dam project, access road and bridges linking Nanga Mujong to the proposed dam site in upper Baleh will be built. The proposed 73 kilometres access road, expected to be completed by 2019 , will open up the mid to upper Baleh area, which is currently completely dependent on river transportation. The current three-hour journey by express boats from upper Baleh to Kapit Town is expected to take only an hour by land transport once this access road is completed (RECODA, 2016; Sarawak Energy, 2016).

Opening up the previously inaccessible and rural Kapit District could be seen as both positive benefits and negative consequences to the people of Baleh. The key questions are: whether (a) these new development project accelerate or slow the de-agrarianisation process?; (b) whether these new developments and improved accessibility will expand or reduce the practice of multi-local living among the residents of Baleh river basin?; and (c) whether the level of inequality will be expanded or reduced?

Using my study as a basis, I address three possible scenarios of the likely implications of changing levels of accessibility and development in Baleh river basin. The key issue is that development at this scale is expected to make Kapit District more accessible - but the question is, what will happen based on my study? 


\subsubsection{Scenario 1: Transformation of Iban society}

One of the implications that I foresee for the people of Baleh river basin is the increased level of accessibility, which means that they would be able to travel from one place to another more freely than when they are dependent only on river transportation. This increased accessibility can be seen as an impetus for both individual, household and community development. This transformation as a consequence of road network availability could see the present day transitional Iban society evolves into contemporary Iban society. The central features of this contemporary society is its predominantly individualistic households, with minimal ties to their ancestral longhouse, largely urban-based, in single (non-longhouse) dwellings and working in non-farm sectors. Their ties to their villages are defined by their rights to ancestral land, rather than through active residence. These characteristics are in complete contrast to the traditional, close-knit Iban community, living in a longhouse and working the land for their living (e.g. as described by Freeman, 1955; 1970).

\subsubsection{Permanent move to the urban centres}

This predicted transformation of urban-based Iban living permanently in town and cities would not happen overnight. The process is expected to happen gradually over a long period of time - maybe over a few generations. This transformation is the long-term implication from widespread multi-local living, shifting from short, temporary multi-local practice and evolve into longer stay, and permanent shift in the long run. All these are basically originating from the pursuit for greater accessibility to market and higher levels of individual and household development. Improvement in accessibility would play a huge role in facilitating this societal transformation. What was initially a strategy of multilocal living, which facilitates greater accessibility to market and higher levels of development, could end up as a permanent move from longhouses in Kapit District to major urban areas in Sarawak or Malaysia.

This change is inevitable as the practice of multi-local living can be seen as unsustainable to maintain family harmony and effective organisation. A father who works outside of the area would be forced to make decisions whether to go back to the village, where opportunities for development are limited, or to stay and work in urban centres. His other option is to bring his own nuclear family with him and together, as a family unit, they practice multi-local living in urban area. Similar situation was observed by Fan et al. (2011) in their study of split families in China. This household then expands, with new addition into the family, with their own children born, raised and educated in urban areas. This 
situation is currently happening in the case study area, as well as other parts of Sarawak, and is evident by the high number of elderly parents as pun bilik at the longhouses.

Soda (2001, p.103) observes how the multi-local Iban households in his case study in Kanowit acknowledged the potential for the socio-economic performance of their children who may want to remain permanently in urban centres. Similarly, Cramb (2012) observes how household in his case study area now consists of members who are residents of longhouse, and permanent urban-based residents. My analysis of bilik-member profile has illustrated that nearly every bilik-families has at least one bilik-member residing in urban area, and that nearly half of the bilik-families in my study indicated that they have family members who are urban-based, i.e. live and work in urban areas with their nuclear family, and only to visit the longhouse once or twice a year during festivals.

There is a lack of association between these urban-based children with the longhouse ways of life, and their ties to their pun bilik and their ancestral land is minimal at best. If, and when, a majority of rural Iban population become urban-based as I predicted, the whole structure of traditional Iban household will change. The notion that an Iban has to belong to a longhouse may no longer be true if the generations of urban-based Iban are unfamiliar with the longhouse culture, custom and way of life. The close knit nature of Iban social organisation through the practice of longhouse domicile, as described by Freeman (1970) will be a thing of the past. The implications of this can be far reaching, given the fact that households still have claims to their ancestors' rural farm land in Kapit District.

Conversations with respondents who are practicing multi-local living highlight how those who grew up in the longhouse wanted to go back to the longhouse when they retire or to frequently visit and still becoming part of their longhouse communities. Soda (2000) also observes similar responses in his interviews with rural Iban migrants in Sibu. These elder generations of urban-based family, usually in their 50s, are keen to maintain their rural ties. They firmly believe that an Iban and longhouse are inseparable. I, however, believe that this 'romantic' view is difficult to sustain in reality. Firstly, as I explained before, the younger generations of urban-based multi-local family might not have the same romantic sentiment on being an Iban in a longhouse. They are the generations who are born, raised and educated in the cities and unfamiliar with longhouse. They might view their longhouses as their connection to the grandparents and nothing more. Secondly, this practice is not sustainable as, in the long run, various members of the longhouse will be based in different locations - and returning home requires commitment. Particularly, if the longhouse does not offer the same accessibility to markets 
and services as its urban counterpart, for the younger generation, returning to the longhouse permanently might limit their development potential.

However, longhouse could still be a dominant presence in rural Baleh if there is a strong motivation for its non-resident members to continuously maintain their ties with their longhouses. One of them is through strong leadership of tuai rumah, whereby tuai rumah stipulates conditions for maintaining longhouse membership. During my fieldwork, I found that a number of longhouses required its members to return and stay at their bilik in the longhouse at least once a year in order to retain their membership to the community. Different longhouses have different conditions - as agreed by the longhouse community itself. However not all longhouses have those conditions for membership. My argument here is that, if this style of leadership is strong and the community 'enforces' it, the longhouse will still be an important feature in the life of an urban-based Iban as they are committed to return periodically. If the leadership is weak, its members may cut off their ties permanently with the longhouse and become completely urban-based.

Another factor that could tie urban-based and multi-local households to their longhouse is their inheritance - namely their ancestral land. As previously mentioned at the beginning of this thesis, only an acknowledged bilik-members can inherit bilik's property and as the property is usually in the form of native land, individuals have to be members of the longhouse community.

\subsubsection{Ties to their rural inheritance}

The ties of the urban-based Iban families to their ancestral land are significant both culturally and because of the potential economic value of their ancestors' farmland. If the household structure change, active residence in longhouses no longer matter and the urban-based households' rights to the land will be the only thing that ties them to their ancestral land. We can expect to see their ties to their longhouses weaken, and only limited to the fact they have ancestors in the area. When the whole area in Kapit District is open up for development and other investment opportunities, then there will be tensions between the landowners, both residents and non-residents.

I foresee possible tensions between residents and non-residents (i.e. the urban-based families with limited ties to longhouses) in the future. These tensions are likely to be exacerbated by the major development projects in the area: the dam construction in upper Baleh, and the road construction linking Sibu to Kapit. 
Once the area becomes more accessible, its economic potential will increase tremendously. In particular, as Ngidang $(2012$, p.183) predicted, 'these major development will further facilitate the opening of the hinterland of Kapit District for potential agricultural and tourism development'. Kapit District, with its vast tract of underutilised land, is expected to attract oil palm companies to invest and start large-scale joint venture oil palm schemes here. Large commercial oil palm plantation working in joint venture schemes has been the State's favoured agricultural scheme (Colchester et al., 2007; Cramb, 2011a; De Koninck, Bernard, \& Bissonnette, 2011). Colchester et al. (2007), for example, argue that Sarawak has been encouraging Peninsular-based oil palm companies to invest in the State to take advantage of the short supply of land suitable for plantation in Peninsular Malaysia. Cramb (2011) attributes the rapid and pervasive agrarianisation in the State since 1980s as a result of large scale commercial plantation (the majority being oil palm plantation). However, due to its inaccessibility, these schemes have yet to make it into Kapit District.

The effects of these joint venture oil palm operations in Malaysia, and in Sarawak have been well documented. For example, Andersen et al. (2016) highlight how political intervention and internal rifts between participants exist in negotiating the case for large-scale oil palm plantation. Similarly observation was made by Colchester et al. (2007) who argue that the indigenous communities affected by the large-scale oil palm joint venture often complained of conflicts and disputes regarding land rights, payment of compensation and lack of transparency in disseminating information to the participant. Thus, the effects are not all positive or benefitting the local community.

How successful a multi-local household will be in claiming their rural inheritance will depend on a number of factors. Chief among them is their ties to the longhouse. If they still have family members, e.g. elderly parents, actively residing in the area, their claim can be substantiated. This is because they still have a pun bilik in the longhouse, 'guarding' their rights to the land, despite not actively living in the area themselves.

If there is no pun bilik, or other family members, actively residing in the area, their links to the ancestral land could be weaken, or denied altogether. This is particularly true for urban-based individuals, who do not know the exact location or boundaries of their ancestral land. Cramb (2012) notes similar observations in his study,

"Older men who know the territory intimately, having farmed, hunted and foraged along every ridge and valley throughout their lives, remember where farm boundaries were 
established and forest trees were claimed. Those who have spent most of their adult lives away from the longhouse are at a disadvantage when it comes to asserting ownership rights ... example, when compensation for road construction or land-shares for rubber are being determined."

(Cramb, 2012, p. 85)

This problem arises because of the customary nature of the land. The residents of longhouses are seen as having stronger claim to the land, compared to their urban-based counterparts. Along the same line, Ngidang (2012) expresses concerns regarding the future of landowners in Kapit District,

"...longhouse communities in rural areas will face even greater challenges in the near future especially with respect to the legality of rural settlements. From time to time, we see provoking statements being echoed by public officials that land without title belongs to the state, and that occupiers of state lands are merely licenses, which is short of saying that all longhouses are illegally built on state land."

(Ngidang, 2012, p. 175)

This last statement implies the insecurity on both active residents of the longhouses and their urbanbased counterparts regarding their accessibility and 'ownership right' to their ancestral land. Both groups could potentially face obstacles in claiming their rights to the land if other cases of native land disputes among the Iban and the government and/or commercial plantation companies throughout Sarawak are any indication. It should be noted here that there are more than 300 cases of land disputes pending in courts and a majority was due to the conflicting definition of native customary land (Borneo Post, 2014). Potentially, regardless of the strength of their ties to the community, or their locality, both groups, i.e. residents and non-residents of longhouses along Batang Baleh, could face frictions and legal contention with the government when it comes to claiming rights to their land. A major factor complicating this matter is the customary status of the native land, or known as the Native Customary Right (NCR) land.

\subsubsection{Scenario 2: Value of native customary land}

As the roads open up the accessibility as well as pushing the demand for land in the area, landowners are put in a position where they now have more options with regards to what to do with their ancestral land. One of the alternative ways to deal with potential frictions regarding land ownership is by selling the land, which is easier said than done. The land in Baleh river basin is largely NCR land. This means that it is classified as land where only the native people can exert their rights on the land based on their native customary rights and tenure. According to the 1958 Land Code, native customary rights 
can be acquired through the felling of virgin jungle and the occupation of the land thereby cleared; the planting of land with fruit trees; the occupation or cultivation of land; the use of land for burial ground or shrine; the use of land of any class for rights of way; or any other lawful methods (Foo, 1986; pg.32).

Bissonnette (2011, p. 97) argues that native customary land titles granted during the colonial era, although lawful, nowadays are often interpreted by governmental land management authorities as mere recognition of land utilisation rights over a communal territory. As a result, native customary land becomes the centre of conflict and power struggles between landowners and the authority and/or outsiders with vested interests. How will this affect land rights, and subsequently the livelihood of the rural dwellers, in the case study area is likely to be a key question in the future.

In formal land market, due to the customary nature of the land, the native customary right land has very little economic value because it is without any legal title. It cannot be sold, cannot be used as collateral, and any exchange is restricted to certain ethnicity (i.e. natives). The potential for trade is available as Ngidang (2012) has shown in the thriving informal land markets in Kapit District, particularly at the periphery of Kapit Town, since the 1980s. In this case the sales in 'informal land market' has been due to demand from Iban migrants, especially those practicing multi-local living and, more specifically dual residency, in Kapit Town.

Prior to 1970s, buying and selling land for profit was an uncommon practice among the Iban in Kapit District (Ngidang, 2012). However, as people become more aware of its economic value, this perception swiftly changed. I am expecting that the value of rural land in Baleh will increase, as the area becomes more accessible. A more accessible area means there will be greater opportunities for development, and for that development to happen, land is required. While demand for the land for commercial agricultural purposes may increase with this potential improvement in accessibility, the tensions between households in a longhouse and between members of same households may also rise. This conflict may be associated with the sharing of bilik's land sale potential and who are the custodian of their bilik's or longhouse's NCR land. This issue is particularly crucial in cases when the landowner is approach to join large-scale commercial plantation (detailed below) or if a member of the bilik wants to set up his/her own small-scale plantation. 


\subsubsection{Scenario 3: Joint ventures}

One possible scenario offered to the landowners of native land in the District is 'partnership' in a joint venture with large-scale oil palm plantation companies. The joint venture concept is the State's most favoured development strategy, whereby native landowners are encouraged to join in a partnership to develop their idle or underutilised land with the government and a private sector company. The government and the private sector company provide the expertise and capital in this partnership while the land owners become shareholders by providing the land. This joint venture approach has been introduced since 1990s but up till today, there has been no such arrangement in Kapit District due to its remote location and inaccessibility.

Since its introduction in the 1990s, the joint venture approach has been inundated with controversies, and chief among them is relating to lack of clarity on exactly how native landowners get benefits during the schemes and how they can reclaim their land back - if at all - at the end of the partnership (Colchester et al., 2007). This brings challenges in relation to land rights and land ownership. Landowners might find that land that they thought was their ancestral land might not be their land after all - as experienced by the Iban in other parts of Sarawak due to the interpretation of Land Code and its subsequent amendments (Colchester et al., 2007). This issue of land ownership could be further complicated if there were interests in developing the land in joint venture approach, pushing the demand for the land, as well as its economic, both real and perceived, values.

The other possible scenario is a partial reversal of de-agrarianisation as a result of improved road linkage because of the rise of individual 'farmers' in Kapit District. Interviews with respondents highlighted how they also want to set up their own oil palm plantation if they have access to road connection and to processing mills. I believe that, with improved road connection, there will be an increase in a number of farmers in the area, utilising their currently underutilised or idle farm land. Again, this potential is more attractive to households with access to better socio-economic background as starting a plantation requires a significant capital. Therefore, perhaps only limited households and individuals can afford to venture into these opportunities.

\subsection{Significance and contribution of the research}

Past literature and, in some cases, official government statistics, still described rural area as predominantly agriculturally based (i.e. main income come from agricultural activities), and that rural dwellers consist only of farming families (Berma, 2001; Firman, 1994; Rigg, 2003; Rigg \& Nattapoolwat, 
2001). Berma, for instance, argues that there is a tendency to classified rural households, especially in research on Sarawak, as farming families even though the households' main source of income is not from agriculture. Similar sentiments are expressed by Rigg based on his study of Southeast Asian villages of Thailand, Laos and Vietnam. The findings of my research had highlighted how the common (traditional) preconception of rural-ness is no longer true. The preconception that rural area and rural livelihoods are very much intertwined with agriculture-related livelihood strategies has been proven as not entirely true as illustrated by my findings of rural Baleh, Kapit District, Sarawak. These findings, and its related discussion, are altering our preconception of rural living. Recognising that change is, in itself, a crucial step in understanding rural change and the future direction of research into rural area and rural change.

This preconception of rural-ness, or defining rural-ness from the traditional view has to be set straight in order to clearly see how the rural area has transformed over time. Setting it right here means acknowledging that rural areas had changed and, will keep on changing, due to the fluid and dynamic nature of rural area and its occupants. This is important, especially taking into consideration the deagrarianisation process which had occurred not just in Kapit District, but also globally. A number of scholars have been discussing the process and effects of de-agrarianisation in, amongst other, Asia (Kelly, 2022; McKay, 2005; Rigg \& Nattapoolwant, 2001), Africa (Bryceson, 1996; Ncube, Tanga \& Bhumira, 2014) and Latin America (Bryceson, Kay \& Mooij, 2000) in the past few decades.

My research has highlighted the correlation between accessibility and development, but understanding the full consequences of this relationship requires a flexible conceptual description of both accessibility and development. The implications of several different accessibility-development relationships were studied in the context of de-agrarianisation and I have shown how they affected the lives of rural dwellers in Kapit District at the levels of the community, the household and the individual. My findings show that there is a weak relationship between accessibility and development at the community level, but, in contrast, relationship at individual level is stronger. In the case of the latter is, e.g. in terms of how an individual, who have access to tertiary education are earning higher income indicated a potentially widening gap between those who have access to tertiary education and those who do not.

My findings and discussions provided snapshots of the livelihood in $21^{\text {st }}$ Century of rural Iban in Kapit District, Sarawak. The Iban are currently in the transitional stage, between their traditional way of lives and a more contemporary social arrangement, and a re-working of the roles of Iban households 
and individuals within households. This transitional phase that they experienced, will experience for the foreseeable future, is not entirely of their own making. External forces, at State, Federal and global levels generate and condition the events which they must react to. Global prices of agricultural commodities, for example, affect household decisions on what to farm, how much to farm or whether to continue farming. Low returns discourage farmers to continue and/or expand their farmlands. Lack of physical infrastructure (i.e. road connectivity) in the District, which affects the type of products they can cultivate, are the result of decisions and policies made at the State and Federal levels. Decisions made in Kuching or Kuala Lumpur have huge implications, both direct and indirect, on the Iban's accessibility to market in Kapit District. With these challenges, and coupled with the availability of other alternative income generating activities, most rural dwellers have responded by abandoning farming as well as their longhouses leaving only individual rights to the land.

Similar situations had occurred in other rural Southeast Asian regions, such as Indonesia (Firman, 1994), Thailand (Rigg, 2003; Rungmanee, 2014) and the Philippines (Kelly, 2011; McKay, 2003) in the 1960s and 1970s. Fiman describes how the rural labour force of Javanese households abandoned farming and migrated temporarily in cities in Indonesia in search for higher income. McKay's study explores how female migration is crucial in transforming livelihoods in rural Philippine through multilocal living and remittances. Therefore, what is happening in Baleh river basin at the present is nothing new.

What is intriguing for me is the future direction as a result of this change. If more and more rural dwellers in the District are moving away, albeit practicing multi-local living, some with the intention of returning back to the longhouses while some opt for a permanent move, the impacts on Iban community and Iban family structure, and the individual role within the bilik-family are monumental. The number of farming families decreases, but the number of 'guardians of the estate' increases as discussed in the previous Chapter Seven. The latter refers to elderly parent(s) or pun bilik, who are no longer able to farm intensively, but act as guardian to his/her farm land (collectively owned by the bilik) until such a time when the land is divided between his/her acknowledged bilik-members. The bilik-members' decision on what to do with the land in the future is also interesting, as their decisions could change the present rural landscape of Kapit District forever. That, however, is not a simple decision to make, as their rural land is predominantly customary in nature. Those who have rights to the land are bound by certain conditions (e.g. not transferable, and cannot be sold outside of the 'ethnicity'). 
Acknowledging that the Iban are changing - in their way of lives, their household structure and their roles within their own household - is not enough. That notion of rural-ness as traditionally defined no longer exist, at least not at its entirety, but it has been replaced by a highly dynamic and fluid rural society. Therefore, it is only fitting for that change to be acknowledged and incorporated in the policies and framework guiding rural development in the region, and Sarawak as a whole. Findings from this research showed that several key implications of accessibility-development relationships are going to be monumental in the future: diversified sources of income, multi-local living, dispersed households, quest for better educational attainment among the younger generations, and elderly parents' role as guardians of the estate. All of these should be taken into account in future policy making pertaining to Sarawak rural development.

Past policies for rural development in Sarawak (and Malaysia in general) often favoured promoting agricultural based schemes in rural areas (Department of Agriculture Sarawak, 2016; Economic Planning Unit Malaysia, 2006; Ngidang, 1995; State Planning Unit, 2016). This move is akin to 'forcing' rural dwellers to take up farming and/or continue with farming so that the government can minimise rural-urban migration, and its subsequent effects on urban capacity and urban infrastructure. Previous agricultural schemes, which are generally income enhancing schemes, came complete with assistance package in the form of ad-hoc subsidies and agricultural tools. However, discussions with participants and officials in Department of Agriculture have indicated that such schemes have not really been effective in Kapit District. Moreover, I found that a majority of the participants have indicated that they do not want to farm or extend their current farm in the future despite having more farmland for such purposes. Hence, I believe that the government's plan to continue with ad-hoc agricultural schemes may only continue to work as long as the subsidies last. Once the assistance and subsidies are no longer available, the schemes will probably fail.

There is a need to accept that rural area in Kapit District, and in Sarawak, is changing and will continue to do so in the foreseeable future. Therefore, policies that take into account these changes, as highlighted by my findings, should be considered in order to better develop the rural area, and taking into consideration the fact that very few rural dwellers and landowners are interested in continuing to farm as their livelihood strategy. It is unlikely that increased agricultural activities able to provide employment for the rural dwellers in Baleh river basin, and may be more convenient (and feasible) for the rural dwellers, with improved road connection, to seek employment elsewhere? 
For these reasons, there is a need to 'redefine' market and 'accessibility to market' in order to be more reflective of the current situation in rural areas, especially during period of de-agrarianisation and, to use Rigg's term, delinking of livelihood from farming activities. Another contribution of my research is that it had highlighted the fluid nature of accessibility to contemporary market amongst the research participants - and that their isolated geographical location is not a barrier for them to access markets beyond the boundary of Kapit District. Evidently, accessibility to contemporary markets can be improved through, among other factors, investment in human capital. This link between accessibility to contemporary market and the significance of human capital was illustrated in the findings, which highlight that accessibility to services is also important as accessibility to market. Accessibility to services ensures that participants have the potential to improve their educational attainment, work experience, and personal network.

Another significant contribution of my research is how a geographic framework of accessibility and development can be used as an empirical framework for exploring and understanding social change amongst the Iban in rural Baleh. I have used the accessibility-development paradigm acts as heuristic device to expose the practice and implications of de-agrarianisation and multi-local living that have occurred in absence of improved accessibility to market and services along with its social and economic consequences. The von Thünen model does not answer the question about what happens to households located beyond the margin of the farming economy - those who can supply commodities to the market. My study does.

\subsection{Limitations of the research}

One of my aims in embarking on research into the relationship between accessibility and development was to see if different types of accessibility influence development of communities, households and individuals. This idea was prompted by the fact that we are now living in a digital age, where nearly all households and individuals, regardless of their locations, own at least one mobile phone. I wanted to reflect the significance of information and communication technologies (i.e. mobile phones, internet and computers) and their accessibility to market and services in today's societies as suggested by Warren (2007), Kwan and Weber (2003) and Cecchini and Scott (2003).

However, I was not able to pursue this avenue for two reasons. Firstly, I found that a large majority of my participants did not have the skills to use computer or their phones to access to markets or services electronically. While the younger generations may be different as they are taught to be computer 
literate in schools. I did not include anyone under 18 years old as my participants. The research question remains, however, and a future possibly follow-up project could test the degree to which contemporary technologies have allowed them to improve their accessibility to non-conventional markets and services. It will be interesting to see how this younger generation of rural Iban in Baleh river basin uses technology to improve their accessibility to market, as well as its implications on their household and individual development, ten to twenty years from now.

The other reason why this aspect of research could not be pursued was because the current information and communication technology infrastructure in Kapit District does not support sufficient use of contemporary technology in the area. The mobile coverage in general is unevenly distributed, was almost non-existent in most areas in mid to upper Baleh during the time of the fieldwork in 2014. Therefore, I was not able to use it as an indicator of accessibility in my study.

A further limitation of my research was the research constraint. I had used a random number generator to sample longhouses, households and individuals within household. By pure chance, all of my randomly selected longhouses were conveniently located along Batang Baleh, Sungai Sut and Sungai Mujong. None of the longhouses that came up were located further in the interior of these tributaries. I am not sure what the situations are for the longhouses, communities, households and individuals that are located in the more remote locations. However, I have a feeling that their accessibility-development relationship would exhibit more variety that what I had discovered in my selected sample.

\subsection{Direction of future research}

In addition to the use of digital technologies in rural areas, there is another possible future project. The first is the possibility of expanding the investigation on the transition of Iban household - and how they adapt to change as well as their transformation into a more contemporary urban-based lifestyle. Secondly, the study could focus on the implications of multi-local living from the generational perspectives. This study would be able to shed some light on how the different Iban generations, who practice multi-local living view themselves - their identity as an Iban and their connection to the longhouse. The third possible project should focus on how the phenomenon of spatially dispersed households are linked to the guardianship roles of the elderly Iban in terms of their future ties to their ancestral land. This is especially significant in the light of new major developments, which will opens up the area like never before experienced in Baleh since the first Iban migration in 1880s. These large 
development projects - road construction and hydroelectricity dam - are the impetus for development in the context of Kapit District.

\subsection{A final note}

The stories of my participants, the residents of longhouses along Batang Baleh and its tributaries, have shown that as accessibility to market and services does correlate to the level of their development, depending on how 'development' was measured and defined. But accessibility to market is not the only factor as the size of the market also matters. At the same time, as accessibility to market and services increases, so does the level of inequality between individuals in the same households and between households in the same community. As we recognised that different definitions of development and accessibility resulted in different relationships between accessibility and development under study, we also need to redefine the notion of market beyond just those involving commodities. Because if we define market as I did in this research (i.e. Kapit Town as the main local market), we will miss out on the variations of relations between accessibility and development that exist in rural Baleh river basin.

In conclusion, my study has highlighted the contingent nature of the positive correlation between development and accessibility to market. The direction and strength of the relationship is highly dependent on access to multiple markets, ones in which markets for agricultural commodities are being replaced by markets for wage and salaried works, and some portion of that wage or salary is being remitted to declining, and ageing households back in the longhouses. Successive generations of households whose parents or grandparents farmed in rural areas are now living in urban areas. Because of the spatially dispersed nature of households, their ties to their pun bilik in the longhouses are weakening. This could also potentially weaken their ties to their rights to their ancestral land. The future of these relationships is uncertain in the light of the expected improvement in accessibility in the District as a whole. 


\section{References}

Aglietta, M., Alkire, S., Bourguignon, F., Clark, A. E., Deaton, A., \& Senik, C. (2011). Measure for measure. How Well Do We Measure Development? Paper presented at the 8Th AFD-EUDN Conference, Paris.

Alsnih, R., \& Hensher, D. A. (2003). The mobility and accessibility expectations of seniors in an aging population. Transportation Research Part A: Policy and Practice, 37(10), 903-916.

Alther, C., Castella, J.-C., Novosad, P., Rousseau, E., \& Hieu, T. T. (2002). Impact of accessibility on the range of livelihood options available to farm households in mountainous areas of northern Vietnam. Doi Moi in the Mountains: Land use changes and farmers' livelihood strategies in Bac Kan Province, Vietnam. Hanoi, Vietnam: The Agricultural Publishing House, 121-146.

Anand, S., \& Sen, A. (2000). Human development and economic sustainability. World development, 28(12), 2029-2049.

Andersen, A. O., Bruun, T. B., Egay, K., Fenger, M., Klee, S., Perdersen, A. F., . . Villanueva, V. S. (2016). Negotiating development narratives within large-scale oil palm projects on village lands in Sarawak, Malaysia. The Geographical Journal, 182, 1-11.

Anderson, W. P. (2012). Economic geography. Oxon: Routledge.

Atkins, P. (1987). The charmed circle: von Thünen and agriculture around nineteenth century London. Geography, 129-139.

Babbie, E. (2008). The Basics of Social Research: CengageBrain. com.

Barrett, C. B., Reardon, T., \& Webb, P. (2001). Nonfarm income diversification and household livelihood strategies in rural Africa: concepts, dynamics, and policy implications. Food policy, 26(4), 315-331.

Berma, M. (2001). Constraints to rural community involvement and "success" in non-agricultural activities: some evidence from Sarawak, Malaysia. Humanomics, 17(1), 99-115.

Berma, M., Shahadan, F., \& Abdul Gapor, S. (2006). Alleviating Bumiputera Poverty In Sarawak: Reflections And Proposal. Unpublished.

Bissonnette, J.-F. (2011). Claiming territories, defending livelihoods: the struggle of Iban communities in Sarawak. In R. De Koninck, S. Bernard, \& J.-F. Bissonnette (Eds.), Borneo Transformed. Agricultural Expansion on the Southeast Asian Frontier (pp. 94-119). Singapore: NUS Press.

Blaug, M. (1976). The empirical status of human capital theory: a slightly jaundiced survey. Journal of economic literature, 827-855.

Block, D., \& DuPuis, E. M. (2001). Making the country work for the city: von Thünen's ideas in geography, agricultural economics and the sociology of agriculture. American Journal of Economics and Sociology, 79-98.

Borneo Post. (2014, 2 April 2014). Vague definition source of NCR land disputes. Borneo Post. Retrieved from http://theborneopost.com

Bradburn, N. M. (1983). Response effects. Handbook of survey research, 1, 289-328.

Bravo, A. (2002). The impact of improved rural roads on gender relations in Peru. Mountain Research and Development, 22(3), 221-224.

Bryceson, D. F. (1996). Deagrarianization and rural employment in sub-Saharan Africa: a sectoral perspective. World development, 24(1), 97-111.

Bryceson, D. F., Kay, C., \& Mooij, J. (2000). Disappearing peasantries?: rural labour in Africa, Asia and Latin America. Exeter: Intermediate Technology London.

Burki, S. J., \& Haq, M. U. (1981). Meeting basic needs: An overview. World development, 9(2), 167182.

Calderón, C., \& Servén, L. (2004). The effects of infrastructure development on growth and income distribution: World Bank Publications.

Calderón, C., \& Servén, L. (2014) Infrastructure, growth, and inequality: an overview. In W. B. Group (Series Ed.). World Bank Policy Research Working Paper 7034: World Bank 
Cecchini, S., \& Scott, C. (2003). Can information and communications technology applications contribute to poverty reduction? Lessons from rural India. Information Technology for Development, 10(2), 73-84.

Chacko, E. (2004). Positionality and praxis: fieldwork experiences in rural India. Singapore Journal of Tropical Geography, 25(1), 51-63.

Chan, S. (2010). Sarawak scores big. In T. C. Kee (Ed.), March 8: Time for real change. Shah Alam: Marshall Cavendish Editions.

Chen, P., \& Tan, Y. (1982). A primary health care project for Sarawak. Med. J. Malaysia, 37(1), 25-34.

Chin, J. (1997). Politics of federal intervention in Malaysia, with reference to Sarawak, Sabah and Kelantan. Journal of Commonwealth \& Comparative Politics, 35(2), 96-120.

Clark, C. (1967). Von Thunen's isolated state. Oxford Economic Papers, 19(3), 370-377.

Clemens, M. A., \& Pritchett, L. (2008). Income per natural: measuring development for people rather than places. Population and Development Review, 34(3), 395-434.

Colchester, M., Wee, A. P., Wong, M. C., \& Thomas, J. (2007). Land is life: land rights and oil palm development in Sarawak. Moreton-in-Marsh: Forest Peoples Programme (FPP).

Coleman, J. S. (1988). Social capital in the creation of human capital. American journal of sociology, 94, S95-S120.

Cook, N., \& Butz, D. (2011). Narratives of accessibility and social change in Shimshal, northern Pakistan. Mountain Research and Development, 31(1), 27-34.

Cornwall, A. (2007). Buzzwords and fuzzwords: deconstructing development discourse. Development in Practice, 17(4-5), 471-484.

Costanza, R., Hart, M., Talberth, J., \& Posner, S. (2009) Beyond GDP: The need for new measures of progress. In P. C. f. t. S. o. t. L.-R. Future (Series Ed.). Pardee Paper No. 4. Boston: Pardee Center for the Study of the Longer-Range Future.

Cowen, M., \& Shenton, R. (1995). The invention of development. In J. Crush (Ed.), Power of development (pp. 25-42). London: Routledge.

Cramb, R. A. (2011a). Agrarian transitions in Sarawak: Intensification and expansion reconsidered. In R. B. De Koninck, S and Bissonnette, J (Ed.), Borneo transformed: Agricultural expansion on the Southeast Asian frontier (pp. 44-93). Singapore: NUS Press.

Cramb, R. A. (2011b). Re-inventing dualism: policy narratives and modes of oil palm expansion in Sarawak, Malaysia. Journal of Development Studies, 47(2), 274-293.

Cramb, R. A. (2012). Beyond the longhouse: Iban shifting cultivators come to town. In J. Rigg \& P. Vandergeest (Eds.), Revisiting rural places: Pathways to poverty and prosperity in Southeast Asia (pp. 68-87). Singapore: NUS Press.

Cramb, R. A., Colfer, C. J. P., Dressler, W., Laungaramsri, P., Le, Q. T., Mulyoutami, E., ... Wadley, R. L. (2009). Swidden transformations and rural livelihoods in Southeast Asia. Human Ecology, 37(3), 323-346.

Crush, J. (1995). Power of development. London: Routledge.

Davidson, K. B. (1977). Accessibility in transport/land-use modelling and assessment. Environment and Planning A, 9(12), 1401-1416.

De Haan, A., \& Rogaly, B. (2002). Introduction: Migrant workers and their role in rural change. Journal of Development Studies, 38(5), 1-14.

De Haan, L., \& Zoomers, A. (2003). Development geography at the crossroads of livelihood and globalisation. Journal of Economic and Social Geography, 94(3), 350-362.

De Koninck, R., Bernard, S., \& Bissonnette, J.-F. (2011). Borneo transformed: Agricultural expansion on the Southeast Asian frontier. Singapore: NUS Press.

Delbosc, A., \& Currie, G. (2011). Exploring the relative influences of transport disadvantage and social exclusion on well-being. Transport Policy, 18(4), 555-562.

Department of Agriculture Sarawak. (2013). Sarawak agricultural statistics 2013. Retrieved from http://www.doa.sarawak.gov.my/modules/web/pages.php?mod=webpage\&sub=page\&id=7 $\underline{12}$ 
Department of Agriculture Sarawak. (2016). Department of Agriculture Sarawak. Retrieved from www.doa.sarawak.gov.my

Department of Statistics Malaysia. (1997). Yearbook of Statistics Sarawak 1997. Kuching: Department of Statistics Malaysia (Sarawak).

Department of Statistics Malaysia. (2011). Population and housing census of Malaysia 2010. Kuala Lumpur: Department of Statistics Malaysia.

Department of Statistics Malaysia. (2012). Yearbook of Statistics Sarawak 2012. Kuching: Department of Statistics Malaysia (Sarawak).

Department of Survey and Mapping Malaysia. (2010). Kapit Divisional Map. Malaysia: Department of Survey and Mapping Malaysia.

Dick, E., \& Reuschke, D. (2012). Multilocational households in the Global South and North: Relevance, features and spatial implications. DIE ERDE-Journal of the Geographical Society of Berlin, 143(3), 177-194.

Doi, K., Kii, M., \& Nakanishi, H. (2008). An integrated evaluation method of accessibility, quality of life, and social interaction. Environment and Planning B: Planning \& Design, 35(6), 1098.

Dowling, R. (2010). Power, subjectivity and ethics in qualitative research. In I. Hay (Ed.), Qualitative research methods in human geography (Third ed., pp. 26-39). Ontario: Oxford University Press.

Economic Planning Unit Malaysia. (2006). Ninth Malaysia Plan 2006-2010. Retrieved from Kuala Lumpur: http://www.epu.gov.my/en/rmk/ninth-malaysia-plan-2006-2010

Ellis, F. (1998). Household strategies and rural livelihood diversification. Journal of Development Studies, 35(1), 1-38.

Ellis, F. (2000). The determinants of rural livelihood diversification in developing countries. Journal of Agricultural Economics, 51(2), 289-302.

Elmhirst, R. (2012). Displacement, resettlement, and multi-local livelihoods: positioning migrant legitimacy in Lampung, Indonesia. Critical Asian Studies, 44(1), 131-152.

Escobar, A. (1992). Reflections on 'development': grassroots approaches and alternative politics in the Third World. Futures, 24(5), 411-436.

Escobar, A. (2011). Encountering development: The making and unmaking of the Third World. New Jersey: Princeton University Press.

Esteva, G. (2010). Development In W. Sachs (Ed.), Development Dictionary: A guide to knowledge as power (2nd ed., pp. 1-23). London: Zed Books.

Evans, P. (2002). Collective capabilities, culture, and Amartya Sen's Development as Freedom. Studies in comparative international development, 37(2), 54-60.

Fafchamps, M., \& Quisumbing, A. R. (1999). Human capital, productivity, and labor allocation in rural Pakistan. Journal of Human Resources, 369-406.

Fan, C. C., Sun, M., \& Zheng, S. (2011). Migration and split households: a comparison of sole, couple, and family migrants in Beijing, China. Environment and Planning-Part A, 43(9), 2164.

Fernando, P. (1998). Gender and rural transport. Gender, Technology and Development, 2(1), 63-80.

Firman, T. (1994). Labour allocation, mobility, and remittances in rural households: A case from central Java, Indonesia. Sojourn: Journal of Social Issues in Southeast Asia, 81-101.

Folbre, N. (1986). Cleaning house: New perspectives on households and economic development. Journal of Development Economics, 22(1), 5-40.

Fox-Wasylyshyn, S. M., \& El-Masri, M. M. (2005). Handling missing data in self-report measures. Research in Nursing \& Health, 28(6), 488-495.

Fox, M. (1995). Transport planning and the human activity approach. Journal of Transport Geography, 3(2), 105-116.

Freeman, D. (1955). Iban agriculture: a report on the shifting cultivation of hill rice by the Iban of Sarawak. London: HM Stationery Office.

Freeman, D. (1970). Report on the Iban. London: The Athlone Press. 
Goulet, D. (1992). Development: creator and destroyer of values. World development, 20(3), 467475.

Graham, J. W. (2009). Missing data analysis: Making it work in the real world. Annual review of psychology, 60, 549-576.

Greiner, C. (2012). Can households be multilocal? Conceptual and methodological considerations based on a Namibian case study. DIE ERDE-Journal of the Geographical Society of Berlin, 143(3), 195-212.

Grotewold, A. (1959). Von Thunen in retrospect. Economic Geography, 35(4), 346-355.

Guy, C. M. (1983). The assessment of access to local shopping opportunities: a comparison of accessibility measures. Environment and Planning B: Planning and Design, 10(2), 219-238.

Hall, D., Hirsch, P., \& Li, T. M. (2011). Introduction to Powers of Exclusion: Land Dilemmas in Southeast Asia. Singapore: NUS Press.

Hammett, D., Twyman, C., \& Graham, M. (2014). Research and fieldwork in development. Oxon: Routledge.

Hansen, T., \& Mertz, O. (2006). Extinction or adaptation? Three decades of change in shifting cultivation in Sarawak, Malaysia. Land Degradation \& Development, 17(2), 135-148.

Hansen, W. G. (1959). How accessibility shapes land use. Journal of the American Institute of Planners, 25(2), 73-76.

Hawley, J. D. (2004). Changing returns to education in times of prosperity and crisis, Thailand 19851998. Economics of Education Review, 23(3), 273-286.

Hew, C. S. (2011). Coping with change: rural transformation and women in contemporary Sarawak, Malaysia. Critical Asian Studies, 43(4), 595-616.

Hewage, P., Kumara, C., \& Rigg, J. (2011). Connecting and disconnecting people and places: Migrants, migration, and the household in Sri Lanka. Annals of the Association of American Geographers, 101(1), 202-219.

Hicks, N., \& Streeten, P. (1979). Indicators of development: the search for a basic needs yardstick. World development, 7(6), 567-580.

Hirsch, P. (2012). Reviving Agrarian Studies in South-East Asia: Geography on the Ascendancy. Geographical research, 50(4), 393-403.

Hite, J. (1997). The Thunen model and the new economic geography as a paradigm for rural development policy. Review of Agricultural Economics, 19(2), 230-240.

Hopper, P. (2012). Understanding development. Cambridge: Polity Press.

Horton, N. J., \& Lipsitz, S. R. (2001). Multiple imputation in practice: comparison of software packages for regression models with missing variables. The American Statistician, 55(3), 244254.

Hugo, G. (1982). Circular migration in Indonesia. Population and Development Review, 59-83.

Hussein, K., \& Nelson, J. (1998). Sustainable livelihoods and livelihood diversification. IDS Working Paper 69.

Inglehart, R., \& Baker, W. E. (2000). Modernization, cultural change, and the persistence of traditional values. American sociological review, 19-51.

Isenman, P. (1980). Basic needs: the case of Sri Lanka. World development, 8(3), 237-258.

Jaafar, S. B. (1998). Cultural Information Within the Context of the Malaysian National Information Policy. Paper presented at the Second Asia-Pacific Cultural Forum, Seoul, Korea.

James, J. (2005). The global digital divide in the Internet: developed countries constructs and Third World realities. Journal of Information Science, 31(2), 114-123.

Joseph, A. E., \& Bantock, P. R. (1982). Measuring potential physical accessibility to general practitioners in rural areas: a method and case study. Social science \& medicine, 16(1), 8590.

Kahneman, D., \& Krueger, A. B. (2006). Developments in the measurement of subjective well-being. Journal of Economic Perspectives, 20(1), 3-24. 
Kakroo, U. (2007). ICT empowering citizens of Malaysia: Development with Destiny. United Nations Public Administration Network.

Kamruzzaman, M., \& Hine, J. (2012). Analysis of rural activity spaces and transport disadvantage using a multi-method approach. Transport Policy, 19(1), 105-120.

Kapit District Office. (2014). List of longhouses in Kapit District. Kapit District Office. Kapit.

Katungi, E., Edmeades, S., \& Smale, M. (2008). Gender, social capital and information exchange in rural Uganda. Journal of International Development, 20(1), 35-52.

Kedit, P. M. (1993). Iban Bejalai. Kuala Lumpur: Ampang Press.

Keeling, D. J., \& Blomley, N. (2007). Transportation geography-new regional mobilities. Progress in Human Geography.

Kelly, P. F. (2011). Migration, agrarian transition, and rural change in Southeast Asia: Introduction. Critical Asian Studies, 43(4), 479-506.

Kenyon, S., Lyons, G., \& Rafferty, J. (2002). Transport and social exclusion: investigating the possibility of promoting inclusion through virtual mobility. Journal of Transport Geography, 10(3), 207-219.

Kepe, T. (1999). The problem of defining 'community': Challenges for the land reform programme in rural South Africa. Development Southern Africa, 16(3), 415-433.

Kingsbury, D. (2004). Community development. In D. Kingsbury, J. Remenyi, J. McKay, \& J. Hunt (Eds.), Key issues in development (pp. 221-242). Basingstoke: Palgrave Macmillan.

Kingsbury, D., Remenyi, J., McKay, J., \& Hunt, J. (2004). Key issues in development. Basingstoke: Palgrave Macmillan

Kitchin, R., \& Tate, N. J. (2000). Conducting research into human geography: theory, methodology and practice. Harlow: Pearson Education Limited.

Kiyu, A., \& Hardin, S. (1992). Functioning and utilization of rural water supplies in Sarawak, Malaysia. Bulletin of the World Health Organization, 70(1), 125-128.

Kwan, M.-P., Murray, A. T., O'Kelly, M. E., \& Tiefelsdorf, M. (2003). Recent advances in accessibility research: Representation, methodology and applications. Journal of Geographical Systems, 5(1), 129-138.

Kwan, M.-P., \& Weber, J. (2003). Individual accessibility revisited: Implications for geographical analysis in the twenty-first century. Geographical analysis, 35(4), 341-353.

Lam, C. (2006). The Iban population of Sarawak: 1947-2000. Working Paper Series. Institute of East Asian Studies. UNIMAS.

Leinbach, T. R. (2000). Mobility in development context: changing perspectives, new interpretations, and the real issues. Journal of Transport Geography, 8(1), 1-9.

Li, H., \& Zhu, Y. (2006). Income, income inequality, and health: Evidence from China. Journal of Comparative Economics, 34(4), 668-693.

Lipton, M. (1980). Migration from rural areas of poor countries: the impact on rural productivity and income distribution. World development, 8(1), 1-24.

Litman, T. (2003). Measuring transportation: traffic, mobility and accessibility Institute of Transportation Engineers. ITE Journal (Vol. 73, pp. 28).

Mahapa, S. M., \& Mashiri, M. (2001). Social exclusion and rural transport: gender aspects of a road improvement project in Tshitwe, Northern Province. Development Southern Africa, 18(3), 365-376.

McGuirk, P. M., \& O'Neill, P. (2010). Using questionnaires in qualitative human geography. In I. Hay (Ed.), Qualitative research methods in human geography (Third ed., pp. 191-216). Ontario: Oxford University Press.

McKay, D. (2003). Cultivating new local futures: Remittance economies and land-use patterns in Ifugao, Philippines. Journal of Southeast Asian Studies, 34(02), 285-306.

McKay, D. (2005). Reading remittance landscapes: Female migration and agricultural transition in the Philippines. Geografisk Tidsskrift-Danish Journal of Geography, 105(1), 89-99. 
Ministry of Land Development Sarawak. (2016). Ministry of Land Development Sarawak. Retrieved from www.mlds.sarawak.gov.my/

Morris, J. M., Dumble, P., \& Wigan, M. R. (1979). Accessibility indicators for transport planning. Transportation Research Part A: General, 13(2), 91-109.

Morrison, P. S. (1993). Transitions in Rural Sarawak: off-farm employment in the Kemena Basin. Pacific Viewpoint, 34(1), 45-68.

Morrison, P. S. (1997). Transforming the periphery: the case of Sarawak, Malaysia. Asia-Pacific: New Geographies of the Pacific Rim, Hurst \& Company, London, 302-317.

Myers, T. A. (2011). Goodbye, listwise deletion: Presenting hot deck imputation as an easy and effective tool for handling missing data. Communication Methods and Measures, 5(4), 297310.

Nafukho, F. M., Hairston, N., \& Brooks, K. (2004). Human capital theory: Implications for human resource development. Human Resource Development International, 7(4), 545-551.

Naidu, G. (2008). Infrastructure development in Malaysia. In N. Kumar (Ed.), International infrastructure development in East Asia. Towards balanced regional development and integration. (pp. 204-227). Chiba: ERIA Research Project.

Ncube, N., Tanga, P. T., \& Bhumira, B. (2014). The Impact of De-agrarianisation on the Socioeconomic Well-being of Rural Inhabitants in South Africa. J Hum Ecol, 48(3), 399-406.

Neelsen, J. P. (1975). Education and social mobility. Comparative Education Review, 19(1), 129-143.

Ngidang, D. (1995). The politics of development in longhouse communities in Sarawak, East Malaysia. Development in Practice, 5(4), 305-312.

Ngidang, D. (2002). Contradictions in land development schemes: the case of joint ventures in Sarawak, Malaysia. Asia Pacific Viewpoint, 43(2), 157-180.

Ngidang, D. (2012). From frontier region to genturung pendiau. Dual residency and the making of new Iban settlements in peri-urban Kapit. Borneo Research Bulletin, 43, 162-185.

O'Kelly, M., \& Bryan, D. (1996). Agricultural Location Theory: von Thiinen's Contribution to Economic Geography'. Progress in Human Geography, 20(4), 457-475.

Oberai, A. S., \& Singh, H. (1980). Migration, remittances and rural development: Findings of a case study in the Indian Punjab. Int'l Lab. Rev., 119, 229.

Ogunsanya, A. (1987). Rural accessibility problems and human resource development: Case study from Nigeria. Journal of Rural studies, 3(1), 31-42.

Olaniyan, D., \& Okemakinde, T. (2008). Human capital theory: Implications for educational development. Pakistan Journal of Social Sciences, 5(5), 479-483.

Olsson, J. (2009). Improved road accessibility and indirect development effects: evidence from rural Philippines. Journal of Transport Geography, 17(6), 476-483.

Osaki, K. (2003). Migrant remittances in Thailand: economic necessity or social norm? Journal of Population Research, 20(2), 203-222.

Ozkul, B. D. (2015). Von Thünen Revisited. Built Environment, 41(1), 99-111.

Padoch, C. (1982). Migration and its Alternatives among the Iban of Sarawak (Vol. 98): Koninklyk Instituut Voor Taal Land.

Padoch, C., Coffey, K., Mertz, O., Leisz, S. J., Fox, J., \& Wadley, R. L. (2007). The demise of swidden in Southeast Asia? Local realities and regional ambiguities. Geografisk Tidsskrift-Danish Journal of Geography, 107(1), 29-41.

Páez, A., Mercado, R. G., Farber, S., Morency, C., \& Roorda, M. (2010). Relative accessibility deprivation indicators for urban settings: definitions and application to food deserts in Montreal. Urban Studies, 47(7), 1415-1438.

Páez, A., Scott, D. M., \& Morency, C. (2012). Measuring accessibility: positive and normative implementations of various accessibility indicators. Journal of Transport Geography, 25, 141153.

Parpart, J. L. (1995). Post-modernism, gender and development. In J. Crush (Ed.), Power of development (pp. 247-258). London: Routledge. 
PEMANDU. (2013). Government Transformation Programme. Improving rural development. Retrieved from http://www.pemandu.gov.my/gtp/upload/GTP2 ENG Cp8.pdf

Perle, E. D., Bauder, H., \& Beckett, N. (2002). Accessibility measures in spatial mismatch models. Professional Geographer, 54(1), 106-110.

Pick, J. B., \& Azari, R. (2008). Global digital divide: Influence of socioeconomic, governmental, and accessibility factors on information technology. Information Technology for Development, 14(2), 91-115.

Pieterse, J. N. (1998). My paradigm or yours? Alternative development, post-development, reflexive development. Development and Change, 29(2), 343-373.

Porter, G. (2007). Transport, (Im) Mobility, and Spatial Poverty Traps: Issues for Rural Women and Girl Children in Sub-Saharan Africa. Paper presented the Understanding and addressing spatial poverty traps: an international workshop, 29th March, Cape Town.

Posel, D. R. (2001). Intra-family transfers and income-pooling. South African Journal of Economics, 69(3), 501-528.

Preston, D. A. (1989). Too busy to farm: Under-utilisation of farm land in central Java. Journal of Development Studies, 26(1), 43-57.

Preston, J., \& Rajé, F. (2007). Accessibility, mobility and transport-related social exclusion. Journal of Transport Geography, 15(3), 151-160.

Pringle, R. (1970). Rajahs and rebels: the Ibans of Sarawak under Brooke rule, 1841-1941. New York: Cornell University Press.

Ranis, G., Stewart, F., \& Ramirez, A. (2000). Economic growth and human development. World development, 28(2), 197-219.

Reardon, T. (1997). Using evidence of household income diversification to inform study of the rural nonfarm labor market in Africa. World development, 25(5), 735-747.

RECODA. (2016a). Better Baleh connectivity in the cards [Press release]. Retrieved from http://www.recoda.com.my/news-events/press-release/better-baleh-connectivity-in-thecards/

RECODA. (2016b). The Regional Corridor Development Agency. Retrieved from Website: (www.recoda.com.my)

Remenyi, J. (2004). What is development. In D. Kingsbury, J. Remenyi, J. McKay, \& J. Hunt (Eds.), Key issues in development (pp. 22-44). Basingstoke: Palgrave Macmillan.

Rigg, J. (2003). Southeast Asia: The human landscape of modernization and development. London: Routledge.

Rigg, J. (2005). Poverty and livelihoods after full-time farming: A South-East Asian view. Asia Pacific Viewpoint, 46(2), 173.

Rigg, J. (2006). Land, farming, livelihoods, and poverty: rethinking the links in the rural South. World development, 34(1), 180-202.

Rigg, J. (2007). An everyday geography of the global south. London: Routledge.

Rigg, J., \& Nattapoolwat, S. (2001). Embracing the global in Thailand: activism and pragmatism in an era of deagrarianization. World development, 29(6), 945-960.

Rigg, J., \& Salamanca, A. (2011). Connecting lives, living, and location: mobility and spatial signatures in Northeast Thailand, 1982-2009. Critical Asian Studies, 43(4), 551-575.

Rigg, J., Salamanca, A., \& Parnwell, M. (2012). Joining the dots of agrarian change in Asia: A 25 year view from Thailand. World development, 40(7), 1469-1481.

Rist, G. (2007). Development as a buzzword. Development in Practice, 17(4-5), 485-491.

Rogers, A. (2000). Measuring development. Geography Review, 13(4), 40-41.

Romer, P. M. (1986). Increasing returns and long-run growth. Journal of Political Economy, 94(5), $1002-1037$.

Ruekeith, G. O. (2016, 30 April 2016). Road to Baleh Dam from Nanga Mujong to start soon. Borneo Post. Retrieved from http://www.theborneopost.com/2016/04/30/road-to-baleh-dam-fromnanga-mujung-to-start-soon 
Rungmanee, S. (2014). The dynamic pathways of agrarian transformation in the Northeastern ThaiLao Borderlands. Australian Geographer, 45(3), 341-354.

Sandin, B. (1967). The Sea Dayaks of Borneo before white rajah rule. Glassgow: University Press.

Sarawak Energy. (2016). Sarawak Energy Website. Retrieved from http://www.sarawakenergy.com.my/

Sarawak Government. (2016). Official website of the Sarawak Government. Retrieved from http://www.sarawak.gov.my/web/home/index

Sather, C. (2006). "All threads are white": Iban egalitarianism reconsidered. In J. J. Fox \& C. Sather (Eds.), Origins, ancestry and alliance: Explorations in Austronesian ethnography (pp. 73-112). Canberra: Australian National University Press.

Scheyvens, R. (2014). Development fieldwork: A practical guide (2 ed.). London: Sage.

Schier, M., Hilti, N., Schad, H., Tippel, C., Dittrich-Wesbuer, A., \& Monz, A. (2015). Residential MultiLocality Studies-The Added Value for Research on Families and Second Homes. Tijdschrift voor economische en sociale geografie, 106(4), 439-452.

Schier, M., Schlinzig, T., \& Montanari, G. (2015). The Logic of Multi-Local Living Arrangements: Methodological Challenges And the Potential of Qualitative Approaches. Tijdschrift voor economische en sociale geografie, 106(4), 425-438.

Schmidt-Kallert, E. (2009). A new paradigm of urban transition: tracing the livelihood strategies of multi-locational households. Die Erde, 140(3), 319.

Schultz, T. W. (1961). Investment in human capital. The American economic review, 1-17.

Scott, S., Miller, F., \& Lloyd, K. (2006). Doing fieldwork in development geography: research culture and research spaces in Vietnam. Geographical research, 44(1), 28-40.

Sen, A. (2001). Development as freedom. Oxford: Oxford Paperbacks.

Shen, Q. (1998). Spatial technologies, accessibility, and the social construction of urban space. Computers, environment and urban systems, 22(5), 447-464.

Sinharay, S., Stern, H. S., \& Russell, D. (2001). The use of multiple imputation for the analysis of missing data. Psychological methods, 6(4), 317.

Soda, R. (2000). Living strategies of the urban poor in a local town in Sarawak, Malaysia: population mobility of the Iban between urban and rural areas. Geographical review of Japan, Series B., 73(2), 139-164.

Soda, R. (2001). Rural-urban migration of the Iban of Sarawak and changes in long-house communities. Geographical review of Japan, Series B., 74(1), 92-112.

Soda, R. (2003). Development policy and human mobility in a developing country: voting strategy of the Iban in Sarawak, Malaysia. Southeast Asian Studies, 40(4).

Soda, R. (2005). Iban city dweller and rural property. Sarawak Development Journal, 7(1), 38-47.

Soda, R. (2007). Mover-oriented approach to understand rural-urban interaction: a case from Sarawak, Malaysia. Journal of the Graduate School of Letters, 2, 47-58.

Son, H. H. (2010). Human Capital Development. Retrieved from Manila: https://papers.ssrn.com/sol3/papers.cfm?abstract id=1695806

State Planning Unit. (2014). Sarawak: Facts and Figures 2014. Retrieved from Kuching: http://www.spu.sarawak.gov.my/download/Sarawak\%20Facts\%20\&\%20Figures\%202014.pd $\underline{f}$

State Planning Unit. (2016). Sarawak State Planning Unit. Retrieved from http://www.spu.sarawak.gov.my/

Stiglitz, J. E., Sen, A., \& Fitoussi, J.-P. (2009). Report by the Commission on the Measurement of Economic Performance and Social Progress. Retrieved from http://library.bsl.org.au/jspui/bitstream/1/1267/1/Measurement of economic performanc e and social progress.pdf

Streeten, P. (1984). Basic needs: some unsettled questions. World development, 12(9), 973-978.

Streeten, P., \& Burki, S. J. (1978). Basic needs: some issues. World development, 6(3), 411-421. 
Sultana, F. (2007). Reflexivity, positionality and participatory ethics: Negotiating fieldwork dilemmas in international research. ACME: An International E-Journal for Critical Geographies, 6(3), 374-385.

Sutlive, V. (1992). The Iban of Sarawak: chronicle of a vanishing world. Kuala Lumpur: S. Abdul Majeed \& Co.

Taylor, J. E., \& Yunez-Naude, A. (2000). The returns from schooling in a diversified rural economy. American Journal of Agricultural Economics, 82(2), 287-297.

UNDP. (2008). Malaysia Inland Waterway. Transport system in Sarawak. Kuala Lumpur: United Nation Development Programme (UNDP), Malaysia.

Uteng, T. P. (2009). Gender, ethnicity, and constrained mobility: insights into the resultant social exclusion. Environment and Planning A, 41(5), 1055.

Van de Walle, D. (2002). Choosing rural road investments to help reduce poverty. World development, 30(4), 575-589.

van Melis-Wright, M., Stone, D., \& Miller, M. (1993). Psychological variables associated with respondents' sensitivity to the income question and a measure of their willingness to give financial information on government surveys. Paper presented at the Proceedings of the Section on Survey Research Methods.

von Thünen, J. H., \& Hall, P. G. (1966). Isolated state: an English edition of Der isolierte Staat. London: Pergamon Press.

Wachs, M., \& Kumagai, T. G. (1973). Physical accessibility as a social indicator. Socio-Economic Planning Sciences, 7(5), 437-456.

Warren, M. (2007). The digital vicious cycle: Links between social disadvantage and digital exclusion in rural areas. Telecommunications Policy, 31(6), 374-388.

Weibull, J. W. (1980). On the numerical measurement of accessibility. Environment and Planning A, 12(1), 53-67.

Weichhart, P. (2015). Residential Multi-Locality: In Search of Theoretical Frameworks. Tijdschrift voor economische en sociale geografie, 106(4), 378-391.

Willis, K. (2005). Theories and practicies of development. New York: Routledge.

Windle, J. (2002). Envelopment or development? The role of roads as conductors of change in upland areas of Sarawak, Malaysia. Bijdragen tot de Taal-, Land-en Volkenkunde, 821-835.

Windle, J., \& Cramb, R. A. (1997). Remoteness and rural development: economic impacts of rural roads on upland farmers in Sarawak, Malaysia. Asia Pacific Journal, 38(1), 37-53.

Wittayapak, C. (2012). Who are the farmers? Livelihood trajectories in a Northern Thai village. In J. Rigg \& P. Vandergeest (Eds.), Revisiting rural places. Pathways to poverty and prosperity in Southeast Asia. Hawai'i: University of Hawai'i Press.

Wong, S. (2005). Market Gardening as a Livelihood Strategy: a Case Study of Rural-Urban Migrants in Kapit, Sarawak, Malaysia. (Honours), Victoria University of Wellington, Unpublished Thesis.

Wood, G., Hilti, N., Kramer, C., \& Schier, M. (2015). A Residential Perspective on Multi-Locality: Editorial. Tijdschrift voor economische en sociale geografie, 106(4), 363-377.

World Bank. (2009). World Development Report: Reshaping economic geography. Retrieved from Washington: http://siteresources.worldbank.org/INTWDRS/Resources/4773651327525347307/8392086-1327528510568/WDR09 bookweb 1.pdf

Yamanaka, K. (2005). Changing family structures of Nepalese transmigrants in Japan: splithouseholds and dual-wage earners. Global networks, 5(4), 337-358.

Zhiqiang, L. (2008). Human capital externalities and rural-urban migration: Evidence from rural China. China Economic Review, 19(3), 521-535. 


\section{Appendix 1: Questionnaire for Tuai Rumah (longhouse level)}

This questionnaire is for the selected tuai rumah (i.e. head of an Iban longhouse) and aims to gather general information about the longhouse, its main socio-economic activities, level of development and standard of living.

[Note: Researcher will write a brief description of the village based on observation and fill in the checklist of inventory for each longhouse]

\section{Settlement}

GPS coordinates

Tuai Rumah
Accessibility Zone:

$1=$ High Accessibility Zone

2 = Medium Accessibility Zone

3 = Low Accessibility Zone
Location (River)

Date of interview :

Section 1: General information on the longhouse (information is based on the scenario on $1^{\text {st }}$ April 2014, unless stated otherwise).

\section{Q.1.1 When was this longhouse}

constructed?

(a) Has it always been at this location?

$0=$ No $\quad 98=$ Don't know

$1=$ Yes $\quad 99=$ Refused

(b) If No, where was your former location? (Map will be provided so that respondent can indicate the location in the map)

(c) If Yes, why did you move to the current location? Elaborate if necessary.

\section{Q.1.2 Do you, as a community, have $\quad$ Q.1.3 At present, how many biliks}

any plan of moving to a different

location in the next 5 year

s?

No. of bilik:

Male HH:

Female HH:

(a) If Yes, where do you plan to move?

(b) Indicate the reason(s) behind the selection of new location. Elaborate

Total population: 2014?

No. of bilik: (a) Out of the above figure, how many biliks were occupied on $1^{\text {st }}$ April

Male $\mathrm{HH}$ :

Female HH:

Total population:

(b) How many biliks (out of those that were occupied) have family members who work/live away from the village?

No. of bilik:
Q.1.4 How many biliks (if any) are vacant on $1^{\text {st }}$ April 2014?

No. of bilik:

Male HH:

Female HH:

Q.1.5 At present, do you have any abandoned bilik in this longhouse?

(a) Are these families still acknowledged members of this longhouse community despite not residing here?

If Yes, indicate the mean(s) by which they retain their "membership" in this community. Note: if there is more than one, rank them in the order of relevance, with 1 being the most relevant.
[Note: Ask the respondent if there is any difference to the occupant's legal

entitlement in cases of vacant and abandonment of bilik in the longhouse.] 
Continue: General information on the longhouse (information is based on the scenario on $1^{\text {st }}$ April 2014, unless stated otherwise).

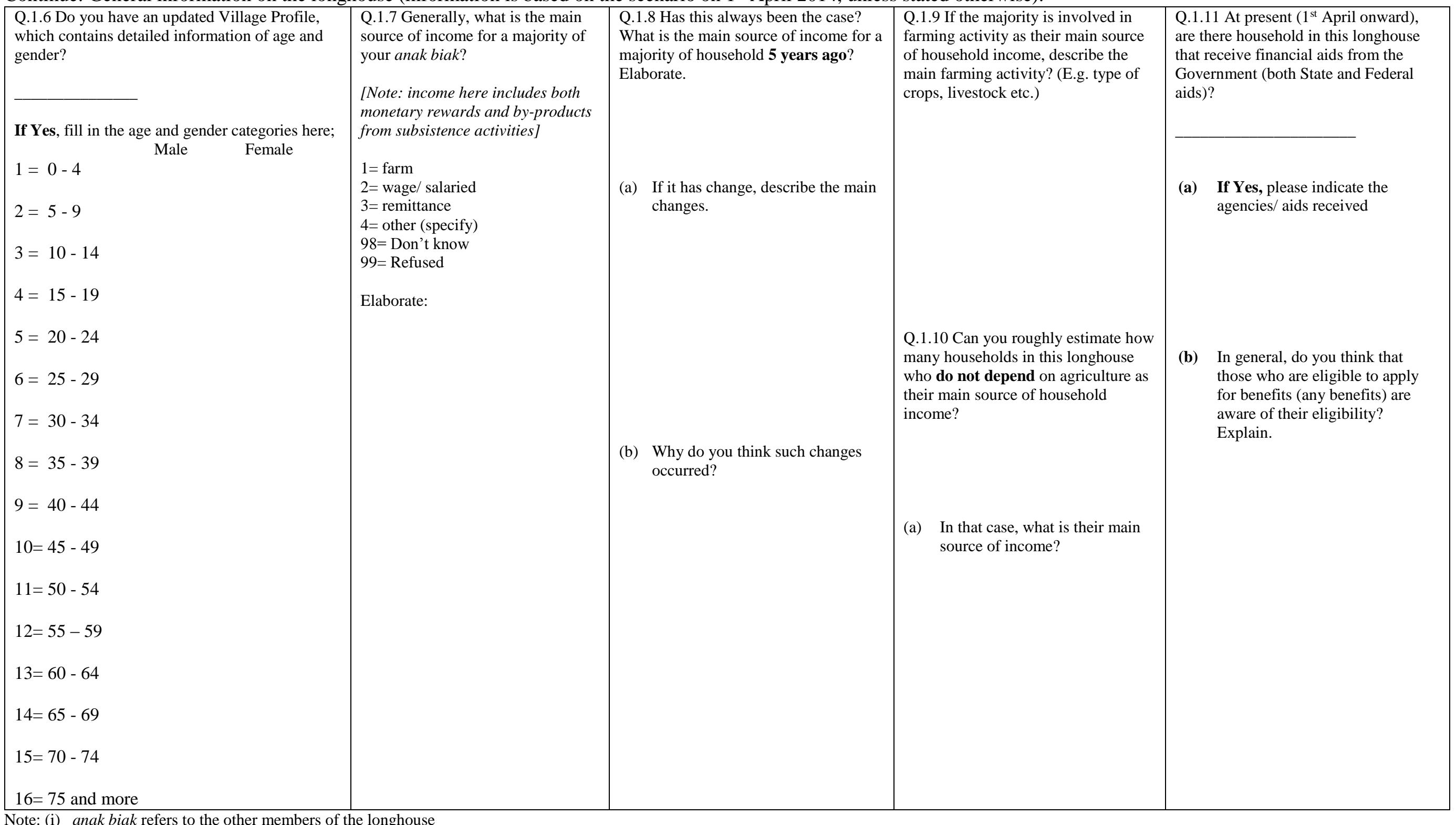

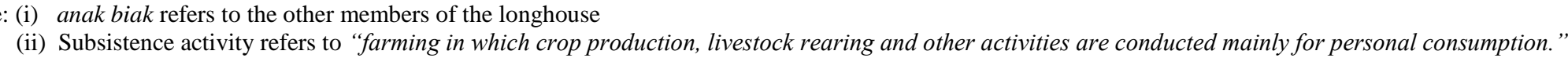


(iii) “Other" in Q.1.6 includes pension, and selling jungle products and home-made goods.

Section 2: Transportation and communication (information is based on the scenario on $1^{\text {st }}$ April 2014, unless stated otherwise).

\begin{tabular}{|l|l|l|l|l}
\hline Q.2.1 At present (as of $1^{\text {st }}$ April 2014), what is the & Q.2.2 In general, what is your view on the effects & Q.2.3 Is river transportation still relevant in your
\end{tabular} main mode of transport to the nearest town from this longhouse?

of road connection (or lack of road connection) to

your (and your anak biak) daily routine?

[Note: prompt for local context and example]

(a) If your area has access to road network, describe the road connectivity (to the nearest town) in the last one year.

(b) If it is connected by road to the nearest town (including dirt road and gravelled road), when was the road constructed?

(c) If it is just a partial connection, how do you and your anak biak access the road from this longhouse? \begin{tabular}{l|l}
$\begin{array}{l}\text { Q.2.3 Is river transportation still relevant in your } \\
\text { (and anak biak's) daily routine? }\end{array}$ & $\begin{array}{l}\text { Q.2.4 Have there been changes to the way you and } \\
\text { your anak biak travel to the nearest town in the last 5 }\end{array}$
\end{tabular} years?

(a) Describe the changes and how it affect the way

(a) If it is still relevant, describe what activities do you rely on the river transportation for. you and your anak biak travel, and or organize their routine.

Q.2.5 In your own view, where do you rank your longhouse in terms of ease of transportation compared to the other longhouses along Batang Baleh? 
Section 3: Community mobility (information is based on the scenario on $1^{\text {st }}$ April 2014, unless stated otherwise).

Social organization

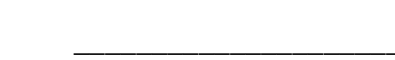

(a) If Yes, are the committee active (i.e. meeting frequently and organizing activities all year round)?

(b) Apart from that, do you and/or any members of your community, either collectively or individually, a member of any organization?

(c) If Yes, identify the organization that you (or your anak biak) currently join.

(d) How do you, collectively, benefit from joining such organization(s)?

(e) Compared to the other longhouses in this river tributary, where do you rank your longhouse in terms of participation in social organization?
Job mobility

Q.3.2 In the last one year, do you think that your anak biak have experienced satisfying job mobility (i.e. ease of getting job and/or moving from one job to another)?

(a) Why do you say that?

(b) Do you think that you location have anything to do with your response in Q.3.2? Elaborate.

(c) In the past twelve months, has there been an increase in number of people from this longhouse moving out in order to search for employment and/or because of getting a job outside of this area?
Economic mobility

Q.3.3 In the last 12 months, do you think that there has been significant improvement in terms of household economic improvement amongst your anak biak?

[includes those getting new jobs, better jobs, improved living conditions etc.]

a) Looking back to $\mathbf{5}$ years ago, was the scenario the same as it is now? Elaborate your answer. 
Section 3: Continued (Community mobility).

Physical mobility

as mobile (i.e able to move from one place to another easily and with limited

obstacles)?

(a) Why did you say that?

[Note: try to get the respondent to provide local example/ context]

(b) During the last one year, does the level of motorised vehicle or boat ownership (whichever is relevant) increases?

(c) Compared to the last 5 years, has the level of mobility (movement of people in and out of the area) in this longhouse change: improved, remained the same or deteriorated?

Q.3.5 In your opinion, what are the key factors that often play significant roles in influencing the community mobility (referring to all aspect of mobility discussed earlier)?

[note: let the respondent elaborate and it can be more than one answer]

(a) If you compared your own longhouse with the other longhouse in this river tributary, where do you rank your longhouse in terms of mobility? [Note: explain what do you mean by mobility to the respondent 
Section 4: Overall satisfaction

Q.4.1 In general, as the tuai rumah, are you satisfied

with the level of physical development that has been

experienced by this longhouse? (inc electricity, piped

water, road, telecommunication)

(a) What area of physical development are you (and your anak biak) satisfied with in the last one year?

(b) What area of physical development do you feel are still lacking?

(c) If you compared your own longhouse with the other longhouse in this river tributary, where do you rank your longhouse in terms of physical development? (a) Do you feel that this level of development as it is now would be different if the level of accessibility (physical access) of the area is different? Elaborate

[Note: prompt for local example and context].

Q.4.2 What about the area of human development/ human capital in your longhouse [explain what you mean by human

development to the respondent]? In general, do you feel that your

anak biak has shown progress in terms of human capital

development in the last one year?

(b) Compared to the last $\mathbf{5}$ years, has the level of human capital development in this longhouse change: improved, remained the same or deteriorated?

(c) If you compared your own longhouse with the other longhouse in this river tributary, where do you rank your longhouse in terms of progress in human capital?
Q.4.3 Are you, in general, satisfied with the education and health

facilities that are available to your anak biak? Elaborate.

Are you satisfied with your community's access to education in the last one year? What about the access to health facilities?

Have there been changes in the last 5 years in terms of your anak biak's access to education? Relate in term of enrolment and drop-out rate.
Q.4.5 To cap off this conversation, how do you rank this longhouse in terms of its overall development, compared to the other longhouses in this area (i.e. tributary)?

(a) Do you think a majority of your anak biak will agree with you on this rank? Elaborate. 


\section{Appendix 2: Questionnaire for Head of Household (Bilik-family)}

This questionnaire is for the second unit of analysis i.e. head of household (bilik-family). Head of bilik-family, who is randomly selected from the randomly selected longhouse (first unit of analysis), will be interviewed. The aim is to obtain the information about the profile of the bilik-family, their socio-economic background and collective access to capital, health and education.

Section 1: General information of bilik-members (Note: the information obtained from the respondents is based on their situations as of $1^{\text {st }}$ April 2014, unless stated otherwise)

\begin{tabular}{|c|c|c|c|c|c|c|c|c|c|c|c|c|c|c|c|c|}
\hline & $\begin{array}{l}\text { Q.1.1 } \\
\text { Bilik-members } \\
\text { (including the head } \\
\text { of household) } \\
\text { List the name of the } \\
\text { persons who are } \\
\text { acknowledged } \\
\text { members of your } \\
\text { bilik as of } 1^{\text {st }} \text { April } \\
2014\end{array}$ & $\begin{array}{l}\text { Q.1.2 } \\
\text { Relation- } \\
\text { ship with } \\
\text { head of } \\
\text { household }\end{array}$ & $\begin{array}{l}\text { Q.1.3 } \\
\text { Gender }\end{array}$ & $\begin{array}{l}\text { Q.1.4 } \\
\text { Age } \\
\text { (year) }\end{array}$ & $\begin{array}{l}\text { Q.1.5 } \\
\text { Marital } \\
\text { status }\end{array}$ & $\begin{array}{l}\text { Q.1.6 } \\
\text { Number } \\
\text { of } \\
\text { children }\end{array}$ & $\begin{array}{l}\text { Q.1.7 } \\
\text { Highest } \\
\text { level of } \\
\text { education }\end{array}$ & \begin{tabular}{|l|} 
Q.1.8 \\
Occupation \\
(note: this \\
refers to the \\
main \\
occupation)
\end{tabular} & $\begin{array}{l}\text { Q.1.9 } \\
\text { Gross } \\
\text { monthly } \\
\text { income } \\
\text { (Note: } \\
\text { wage or } \\
\text { salary } \\
\text { should } \\
\text { be } \\
\text { clearly } \\
\text { stated) }\end{array}$ & $\begin{array}{l}\text { Q.1.10 } \\
\text { Does } \\
\text { this } \\
\text { member } \\
\text { of the } \\
\text { bilik } \\
\text { send } \\
\text { remittan } \\
\text { ce in the } \\
\text { past one } \\
\text { year? }\end{array}$ & $\begin{array}{l}\text { Q.1.11 } \\
\text { If yes, } \\
\text { how } \\
\text { regular } \\
\text { does } \\
\text { he/she } \\
\text { send } \\
\text { remittance } \\
\text { in the last } \\
12 \text { months } \\
\text { (April } 13 \\
\text { - March } \\
\text { 14) } \\
\end{array}$ & $\begin{array}{l}\text { Q.1.12 } \\
\text { Average } \\
\text { monthly } \\
\text { amount } \\
\text { remitted } \\
\text { in the } \\
\text { last } 12 \\
\text { months }\end{array}$ & $\begin{array}{l}\text { Q.1.13 } \\
\text { Forms } \\
\text { of } \\
\text { remit- } \\
\text { ance }\end{array}$ & $\begin{array}{l}\text { Q.1.14 } \\
\text { What are } \\
\text { the uses of } \\
\text { remittances } \\
\text { by the } \\
\text { receiving } \\
\text { household? } \\
\text { [Note: Rank } \\
\text { the top } 3 \\
\text { uses] }\end{array}$ & $\begin{array}{l}\text { Q.1.15 } \\
\text { Place of } \\
\text { residence } \\
\text { (on 1 } 1^{\text {st }} \\
\text { April } \\
\text { 2014) }\end{array}$ & $\begin{array}{l}\text { Q.1.16 } \\
\text { Place of } \\
\text { residence } \\
5 \text { years } \\
\text { ago }\end{array}$ \\
\hline 1. & & & & & & & & & & & & & & & & \\
\hline 2. & & & & & & & & & & & & & & & & \\
\hline 3. & & & & & & & & & & & & & & & & \\
\hline 4. & & & & & & & & & & & & & & & & \\
\hline 5. & & & & & & & & & & & & & & & & \\
\hline 6. & & & & & & & & & & & & & & & & \\
\hline 7. & & & & & & & & & & & & & & & & \\
\hline 8. & & & & & & & & & & & & & & & & \\
\hline 9. & & & & & & & & & & & & & & & & \\
\hline 10 & & & & & & & & & & & & & & & & \\
\hline
\end{tabular}

Note: Household refers to domestic family unit (known as bilik-family), with the following characteristics (i) its members constitute a single household; (ii) sharing resources; and (iii) have usufructs rights to property and land collectively (bilik-based). 
Section 2: Economic activities (Note: Information is based on the respondent's scenario on $1^{\text {st }}$ April 2014 onwards, unless stated otherwise)

Is subsistence agriculture part of your household economic activity?

$$
0=\text { No } \quad 1=\text { Yes }
$$

If Yes, how many members of your household are involved in this activity?

Note: If there is a school going member of household and those below 18 years old, is he/she actively involved in your household subsistence agriculture activity? Explain.

$0=$ No $\quad 1=$ Yes
Q.2.2
Which source of income contributes the most to your

household in a year? [Note: Income includes both monetary rewards and by-products from subsistence activity]

$1=$ farm

$2=$ wage $/$ salaried

$3=$ remittance

$4=$ others (specify)

$98=$ Don't know

$99=$ Refused
Q.2.3

What is the other source of your household income in the last one year? If there is more than one source of income, rank the top 3 sources of your household income (Note: $1=$ highest rank)

$1=$ farm

$2=$ wage $/$ salarie

$3=$ remittance

$4=$ others (specify)

$98=$ Don't know

$99=$ Refused

Note: (i) Subsistence farming refers to "farming in which crop production, livestock rearing and other activities are conducted mainly for personal consumption.

(ii) Others in Q.2.2 and Q.2.3 include (a) pension; and (b) selling forest products and home-produced goods.

Answer the questions in the following table if your household is involved in subsistence farming

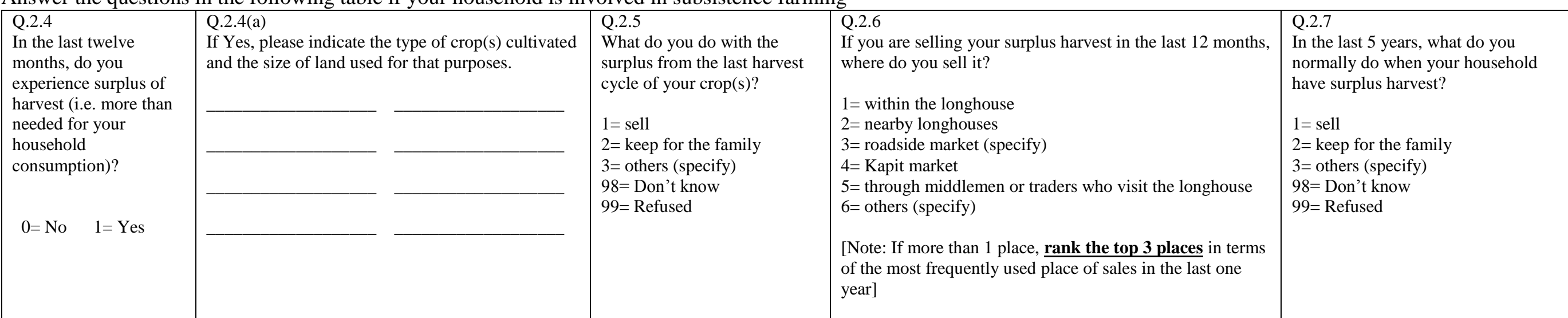


The table below contains questions on income from farming activities. The term income includes monetary gain from the farming activities as well as farm products that are used for household consumptions by the bilik-family.

\begin{tabular}{|c|c|c|c|c|c|}
\hline Type of crops & $\begin{array}{l}\text { Q.2.8 } \\
\text { Quantity harvested } \\
\text { in a year } \\
\text { (specify the } \\
\text { measurement: in } \\
\text { KG/ gunny sacks or } \\
\text { equivalent) }\end{array}$ & $\begin{array}{l}\text { Q.2.9 } \\
\text { Gross Total income } \\
\\
\text { [To find out the rough } \\
\text { approximation of total } \\
\text { income that the household } \\
\text { get from farm-based } \\
\text { activities, includes both } \\
\text { monetary profit and "in- } \\
\text { kind" farm produce] }\end{array}$ & $\begin{array}{l}\text { Q.2.10 } \\
\text { Where do you and/or members of your household sell } \\
\text { this produce (from the last harvest cycle)? } \\
1=\text { within the longhouse } \\
2=\text { nearby longhouses } \\
3=\text { roadside market (specify) } \\
4=\text { Kapit market } \\
5=\text { through middlemen or traders who visit the longhouse } \\
6=\text { others (specify) } \\
98=\text { Don't know } \\
99=\text { Refused }\end{array}$ & $\begin{array}{l}\text { Q.2.11 } \\
\text { In the last one year, what has been the most } \\
\text { significant obstacle that you and your household } \\
\text { faced in terms of farming these crops? } \\
1=\text { lack of fund } \\
2=\text { lack of markets (includes price fluctuations) } \\
3=\text { lack of equipment } \\
4=\text { lack of fertilizers } \\
5=\text { poor soil } \\
6=\text { no funds } \\
7=\text { others (specify) }\end{array}$ & $\begin{array}{l}\text { Q.2.12 } \\
\text { If you and your household } \\
\text { want to expand your farm, } \\
\text { would land be available to } \\
\text { you and/or your household? } \\
\qquad 0=\mathrm{N} \mathrm{o} \quad 1=\text { Yes } \\
\begin{array}{l}\text { [give opportunity for the } \\
\text { respondent to elaborate } \\
\text { his/her answer] }\end{array}\end{array}$ \\
\hline $\begin{array}{l}\text { Food crops } \\
\begin{array}{r}\text { Wet padd } \\
\text { Hill padd } \\
\text { Vegetabl } \\
\text { Others (specify }\end{array}\end{array}$ & & & & & \\
\hline $\begin{array}{l}\text { Cash crops } \\
\text { Rubbe }\end{array}$ & & & & & \\
\hline Other (Specify) & & & & & \\
\hline
\end{tabular}

Q.2.13 How do you and/or your bilik-family travel to market place mentioned in Q.2.6 and Q.2.10? Elaborate (or refer to the other sections which talk about access and transport)? 
Section 3: Access to information, capital, health and education. Note: all information is based on household scenario on $1^{\text {st }}$ April 2014 onwards, unless stated otherwise

Table below contains questions in relation to household's access to information, as of $1^{\text {st }}$ April 2014 onwards, unless stated otherwise.

\begin{tabular}{|c|c|c|c|c|}
\hline $\begin{array}{l}\text { Q.3.1 } \\
\text { Does your household own any of the } \\
\text { following items? } \\
\qquad \begin{array}{l}0=\mathrm{No} \quad 1=\text { Yes }\end{array}\end{array}$ & $\begin{array}{l}\text { Q.3.2 } \\
\text { In terms of obtaining information } \\
\text { regarding government activities and/or } \\
\text { programmes, what is the most important } \\
\text { source for your household? } \\
\text { [Rank the top } 3 \text { sources of information] }\end{array}$ & $\begin{array}{l}\text { Q.3.3 } \\
\text { How do you and/or family members communicate } \\
\text { with the other members of your bilik who live } \\
\text { away from the longhouse? } \\
\text { [Rank the top } 3 \text { sources of information] }\end{array}$ & $\begin{array}{l}\text { Q.3.4 } \\
\text { Compared to the situation in } \\
\text { this household } 5 \text { years ago, has } \\
\text { the access to information } \\
\text { improved, deteriorated or } \\
\text { remained the same (in } \\
\text { general)? } \\
1=\text { deteriorated } \\
2=\text { remained the same } \\
3=\text { improved } \\
98=\text { Don't know } \\
99=\text { Refused }\end{array}$ & $\begin{array}{l}\text { Q.3.5 } \\
\text { Comparing your household } \\
\text { with the other household in } \\
\text { this longhouse, where do you } \\
\text { see your bilik in terms of } \\
\text { "access to information"? } \\
\text { Note: make a "ladder" with } \\
\text { "best possible household" at } \\
\text { one end, and "worst possible } \\
\text { household" on the other end. } \\
\text { Ask respondents to situate } \\
\text { their answers based on the } \\
\text { ladder }\end{array}$ \\
\hline Television & Television & Telephone (landline) & & \\
\hline Radio & Radio & Mobile phone & & \\
\hline Personal computer/ laptop/ tablets & Local newspaper & Internet (email, skype, social networking sites) & Elaborate: & \\
\hline Telephone (landline) & Internet & Letters & & \\
\hline Mobile phone & Community leaders/representatives & Relatives/ friends/ neighbours & & \\
\hline Postal address & Relatives/ friends/ neighbours & Others (specify) & & \\
\hline Others (specify) & $\begin{array}{l}\text { Representatives from the Government } \\
\text { Others (specify) }\end{array}$ & & & \\
\hline
\end{tabular}


Table below contains questions in relation to household's access to capital, as of $1^{\text {st }}$ April 2014 onwards, unless stated otherwise.

\begin{tabular}{|c|c|c|c|c|}
\hline $\begin{array}{l}\text { Q.3.6 } \\
\text { Do you or any members of your } \\
\text { household have access to the following } \\
\text { items? } \\
0=\text { No } \quad 1=\text { Yes } \\
98=\text { Don't know } \\
99=\text { Refused }\end{array}$ & $\begin{array}{l}\text { Q.3.6(a) } \\
\text { If Yes, what is the main purpose of the } \\
\text { saving and/or investment account(s)? } \\
\text { 1= education } \\
2=\text { land/ property acquisition } \\
3=\text { house building/ renovation } \\
4=\text { others (specify) } \\
\text { [Note: If more than } 1 \text { main purpose, rank } \\
\text { the top } 3 \text { in terms of the main purposes } \\
\text { of having saving/investment accounts in } \\
\text { the last one year] }\end{array}$ & $\begin{array}{l}\text { Q.3.7 } \\
\text { Do you and your household own land and } \\
\text { property? } \\
\text { [Note: This includes all assets that are own } \\
\text { collectively and whereby the household has } \\
\text { usufruct rights to such assets] } \\
\qquad 0=\text { No } \quad 1=\text { Yes } \\
\text { Note: Please indicate size of land whenever } \\
\text { possible }\end{array}$ & $\begin{array}{l}\text { Q.3.8 } \\
\text { Compared to the situation in } \\
\text { your bilik-family } 5 \text { years ago, } \\
\text { has the access to capital } \\
\text { improved, deteriorated or } \\
\text { remained the same (in general)? } \\
\text { 1= deteriorated } \\
2=\text { remained the same } \\
\text { 3= improved } \\
98=\text { Don't know } \\
99=\text { Refused }\end{array}$ & $\begin{array}{l}\text { Q.3.9 } \\
\text { Comparing your household with the } \\
\text { other household in this longhouse, } \\
\text { where do you see your bilik in terms } \\
\text { of "access to capital"? } \\
\text { Note: make a "ladder" with "best } \\
\text { possible household" at one end, and } \\
\text { "worst possible household" on the } \\
\text { other end. Ask respondents to situate } \\
\text { their answers based on the ladder }\end{array}$ \\
\hline $\begin{array}{l}\text { Saving account } \\
\text { Amanah Saham Bumiputera (or } \\
\text { other Investment related account) } \\
\text { Others (specify) }\end{array}$ & & $\begin{array}{l}\text { Land (titled) } \\
\text { Land (have usufruct rights) } \\
\text { Property (apart from the bilik in } \\
\text { the longhouse) } \\
\text { Others (specify) }\end{array}$ & & \\
\hline
\end{tabular}


Table below contains questions in relation to household's access to education, as of $1^{\text {st }}$ April 2014 onwards, unless specified otherwise.

\begin{tabular}{|c|c|c|c|c|}
\hline $\begin{array}{l}\text { Q.3.10 } \\
\text { Do you have any bilik } \\
\text { members who are still at } \\
\text { school? } \\
\text { [Note: this includes those } \\
\text { who attend kindergarten to } \\
\text { institute of higher education] } \\
0=\text { No } \quad 1=\text { Yes } \\
98=\text { Don't know } \\
99=\text { Refused }\end{array}$ & $\begin{array}{l}\text { Q.3.11 } \\
\text { If Yes, please indicate the education level/ } \\
\text { school level of the said bilik member(s). } \\
\text { [Note: indicate the number of person still at } \\
\text { school at each level below - where appropriate] } \\
\text { 1= preschool } \\
2=\text { primary school } \\
3=\text { secondary school } \\
4=\text { tertiary institution (until undergraduate level) } \\
5=\text { others (specify) } \\
98=\text { Don't know } \\
99=\text { Refused }\end{array}$ & $\begin{array}{l}\text { Q.3.12 } \\
\text { Indicate whether those identified in } \\
\text { Q.3.11 are boarders (i.e. staying at } \\
\text { school/ institution of learning } \\
\text { during term time) or daily students } \\
\text { (i.e. commuting daily from home to } \\
\text { school/institution). } \\
\text { 1= boarder (specify name of } \\
\text { school) } \\
2=\text { daily } \\
3=\text { others (specify) } \\
98=\text { Don't know } \\
99=\text { Refused }\end{array}$ & $\begin{array}{l}\text { Q.3.13 } \\
\text { In the last one year, how satisfied are you } \\
\text { and/or member of your bilik with the } \\
\text { education services that are available to you } \\
\text { and/or bilik members? } \\
1=\text { very unsatisfied } \\
2=\text { unsatisfied } \\
3=\text { neutral } \\
4=\text { satisfied } \\
5=\text { very satisfied } \\
98=\text { Don't know } \\
99=\text { Refused }\end{array}$ & $\begin{array}{l}\text { Q.3.14 } \\
\text { Comparing your household with the } \\
\text { other household in this longhouse, } \\
\text { where do you see your bilik in terms of } \\
\text { "access to education"? } \\
\text { Note: make a "ladder" with "best } \\
\text { possible household" at one end, and } \\
\text { "worst possible household" on the } \\
\text { other end. Ask respondents to situate } \\
\text { their answers based on the ladder }\end{array}$ \\
\hline
\end{tabular}

Table below contains questions in relation to household's access to health, as of $1^{\text {st }}$ April 2014 onwards, unless specified otherwise.

\begin{tabular}{|c|c|c|c|}
\hline $\begin{array}{l}\text { Q.3.15 } \\
\text { Where do you and/or member(s) of your } \\
\text { bilik normally seek help when a member of } \\
\text { your family is sick? } \\
\text { 1= nearest health clinic (specify) } \\
2=\text { private clinic in Kapit } \\
\text { 3= Kapit Hospital } \\
\text { 4= traditional healer } \\
5=\text { chemist/ pharmacist } \\
6=\text { others (specify) } \\
98=\text { Don't know } \\
99=\text { Refused }\end{array}$ & $\begin{array}{l}\text { Q.3.16 } \\
\text { Does any member of your bilik } \\
\text { (including yourself) have medical } \\
\text { conditions that require regular visit to } \\
\text { health clinic and/or hospital? } \\
0=\text { No } \quad 1=\text { Yes } \\
98=\text { Don't know } \\
99=\text { Refused }\end{array}$ & $\begin{array}{l}\text { Q.3.17 } \\
\text { In the last one year, how satisfied are you and/or } \\
\text { member of your bilik with the health services that are } \\
\text { available to you and/or bilik members? } \\
\text { 1= very unsatisfied } \\
2=\text { unsatisfied } \\
3=\text { neutral } \\
4=\text { satisfied } \\
5=\text { very satisfied } \\
98=\text { Don't know } \\
99=\text { Refused }\end{array}$ & $\begin{array}{l}\text { Q.3.18 } \\
\text { Compared to the situation in this household } 5 \text { years ago, has } \\
\text { the access to health and education available to your } \\
\text { household/community improved, deteriorated or remained } \\
\text { the same (in general)? } \\
1=\text { deteriorated } \\
2=\text { remained the same } \\
3=\text { improved } \\
98=\text { Don't know } \\
99=\text { Refused }\end{array}$ \\
\hline
\end{tabular}


Table below contains questions in relation to household's access to transportation, as of $1^{\text {st }}$ April 2014 onwards, unless specified otherwise.

\begin{tabular}{|c|c|c|c|c|}
\hline $\begin{array}{l}\text { Q.3.19 } \\
\text { Do you and your bilik members own any } \\
\text { of the following modes of transport? } \\
0=\text { No } \quad 1=\text { Yes } \\
98=\text { Don't know } \\
99=\text { Refused }\end{array}$ & 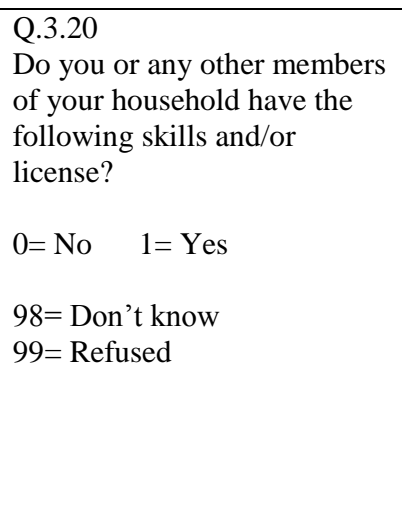 & $\begin{array}{l}\text { Q.3.21 } \\
\text { Is there any specific } \\
\text { person in your household } \\
\text { who can operate the said } \\
\text { mode of transport? } \\
\text { [Note: identify the } \\
\text { person(s)] } \\
0=\text { No } \quad 1=\text { Yes } \\
98=\text { Don't know } \\
99=\text { Refused }\end{array}$ & $\begin{array}{l}\text { Q.3.22 } \\
\text { How do you and/or member(s) of your bilik-family } \\
\text { usually travel to the nearest town (Kapit)? } \\
\text { 1= by boat } \\
2=\text { by own private } \\
3=\text { by van (owned by other people) } \\
4=\text { a combination of boat and car/van (privately owned) } \\
5=\text { a combination of boat and car/van (partly owned) } \\
6=\text { a combination of boat and car/van (owned by others) } \\
7=\text { others (specify) } \\
98=\text { Don't know } \\
99=\text { Refused }\end{array}$ & $\begin{array}{l}\text { Q.3.23 } \\
\text { In the last one year, how satisfied are you } \\
\text { and/or member of your } b i l i k \text { with the } \\
\text { transportation choices and facilities that } \\
\text { are available to you and/or bilik } \\
\text { members? } \\
1=\text { very unsatisfied } \\
2=\text { unsatisfied } \\
3=\text { neutral } \\
4=\text { satisfied } \\
5=\text { very satisfied } \\
98=\text { Don't know } \\
99=\text { Refused }\end{array}$ \\
\hline $\begin{array}{l}\text { Bicycle } \\
\text { Car/ Van } \\
\text { Other land-based motorised transport } \\
\text { Long boat (with outboard motor) } \\
\text { Long boat (without outboard motor) } \\
\text { Others (specify) }\end{array}$ & $\begin{array}{l}\text { Driving license } \\
\text { Skills to use boat } \\
\text { (with outboard motor) } \\
\text { Skills to use boat } \\
\text { (without outboard motor) } \\
\text { Others (specify) }\end{array}$ & & Elaborate: & Elaborate (on the dissatisfaction) \\
\hline
\end{tabular}




\section{Appendix 3: Questionnaire for Individual Members of Household (Bilik-family)}

This questionnaire is for the third unit of analysis i.e. individual member of household (bilik-family). The respondent will be randomly selected from the bilik-family (in second tier of sampling). The aim is to obtain the information about the socio-demographic profile of the individual members of the bilik-family, their asset ownership and personal views of development.

\section{Respondent ID (Name)}

Settlement

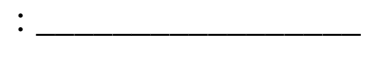

Household Head

Location (River)

Section 1: Demographic profile of individual member of household

(Note: the information obtained from the respondent is based on his/her situation as of $1^{\text {st }}$ April 2014, unless stated otherwise).

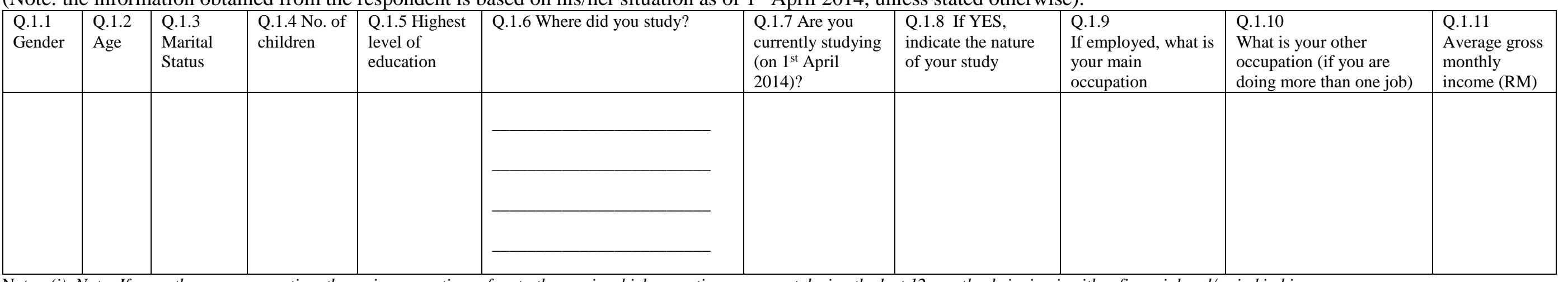

Note: (i) Note: If more than one occupation, the main occupation refers to the one in which more time was spent during the last 12 months, bringing in either financial and/or in kind income sources (ii) Other occupation refers to the respondent's other jobs, which include both financial and in-kind income sources.

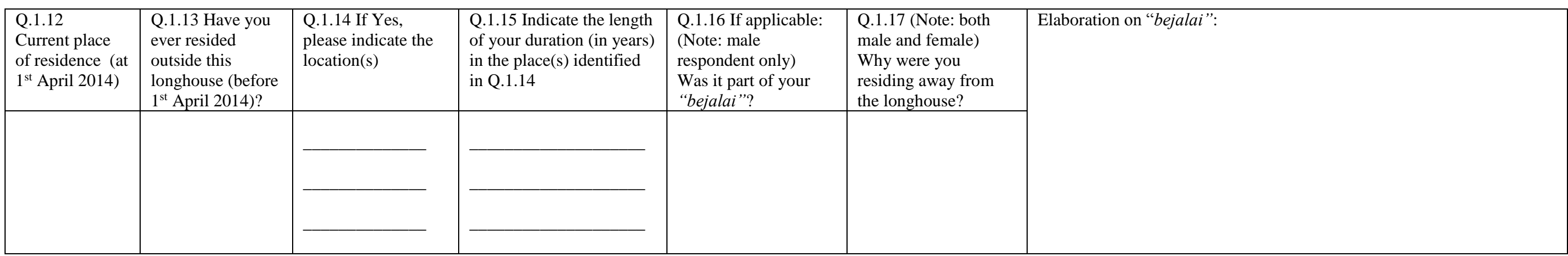

Note: (i) O.1.14 - the respondent may list out more than one place. Note the duration and places as well for further elaboration.

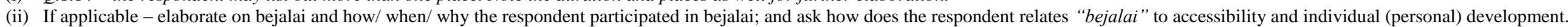

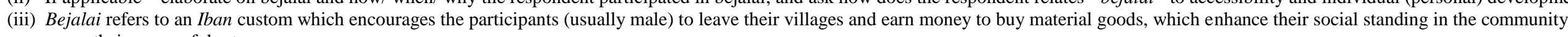
upon their successful return. 


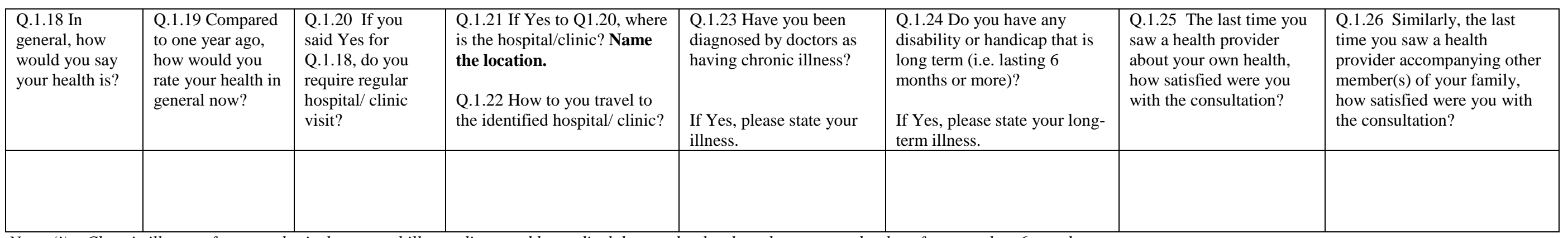

Note: (i) Chronic illness refers to a physical or mental illness, diagnosed by medical doctor, that has lasted, or expected to last, for more than 6 months.

(ii) Long term illness refers to illness that was diagnosed by doctor that has lasted 6 months or more, or is expected to last 6 months or more.

Section 2: Individual asset ownership (Note: the information obtained from the respondent is based on his/her situation as of $1^{\text {st }}$ April 2014, unless stated otherwise).

Q.2.1
Do you own a mobile phone?
(a) If No, do you have access to a mobile phone that is owned by members
of your bilik?
of your bilik?

(b) If Yes (to Q.2.1), is it a smartphone?

(c) When did you first purchase a mobile phone?

(d) What do you normally use your mobile phone for? (Rank top 2 usage)

(e) Do you use your mobile phone to access the internet?

(f) Do you have an email account?

\section{Do you own a personal computer or laptop?}

(a) If No, do you have access to a computer or laptop that is owned by others in your family?

(b) If Yes to Q.2.2, when did you purchase the said item(s)?

(c) What do you normally use your computer or laptop for? (Rank top 2 usage)

(d) Do you use your laptop or computer to access the internet?

(e) Is there anyone else in your bilik-family who use (or have access to) your computer and/or laptop?

(f) If Yes to the above, please identify the person(s) who use the item; and for what purpose?
Do you have bank account(s)?

(a) If Yes, when did you first open the bank account?

(b) Do you have investment-related account(s)?

(c) If Yes, please state the type of account.

(d) When did you first open the aforementioned investment-related account(s)?

(e) What are the reason(s) you have bank account(s) and/or investment-related account(s)? Rank the top 2 usages. 
Note: Investment-related account includes Amanah Saham Bumiputera, Amanah Saham Pendidikan, investment-linked insurance account, and other investment related accounts. Section 2: continued (asset ownership)

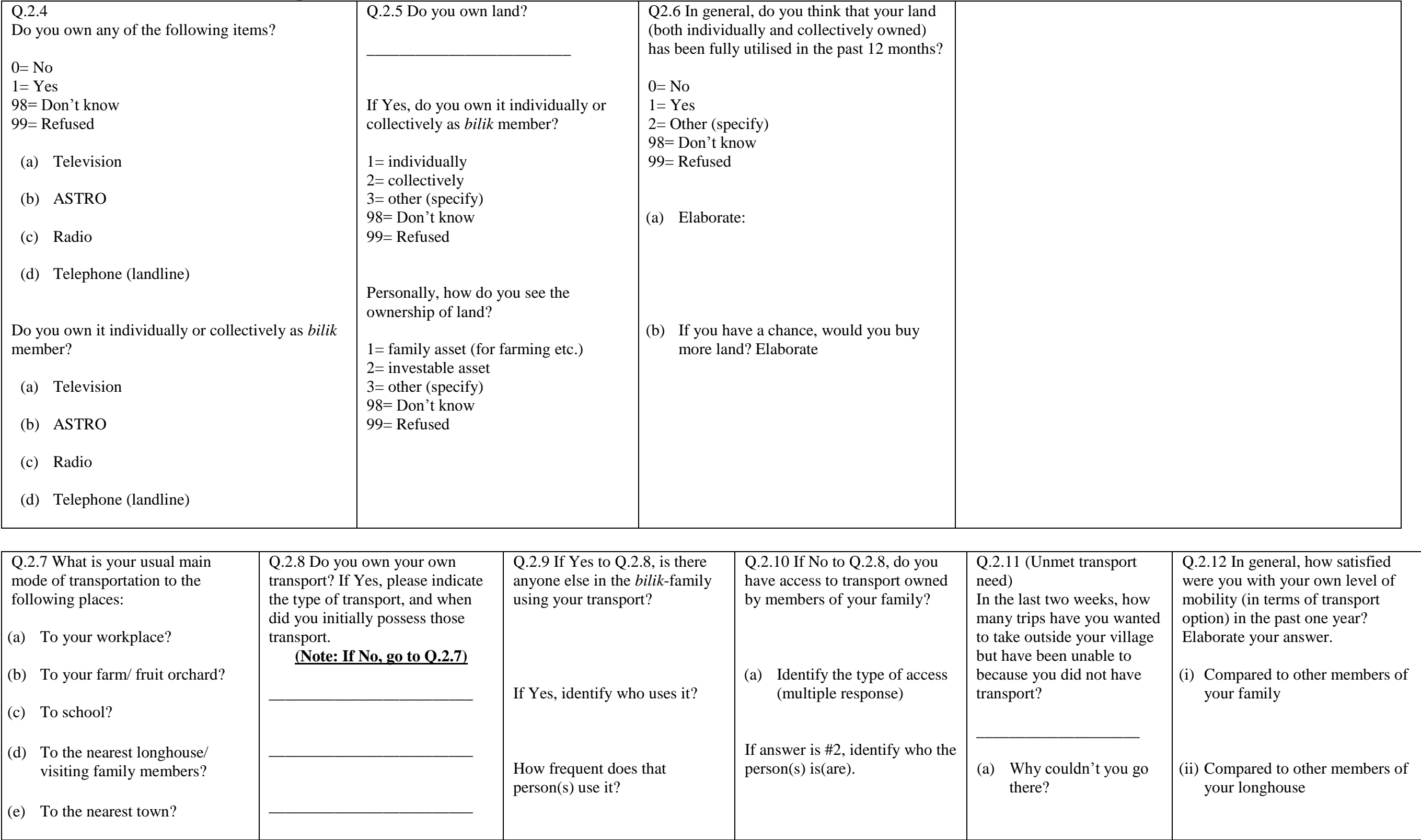




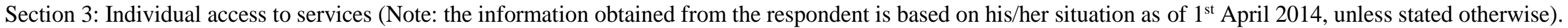

\begin{tabular}{|c|c|c|c|}
\hline $\begin{array}{l}\text { How do you rate your access to the } \\
\text { services listed below? }\end{array}$ & $\begin{array}{l}\text { Perception as the user } \\
\text { of the service } \\
1=\text { very poor access } \\
2=\text { poor access } \\
3=\text { reasonable access } \\
4=\text { good access } \\
5=\text { very good access } \\
98=\text { Don't know } \\
99=\text { Refused }\end{array}$ & 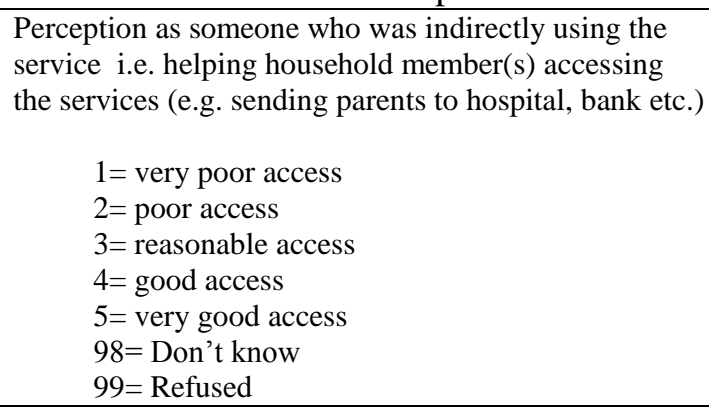 & Elaborate (especially if the answer is 1 and 2 ) \\
\hline \multicolumn{4}{|l|}{$\begin{array}{l}\text { Q.3.1 Education service (school) } \\
\text { available in the area }\end{array}$} \\
\hline \multicolumn{4}{|l|}{$\begin{array}{l}\text { Q.3.2 Health services (clinics) } \\
\text { available in the area }\end{array}$} \\
\hline \multicolumn{4}{|l|}{ Q.3.3 Job training/ employment } \\
\hline \multicolumn{4}{|l|}{ Q.3.4 Credit/ finance } \\
\hline \multicolumn{4}{|l|}{$\begin{array}{l}\text { Q.3.5 Transport (ease of accessing } \\
\text { mean and mode of transport) }\end{array}$} \\
\hline \multicolumn{4}{|l|}{$\begin{array}{l}\text { Q.3.6 Involvement in bilik decision } \\
\text { making }\end{array}$} \\
\hline $\begin{array}{l}\text { Q.3.7 Involvement in longhouse } \\
\text { decision making }\end{array}$ & & & \\
\hline
\end{tabular}

Note: Services refer to a range of services available within and for the community in the longhouse.

: Map will be shown so that respondent( $(s)$ will be able to indicate the location of services relevant to them. 
Section 3: Continued (Individual access to services)

\section{Q.3.8 Are you at present receiving any state and/or federal}

benefits in your own right (i.e. you are the named recipient)?

(a) If Yes, indicate the name of the benefit(s) received
Q.3.9 In your view, does your location matters in determining your access to all the services discussed before this? Elaborate your answer.
Q.3.10 In general, how satisfied were you with your personal level of accessibility in the past 12 months? Elaborate.

(i) Compared to other members of your family

(ii) Compared to other members of your longhouse
Q.3.11 In your opinion, in what ways could you improve your personal level of accessibility? Note: this includes physical, social and economic accessibilities. (b) If No, are you eligible to apply for such benefits?

(c) Have you received such benefits in the past?

\section{Section 4: Individual perception of development [pemansang]}

\begin{tabular}{|c|c|c|c|c|c|c|}
\hline $\begin{array}{l}\text { Q.4.1 In your view, what } \\
\text { does the term } \\
\text { 'pemansang' mean? } \\
\text { Elaborate with specific } \\
\text { example relevant to the } \\
\text { community or location. }\end{array}$ & $\begin{array}{l}\text { Q.4.2 Which of these elements do } \\
\text { you think should be incorporated in } \\
\text { pemansang in the context of your } \\
\text { longhouse and locality. } \\
\text { [Note: Rank in the order of priority, } \\
\text { with } 1 \text { being the top priority] } \\
\text { Electricity } \\
\text { Piped water } \\
\text { Primary school } \\
\text { Secondary school } \\
\text { Health clinic } \\
\text { Road transport system } \\
\text { Safe river transport } \\
\text { Ease of movement (from your } \\
\text { longhouse) } \\
\text { Others (specify): }\end{array}$ & $\begin{array}{l}\text { Q.4.3 Besides those } \\
\text { listed in Q.4.2, what are } \\
\text { the other elements that } \\
\text { you think should be taken } \\
\text { into consideration when } \\
\text { discussing pemansang in } \\
\text { your area? }\end{array}$ & $\begin{array}{l}\text { Q.4.4 Identify the area(s) } \\
\text { in which you think } \\
\text { development has } \\
\text { occurred (or areas that } \\
\text { you believe have } \\
\text { improved) in your } \\
\text { longhouse. }\end{array}$ & $\begin{array}{l}\text { Q.4.5 What do you } \\
\text { think has been the } \\
\text { pressing development } \\
\text { issues in this locality } \\
\text { in the last } 12 \text { months? }\end{array}$ & $\begin{array}{l}\text { Q.4.6 Compared to the last } 5 \\
\text { years, do you think this } \\
\text { longhouse has improved, } \\
\text { deteriorated or remained the } \\
\text { same if compared to the } \\
\text { development of the other } \\
\text { longhouses in this river } \\
\text { tributary within the same } \\
\text { time frame? } \\
\text { 1= deteriorated } \\
2=\text { remained the same } \\
3=\text { improved } \\
98=\text { Don't know } \\
99=\text { Refused } \\
\text { Elaborate: }\end{array}$ & $\begin{array}{l}\text { Q.4.7 What about your bilik } \\
\text { family? Do you think that } \\
\text { your bilik family has } \\
\text { generally improved, } \\
\text { deteriorated or remained the } \\
\text { same compared to the other } \\
\text { bilik family - in the last } 5 \\
\text { years? } \\
\text { (i) Compare to other bilik } \\
\text { family in the same } \\
\text { longhouse } \\
\text { (ii) Compared to other bilik } \\
\text { family in the tributary. }\end{array}$ \\
\hline
\end{tabular}

Note: (i) the term 'pemansang' has been used in Iban language when describing 'development'. The origin of the term is unknown. 
Section 5: Individual travel patterns and perception on accessibility

\begin{tabular}{|c|c|c|c|c|}
\hline $\begin{array}{l}\text { Q.5.1 Looking back at your activity } \\
\text { last month, how frequent do you travel } \\
\text { outside of your home? }\end{array}$ & $\begin{array}{l}\text { Q.5.2 In your view, does your } \\
\text { location restrict your travel } \\
\text { behaviour? (i.e. if you live } \\
\text { elsewhere will your travel } \\
\text { behaviour be different) }\end{array}$ & $\begin{array}{l}\text { Q.5.3 Do you think in general that you } \\
\text { would make more trips outside of this } \\
\text { longhouse in a month if your } \\
\text { longhouse is located nearer to Kapit? }\end{array}$ & $\begin{array}{l}\text { Q.5.4 Do you consider the cost* of travel } \\
\text { before making trip(s) to the nearest town? } \\
\text { [Note: Cost here includes the cost and } \\
\text { time taken to make one trip] }\end{array}$ & $\begin{array}{l}\text { Q.5.5 Based on your travel needs and } \\
\text { pattern over the last one month, how do } \\
\text { you rate the level of accessibility in your } \\
\text { locality in relation to ease of travel to } \\
\text { Kapit? }\end{array}$ \\
\hline (a) Where did you go? & $\begin{array}{l}\text { (a) If Yes, what would have } \\
\text { been different in terms of } \\
\text { your travel behaviour? }\end{array}$ & Elaborate your answer. & $\begin{array}{l}\text { (a) If the financial cost is lower, do you } \\
\text { think you would make more trips } \\
\text { outside the longhouse in a month? }\end{array}$ & $\begin{array}{l}1=\text { low accessibility } \\
2=\text { medium accessibility } \\
3=\text { high accessibility } \\
98=\text { Don't know } \\
99=\text { Refused }\end{array}$ \\
\hline $\begin{array}{l}\text { (b) Is that a typical travel pattern } \\
\text { undertaken by you? } \\
\text { (c) If No, why was it different? }\end{array}$ & (b) If No, why not? & & $\begin{array}{l}\text { (b) If the time is shorter, do you think } \\
\text { you would make more trips outside } \\
\text { the longhouse in a month? }\end{array}$ & $\begin{array}{l}\text { (a) What elements do you take into } \\
\text { account when measuring } \\
\text { accessibility? Rank the top 3, with } 1 \\
\text { being the highest. } \\
1=\text { cost (time taken) } \\
2=\text { cost (financial cost involved) } \\
3=\text { existence of road network } \\
4=\text { multiple choices (mode of transport) } \\
5=\text { availability of contemporary } \\
\text { communication } \\
6=\text { other (specify) } \\
98=\text { Don't know } \\
99=\text { Refused }\end{array}$ \\
\hline
\end{tabular}

Thank you for participating in this research. 